\title{
About goats, girls, boys and the bees : promoting adolescents' sexual and reproductive health and rights in Uganda, Indonesia and Thailand; an Intervention Mapping approach
}

Citation for published version (APA):

Leerlooijer, J. N. (2013). About goats, girls, boys and the bees : promoting adolescents' sexual and reproductive health and rights in Uganda, Indonesia and Thailand; an Intervention Mapping approach. [Doctoral Thesis, Maastricht University]. Datawyse / Universitaire Pers Maastricht. https://doi.org/10.26481/dis.20130701jl

Document status and date:

Published: 01/01/2013

DOI:

10.26481/dis.20130701jl

Document Version:

Publisher's PDF, also known as Version of record

\section{Please check the document version of this publication:}

- A submitted manuscript is the version of the article upon submission and before peer-review. There can be important differences between the submitted version and the official published version of record. People interested in the research are advised to contact the author for the final version of the publication, or visit the DOI to the publisher's website.

- The final author version and the galley proof are versions of the publication after peer review.

- The final published version features the final layout of the paper including the volume, issue and page numbers.

Link to publication

\footnotetext{
General rights rights.

- You may freely distribute the URL identifying the publication in the public portal. please follow below link for the End User Agreement:

www.umlib.nl/taverne-license

Take down policy

If you believe that this document breaches copyright please contact us at:

repository@maastrichtuniversity.nl

providing details and we will investigate your claim.
}

Copyright and moral rights for the publications made accessible in the public portal are retained by the authors and/or other copyright owners and it is a condition of accessing publications that users recognise and abide by the legal requirements associated with these

- Users may download and print one copy of any publication from the public portal for the purpose of private study or research.

- You may not further distribute the material or use it for any profit-making activity or commercial gain

If the publication is distributed under the terms of Article $25 \mathrm{fa}$ of the Dutch Copyright Act, indicated by the "Taverne" license above, 


\section{About goats, girls, boys and the bees}

Promoting adolescents' sexual and reproductive health and rights in Uganda, Indonesia and Thailand; an Intervention Mapping approach 


\section{Colophon}

Cover design: Nora Oosting Lay-out: Joanne Leerlooijer Print: Datawyse Maastricht

(C) Joanne N. Leerlooijer, Maastricht 2013

ISBN: 9789461592392

Universitaire Pers Maastricht 


\section{About goats, girls, boys and the bees}

Promoting adolescents' sexual and reproductive health and rights in Uganda, Indonesia and Thailand; an Intervention Mapping approach

\section{Proefschrift}

ter verkrijging van de graad van doctor aan de Universiteit Maastricht, op gezag van de Rector Magnificus, Prof. dr. L. L. G. Soete volgens het besluit van het College van Decanen, in het openbaar te verdedigen op maandag 1 juli 2013 om 16.00 uur

door Janneke Nanne Leerlooijer geboren op 29 maart 1977 te 's-Hertogenbosch (Nederland)

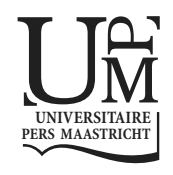




\section{Promotores}

Prof. dr. R. A. C. Ruiter

Prof. dr. G. J. Kok

\section{Copromotor}

Dr. A. E. R. Bos (Open Universiteit, Heerlen)

\section{Beoordelingscommissie}

Prof. dr. F. R. H. Zijlstra (voorzitter)

Prof. dr. H. W. van den Borne

Prof. dr. N. H. Gottlieb (University of Texas, USA)

Dr. A. Krumeich

Prof. dr. N. K. de Vries

The 'The World Starts With Me' studies presented in this dissertation were funded by Rutgers WPF and the Westberg Foundation. 


\section{Contents}

Chapter 1. General Introduction

Chapter 2. Impowering teenage mothers in Uganda: The development of a community-based intervention to improve psychological and social well-being of unmarried teenage mothers

Chapter 3. Qualitative evaluation of the Teenage Mothers Project in Uganda: A community-based empowerment intervention for unmarried teenage mothers

Chapter 4. Psychosocial correlates of the motivation to abstain from sexual intercourse among Indonesian adolescents

Chapter 5. Breaking taboos about sexuality: Effects of the school-based programme The World Starts with Me in Uganda and Thailand on disclosure about sensitive issues

Chapter 6. The World Starts With Me: Using Intervention Mapping for the systematic adaptation and transfer of school-based sexuality education from Uganda to Indonesia

Chapter 7. General Discussion

References

Summary

Samenvatting 165

Dankwoord/ Acknowledgements 169

About the Author

Publication List 



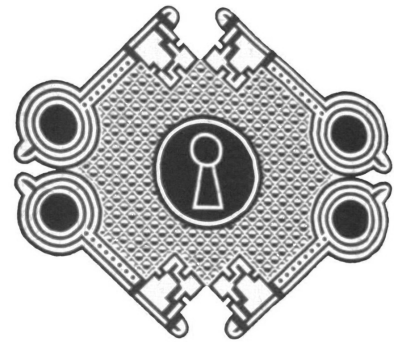

Chapter 1

General Introduction 
Over the past few decades, sexual and reproductive health and rights (SRHR) have become significant social and public health issues worldwide, particularly in countries in sub-Saharan Africa and the Asian Pacific region. Rapid global population growth, the beginning of the AIDS epidemic in 1981, and women's impaired health and well-being have had a significant impact on countries' stability, governance, economic development, and the well-being of its people (Varkey, Kureshi, \& Lesnick, 2010). These have been major concerns for local, national, and international communities (Population Reference Bureau, 2011).

The Programme of Action of the 1994 International Conference on Population and Development and the United Nations Millennium Development Goals Declaration in 2000 have guided the promotion of sexual and reproductive health and rights worldwide in the past two decades (United Nations, 1994; United Nations, 2000). Sexual and reproductive health (SRH) is defined as 'a state of complete physical, mental, and social well-being and not merely the absence of disease or infirmity, in all matters relating to the reproductive system and to its functions and processes. Reproductive health therefore implies that people are able to have a satisfying and safe sex life and that they have the capability to reproduce and the freedom to decide if, when and how often to do so' (United Nations, 1994). In both declarations SRH was placed in the context of human rights which shifted the focus from problems and diseases only, to the inclusion of what should be positive experiences around pregnancy and parenthood, sexuality, and relationships.

In an international technical consultation, facilitated by the World Health Organization (2010), sexual rights were defined as the right of all individuals, free of coercion, discrimination, and violence, to the highest attainable standard of sexual health, information related to sexuality and sexuality education; to decide about their partner, whether or not to be sexually active, and whether or not, and when, to have children; respect for bodily integrity and consensual sexual relations and marriage; and to pursue a satisfying, safe, and pleasurable sexual life. Sexuality was defined as 'a central aspect of humanity and encompasses sex, gender identities, and roles, sexual orientation, eroticism, pleasure, intimacy, and reproduction. Sexuality is experienced and expressed in thoughts, fantasies, desires, beliefs, attitudes, values, behaviours, practices, roles, and relationships. Although sexuality can include all of these dimensions, not all are always experienced or expressed. Sexuality is affected by the interaction of biological, psychological, social, economic, political, cultural, ethical, legal, historical, religious, and spiritual factors' (World Health Organization, 2010).

Despite improvement of adolescent sexual and reproductive health and rights in the past decades, evidence indicates a continued need to address negative outcomes of early pregnancy and sexually transmitted infections (STIs), including HIV/AIDS, that impair adolescents' health and quality of life (Bearinger, Sieving, Ferguson, \& Sharma, 2007; Haslegrave, 2004). This dissertation focuses on the SRHR promotion of adolescents in Uganda, Indonesia, and Thailand. 


\section{Adolescents' SRHR in sub-Saharan Africa and the Asian Pacific region}

Today's generation of young people is the largest in history: more than 1.8 billion people of the world's population are aged 10-24 years, comprising a quarter of the global population. Nearly $90 \%$ of young people live in low-income and middleincome countries where they constitute a far greater proportion of the population than in high-income countries (World Health Organization, 2009). Internationally, policies and programmes use the term adolescents for people aged 10-19 years, young people for those aged 10-24 years, and youth for those aged 15-24 years (World Health Organization, 2010).

Adolescence is a period of transition, marked by physical, psychological, and cognitive changes underpinned by biological factors. During adolescence many young people become sexually active and start to explore their sexuality and intimate relationships. Sexual activity also implies increased sexual and reproductive health risks. Negative outcomes of early pregnancy and STIs, including HIV/AIDS, impair the health of adolescents worldwide (Bearinger, Sieving, Ferguson, \& Sharma, 2007; Glasier et al., 2006; Hindin \& Fatusi, 2009; Hindin, Christiansen, \& Ferguson, 2013; Blum \& Nelson-Mmari, 2004). The reliability of figures related to these negative outcomes however is limited as a result of limitations in the collection of national data on adolescents' health and behaviour in countries in sub-Saharan Africa and in the Asian Pacific region. Generally, more reliable evidence on adolescents' SRHR is available for countries in sub-Saharan Africa than for the Asian Pacific region (Doyle et al., 2012; Gray et al., 2011).

Even though in some countries HIV/AIDS prevalence has decreased tremendously, it remains a significant health threat, especially for people in areas with limited access to antiretroviral therapy. In sub-Saharan Africa, which contains almost two-thirds of all youth living with HIV/AIDS worldwide, the main mode of transmission is heterosexual intercourse. In most countries in Asia, HIV/AIDS remains concentrated in key populations, including sex workers and their clients, men who have sex with men (MSM), and intravenous drug users (IDU). However, the contribution of transmission to spouses of those currently or formerly at higher risk increased in several countries in recent years (Gouws \& Cuchi, 2012). The acquisition of other STIs is another health risk for adolescents worldwide, often with devastating effects on future fertility (Low et al., 2006). Of the estimated 333 million new STIs (i.e., syphilis, gonorrhoea, chlamydia, and tricho moniasis) that occur in the world every year, at least one-third occur in young people under the age of 25 years (World Health Organization, 2001).

Early teenage pregnancy and its consequences are also a major SRHR concern in developing countries. Complications of pregnancy and childbirth are the leading cause of death in women aged 15-19 years and maternal death rates for adolescents are twice that of older women (Reynolds \& Wright, 2004). Despite a decline in the past decades, pregnancy rates among adolescents are still high (Garenne \& Zwang, 2009). Although teenage childbearing has always been common 
in most sub-Saharan African societies, it is only recently that it has become a social problem. It was common for women to marry at very young ages and most teenage childbearing occurred within marriage. More recently, a substantial proportion of adolescent childbearing has occurred to never-married girls. One of the countries in sub-Saharan Africa with the highest fertility rate is Uganda (6.2 children per woman in 2011), which is largely a result of early childbearing: one out of four females aged 15-19 in Uganda delivers a child (Uganda Bureau of Statistics, 2012). In sub-Saharan Africa as a whole, $20 \%$ of female adolescents commences childbearing (Doyle et al., 2012). Teenage pregnancy and childbearing are less prevalent in Asian countries than in sub-Saharan Africa, with, for example, total fertility rates of 2.2 in Indonesia and 1.5 in Thailand (United Nations, 2011). Early, unplanned teenage pregnancies are associated with increased levels of induced abortion, which when carried out in unsafe conditions, carries severe health risks and can even lead to death (Shah \& Åhman, 2004). In 2008, there were an estimated three million unsafe abortions in developing countries among adolescents (Bearinger, Sieving, Ferguson, \& Sharma, 2007). Other, psychological and social, consequences of early childbearing include stigma, violence, lack of schooling, and livelihood insecurity (Levandowski et al., 2012; Biddlecom, Gregory, Lloyd, \& Mensch 2008; Atuyambe et al., 2009).

Sexual and domestic violence, stigma, and discrimination of adolescents because of their health status (e.g., being HIV positive), gender, sexual orientation, or out-ofwedlock pregnancy, also impair their health and quality of life and can affect their dignity and development (Stutterheim et al., 2009; Levandowski et al., 2012; De Grace \& Clarke, 2012; Ueno, 2005). Female adolescents in certain contexts have limited chance to take their own decisions and face forced marriages, sexual exploitation, and harmful cultural practices including female circumcision and sexselective abortions (Lopez-Claros \& Zahidi, 2005).

The sexual and reproductive health and rights of adolescents are determined by many intrapersonal, interpersonal, and external factors. Intrapersonal factors that contribute to or hinder adolescents' health and access to rights comprise their health seeking behaviours, sexual behaviours, beliefs, and skills. Globally, a shift towards later marriage in most countries has led to an increase in premarital sex (Wellings et al., 2006; UNFPA, 2012b). International comparisons show that adolescents in sub-Saharan Africa start earlier with sex than adolescents in countries in the Asian Pacific region (Doyle et al., 2012; Zuo et al., 2012). Findings from subSaharan Africa suggest that adolescents increasingly delay their onset of sexual intercourse and increasingly use condoms during sexual intercourse (Doyle et al., 2012). However, very small proportions of unmarried sexually experienced female adolescents in sub-Saharan Africa use medical contraceptive methods at most recent sex (e.g., $8 \%$ in Uganda). Female adolescents face obstacles when seeking contraceptive methods, including insufficient knowledge about modern methods, limited access to services, and active discouragement by health-care of contraceptive use by adolescents.

Unprotected sexual behaviours and limited health seeking behaviours of adolescents are in turn influenced by many personal, interpersonal and external factors. One of the models that are commonly used to analyse and understand 
sexual behaviour is the Theory of Planned Behaviour (TPB; Ajzen, 1991) or related theories such as the Theory of Reasoned Action (Fishbein \& Ajzen, 1975; Ajzen \& Fishbein, 1980) and the Reasoned Action Approach (Fishbein, 2008). The constructs in these models are to a large extent similar (Montano \& Kasprzyk, 2008) and research with these theories has particularly focused on the TPB. TPB suggests that the most important predictor of behaviour is an individual's intention to perform or not to perform the behaviour (Ajzen, 1991). Intention, in turn, is determined by (1) attitude, referring to a person's overall evaluation of the proposed behaviour, (2) subjective norms, which refer to beliefs about whether significant others like friends, family, and society approve of behaviour and whether that approval is valued, and (3) perceived behavioural control, i.e., the person's anticipated mastery of the behaviour. Meta-analyses have provided evidence of the (causal) link between attitude, subjective norm, and perceived behavioural control and the intention and behaviour (Armitage \& Conner, 2001; Sheeran, Abraham, \& Orbell, 1999; McEachan, Conner, Taylor, \& Lawton, 2011).

Compared to studies exploring condom use behaviours, relatively few research studies have explored the correlates of adolescents' intention to abstain from sexual intercourse or intention to abstain from sex (Buhi \& Goodson, 2007). Studies worldwide that measured correlates of adolescents' intention to abstain from sexual intercourse found attitudes, subjective norms, and perceived behavioural control being the strongest predictors (Basen-Engquist \& Parcel, 1992; Basen-Engquist, Tortolero, \& Parcel, 1997; Collazo, 2005; Villarruel, Jemmott III, Jemmott, \& Ronis, 2004). Other research reported gender (being female) and lack of previous sexual experience as predictors of intention to abstain from sexual intercourse (Nahom et al., 2001). Several studies included past behaviour as dependent variable, instead of intention, and found that low frequency of being in sexual situations, positive attitudes towards abstinence from sex, perceived abstinence from sex among peers, higher education level of parents (particularly the father), high self-esteem, good parental relationships, and higher level of education are associated with abstinence from sexual intercourse (Mehrotra, Zimmerman, Noar, \& Dumenci, 2013; Carvajal et al., 1999; Price \& Hyde, 2009).

A meta-analytic review of psychosocial correlates of heterosexual male condom use identified four cognition measures with medium to large correlations with condom use (Sheeran, Abraham, \& Orbell, 1999): attitudes toward condoms, descriptive norms in relation to condom use (i.e., perceptions that others approve of and use condoms), intentions to use condoms, and pregnancy motivation (e.g., the belief that condoms should be used for contraceptive purposes, as well as, STI protection). Perceived control over the behaviour (including self-efficacy) was found in another meta-analysis to be correlated with condom use (Albarracín, Johnson, Fishbein, \& Muellerleile, 2001). A review of 11 studies in sub-Saharan Africa showed strong correlations between intention to have safe sex (defined as condom use, not engaging in pre-marital sexual relations, and use contraceptives) and attitudes and subjective norms, whereas no clear conclusions could be reached for perceived behavioural control due to wide discrepancies in operationalization across studies (Protogerou, Flisher, Aarø, \& Mathews, 2012). 
In addition to adolescents' own behaviour, attitudes, perceived norms, and perceived behavioural control, interpersonal and external factors hinder or contribute to adolescents' health and well-being. Sexual and reproductive rights of adolescents have been a sensitive and controversial topic for many policy makers, professionals, communities, and parents worldwide. As a result, interpersonal and external determinants of adolescents' health include the content and implementation of relevant policies, cultural, religious, and social norms, and the availability, accessibility, and affordability of health services, education, support, and information (Bearinger, Sieving, Ferguson, \& Sharma, 2007; Hindin, Christiansen, \& Ferguson, 2013).

This dissertation describes the development and effect evaluation of two interventions aiming at the promotion of adolescents' sexual and reproductive health and rights in sub-Saharan Africa and the Asian Pacific region. The first intervention is the community-based Teenage Mothers Project in Uganda, aiming at the empowerment of unmarried teenage mothers and their rural resident communities. The second intervention is the comprehensive sexuality education programme 'The World Starts With Me' (WSWM), implemented in secondary schools in Uganda, Indonesia, and Thailand. WSWM aims at the empowerment of adolescents to take their own sexuality- and SRHR-related decisions. The planning and contents of both interventions are based on an empowerment approach, health promotion, and a human rights-based approach.

\section{Empowerment, health promotion, and human rights}

Human rights perspectives on health became increasingly prominent in the early years of the 21st century and influenced discourse on participation, empowerment, and development (Hunt, 2002; Cornwall \& Nyamu-Musembi, 2004). A lot of work has been based on Sen's work on equity, who argued that individuals act in their best interest whenever they have the choice, that is, when they possess adequate knowledge, competencies, and resources (Sen, 1985; Sen, 1999). Concepts of freedom, rights, individual entitlements, and people's capabilities are central to Sen's empowerment concept.

Global attention to a rights-based approach came to the forefront in 1997 when Kofi Annan, then UN Secretary General, called for the United Nations to integrate human rights into all of its work (United Nations Secretary General, 1997). Rightsbased approaches to development comprise two elements. First, governments have to incorporate international human rights conventions into national law. This is effectively a top down and legalistic strategy that accords with the focus on rights (individual, group, human) that appears in legal studies and moral philosophy. Second, at the local level, people should be informed of their rights and empowered to exercise them, and if needed, claim their rights from the state. This approach implies a degree of social mobilisation from below and idea of government accountability to citizens. A rights-based approach is particularly relevant when the 
needs and rights of the general population or of specific vulnerable groups (rightsholders) are not addressed by responsible governments (duty-bearers).

The International Conference on Population and Development (ICPD) in 1994 marked a major shift towards a rights-based approach to population issues. Before 1994, the international community focused on family planning and promotion of contraceptives primarily aiming to reduce global population growth. During the ICPD conference, the focus shifted towards people's individual needs and rights with regard to safe sex and pregnancy, which are free from coercion, discrimination, and violence (United Nations, 1994; Wheeler, 1999). The ICPD Programme of Action, agreed upon by 179 countries, reflected the growing awareness that population, poverty, health, education, patterns of production and consumption, and the environment are all inextricably linked and that population concerns could not be separated from other economic and social development agenda's, particularly the need for women's empowerment. Specific attention in the ICPD Programme of Action is paid to the rights of adolescents and young people. In subsequent meetings (e.g., the ICPD +5 review meeting, and CPD meetings in 2009 and 2012), adolescents' and young people's rights have been more elaborately described, including the right to comprehensive sexuality education, youth friendly services, access to contraception, and their reproductive rights (UNFPA, 2012a).

The ICPD Plan of Action is underlined by other international agreements. The United Nations Convention of the Rights of the Child (CRC) acknowledges the rights of children and adolescents to have access to education and the highest attainable standard of health, and to be free of violence, pressure, and discrimination (United Nations, 1989). And the 1995 Beijing World Conference on Women acknowledged that women's rights are human rights and that women's emancipation is key to development (United Nations, 1995). In 2000, the ICPD Programme of Action, and benchmarks added at the ICPD+5 review, went on to inform the eight Millennium Development Goals (MDGs). Even though no specific MDG on SRHR was formulated, SRHR are reflected in four MDGs: to achieve universal primary education, with a focus on girls' education (MDG 2), to promote gender equality and to empower women (MDG 3), to improve maternal health (MDG 5), and to combat HIV/AIDS, malaria, and other diseases (MDG 6) (United Nations, 2000; Abrejo, Shaikh, \& Saleem, 2008).

Over the past 20 years, the public health community also shifted its focus to the perspective that a human rights lens on health helps to shape understanding of who is disadvantaged and who is not; who is included and who is ignored; and whether a given disparity is merely a difference or an actual injustice (Annas, 1998; Gruskin, Mills, \& Tarantola, 2007). This shift is reflected in the 1986 Ottawa Charter for Health Promotion (World Health Organization, 1986). The Ottawa Charter steered health promotion beyond dominant health education models of individual lifestyle and behaviour change, towards a socio-ecological version of health promotion that addresses well-being and structural determinants of health including socioeconomic contexts, ecological sustainability, holism, and interdependency, and embracing community empowerment and participation (Robertson \& Minkler, 1994; Nutbeam, 2008). Health promotion was defined as a process of empowerment and 
capacity building, enabling people to increase control over and to improve their health (World Health Organization, 1986; Woodall, Warwick-Booth, \& Cross, 2012; Woodall, Raine, South, \& Warwick-Booth, 2010). In contrast to the medical paradigm, the goal of health promotion within public health is the prevention of disease and promotion of positive health rather than treatment of the sick. Health promotion interventions target the public or the community and not individual patients and facilitate the behavioural, societal, and environmental changes necessary for health promotion in communities as a whole (Kar, Pascual, \& Chickering, 1999). Health promotion has continued to build on the evidence experience derived from health education and individual behaviour change, but extended its approach towards structural and environmental change and embedding health in a broader context of well-being.

The three related approaches, i.e., empowerment, health promotion, and human rights, emphasise the importance of positioning health within a broader context of people's economic, social and psychological well-being by addressing the intrapersonal as well as structural and environmental determinants of health and well-being. The three approaches differ with regard to their overall aims and objectives of SRHR promoting policies and interventions, i.e., changing power relations (empowerment approach), changing behavioural, societal, and environmental factors to promote health (health promotion), and meeting people's rights to information, services, and decision making freedom (rights-based approach).

How to translate these approaches to the practice of policy making, programme development, implementation, and evaluation is challenging for actors who aim to promote SRHR worldwide, including academics, the United Nations, government agencies, and non-governmental organisations (NGOs). Particularly the operationalization of a rights-based approach to health is challenging, due to the variety of definitions and the construction of rights in policy and programmes and in advocacy for people's rights (Gruskin, Bogecho, \& Ferguson, 2010; Standing et al., 2011, Cornwall \& Nyamu-Musembi, 2004; Oronje et al., 2011; Shaw, 2009). In many contexts, the language of rights is not necessarily how people, including policy makers, frame their understanding of reproductive and sexual well-being or their sense of entitlement to it.

Empowerment, health promotion, and human rights are integrated in the planning and evaluation of the two SRHR promotion interventions that are described in this dissertation. Three strategies can be identified in interventions that address adolescents' SRHR worldwide that together are essential for improving their health and rights: clinical services that assure accessible and high-quality reproductive health care; sexuality education programmes that provide developmentally appropriate, evidence-based information; and youth development strategies to enhance life skills, connections to supportive adults, and educational and economic opportunities (Bearinger, Sieving, Ferguson, \& Sharma, 2007). Wellings et al. (2006) pointed out that '...no general approach to sexual health promotion will work everywhere, and no single-component intervention will work anywhere'. This dissertation elaborates on a community-based and a school-based intervention that 
are tailored to particular groups of adolescents in particular contexts in sub-Saharan Africa and the Asian Pacific region.

\section{Community- and school-based interventions}

\section{Community-based empowerment}

A community can be defined as a group of people with diverse characteristics who are linked by social ties, share common perspectives, and engage in joint action in geographical locations or settings (MacQueen et al., 2001). Community development emphasises the participation of people in their own development, recognises and uses people's assets, encourages the participation of people in the generation of information about community needs and assets, empowers people to make choices and involves people in the political processes that affect their lives (Bracht, 1999).

In practice, community development programmes vary from 'bottom up' to 'top down'. Bottom-up programmes, associated with community empowerment and a rights-based approach, take the concerns of particular groups or individuals as starting point and regard improvement of their overall power or capacity as the important health outcome. Top down programmes, mainly associated with disease prevention efforts, begin by seeking to involve particular groups or individuals in issues and activities largely defined by health agencies and regard improvement in particular behaviours as the important health outcome. In the latter approach, community empowerment is viewed more instrumentally as a means to the end of health behaviour change (Laverack \& Labonte, 2000; De Vos et al., 2009). However, according to Laverack \& Labonte (2000), the dichotomy between top-down disease prevention/ lifestyle change and bottom-up community approaches is not as fixed as it is sometimes portrayed and the one is not better than the other. In practice, there is often a tension between inclusion of the concerns and issues of the community from a bottom-up approach and the top-down programming approach that usually characterises funding mechanisms and organisational structures. Laverack \& Labonte (2000) suggest to take practice as starting point and to systematically accommodate community empowerment goals within regular approaches to any programming and planning of interventions.

The concept of empowerment relates to terms such as agency, autonomy, selfdirection, self-determination, liberation, participation, mobilisation, and selfconfidence. Empowerment is a debated term, which has been ascribed a wide variety of definitions and meanings in various contexts, referring both to a change process as well as the outcome of that process (Perkins \& Zimmerman, 1995; Ibrahim \& Alkire, 2007). In this dissertation, empowerment is viewed as an approach to enable people who lack power to become more powerful and gain some degree of control over their lives and health (Green, 2010). This suggests that approaches aimed at empowerment must operate at various levels, focussing both on the individual and on organisations and communities (Zimmerman \& Rappaport, 1988). 
Empowerment can further be defined as the result of the interaction between individual agency, i.e., the freedom to do whatever one needs to do to achieve goals or values that one views as important, and opportunity structure, i.e., the broader institutional, social, and political context of formal and informal rules and norms within which actors pursue their interests (Alsop \& Heinson, 2005; Ibrahim \& Alkire, 2007; Sen, 1985). This socio-ecological approach towards individual and community empowerment addresses relevant intrapersonal, interpersonal, community, organisational, national, and global determinants of health and well-being. It recognises and tackles the structural contexts which shape and limit people's agency and therefore ability to act (Green, Richard, \& Potvin, 1996; Bronfenbrenner, 1979). Structural interventions are therefore defined as public health interventions that promote health by altering the structural context within which health is produced and reproduced (Blankenship, Friedman, Dworkin, \& Mantell, 2006). The number of more complex multilevel programmes in health promotion has increased over the past years (Kok, Gottlieb, Commers, \& Smerecnik (2008).

\section{Effectiveness of empowerment interventions}

Empowerment interventions that focus on the individual have increased participants' psychological well-being, including self-efficacy, confidence, and selfesteem (Woodall, Warwick-Booth, \& Cross, 2012). However, there is relatively limited evidence with regard to the effects of multilevel and structural interventions on empowerment. Evaluation of such programmes presents a number of challenges, including restricted opportunities for randomisation, inadequate effect attribution to specific interventions, and limited control over implementation (Craig et al., 2008; Gibbs, Willan, Misselhorn, \& Mangoma, 2012). In general, limited research is conducted measuring the effect of community empowerment programmes on health outcomes of individuals, groups, and communities (Laverack, 2011).

With regard to community-based empowerment interventions that promote women's sexual and reproductive health and rights, most evidence is available regarding the effect of (combined) gender transformative and microfinance interventions on HIV prevention and/or intimate partner violence among women and girls. A meta-analysis of case studies, aiming to identify methods that are frequently used in women's empowerment interventions, showed that established methods were enabling services and support, rights protection and promotion, public education and participation, media use and advocacy, and organising associations and unions, empowerment education and training, and work training and micro-enterprise (Kar, Pascual, \& Chickering, 1999). Effect studies show mixed results (Dworkin \& Blankenship, 2009; Gibbs, Willan, Misselhorn, \& Mangoma, 2012; Pronyk et al., 2006). Research showed that women's and girls' school attendance delays early marriage, improves access to income, increases young women's economic aspirations and success, and is an effective HIV prevention intervention (Hargreaves et al., 2008). However, even though other studies showed considerable reduction of dropout of school through cash transfer interventions (Hallfors et al., 2011) or provision of school uniforms (Duflo, Dupas, Kremer, \& Sinei, 2006), these interventions required large financial inputs and did not contribute to structural 
changes in family income generation. In addition, research showed that microfinance programmes appear to be most successful in supporting women with already existing small-scale businesses, rather than in enabling new businesses to emerge (Dworkin \& Blankenship, 2009). Economic development and poverty reduction may have protective impacts on intimate partner violence at an individual and household level. Context specific factors influence whether financial autonomy is protective or associated with increased risk (Vyas \& Watts, 2009).

With regard to interventions aiming at the empowerment of a specific group of women, unmarried teenage mothers, it is suggested that these might be most effective when using an ecological, community based approach that takes the specific behaviours and their contexts into account (Blankenship, Friedman, Dworkin, \& Mantell, 2006; Araújo Pedrosa et al., 2011; Beers \& Hollo, 2009). However, empirical findings on the effectiveness of such interventions for this specific target group are lacking.

\section{School-based sexuality education}

Another strategy to promote adolescents' SRHR is school-based sexuality education. School-based interventions have great potential for sexuality education because students are expected to attend regularly and the majority begin attending before becoming sexually active. Sexuality education programmes comprise a variety of programmes with varying content, approaches, implementation settings, and deliverers. Sexuality education programmes can be divided into abstinence-only and comprehensive sexuality education (Chin et al., 2012). Abstinence education interventions promote abstinence from sexual activity, either delayed initiation or abstinence until marriage, and restrict information about the use of condoms and contraceptive measures. Comprehensive sexuality education is an age-appropriate, culturally relevant approach to teaching about sex and relationships by providing scientifically accurate, realistic, non-judgemental information (UNESCO, 2010). This implies the promotion of behaviours, including abstinence and contraceptive use (including condoms), that prevent or reduce the risk of pregnancy, HIV, and other STIs. The distinction between abstinence-only and comprehensive sexuality education reflects a long standing debate among parents, providers, and policy makers about the most appropriate goal and content of sexual behaviour interventions for adolescents.

\section{Effectiveness of sexuality education}

With regard to the effectiveness of abstinence-only and comprehensive sexuality education programmes, most research has been conducted on measuring the effectiveness of programmes on adolescents' changed behaviour and behavioural correlates, i.e., delay of sex or sexual intercourse, increased abstinence from sex or sexual intercourse, and use of contraceptives and/or condoms. Meta-analyses and reviews of these studies showed that abstinence-only education found minimal or inconsistent effects, which have been attributed to the limited number of studies meeting the reviewers' inclusion, weak designs, the heterogeneity of programme 
curricula and their implementation, and the lack of providing adolescents with the information they need to protect their health and well-being (Chin et al., 2012; Underhill, Montgomery, \& Operario, 2007; Kohler, Manhart, \& Lafferty, 2008). A recent review (Chin et al., 2012) showed that comprehensive sexuality education is an effective strategy and found favourable effects for current sexual activity, frequency of sexual activity, number of sexual partners, frequency of unprotected sexual activity, use of protection (condoms and/or hormonal contraception), pregnancy, and STIs.

An analysis of effective comprehensive sexuality education programmes revealed a number of characteristics that contributed to changed behaviours (condom use and abstinence from sexual intercourse) and behavioural correlates of adolescents (Kirby, Laris, \& Rolleri, 2007; UNESCO, 2010; Poobalan et al., 2009; Rotheram-Borus, Ingram, Swendeman, \& Flannery, 2009; Romero, Galbraith, Wilson-Williams, \& Gloppen, 2011). These characteristics can be divided into characteristics related to the process of intervention planning, the intervention itself, and the adoption and implementation of the programme (Kirby, Laris, \& Rolleri, 2007). Commonly cited characteristics are cultural and community relevance, gender specificity, clear messages about the risks and how to reduce them, emphasis on both abstinence and protection from STIs and pregnancy, and adolescents' access to health and reproductive services in addition to sexuality education programmes. With respect to the adoption and implementation of sexuality education, it appears that characteristics of effective programmes included the selection of capable and motivated educators to implement the programme, provision of quality training to educators, and provision of on-going management, supervision, and oversight (Kirby, Laris, \& Rolleri, 2007). The implementation of sensitive and sometimes controversial education is difficult for implementers and requires specialist expertise in both programme design and delivery by facilitators (e.g., teachers) (Schaalma, Abraham, Gillmore, \& Kok, 2004). In addition, adoption and implementation of optimally effective, comprehensive programmes may be limited by policy and cultural constraints.

Most reviews and meta-analyses have included studies that were conducted in the USA (Chin et al., 2012; Kirby, 2008; Kohler, Manhart, \& Lafferty, 2008; Trenholm et al., 2008). A study that included studies from the USA, other developed countries, and developing countries found that curriculum-based sex and HIV education programmes were effective in changing sexual behaviour (delay or decrease of sexual behaviours or increase of condom or contraceptive use) and mediating factors across a wide variety of countries, cultures, and groups of youth (Kirby, Laris, \& Rolleri, 2007). The 18 studies in developing countries that met the review inclusion criteria had been conducted in countries in Latin-America and sub-Saharan Africa. No studies were included of the Asian Pacific region, indicating that limited research has been conducted with regard to effectiveness of sexuality education in Asian countries. Another review of studies that only included developing countries concluded that behavioural impact was not found in a sizeable proportion of the interventions reviewed (Speizer, Magnani, \& Colvin, 2003). Interventions that 
targeted multiple behavioural outcomes more often than not failed to achieve such impact, although they often had impact on one or more targeted behaviour.

\section{School-based sexuality education in sub-Saharan Africa and the Asian Pacific region}

Studies that reviewed the effectiveness of HIV-prevention/sexuality education programmes for adolescents in Sub Saharan Africa found mixed effects. Systematic reviews of evaluation studies of HIV prevention programmes for young people found either no or limited effects on sexual behaviour and condom use (Michielsen et al., 2010) or found positive effects on reduced risky sexual behaviour (Napierala Mavedzenge, Doyle, \& Ross, 2011). Reviews of studies evaluating school-based sexual health interventions showed that most studies revealed effects on knowledge, attitudes, and communication about sexuality and sexual health (Kaaya, Mukoma, Flisher, \& Klepp, 2002; Paul-Ebhohimhen, Poobalan, \& Van Teijlingen, 2008). Limited research in sub-Saharan Africa has been conducted measuring the impact of sexuality education on biological outcomes. Two large cluster randomised trials (CRTs), MEMA kwa Vijana in Tanzania (Ross et al., 2007) and Regai Dzive Shiri in Zimbabwe (Cowan et al., 2008; Cowan et al., 2009), evaluated multi-component interventions with activities in schools, health services, and geographically-defined communities. Neither demonstrated a significant effect on any of the biological outcomes of HIV-reduction, reduction in other STIS, and reduction in early pregnancies.

No reviews of studies were found for the impact of sexuality education on adolescents' sexual behaviour in the Asian Pacific region. A review of studies about a general population in Asia showed that behavioural interventions for reducing sexual risk in Asia are efficacious, whereas the magnitude of the effects co-varies with specific intervention and structural components (Tan et al., 2011). An overview of adolescent education programmes in the Asian Pacific region shows that these programmes are largely information-based, but with an emphasis on life-skills such as assertiveness and negotiation (Smith, Kippax, Aggleton, \& Tyrer, 2003). Specific sexual practices are rarely discussed in the schools, except in a somewhat mechanistic way, focusing mainly on human reproduction and anatomy. However, those countries most affected by the HIV/AIDS epidemic are beginning to re-think their approaches. An increasing openness about sexual and drug injecting practices, and how to communicate these issues with young people, is beginning to become apparent. An evaluation of a sexuality education programme in Thailand showed effects on decreased sexual intercourse of adolescents, intention to refuse sex, lower frequencies of sexual intercourse across time, increased intention to use condoms, but no effects on consistent condom use (Thato, Jenkins, \& Dusitsin, 2008; Kay, Jones, \& Jantaraweragul, 2010).

\section{Communication about sensitive topics}

Based on evidence, various authors have suggested that comprehensive behavioural interventions are needed that take account of the social context in individual-level programmes, aiming to modify social norms to support uptake and maintenance of 
behaviour change, and tackle the structural factors that contribute to risky sexual behaviour (Wellings et al., 2006; DiClemente, Salazar, \& Crosby, 2007; Tan et al., 2011; Widman, Welsh, McNulty, \& Little, 2006; Auerbach, Parkhurst, Caceres, \& Keller, 2009; Gupta et al., 2008). Frequently mentioned structural factors in sexual and reproductive health promotion are social norms, values, and related taboos (Evans, Avery, \& Pederson, 1999). Taboos can be defined as beliefs that constrain actions by making certain behaviours and communication about certain topics forbidden or discouraged (Montgomery, 2009). Examples of common sexuality related taboos include personal disclosure about sexual orientation, HIV-status, and experience with violence, out-of-wedlock pregnancy, or abortion; about sexual histories, sexual desires, and preferences, boundaries, menstruation, sexual behaviour, and contraceptive use; and about beliefs and intentions that may not align with societal or community norms (Montgomery, 2009; Wood, Maforah, \& Jewkes, 1998; Stutterheim et al., 2011).

Lack of communication about sexuality related topics can lead to ambiguity, misunderstanding, and misconceptions (Marston \& King, 2006; Varga, 1997; Ingham, Woodcock, \& Stenner, 1991; Schalet, 2011). On the contrary, adolescents' open communication with peers, parents, sexual partners, and health service providers and other professionals can contribute to problem solving and support seeking behaviours (Rodríguez, Sheldon, Bauer, \& Pérez-Stable, 2001), to express thoughts and feelings, to a sense of self and to intimacy in relationships (Chaudoir \& Fisher, 2010; Greene, Derlega, \& Mathews, 2006; Derlega, Winstead, Mathews, \& Braitman, 2008), to decreased stigma and discrimination (Stutterheim et al., 2011), and to abstinence of sex, consensual sex, and use of condoms or contraceptives (Bastien, Kajula, \& Muhwezi, 2011; Sheeran, Abraham, \& Orbell, 1999; Allen, Emmers-Sommer, \& Crowell, 2002; Noar, Carlyle, \& Cole, 2006).

Taboos can be addressed by changing norms with regard to behaviours and by increasing communication about it. Communication about sensitive topics is also referred to as self-disclosure and can be defined as an interaction between at least two individuals where one intends to deliberately reveal highly sensitive information such as personal fears, deeply held religious convictions or potentially stigmatising information to another (Derlega, Metts, Petronio, \& Margulis, 1993; Greene, Derlega, \& Mathews, 2006). Self-disclosure skills of adolescents are critical to be prepared for intimate and sexual interactions and for seeking support and services. Sexuality education programmes can contribute to open communication by providing adolescents a safe opportunity to explore and articulate their thoughts about intimacy, sexuality, desires, preferences, and boundaries, and support them to discuss these issues openly with their sexual partners (Widman, Welsh, McNulty, \& Little, 2006). A review of studies throughout the world showed an effect of sexuality education programmes on communication with partners about AIDS, STIs, and past partners and on communication with parents or other adults about sex. However, limited effects were found on communication with a boyfriend/ girlfriend or partner regarding abstinence or contraception (Kirby, Laris, \& Rolleri, 2007). 


\section{Systematic intervention planning}

\section{Perspectives}

A comprehensive approach to the systematic planning or adaptation of theory- and evidence-based health promotion interventions is Intervention Mapping (IM) (Bartholomew et al., 1998, 2001, 2006; Bartholomew, Parcel, et al., 2011). IM is a stepwise framework and describes an iterative process from problem identification to problem solving or mitigation through planning theory- and evidence-based behavioural and environmental change programmes.

IM is characterised by three general perspectives that are applied throughout the planning process. Firstly, the involvement of all relevant stakeholders in planning is emphasised. Relevant stakeholders may include community members, potential beneficiaries, programme implementers, and other persons with an interest in the health problem and outcomes (Bracht, 1999; Minkler \& Wallerstein, 2011). Stakeholders can be involved to enhance ownership, to influence diffusion and sustainable implementation, to embed the intervention in existing policies, and to complement other relevant programmes. The collaboration between the programme developers and intended programme users can be organised in a linkage system (Orlandi, Landers, Weston, \& Haley, 1990).

Secondly, IM provides a framework to use multiple relevant social and behavioural science theories and supporting evidence to explain the problem of interest and to give guidance for change. Multiple decisions have to be made in the process of intervention planning and theories are one tool to enable planners to make these choices. Evidence is defined as not only data from research studies as represented in the scientific literature but also opinions and experience of community members and planners (Bartholomew, Parcel, et al., 2011).

Thirdly, problem identification and problem solving are approached from a social ecological perspective (Green, Richard, \& Potvin, 1996; Bronfenbrenner, 1979). In the social ecological model, health is viewed as a function of individuals and of the social environments in which individuals live, including family, social networks, organisations, communities, and societies. Individual behaviour is influenced by factors at these intrapersonal, interpersonal, and environmental levels. From this perspective an intervention is viewed as an event occurring in a system within which many factors interact with and influence targeted behavioural or environmental change. Risk behaviours of the at risk group(s) as well as impeding environmental factors are converted into problem solving behaviours of actors on interpersonal, community, societal, and global levels that have power to change these factors (Bartholomew, Parcel, et al., 2011).

The three perspectives are applied in the planning of new interventions and in the adaptation of existing interventions to a new priority population and setting (Bartholomew, Fernández, et al., 2011). Adaptation can comprise adding or deleting programme components, changing programme components or content, changing the process or intensity of implementation, or making cultural modifications (Backer, 2001). One of the major challenges in programme adaptation is finding a balance between (1) fidelity to the original programme and (2) modifying the 
programme to fit the new cultural, organisational, and policy context (Castro, Barrera, \& Martinez, 2004; Bell et al., 2007). Fidelity to the original programme means that core elements, protocols, procedures, and content are kept in the new programme and the programme is implemented in the new setting as it was in the original programme. The programme's core elements are, for most programmes, a combination of the following: (1) theoretical methods that are intended to change determinants of behaviour of the at-risk group and the environmental agents, (2) practical applications of the methods, including delivery channels, (3) characteristics of programme materials and messages, including cultural elements, and (4) characteristics of programme implementation (Bartholomew, Fernández, et al., 2011).

Using a systematic approach to adaptation is important for preserving the programme's core elements (Cuijpers, De Graaf, \& Bohlmeijer, 2005; Wandersman et al., 2008; Wingood \& DiClemente, 2008; Abraham \& Michie, 2008; Albarracín et al., 2005) and can assist planners to produce a programme that fits with the health needs and behaviour change focus of the priority group, is implementable in the new context, fits with governmental and organisational policies, matches the capacities of programme deliverers, and is culturally acceptable. The disadvantage of a non-systematic approach to intervention adaptation is that adaptations are not documented, depend largely on individual decisions rather than formative research, and planners do not gain insight into why particular programme elements are removed, added, or maintained in the programme. A risk of non-systematic adaptation is that the programme may not address the needs of the new priority group or fit with the new implementation setting. In addition, essential programme elements may be removed from the original programme, decreasing the programme's effectiveness (Paine-Andrews et al., 1999; Castro, Barrera, \& Martinez, 2004).

\section{IM steps}

The six steps that IM encompasses can be applied in the planning of new interventions and in the adaptation of existing interventions. In most projects, intervention planning is an iterative process, guiding planners to go back and forth through the six steps (see Figure 1.1). The first step is a needs assessment (IM Step $1)$, an analysis of the problem and its possible solutions. The formation of the linkage system to organise the involvement of all relevant stakeholders is the first task in step 1 . The needs assessment can be conducted using a modified version of the PRECEDE model (Green \& Kreuter, 2005), resulting in a 'logic model of the problem' (see Figure 1.2). The (modified) PRECEDE model is a population-based epidemiologic planning framework that is ecological in its perspective. The model directs planners to determine people's quality of life (phase 1) and the health problem characteristics that determine people's quality of life, such as morbidity, mortality, disease risk, and burden of disease (phase 2). Subsequently, planners analyse the behavioural and environmental factors that hinder or contribute to the health problem (phase 3). In phase 4, planners analyse the determinants of behaviours of people at risk and of environmental actors. 


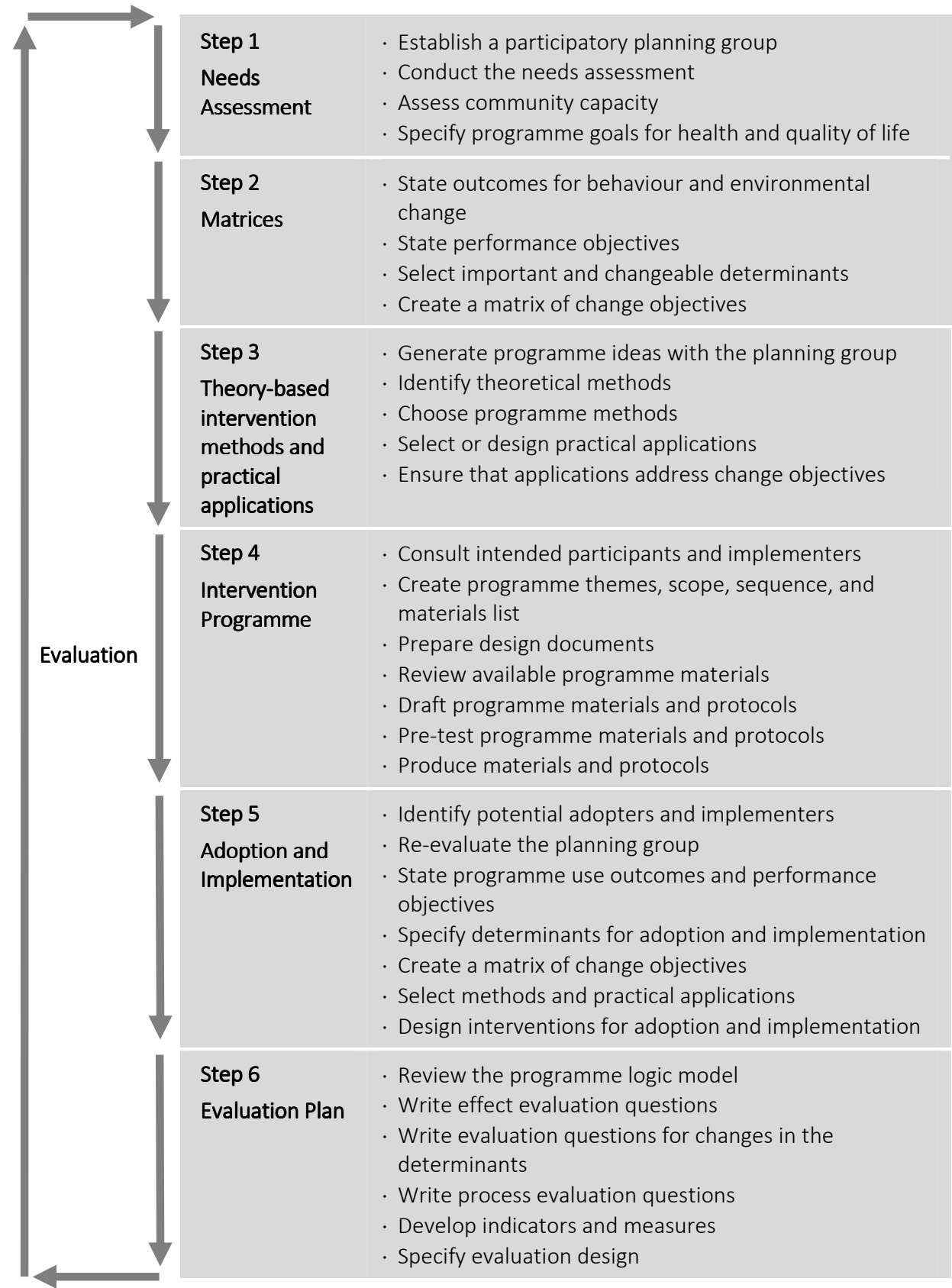

Implementation

Figure 1.1 Intervention Mapping Steps and Tasks (Bartholomew, Parcel, et al., 2011, p.19) 
Behavioural determinants can be analysed using a variety of models and theories, including the Theory of Planned Behaviour (TPB; Ajzen, 1991). TPB is most often applied at the individual level, but can also be applied to other ecological levels (Bartholomew, Parcel, et al., 2011). A needs assessment also comprises an analysis of possible solutions and existing resources to address the problem. When planners use IM to adapt existing interventions to new settings and priority populations, they compare the 'logic model of the problem' of the new setting and priority populations with the logic model of the original setting and population.

In IM step 2, planners identify and select the beneficiaries (target groups) and prioritise for each (sub-) group the most important and changeable objectives. One of the products is a 'logic model of change', composed of (1) behavioural outcomes (desired behaviours of all actors), (2) performance objectives (break down of behavioural outcomes and also referred to as sub-behaviours or preparatory behaviours), and (3) change objectives (for behavioural determinants of the performance objectives). When planners use IM to adapt interventions, they analyse to what extent the 'logic model of change' of the original model sufficiently addresses the needs of the new context and priority populations, and if needed adapt the logic model of change.

After the development of matrices of change objectives, planners select behaviour change methods and practical applications for the behavioural determinants (IM step 3). A behaviour change method is a theory-based technique to influence change in behavioural determinants of at risk groups as well as of actors in their social environment.

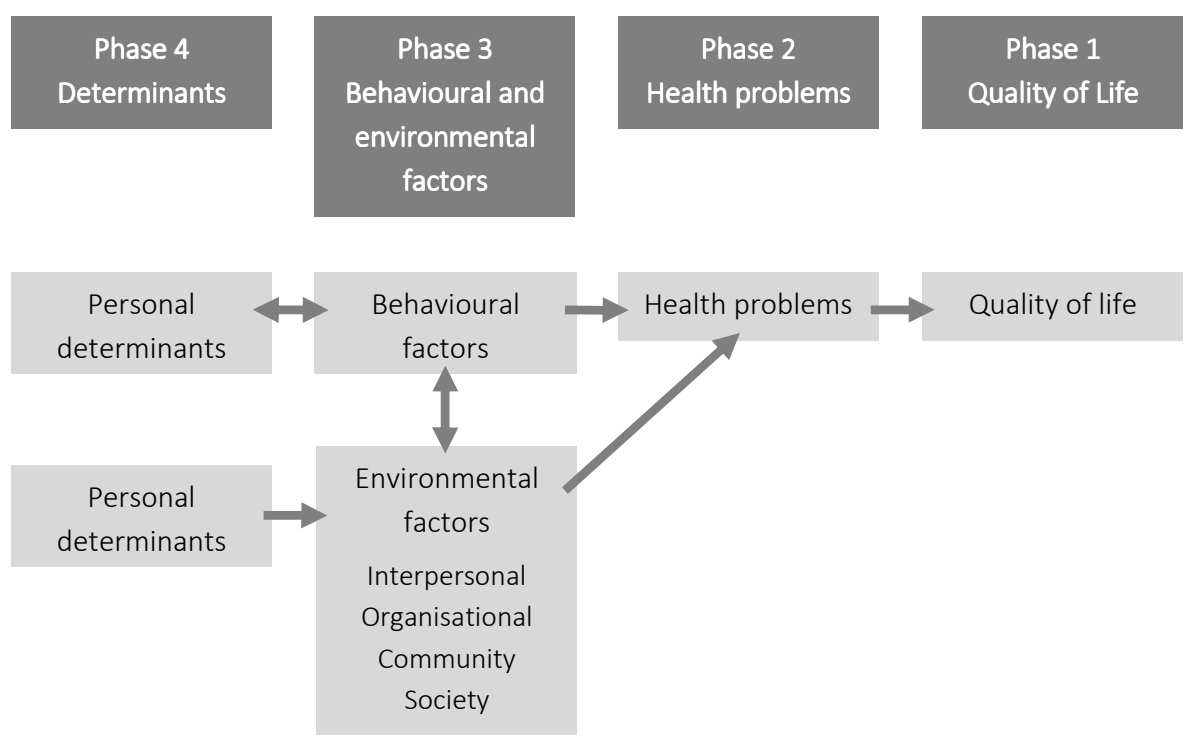

Figure 1.2 Logic Model for Needs Assessment (Bartholomew, Parcel, et al., 2011, p.191) 
Behaviour change methods are only effective when they meet method-specific parameters. For example, some methods are only effective if a source of information is reliable. Practical applications are defined as techniques for the application of the theoretical methods and generally include the intervention's activities and materials (e.g., group discussion). In adaptation, planners analyse the intervention for its theoretical methods and practical applications and make sure that essential behaviour change methods in the original programme are retained in the adapted programme, in order to produce the desired effects in the change objectives. Planners also assess whether the circumstances in the new implementation setting allow the original practical applications or not. Defining which theoretical methods of a given intervention are essential to success and which might be changed in order for the intervention to be of value elsewhere or with other populations, is therefore essential (Schaalma \& Kok, 2009; Albarracín et al., 2005; Abraham \& Michie, 2008).

The methods and applications are the foundation for the design of the intervention in $I M$ step 4 . The integration of applications results in a coherent programme with intervention materials that are produced and tested. In adaptation, the acceptability, attractiveness, and persuasiveness for the new priority group and implementers are considered. Elements of modification of the programme can include language, surface structure (e.g., appearance of role models), and deep structure (e.g., addressing the core values, beliefs and norms of the cultural group's world views and lifestyles; Resnikow et al., 2000).

To guide programme adoption (willingness to use), implementation (ability to use), and sustainability (maintained use), planners design theory- and evidencebased adoption and implementation interventions (IM step 5). If planners do not plan for adoption and implementation, it is likely that health promotion programmes are not fully adopted and implemented (Paulussen, Kok, Schaalma, \& Parcel, 1995). Planners start with conducting an assessment of who will adopt and implement the programme, what they will need to do, and what will determine their adoption and implementation behaviours. Once objectives are defined, theoretical methods and practical applications can be selected, and interventions can be designed to promote programme use. In adaptation, planners conduct a similar analysis and assess whether the willingness to adopt the new programme is equal to the willingness in the original context, whether similar methods and applications for promoting the adoption and implementation of the adapted intervention are applicable in the new setting, and whether the original training and support for implementers are relevant for the new setting.

Finally, planners design an evaluation plan (IM step 6) to analyse the design and implementation process (process evaluation) and measure the intervention's effectiveness (effect evaluation). In adaptation, the objectives of the adapted programme are the evaluation indicators and may therefore differ from the indicators of the original programme. 


\section{Outline of the dissertation}

This dissertation consists of two parts. The dissertation starts with two chapters related to the community-based Teenage Mothers Project, an empowerment intervention which has been implemented in geographically defined communities in Eastern Uganda. The intervention aims at the empowerment of unmarried teenage mothers and their resident rural communities. The intervention is designed and implemented by a local community based organisation (CBO) ARDI and community members in the Manafwa district in Uganda. The project is supported by the Adopteer een Geit foundation in the Netherlands. Chapter 2 describes how Intervention Mapping was used to plan the Teenage Mothers Project. Chapter 3 describes a qualitative effect evaluation of the intervention.

The second part of the dissertation consists of three chapters related to the comprehensive sexuality education programme 'The World Starts With Me' (WSWM). WSWM aims at the empowerment of young people to make their own choices regarding sexuality and their sexual and reproductive health and rights. Young people are approached as actors and social agents of change instead of mere recipients of messages and information. WSWM, originally developed in Uganda, has been implemented in schools, delivered through computers, and facilitated by teachers and peer educators. The intervention is moulded on a rights-based approach towards comprehensive sexuality education. WSWM was developed by SchoolNet Uganda (Uganda), Rutgers WPF (the Netherlands), and Butterfly Works (the Netherlands) and has been adapted to various countries, implementation settings, and target groups, including secondary school students in Indonesia and Thailand. Chapter 4 describes a study exploring the psychosocial correlates of sexual abstinence intentions of school-going young people in Indonesia. Chapter 5 describes a quantitative evaluation of the effects of WSWM on adolescents' selfdisclosure about sensitive sexuality related topics in Uganda and Thailand. Chapter 6 provides an overview of how Intervention Mapping can be used to adapt existing interventions to new contexts and priority populations. The adaptation of the original WSWM programme in Uganda to an Indonesian WSWM is described.

The general discussion in Chapter 7 provides a discussion of the research findings, a reflection on the methodology used, and implications for practice and future research regarding interventions aiming at SRHR promotion of young people worldwide. 


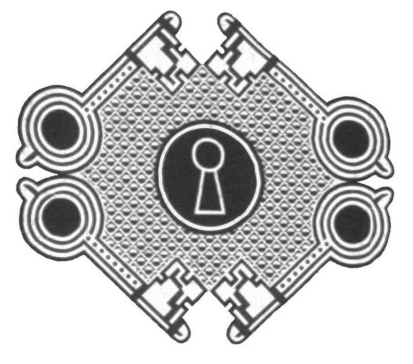

\section{Chapter 2}

Empowering teenage mothers in Uganda: The development of a community-based intervention to improve psychological and social well-being of unmarried teenage mothers

Leerlooijer, J. N., Kok, G., Weyusya, J., Bos, A. E. R., Ruiter, R. A. C.,

Rijsdijk, L. E., Nshakira, N., \& Bartholomew, L. K.

Submitted 


\begin{abstract}
Out-of-wedlock pregnancy among adolescents in sub-Saharan Africa is a major concern, because of its association with health, social, psychological, economic, and demographic factors. This chapter describes the development of the Teenage Mothers Project, a community-based intervention to improve psychological and social well-being of unmarried teenage mothers in low-income communities in rural Uganda. We used the Intervention Mapping (IM) framework for systematically developing a theory and evidence-based comprehensive health promotion programme. A planning group consisting of community leaders, teenage mothers, staff of a community based organisation (CBO), and a health promotion professional was involved in the six steps of IM: needs assessment, programme objectives, methods and applications, intervention design, planning for adoption and implementation, and planning for evaluation. The programme includes five intervention components: community awareness raising, teenage mother support groups, education and income generation, counselling, and advocacy. The interventions are based on a variety of theoretical methods, including participatory planning, modelling, mobilisation of social networks, persuasive communication, entertainment education, advocacy, guided practice, provision of information about relevant others' approval, and social action. The intervention is implemented by trained community based volunteers, CBO staff, and community leaders. Between March 2000 and March 2012, 1.036 unmarried teenage mothers have participated in the project. Positive changes among teenage mothers and actors in their social environment as well as challenges were found in a qualitative study that is reported elsewhere. IM facilitated the planning group to structure the iterative, participatory design of the Teenage Mothers Project and to use evidence and theory. This chapter gives insight in how to use IM for systematic planning of community-based support interventions for unmarried teenage mothers, for bottom-up, participatory planning processes in a real-life setting, and for planning social change interventions.
\end{abstract}




\section{Introduction}

Out-of-wedlock pregnancy among female adolescents in sub-Saharan Africa is a major concern. Despite a decline in the past decades in most sub-Saharan African countries, fertility rates among adolescents aged 15-19 are still high (Garenne \& Zwang, 2009). Compared to other African countries, Uganda has a high fertility rate of 6.2 children per woman (in 2011), which is largely a result of early childbearing: one out of four females aged 15-19 in Uganda delivers a child (Uganda Bureau of Statistics, 2012). Complications during pregnancy, abortion, and childbirth are the leading causes of disability and mortality among female adolescents in Uganda (Population Secretariat, 2001). A large proportion of teenage pregnancies are outof-wedlock and unplanned (Uganda Bureau of Statistics, 2012), causing psychological and social consequences including low self-esteem, depression, physical and physiological violence, as well as stigma, isolation, rejection from families, partners, and community members, limited social and financial support, high rates of school dropout, and limited career opportunities (Population Secretariat, 2001; Biddlecom, Gregory, Lloyd, \& Mensch, 2008; Atuyambe, Faxelid, et al., 2008; Atuyambe et al., 2005 Atuyambe et al., 2009; Levandowski et al., 2012).

A number of studies have explored intervention programmes aiming at primary prevention of teenage pregnancy, HIV/AIDS, and other sexually transmitted infections (STIs) in sub-Saharan Africa (Kaaya et al., 2002; Foss, Hossain, Vickerman, \& Watts, 2007; Michielsen et al., 2010; Rijsdijk et al., 2011), secondary prevention of teenage pregnancy (Corcoran \& Pillai, 2007), maternal health care for teenage mothers (Atuyambe, Mirembe, et al., 2008), and interventions aiming at parenting and psychological support for teenage mothers and their children (Schaffer, Goodhue, Stennes, \& Lanigan, 2012). There is however limited evidence regarding support interventions for unmarried teenage mothers in low-income African settings (Atuyambe, Faxelid, et al., 2008). Reviews of existing evidence suggest that support interventions targeting unmarried teenage mothers may be effective when using an ecological, community based approach that takes the specific behaviours and their contexts into account (Araújo Pedrosa et al., 2011; Kulin, 1988; Beers \& Hollo, 2009). However, there are few well-designed theory and evidence-based interventions that incorporate these suggestions, with a particular scarcity in African settings. We initiated a project to develop such an intervention in a rural low-income setting in Eastern Uganda.

In this chapter we describe the results of the participatory planning of the Teenage Mothers Project, a community based empowerment intervention aiming at improved psychological and social well-being of unmarried teenage mothers. In this project, we defined psychological well-being as the extent to which people feel happy or content with life. Psychological well-being encompasses self-acceptance, personal growth, purpose in life, environmental mastery (the capacity to manage effectively one's life and surrounding world), autonomy, and positive relationships with others (Ryff \& Keyes, 1995). Social well-being was defined as a sense of involvement with other people and communities and comprises social integration 
(relationship to society and community), social contribution, social coherence (the perception of the quality, organisation, and operation of the social world), social actualisation (the evaluation of the potential and the trajectory of society), and social acceptance (the construal of society through the character and qualities of other people as a generalised category) (Keyes, 1998).

The project design was guided by the Intervention Mapping (IM) framework to ensure that the intervention was grounded in theory and evidence and to maximise the likelihood of effectiveness (Bartholomew, Parcel, et al., 2011; Godin et al., 2007). IM is a stepwise framework and describes an iterative process from problem identification to problem solving or mitigation through designing theory- and evidence-based behaviour change programmes. IM is characterised by three general perspectives that are applied in all the steps. Relevant stakeholders are involved in decision making from the beginning of programme planning. Relevant stakeholders include community members, potential beneficiaries, programme implementers, and other persons with an interest in the health problem and outcomes (Bracht, 1999; Minkler \& Wallerstein, 2011). A linkage system that organises the collaboration between the future programme users and programme developers can enhance community ownership and influence diffusion and sustainable implementation (Orlandi, Landers, Weston, \& Haley, 1990). The second perspective is the use of multiple theories and supporting evidence to explain the problem of interest and to give guidance for change. Thirdly, an intervention is viewed as an event occurring in a system within which many factors interact with and influence targeted behaviour or environmental change. IM approaches problem identification and problem solving from an ecological perspective (Green, Richard, \& Potvin, 1996). Risk behaviours of the at risk group(s) as well as impeding environmental factors are converted into problem solving behaviours of actors on interpersonal, community, societal, and global levels that have power to change these factors (Bartholomew, Parcel, et al., 2011). The literature increasingly reports about methods to address environmental factors in structural interventions (Blankenship, Friedman, Dworkin, \& Mantell, 2006; Gibbs, Willan, Misselhorn, \& Mangoma, 2012; Mbonu, Van Den Borne, \& De Vries, 2009; Kim et al., 2007), which can be categorised into six types: policy-legal changes, environmental enablers, shifting harmful social norms, catalysing social and political change, empowerment of communities and groups, and economic empowerment interventions (Auerbach, Parkhurst, \& Cáceres, 2011).

IM encompasses six steps, each leading to a product that guides the next step (see Figure 1.1. Intervention Mapping Steps and Tasks, p. 18). Each planning process starts with a needs assessment (step 1) to analyse the problem and its possible solutions. This results in a 'logic model of the problem' describing the health problem, its impact on quality of life, behavioural and environmental causes of health and quality of life, as well as the factors (determinants) related to these causes. One of the tasks is the formation of the linkage system. In step 2, planners identify the beneficiaries (target groups) and prioritise for each group the most important and changeable objectives. One of the products is a 'logic model of change', composed of behavioural outcomes (desired behaviours of all actors), 
performance objectives (break down of behavioural outcomes and also referred to as sub-behaviours or preparatory behaviours), and change objectives (for behavioural determinants of the performance objectives). Subsequent to the development of matrices of change objectives, planners select theoretical behaviour change methods and practical applications for the behavioural determinants (step 3). A behaviour change method is a theory-based technique to influence change in behavioural determinants. Behaviour change methods are only effective when they meet method-specific parameters, for example reliability of the source of information. Practical applications are defined as techniques for the application of the theoretical methods and generally include the intervention's activities and materials. The methods and applications are the underpinning of the intervention design in step 4. The integration of applications results in a coherent programme with intervention materials that are produced and tested. To guide programme adoption (willingness to use), implementation (ability to use), and sustainability (maintained use), planners design theory- and evidence-based adoption and implementation interventions (step 5). Finally, planners design an evaluation plan (step 6).

\section{Methods/ Design}

The six sequential steps of the IM planning of the Teenage Mothers Project are described below. In reality we did not follow the framework in a linear way. However, we moved back and forth between the steps as suggested by Bartholomew, Parcel, et al. (2011) and the Teenage Mothers Project gradually developed between 2000 and 2011.

\section{Step 1: Needs assessment}

As part of the needs assessment behavioural and environmental causes of harmful consequences of out-of-wedlock pregnancy were assessed and a planning group was established. Existing community structures and resources were analysed in the project's initiation phase. The project was conceived based on a qualitative study and literature review in 1999 regarding sexuality and reproductive health of female adolescents in the Manafwa district of Eastern Uganda. The findings of this assessment have been described in an unpublished report that can be obtained from the author (Leerlooijer, 2001). The qualitative study consisted of focus group and in depth interviews with female adolescents aged 15-19 $(N=85)$. More than half of the participants were not in school and a majority of these young women had experienced out-of-wedlock pregnancy $(N=45)$. In depth interviews were conducted with community members $(N=12)$ including males of various age groups, parents, governmental leaders, and school staff. The study revealed that out-of-wedlock teenage pregnancy, stigma, and violation of the rights of unmarried mothers were a problem in the communities. A majority of community members and community leaders was not aware of its magnitude and harmful consequences for unmarried teenage mothers and the community as a whole (Leerlooijer, 2001). 


\section{Needs assessment results}

The needs assessment showed that the Eastern region had the highest proportion (almost one out of three) of unintended pregnancies in Uganda (Uganda Bureau of Statistics, 2012; Singh, Prada, Mirembe, \& Kiggundu, 2005). This proportion was higher in poorer households and was higher in rural than in urban areas (Uganda Bureau of Statistics, 2012; Agyei, Mukiza-Gapere, \& Epema, 1994). Most unintended pregnancies were out of wedlock, causing harmful psychological and social consequences for unmarried teenage mothers (Kamali et al., 2000). The qualitative study conducted in 1999 in the Manafwa district showed that the majority of the out of school female teenagers who participated in the focus group interviews ( $N=$ 45) had experienced out-of-wedlock pregnancy (Leerlooijer, 2001). They reported emotional turmoil as they strived to cope with their pregnancy and early motherhood and with pregnancy-related stigma. Stigma-related theories distinguish between 4 related aspects of stigma, which were applied to the stigma of unmarried teenage mothers in the Manafwa district: self-stigma, structural stigma, public stigma, and stigma by association (Pryor \& Reeder, 2011).

The first aspect was the social and psychological impact of stigma on the unmarried teenage mothers (self-stigma). The teenage mothers reported limited quality of life, loneliness, insecurity, low self-esteem, limited decision making power, and limited opportunities for personal growth. They described feelings of isolation because of rejection and lack of support from peers and parents/guardians. They also reported lack of belonging in the adult married mothers' social groups and in peer female teenagers groups (James, Van Rooyen, \& Strümpher, 2012; Nash, 1990). They did not have effective coping skills to deal with pregnancy, early motherhood, discontinued education, and with stigma and its harmful consequences (Araújo Pedrosa et al., 2011; Romo \& Nadeem, 2007). Some teenage mothers in the qualitative study reported to have transactional sex to be able to sustain themselves and their child, sometimes resulting in another pregnancy (Leerlooijer, 2001), which is also supported by other studies (Bohmer \& Kirumbira, 2000).

Strong social norms in the community rejecting sex and pregnancy outside a marital relationship made the unmarried teenage mothers outcasts in their communities (structural stigma). This was exhibited by stigmatising attitudes and behaviours of community members towards the teenage mother and her family (public stigma). In general, community members perceived unmarried teenage mothers as 'lost' people, who were not worth to invest in (La Fontaine, 1959).

Influenced by the stigmatising social norms, many parents/guardians (referred to as parents in the remaining of this chapter) felt compelled to send their pregnant daughters away to relatives to mitigate shame and embarrassment (stigma by association). From a historical and cultural perspective, fathers have had rights over their daughters' productive and reproductive labour until access to both would officially be transferred to her husband through the negotiation and exchange of bride wealth. Sexual liaisons with a young woman without consent of her father were therefore considered theft, a crime committed by one man against another man's property (Parikh, 2012; La Fontaine, 1959; Heald, 1999). Many parents 
therefore arranged marriages for their pregnant daughters to earn dowry and few parents supported their daughters to continue their education. As a result, most unmarried teenage mothers did not go back to school after delivery (Atuyambe et al., 2005).

Another factor obstructing the continuation of the teenage mothers' education was the disapproving behaviour and attitudes of school administrators, staff and students (public stigma). School administrators tended to dismiss female teenagers from school after discovering her pregnancy and to publicly stigmatise them in the schools (Atuyambe et al., 2005).

The unmarried teenage mothers also had to cope with the lack of support of the father of their child. Most fathers did not take responsibility for the child and for the teenage mother. The most important reason was their fear to be accused of defilement. The Ugandan Defilement Law has been making it illegal for a man to have sexual intercourse with a female under the age of eighteen years old, whether she consents or not. This can be punished with a fine, imprisonment, and even sentence to death (Parikh, 2012). The qualitative study described a number of stories of teenage mothers who had become pregnant of so-called 'sugar daddies', a widely used term to refer to older men who lure adolescent girls into sexual liaisons often by offering them money or other goods in exchange for sex (Leerlooijer, 2001; Kelly et al., 2003).

\section{Existing community structures and resources}

Existing community structures and resources to address the psychological and social consequences of out-of-wedlock pregnancy were analysed in the project's initiation phase. The analysis was conducted through literature review and formative research. The estimated population of the project area, the Manafwa District located on the Kenyan border, is approximately 183,000. Most people are farmers and some are traders. Young people are often unemployed or are engaged in temporary or seasonal work in the informal economy. Socioeconomic standards and literacy rates are generally low. Decision making power in the district is largely with male governmental, tribal, and religious leaders. Governmental and political leaders on district, sub-county, and village level can influence the implementation of national and district level policies and laws. The sub-county and village leaders are involved in local events, such as burials, weddings, and other community meetings. Tribal leaders include the clan leaders, respected representatives who have regular meetings concerning matters in their own clan, and elders, men who are respected for their life experience and knowledge about the tribe's history. Religious leaders are another influential group that is very well respected by community members. In the Manafwa district, most people are Christian (Protestant or Catholic) and a minority is Muslim. 


\section{Planning group}

After the needs assessment, a planning group was established in 2000, composed of volunteers of the community based organisation African Rural Development Initiatives (ARDI), a health promotion professional, and community leaders and unmarried teenage mothers in the Manafwa district. The ARDI volunteers originated from the intervention communities, had been implementing adult literacy and HIV/AIDS projects, and had built trust among community members and influential leaders. Relevant decision makers in the communities were frequently informed and consulted.

The planning group designed the intervention programme moving back and forth between the IM steps, gradually adding new components to the intervention between 2000 and 2011. The planning process included structured and official as well as unstructured and unofficial participation of the planning group. In the early years of the project, ideas and gaps were generated from teenage mothers and community leaders, discussed, checked with the health promotion professional, and implemented on a small scale. The health promotion professional translated scientific concepts into understandable topics to be discussed by the other planning group members. If monitoring data showed acceptance by implementers and change among beneficiaries, the activities were implemented on a larger scale. For example, one of the community leaders provided a plot of land to support teenage mothers' activities. Monitoring data indicated that his contribution was successful and the activity was subsequently reinforced by ARDI staff and copied by other community leaders. This resulted in a new element that was incorporated in the intervention.

\section{Intended programme beneficiaries and programme outcomes}

Based on the needs assessment the planning group decided to address the consequences of out-of-wedlock pregnancies by intervening among various actors: the teenage mothers themselves, their parents, decision makers on community, school, and national levels, and members of the community at large. There was an evidence base, but not very extensive. However, the project was also started as a result of the rights of teenage mothers to education and a 'good life'. Even though the fathers of the infants were identified in the needs assessment as hindering teenage mothers' well-being by not taking responsibility, they were not included as beneficiaries of the intervention. Pilot implementation at the start of the project showed that teenage mothers tended to shy away if they were asked to disclose names of the fathers of their children. The young mothers worried about negative consequences from the fathers, powerful relatives, or well-known 'sugar daddies'. If the father of the child was someone they loved, they were worried that he would be accused of defilement.

The overall programme outcome was to improve the psychological and social well-being of unmarried teenage mothers in the Manafwa district. Table 2.1 provides an overview of actors on various social ecological levels. 
Table 2.1 Social Ecological Model and the Teenage Mothers Project

\begin{tabular}{|c|c|c|}
\hline $\begin{array}{l}\text { Social ecological } \\
\text { levels }\end{array}$ & $\begin{array}{l}\text { At risk groups and environmental } \\
\text { actors }\end{array}$ & $\begin{array}{l}\text { Beneficiaries and environmental } \\
\text { agents }\end{array}$ \\
\hline \multirow{3}{*}{$\begin{array}{l}\text { Intrapersonal } \\
\text { Interpersonal }\end{array}$} & Unmarried teenage mothers & \multirow[t]{2}{*}{ Unmarried teenage mothers } \\
\hline & Fathers of the baby child & \\
\hline & Parents & Parents \\
\hline Organisation & $\begin{array}{l}\text { School administrators and staff } \\
\text { Health service providers }\end{array}$ & School administrators and staff \\
\hline \multirow[t]{3}{*}{ Community } & \multirow[t]{3}{*}{ Community members } & Community members \\
\hline & & Tribal and religious leaders \\
\hline & & Sub-county and village leaders \\
\hline \multirow[t]{2}{*}{ District/ Nation } & \multirow[t]{2}{*}{$\begin{array}{l}\text { District and national government } \\
\text { officials/ politicians }\end{array}$} & $\begin{array}{l}\text { District and national government } \\
\text { officials/ politicians }\end{array}$ \\
\hline & & Journalists \\
\hline
\end{tabular}

\section{Step 2: Matrices of change objectives}

Working from our needs assessment, the planning group specified three levels of objectives. We defined (1) desired behaviours of all actors (behavioural and environmental outcomes), (2) a breakdown of these behaviours (performance objectives), and (3) change objectives formed by crossing the personal determinants with performance objectives (Bartholomew, Parcel, et al., 2011).

\section{Behavioural and environmental outcomes and performance objectives}

The behavioural outcomes and performance objectives for unmarried teenage mothers are listed in Table 2.2. To improve teenage mothers' psychological and social well-being, the Teenage Mothers Project aimed at improved coping with stigma, improved coping with motherhood, continuation of education, increased income generation, increased abstinence from sex or protected sex, and increased advocacy for the rights of unmarried teenage mothers (Atuyambe, Faxelid, et al., 2008; Baytop, 2006).

Performance objectives for improved coping with stigma were based on emotion-focused strategies (i.e., regulating negative emotions that result from stigma) and problem-focused strategies (i.e., reconciliation of relationships with parents, seeking help and support from counsellors, and sharing experiences with other teenage mothers) (Major \& O'Brien, 2005). Most objectives were stated at the project's initiation, whereas others were added in the course of the project. For example, the behavioural outcome 'Unmarried teenage mothers advocate for their rights', was added once a number of teenage mothers had completed higher levels of education. They were deployed as role models for other teenage mothers and as advocates for the rights of unmarried teenage mothers. 
Table 2.2 Behavioural outcomes and performance objectives for unmarried teenage mothers

Behavioural outcomes

1. Unmarried teenage mothers effectively cope with stigma

2. Unmarried teenage mothers effectively cope with motherhood

3. Unmarried teenage mothers continue their education

4. Unmarried teenage mothers generate income

5. Unmarried teenage mothers have no sex or protected sex to avoid pregnancy, sexually transmitted infections, and HIV/AIDS

6. Unmarried teenage mothers advocate for their rights

\section{Performance objectives}

1.1. Regulate negative emotions that result from stigma

1.2. Reconcile relationships with parents

1.3. Seek help or counselling when needed

1.4. Share experiences with other unmarried teenage mothers

2.1. Regulate negative emotions that result from unplanned motherhood

2.2. Obtain maternal and child health care services

2.3. Attend to feeding and hygiene of the child

2.4. Foster the child's emotional and educational development

3.1. Decide to continue their education

3.2. Return to primary or secondary school

3.3. Attend vocational education

3.4. Use own income to contribute to school fees

4.1. Initiate own business or income generating activity

4.2. Collaborate with others to generate income

4.3. Maintain income generating activities

5.1. Avoid and/or escape situations leading to transactional sex

5.2. Use contraceptives when having sexual intercourse

6.1. Take decisions regarding their own future

6.2. Convince leaders and decision makers of the rights of unmarried teenage mothers

6.3. Act as role models for other unmarried teenage mothers

Because stigmatising norms and behaviours of various actors in the social environment were found to be the major causes of teenage mothers' limited wellbeing, the planning group decided to target change agents in the community (i.e., environmental agents) who could generate support for the unmarried teenage mothers. Environmental outcomes and performance objectives are listed in Table 2.3. 
Table 2.3 Environmental outcomes and performance objectives for environmental agents

\begin{tabular}{|c|c|c|}
\hline Beneficiaries & $\begin{array}{l}\text { Environmental } \\
\text { outcomes }\end{array}$ & Performance objectives \\
\hline \multirow[t]{2}{*}{ Parents } & $\begin{array}{l}\text { 1.Parents care for their } \\
\text { daughter and their } \\
\text { daughter's child }\end{array}$ & $\begin{array}{l}\text { 1.1. Effectively cope with social stigma of their } \\
\text { daughter and themselves } \\
\text { 1.2. Support their daughter to stay or return home } \\
\text { during and after pregnancy and delivery } \\
\text { 1.3. Reconcile relationship with their daughter } \\
\text { 1.4. Do not arrange a marriage for their daughter } \\
\text { 1.5. Support their daughter with material } \\
\text { necessities } \\
\text { 1.6. Support income generation by their daughter }\end{array}$ \\
\hline & $\begin{array}{l}\text { 2.Parents support their } \\
\text { daughter to continue } \\
\text { education }\end{array}$ & $\begin{array}{l}\text { 2.1. Effectively cope with negative norms in society } \\
\text { regarding continued education of unmarried } \\
\text { teenage mothers } \\
\text { 2.2. Communicate with school administrator to } \\
\text { allow their daughter to return to primary or } \\
\text { secondary school } \\
\text { 2.3. Pay school fees and other necessities for } \\
\text { daughter to go to school or vocational skills } \\
\text { training } \\
\text { 2.4. Care for the baby child when their daughter } \\
\text { attends school }\end{array}$ \\
\hline $\begin{array}{l}\text { Community } \\
\text { members }\end{array}$ & $\begin{array}{l}\text { 3. Community members } \\
\text { support unmarried } \\
\text { teenage mothers }\end{array}$ & $\begin{array}{l}\text { 3.1. Treat unmarried teenage mothers respectfully } \\
\text { 3.2. Communicate respectfully with others about } \\
\text { unmarried teenage mothers }\end{array}$ \\
\hline $\begin{array}{l}\text { School } \\
\text { administra- } \\
\text { tors }\end{array}$ & $\begin{array}{l}\text { 4. School administrators } \\
\text { support unmarried } \\
\text { teenage mothers to } \\
\text { continue their } \\
\text { education }\end{array}$ & $\begin{array}{l}\text { 4.1. Allow unmarried teenage mothers to return to } \\
\text { school after pregnancy and delivery } \\
\text { 4.2. Treat unmarried teenage mothers respectfully } \\
\text { 4.3. Communicate respectfully with others about } \\
\text { unmarried teenage mothers } \\
\text { 4.4. Generate support in the school system for } \\
\text { continued education of unmarried teenage } \\
\text { mothers }\end{array}$ \\
\hline $\begin{array}{l}\text { National } \\
\text { government }\end{array}$ & $\begin{array}{l}\text { 5.Political and civil } \\
\text { servant leaders in } \\
\text { relevant ministries } \\
\text { (Education, Health, } \\
\text { Gender) and } \\
\text { parliament support } \\
\text { unmarried teenage } \\
\text { mothers in Uganda }\end{array}$ & $\begin{array}{l}\text { 5.1. Initiate a discussion about the impaired well- } \\
\text { being of unmarried teenage mothers in } \\
\text { Uganda } \\
\text { 5.2. Advocate for continued primary and secondary } \\
\text { education of unmarried teenage mothers } \\
\text { 5.3. Advocate for implementation of laws and acts } \\
\text { that support unmarried teenage mothers }\end{array}$ \\
\hline
\end{tabular}

(Continued) 
Table $2.3 \quad$ Continued

\begin{tabular}{|c|c|c|}
\hline Beneficiaries & Environmental outcomes & Performance objectives \\
\hline & $\begin{array}{l}\text { 6. Political and civil } \\
\text { servant leaders in } \\
\text { relevant ministries and } \\
\text { parliament support } \\
\text { unmarried teenage } \\
\text { mothers in the } \\
\text { Manafwa district }\end{array}$ & $\begin{array}{l}\text { 6.1. Convince leaders, parents, and community } \\
\text { to support unmarried teenage mothers } \\
\text { 6.2. Inspire unmarried teenage mothers to } \\
\text { continue their education and generate } \\
\text { income }\end{array}$ \\
\hline
\end{tabular}

\section{Determinants and change objectives}

Consideration of determinants of behaviour was based on the results of the qualitative needs assessment (Singh, Prada, Mirembe, \& Kiggundu, 2005), a review of relevant literature and a review of theories including Social Cognitive Theory (Bandura, 1986), Theory of Planned Behaviour (Ajzen, 1991), empowerment theories (Alsop \& Heinsohn, 2005; Kabeer, 1999), and stigma-related theories (Dijker \& Koomen, 2003; Link \& Phelan, 2001; Bos, Schaalma \& Pryor, 2008). A matrix of change objectives was developed by crossing the performance objectives and personal determinants. The change objectives define what the target audience has to learn or change in order to be able to accomplish the performance behaviours and are therefore the most direct targets of the intervention. Examples of change objectives for different groups of beneficiaries are presented in Table 2.4.

\section{Step 3: Methods and applications and Step 4: Programme design}

Step 3 and step 4, the selection of theoretical methods and practical applications and the design of a coherent programme, were carried out concurrently in the Teenage Mothers Project. The planning group consulted teenage mothers and community leaders and brainstormed about possible activities (applications) to address the objectives. The brainstorm was discussed with the health promotion professional. Based on available evidence and behaviour change methods and their parameters for use (i.e., considerations to ensure method effectiveness), the applications were adapted when needed (Bartholomew, Parcel, et al., 2011; Abraham \& Michie, 2008). For example, the health promotion professional suggested making use of 'coping' teenage mother role models in the project, instead of mastery models, to increase the chance that beneficiaries could identify with the role model. The suggestion to make use of coping role models (application) was based on evidence that coping models are more effective than mastery models (parameter for use) when applying modelling (behaviour change method) that is based on Social Cognitive Theory (Alsop \& Heinsohn, 2008; Bandura, 1986). 


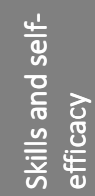

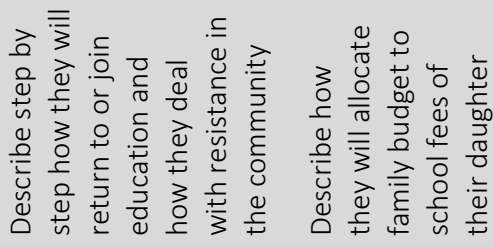

$\stackrel{2}{2}$

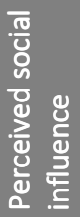

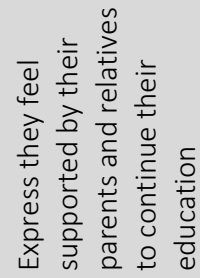

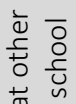

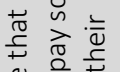

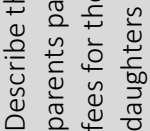

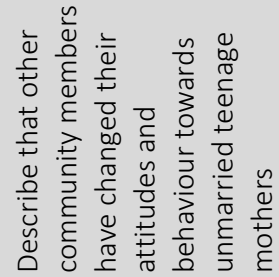

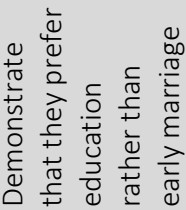

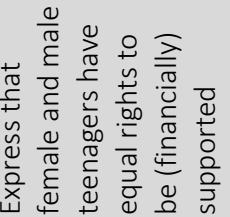

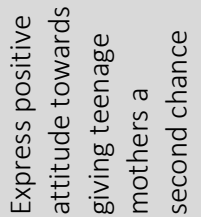

$\stackrel{+}{\check{\pi}}$

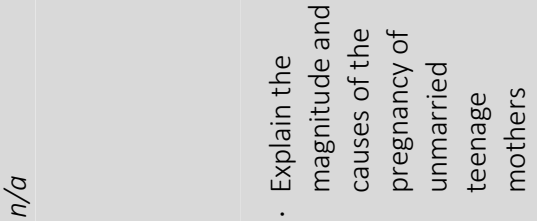

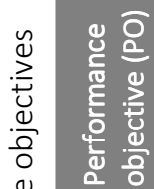

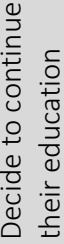

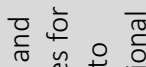

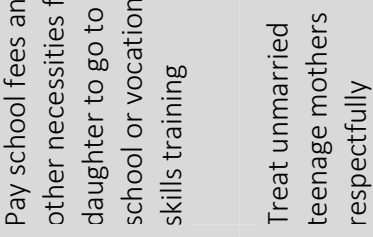

音

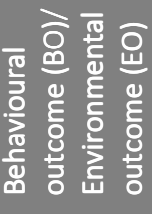

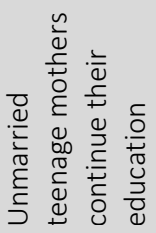

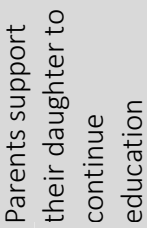

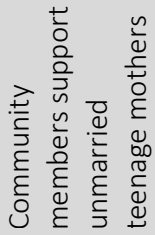

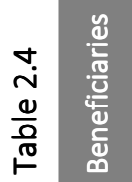

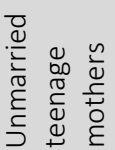

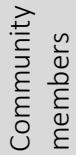


The applications were implemented on a small scale and monitored. If monitoring data indicated that the applications were adopted and implemented well and initiated change, the activities were upscaled within the project and incorporated in the intervention. If monitoring data indicated that the application was not successful, this element was discarded from the project.

\section{Programme components}

The Teenage Mothers Project started in 2000 with the provision of 3 female goats to 30 unmarried teenage mothers. The participants initiated the idea of rearing goats themselves: a goat would provide the teenage mothers with milk for their children and the goats' offspring could be traded for cows. Furthermore, the ownership of goats would gain respect from relatives and community members. The 30 teenage mothers were grouped in groups of 10 participants each, providing an opportunity to share experiences, have contact with peers, and provide reproductive health education.

After 2000, other practical applications based on behaviour change methods were gradually added and incorporated into one coherent programme. In 2011, the Teenage Mothers Project consisted of five components. The first component was community awareness raising, implemented through a variety of community meetings including goats giving ceremonies. A goats giving ceremony was organised in the community where a group of approximately 30 teenage mothers received goats. All leaders and decision makers who were related to the community were invited: religious leaders, tribal leaders, village and sub-county leaders, school staff, and health care workers. Influential leaders provided speeches during the ceremony, committing themselves to the project and inspiring other community members. The unmarried teenage mothers received a goat and, together with their parents and the village leader, they signed an ownership contract. By signing the contract, the unmarried teenage mothers and their parents gave their consent to participate in the Teenage Mothers Project. Role model stories of successful teenage mothers and their parents were included to motivate other teenage mothers and their parents to continue their daughter's education and income generation. The teenage mothers performed songs and theatre plays during the ceremony, aiming at community sensitisation and attitude change of community members (Bos, Schaalma, \& Pryor, 2008; Shanok \& Miller, 2007). National members of parliament and representatives of ministries attended the ceremonies and other awareness raising meetings to advocate for more and better support for unmarried teenage mothers.

The second component was the teenage mothers support group. Each teenage mother was a member of a group with teenage mothers from the same community. The support groups combined a large number of methods and applications including social support, advocacy, income generation, and sexual and reproductive health and rights (SRHR) education. One of the aims of SRHR education was the referral of teenage mothers to qualified, youth friendly health service facilities that provide contraceptives, other preventive services, and maternal and postnatal care and check-ups. 
The third, livelihood component was incorporated in the support groups as well as on individual level (goat rearing). The focus on income generation by and education of unmarried teenage mothers was based on existing evidence indicating that increased economic autonomy and/or increased education levels (primary, secondary or vocational education) result in increased decision making power (agency), contributing to improved psychological and social well-being of unmarried teenage mothers (Gibbs, Willan, Misselhorn, \& Mangoma, 2012; Baytop, 2006).

Counselling was the fourth component aimed at regulation of teenage mothers' negative emotions that result from stigma, reconciliation of relationships between parents and teenage mothers, and persuasion of both parents and teenage mothers to continue education (James, Van Rooyen, \& Strümpher, 2012; Shanok \& Miller, 2007).

Finally, the advocacy component targeted leaders on local, district, and national levels to change and/or implement policies and legislation and to create more awareness and discussion about the well-being of unmarried teenage mothers in Uganda. Advocacy applications included generating media attention, involvement of leaders in the project's activities, and community awareness raising by teenage mothers themselves. The practical applications in the five programme components were based on behaviour change methods and their parameters for use.

\section{General change methods}

Some methods for change are general and useful for all determinants and at all levels at which that method is applied. A general method we applied was cultural similarity, meaning that characteristics of the beneficiaries were used in the sources, messages, and channels of the project components (Kreuter \& McClure, 2004). The project deliverers (i.e., ARDI staff, community based volunteers, and national leaders) originated from the same tribe and communities as the beneficiaries, aiming to contribute to a more positive reception of messages and applications. We also used individualisation, providing opportunities for beneficiaries to have personal questions answered or instructions paced according to their individual progress (Prochaska, Redding, \& Evers, 2008). Counselling sessions with teenage mothers and with parents and frequent informal individual talks and meetings with community leaders provided opportunities for individualisation. To assure that community members shared the responsibility to improve the well-being of unmarried teenage mothers and to contribute to a change of social norms with regard to unmarried teenage mothers, we applied participatory problem solving throughout the project planning. We involved relevant stakeholders in brainstorming and decision making regarding the project's activities (Kreuter \& McClure, 2004). Table 2.5 provides an overview of general methods, parameters for use, applications, and programme components. 


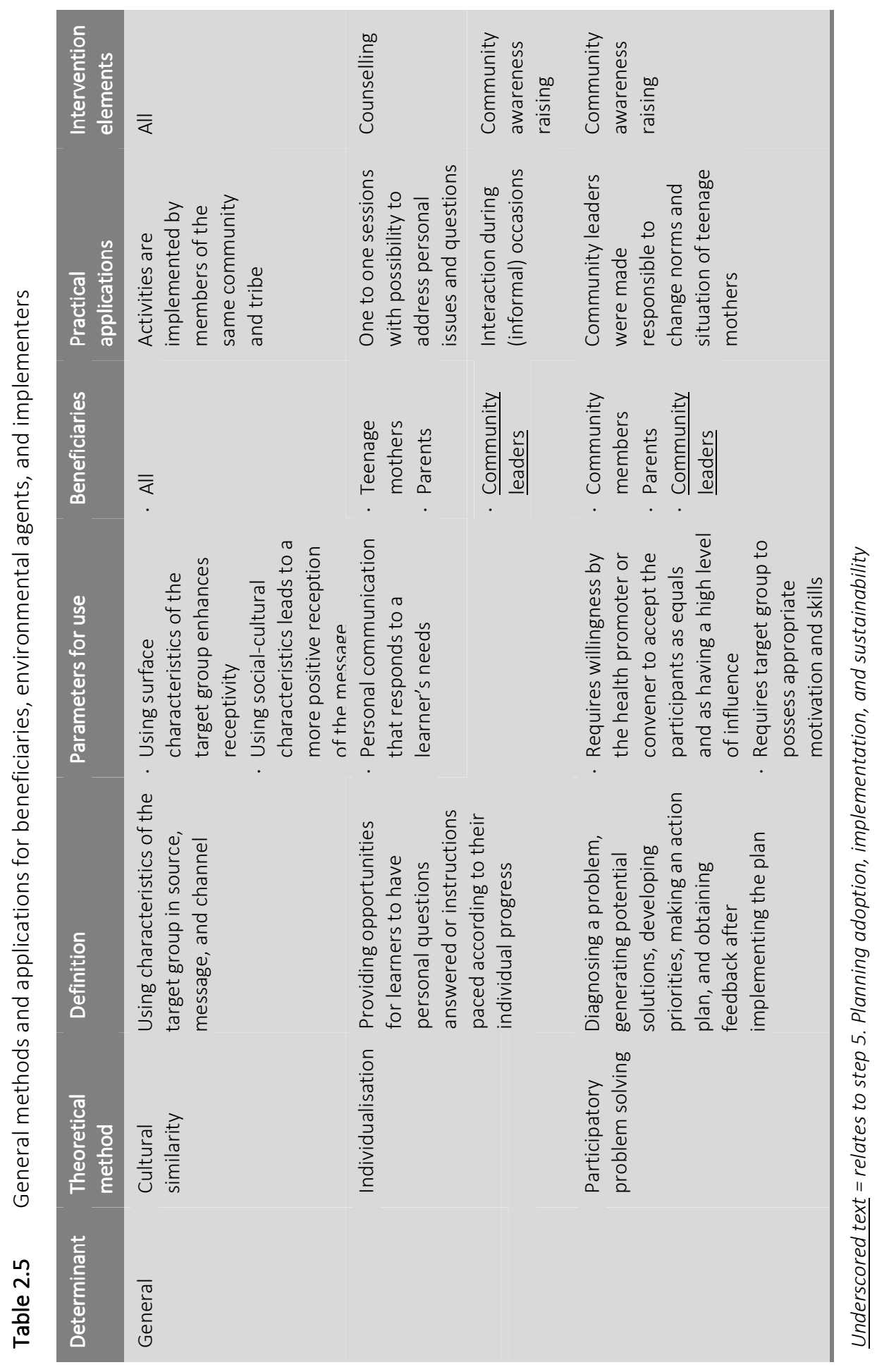




\section{Methods to increase knowledge and awareness and to change attitudes}

Active learning was applied in the education sessions of the teenage mothers groups to encourage SRHR knowledge acquisition from goal-driven and activity-based experience (Petty, Barden, \& Wheeler, 2009). Creating awareness about stigma of unmarried teenage mothers among community members and community leaders was done through entertainment education. Theatre plays and songs performed by teenage mothers were aimed at entertainment of the audience and at education about the consequences of early teenage pregnancy (Rogers, 2003).

The use of persuasive communication (Petty, Barden, \& Wheeler, 2009) was applied to change attitudes of teenage mothers, school administrators, parents, and community leaders. Persuasive communication is particularly effective if messages include (new) arguments, are repeated, are relevant, and are not too discrepant from beliefs of the beneficiaries. Messages in the Teenage Mothers Project included: 'Give unmarried teenage mothers a second chance', 'Do not mistreat the unmarried teenage mothers, but treat them with respect', and 'Help teenage mothers to continue their education'. The messages aimed to incorporate the community's disapproval of out-of-wedlock teenage pregnancy as well as teenage mothers' right to be autonomous and to continue their education. It can be argued whether out-of-wedlock sex and pregnancy are incorrect and whether female teenagers had decision making power when they got pregnant. However, out-ofwedlock pregnancy and sex related beliefs among community members, parents, and leaders were found to be deeply embedded in cultural and religious moral beliefs. Messages were therefore more likely to be effective if they would not be too discrepant and respond to these beliefs. The messages corresponded with messages of a national (media) campaign that started around 2000, emphasising that 'sexual abuse' of girls, and not their own immorality, contributed to their negative social and health outcomes (Parikh, 2012). The persuasive messages were provided by ARDI staff and community based volunteers and in the course of the project increasingly by community leaders.

In addition to persuasive communication with leaders, advocacy (Corrigan \& Kosyluk, 2013) was used to influence national and district leaders to design, adapt, and implement laws and policies that would support the unmarried teenage mothers or at least initiate a public discussion about the subject. Media advocacy was applied by spreading supportive evidence and messages about the Teenage Mothers Project in national newspapers and radio stations via local journalists. Methods and applications for knowledge, awareness and attitude are described in Table 2.6.

\section{Methods to change self-efficacy and skills}

Modelling was applied to change self-efficacy and skills (and attitudes) of parents and teenage mothers. Modelling can be defined as providing an appropriate model being reinforced for the desired action. 


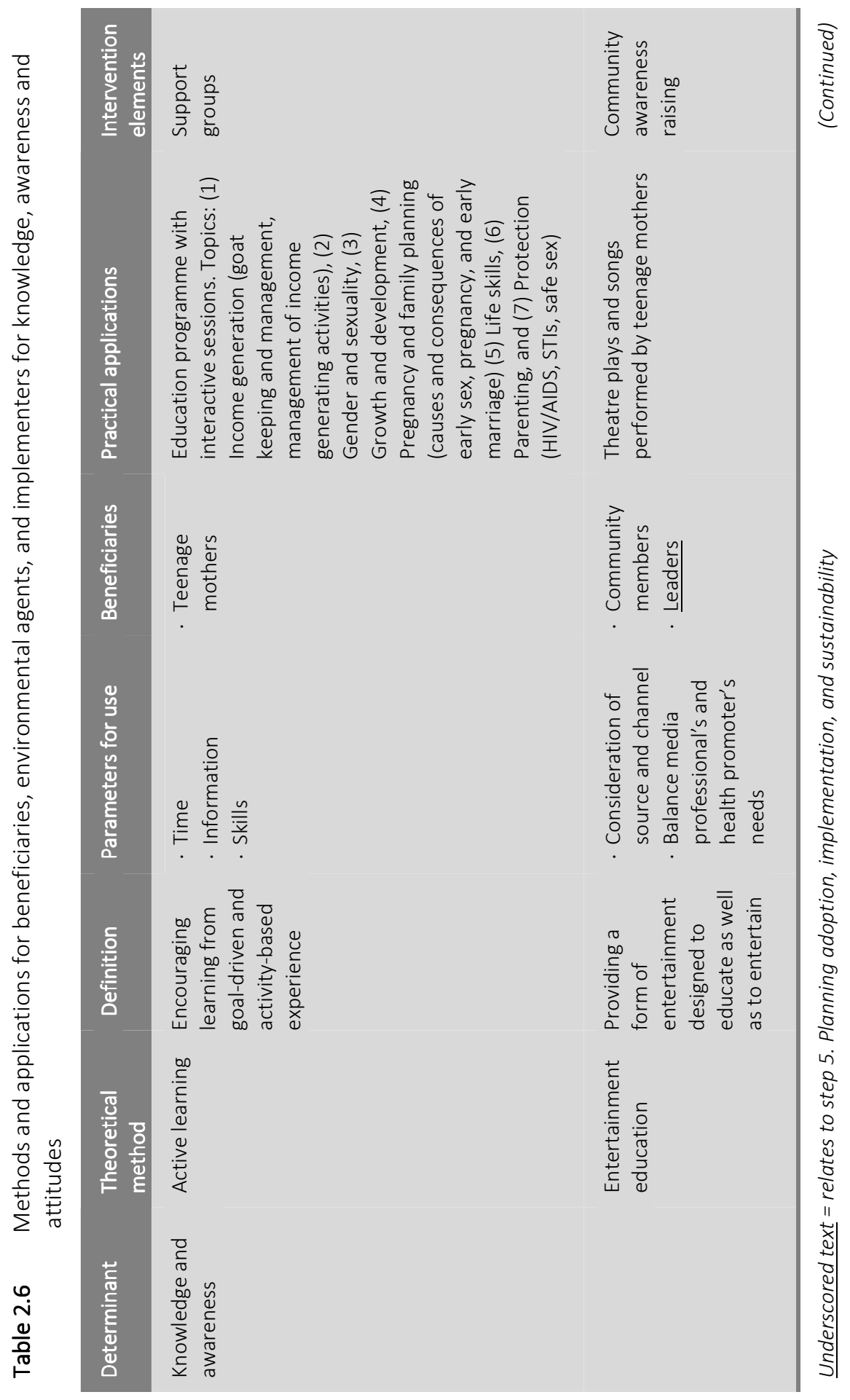




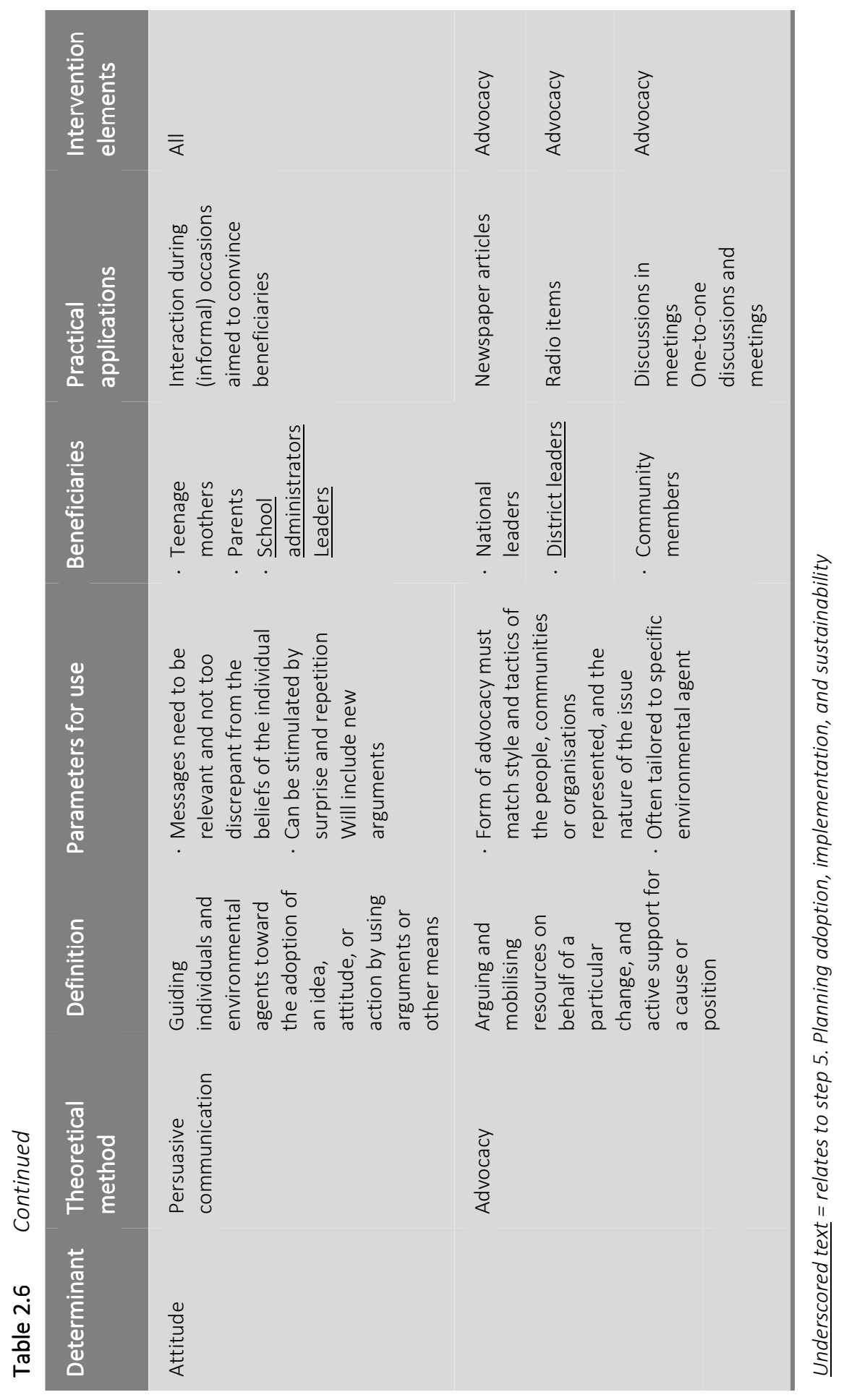


This method is only effective when it meets certain parameters for use: learners need to pay attention, to remember, and to have self-efficacy and skills to model the particular behaviour (McAlister, Perry, \& Parcel, 2008). In addition, learners need to observe reinforcement of the model and need to be able to identify with the (coping) model. In goats giving ceremonies, parent and teenage mother role models provided reasons for adopting the new behaviour (i.e., returning to school, supporting the daughter to return to school), explained how to deal with challenging situations, and stated the perceived reinforcing outcomes they received, such as better education and being valued by others. The successful teenage mothers and parents were rewarded by ARDI staff and community leaders in community gatherings.

Guided practice was applied by tailoring teachers and community based volunteers to educate unmarried teenage mothers about leadership skills and practical skills including tailoring, goat keeping, and implementing a variety of agricultural income generating activities. Guided practice is defined as prompting individuals to rehearse and repeat the behaviour various times, discuss the experience, and provide feedback. To be effective, guided practice should include sub skill demonstration, instruction, and enactment with individual feedback and it requires supervision by an experienced person (McAlister, Perry, \& Parcel, 2008). These parameters for use were incorporated in the training sessions for unmarried teenage mothers. See Table 2.7 for an overview of methods and applications.

\section{Methods to change social influence and support}

Methods and applications related to social influence and support are displayed in Table 2.8. The needs assessment showed that social influence and social norms were important determinants of behaviours of teenage mothers, parents, and other community members. To change perceived norms, information about the approval of relevant others was provided to teenage mothers, parents, community members, and village and sub county leaders (Forsyth, 2006).

A method that was applied to change teenage mothers' behaviour was mobilisation of social networks, as these could help to cope with stigma and other stressful events. Support that was provided in the project's social networks included (1) emotional support, by sharing life experiences and providing empathy, love, trust, and caring (Mngadi, Thembi, Ransjö-Arvidson, \& Ahlberg, 2002; Sieger \& Renk, 2007), (2) instrumental support, including the provision of a goat directly assisting a teenage mother in need, (3) informational support, which involved the provision of advice, suggestions, and information that teenage mothers could use to address problems; and (4) appraisal support, which included the provision of information that would be useful for self-evaluation purposes, including constructive feedback and affirmation (House, 1981). Contingent rewards were provided for the income generating activities that were implemented by the teenage mothers support groups. The support groups had to initiate the income generating activities by themselves and were rewarded with seeds or other supportive products when they were successfully implementing these activities. 


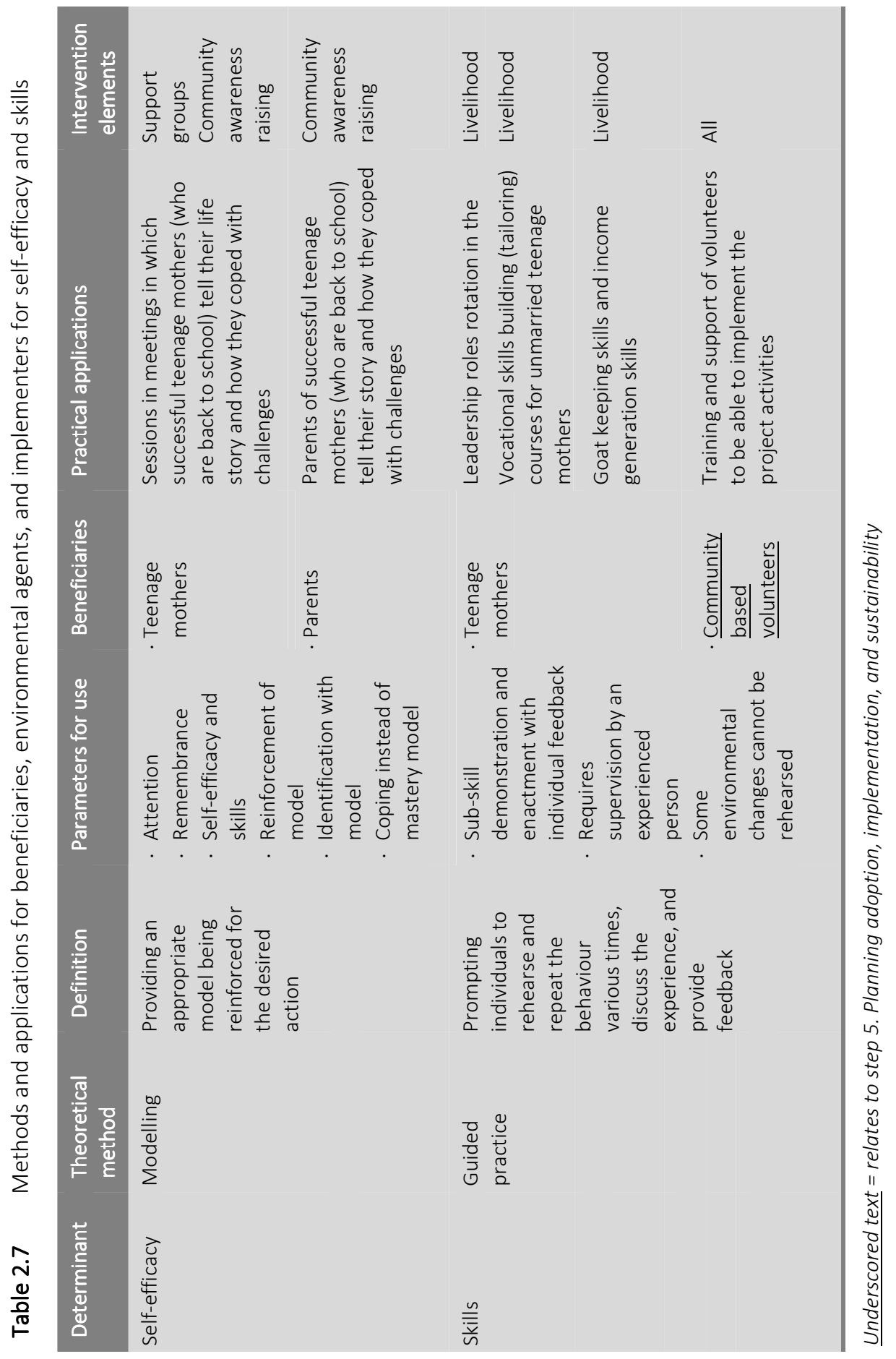




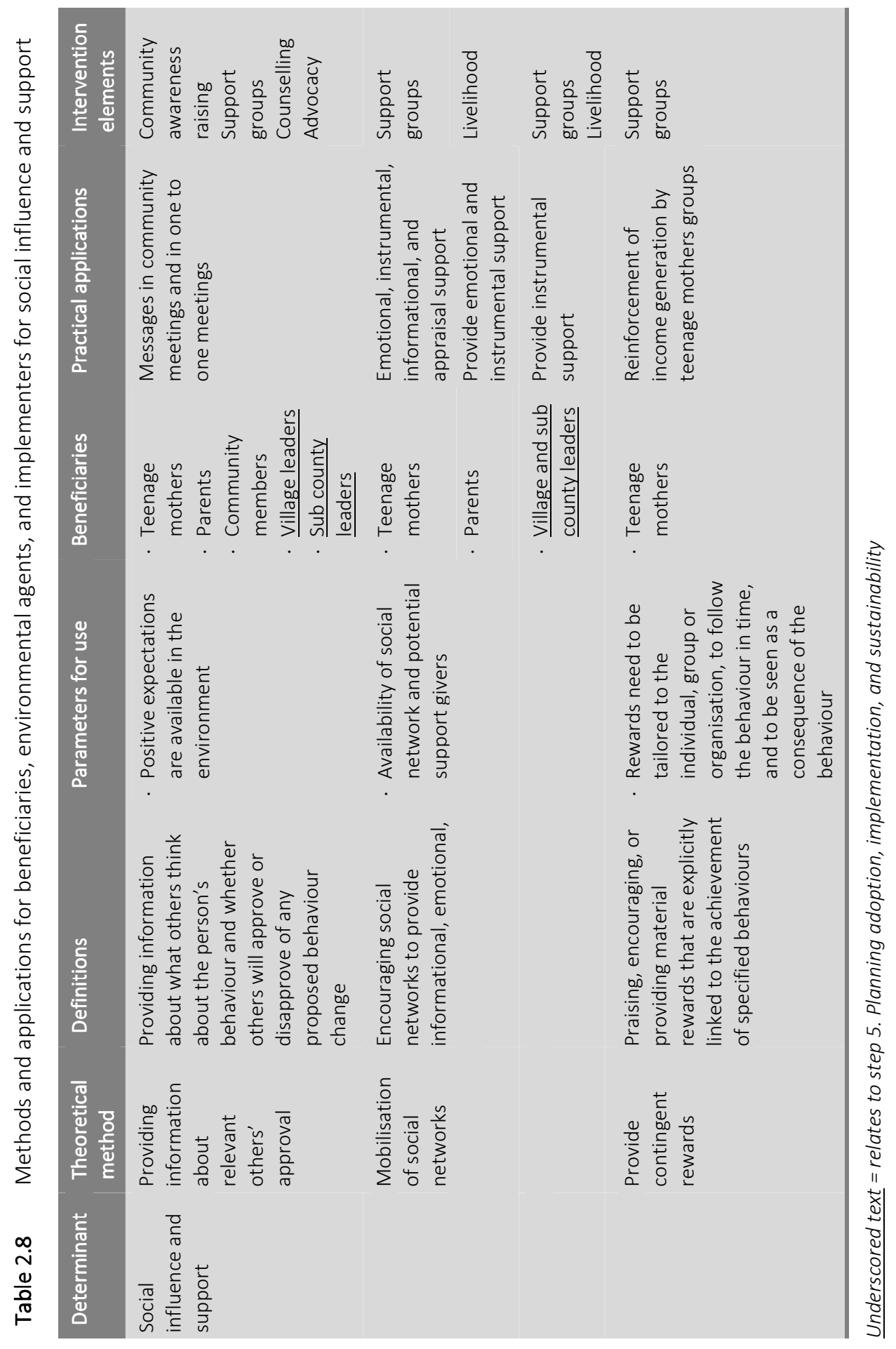




\section{Methods to change stigma-related change objectives}

Various methods were identified to reduce stigmatising cognitions, emotions, and behaviours of community members and leaders (Corrigan \& Kosyluk, 2013; Bos, Schaalma, \& Pryor, 2008; Bartholomew, Parcel, et al., 2011). See Table 2.9 for an overview. One method that was applied to reduce stigma was social creativity, by shifting the focus of the project to the success of teenage mothers' continued education, which would be beneficial for the teenage mothers and for the community at large (Tajfel \& Turner, 1986). This was supported by the provision of de-stigmatising stereotype-inconsistent information to community members and leaders about unmarried teenage mothers. A large number and variation of stereotype-disconfirming teenage mother model stories were presented that were not too discrepant from community members' view on unmarried teenage mothers (Corrigan \& Kosyluk, 2013; Kunda \& Oleson, 1995). The model stories included experiences of teenage mothers who are doing well in school, in vocational training or in income generation.

In addition, teenage mothers were encouraged to protest and advocate for their rights (social action) in a way that would be acceptable for community members and community leaders and would avoid an unintended rebound effect (Corrigan \& Kosyluk, 2013). Finally, interpersonal contact of community members and leaders with unmarried teenage mothers was organised at various occasions, such as the goats giving ceremonies (Allport, 1954; Pettigrew \& Tropp, 2006). By inviting unmarried teenage mothers to share their experiences who were not too discrepant from the image community members had of unmarried teenage mothers, this method was expected to be effective (Corrigan \& Kosyluk, 2013).

\section{Step 5: Planning adoption, implementation and sustainability}

The aim of step 5 was to anticipate the adoption, implementation, and sustainability of the Teenage Mothers Project. In practice, adoption, implementation and sustainability were considered from the start of the project and evolved along with the selection of methods and applications (step 3) and programme design (step 4). The planning group identified objectives and designed theory- and evidence-based activities (applications) for adoption, implementation, and sustainability.

Based on findings in the needs assessment and monitoring data, the planning group stated behavioural outcomes for adopters and implementers. The adopters and implementers of the Teenage Mothers Project included community based volunteers, counsellors, ARDI staff, journalists, tribal and religious leaders, and decision makers and leaders on national, district, sub-county, and village levels. Table 2.10 provides an overview of the behavioural outcomes and performance objectives. 


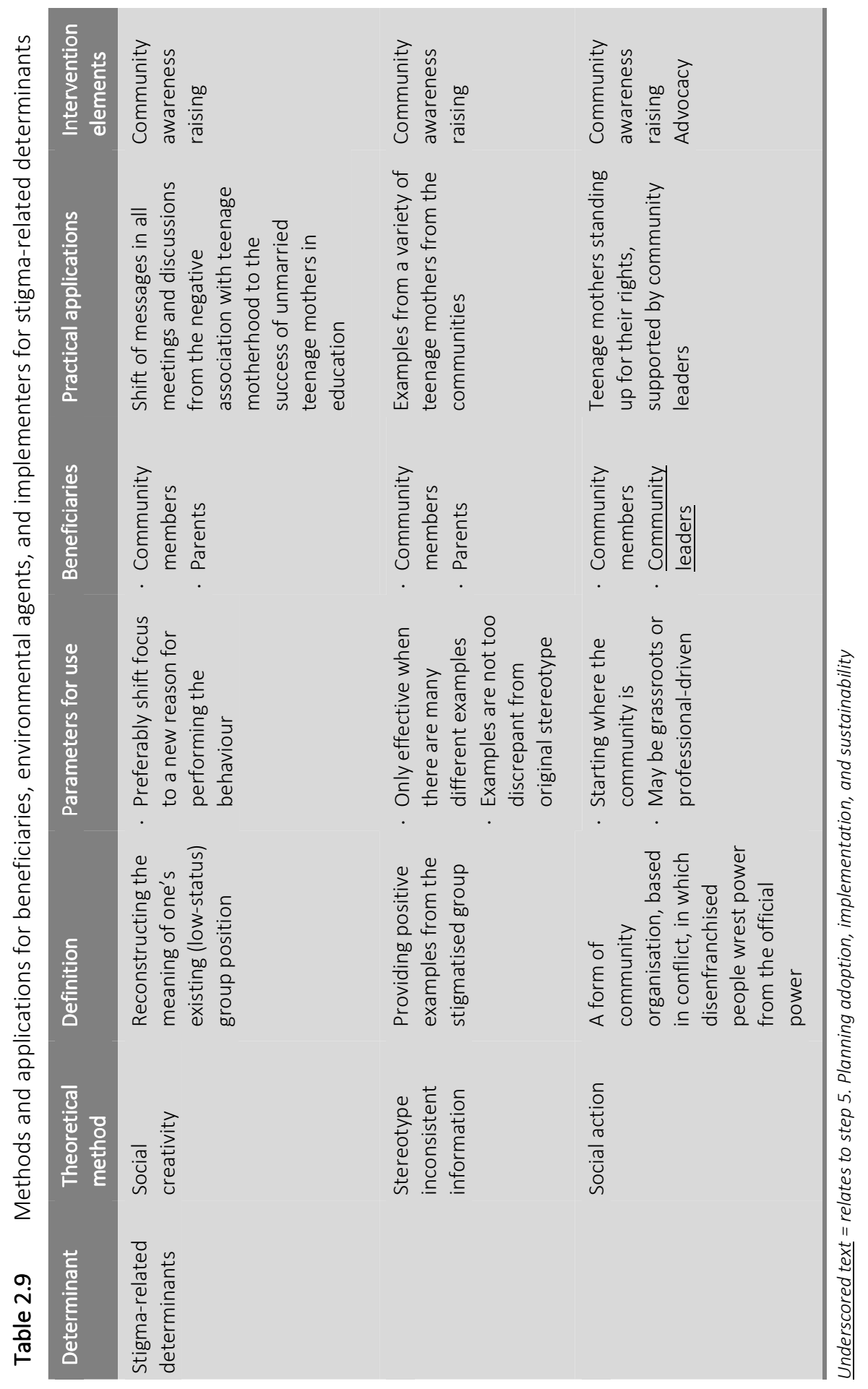




\section{Adoption and implementation}

Adoption and implementation interventions were designed to address the objectives and were based on theoretical methods. Adoption of the programme started with sensitisation of tribal, religious, and governmental leaders and decision makers in a particular community. They were repeatedly exposed to the project's messages and interactions with the teenage mothers, resulting in changed attitudes and supportive communication and behaviour towards the teenage mothers, their parents, other leaders, and the community at large. Subsequently they were involved as implementers by giving them a leading role in community meetings and in the activities of the teenage mothers support groups. Journalists were regularly invited to meetings and occasions in the communities to encourage them to report about the Teenage Mothers Project in newspapers and radio sessions.

As a result of the growing number of participating teenage mothers, support groups, and other activities in the Teenage Mothers Project, coordinators (community based volunteers) in each community were appointed who would implement the activities for unmarried teenage mothers, parents, community members, and relevant decision makers in that particular community. A training and support intervention was developed to address the objectives of the community based volunteers, consisting of information and skills building regarding SRHR, counselling, group management, and income generation. The training consisted of four phases. In phase 1, the volunteers participated in a two-week training, primarily focused on increasing knowledge and attitude change. Phase 2 consisted of field practice of two weeks or more which was supervised by the ARDI staff (guided practice), aiming at self-efficacy and skills building. This was followed by phase 3: a follow up training of one week to merge the training in phase 1 and the field training. Finally, refresher trainings were organised periodically including skills building activities.

\section{Sustainable implementation}

Sustainability of the Teenage Mothers Project was planned for on different levels. On individual level, each teenage mother would have to return one female goat to the project to provide other unmarried teenage mothers with goats. The contract that was signed by each teenage mother, her parents, and the village leader aimed at the prevention of the sale or maltreatment of the goats. On implementation level, community based volunteers would not receive a salary or transport costs but were provided with bicycles and benefitted from the income generating activities of the teenage mothers groups they facilitated.

On project level, sustainability of the Teenage Mothers Project is supported by the adoption of the project by two other organisations in Uganda: Uganda Women Concern Ministry (UWCM) and Phoebe Education Fund for aids Orphans (PEFO). Both organisations have started with project implementation according similar principles in other districts in Eastern Uganda. The three organisations have been exchanging their experiences and plans to sustain and improve the implementation and quality of their respective projects. 
Table 2.10 Behavioural outcomes and performance objectives for adoption, implementation and sustainability

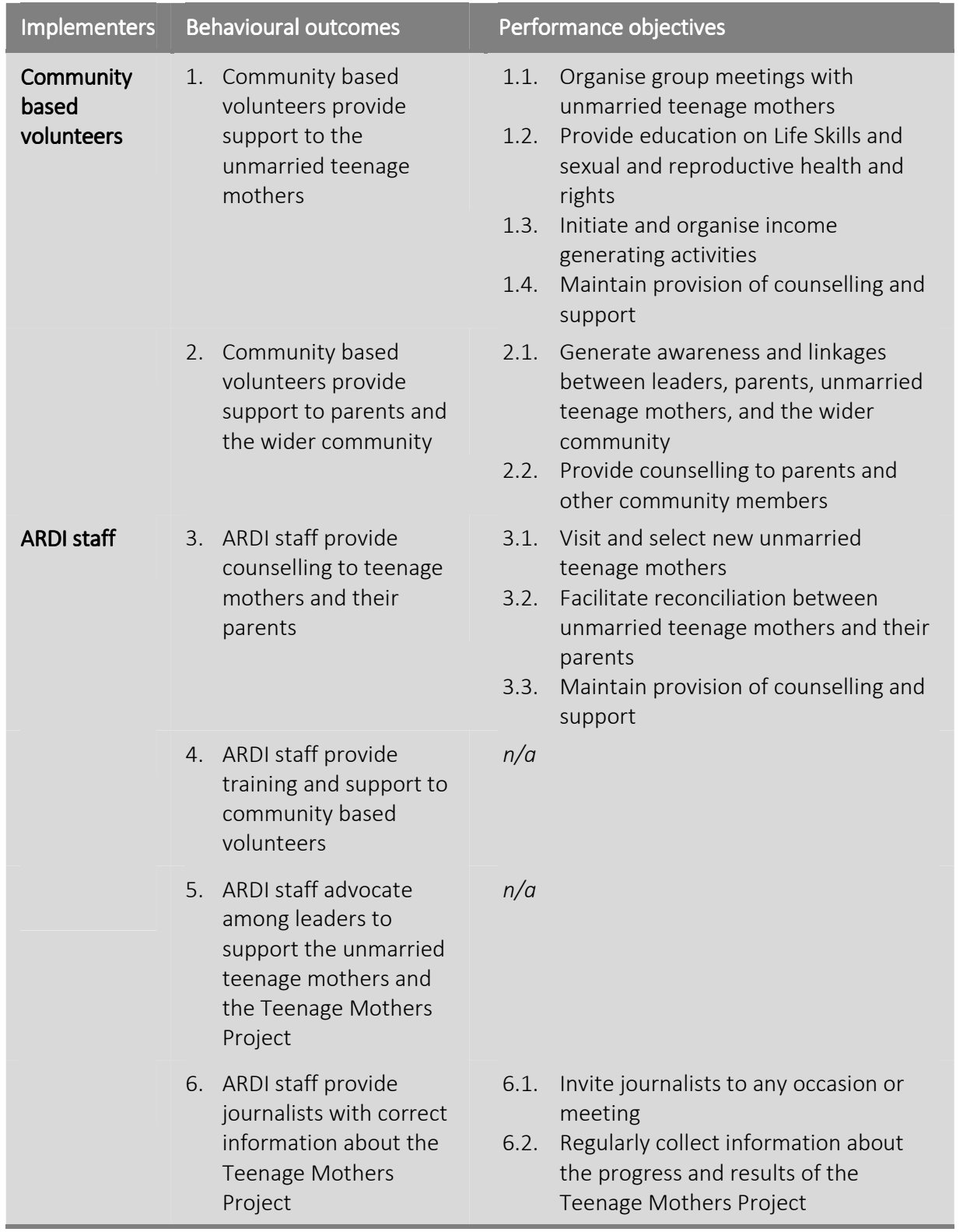


Table 2.10 Continued

\begin{tabular}{|c|c|c|}
\hline Implementers & Behavioural outcomes & Performance objectives \\
\hline \multirow[t]{2}{*}{$\begin{array}{l}\text { District } \\
\text { leaders }\end{array}$} & $\begin{array}{l}\text { 7. District leaders (LC5 } \\
\text { and Chief } \\
\text { Administrative Officer) } \\
\text { contribute to } \\
\text { implementation of laws } \\
\text { and policies in the } \\
\text { Manafwa district that } \\
\text { support unmarried } \\
\text { teenage mothers }\end{array}$ & $n / a$ \\
\hline & $\begin{array}{l}\text { 8. District leaders (LC5 } \\
\text { and Chief } \\
\text { Administrative Officer) } \\
\text { convince other leaders } \\
\text { and the community of } \\
\text { the need to support } \\
\text { unmarried teenage } \\
\text { mothers }\end{array}$ & $\begin{array}{l}\text { 8.1. Convince leaders, parents, and } \\
\text { community to support unmarried } \\
\text { teenage mothers } \\
\text { 8.2. Inspire unmarried teenage mothers to } \\
\text { continue their education and generate } \\
\text { income }\end{array}$ \\
\hline $\begin{array}{l}\text { Sub-county } \\
\text { and village } \\
\text { leaders }\end{array}$ & $\begin{array}{l}\text { 9. Sub-county } \\
\text { government leaders } \\
\text { (Chairman LC } 3 \text { and } \\
\text { Assistant Secretaries) } \\
\text { and village leaders } \\
\text { (Chairman LC1) support } \\
\text { the Teenage Mothers } \\
\text { Project and unmarried } \\
\text { teenage mothers }\end{array}$ & $\begin{array}{l}\text { 9.1. Convince other leaders, parents, and } \\
\text { community to support unmarried } \\
\text { teenage mothers } \\
\text { 9.2. Use any opportunity to share } \\
\text { messages during meetings in the } \\
\text { communities (i.e., burials, marriages, } \\
\text { circumcision ceremonies) } \\
\text { 9.3. Facilitate the teenage mothers groups } \\
\text { by providing land or venues for the } \\
\text { meetings and income generating } \\
\text { activities }\end{array}$ \\
\hline $\begin{array}{l}\text { Tribal and } \\
\text { religious } \\
\text { leaders }\end{array}$ & $\begin{array}{l}\text { 10. Tribal and religious } \\
\text { leaders support the } \\
\text { Teenage Mothers } \\
\text { Project and the } \\
\text { unmarried teenage } \\
\text { mothers }\end{array}$ & $\begin{array}{l}\text { 10.1. Convince other leaders, parents, and } \\
\text { community to support unmarried } \\
\text { teenage mothers } \\
\text { 10.2. Use any opportunity to share } \\
\text { messages during meetings in the } \\
\text { communities (i.e., burials, marriages, } \\
\text { circumcision ceremonies) }\end{array}$ \\
\hline Journalists & $\begin{array}{l}\text { 11. Newspaper and radio } \\
\text { journalists regularly } \\
\text { report about the } \\
\text { Teenage Mothers } \\
\text { Project and unmarried } \\
\text { teenage mothers in the } \\
\text { Manafwa district }\end{array}$ & $n / a$ \\
\hline
\end{tabular}

$n / a=$ not applicable 


\section{Step 6: Planning evaluation}

The final step was the development of an evaluation plan, including a monitoring system and feedback mechanisms to adapt and improve implementation. A qualitative effect evaluation of the Teenage Mothers Project was conducted in March 2012 and reported by Leerlooijer, Bos, et al. (under revision). The study was approved by the Ethical Committee Psychology (ECP) of Maastricht University in the Netherlands and by the chief administrative officer of the Manafwa district. The study showed that between March 2000 and March 2012, 1036 unmarried teenage mothers had participated in the project. Almost half of them were still in the project in March 2012. The research also indicated that a majority had continued either primary or secondary education, or had joined vocational training institutions. Furthermore, the qualitative study showed more supportive community norms regarding unmarried teenage mothers, increased agency, coping, and economic autonomy of the teenage mothers, and a reinforcing interplay between improved well-being of the unmarried teenage mothers and their social environment. On the contrary, the study showed limited support provided by parents, traumatic experiences of unmarried teenage mothers during pregnancy and delivery which could be reduced by intervening earlier, and (financial) barriers to continue with higher education. One of the recommendations in the study was to conduct a quantitative outcome evaluation (Leerlooijer, Bos, et al., under revision).

\section{Discussion}

This chapter describes the participatory development of a community based intervention to support unmarried teenage mothers in Uganda. The intervention, the Teenage Mothers Project, targets a wide range of actors aiming at increased psychological and social well-being of the teenage mothers and at changing social norms and increasing support in the community. The Intervention Mapping framework provided a structure to iteratively plan the complex intervention, to integrate insights from various theories, and to document the contributions of the planning group.

To our knowledge, this chapter is the first to document the systematic planning of interventions that support unmarried teenage mothers to improve their psychological and social well-being and concurrently contribute to a supportive social environment. The limited evidence regarding support interventions for unmarried teenage mothers is understandable given the taboos connected to outof-wedlock sex and pregnancy. However, the lack of studies is also remarkable given the high prevalence of out-of-wedlock pregnancies in sub-Saharan Africa and its harmful physical, psychological, and social consequences (Garenne \& Zwang, 2009). The findings in this chapter provide insight in relevant elements of a planning process of interventions that aim to mitigate the psychological and social consequences of out-of-wedlock teenage motherhood.

This chapter also provides insight in the facilitation of bottom-up, participatory, iterative planning processes in rural communities with limited resources. It 
highlights the importance of involving the community, beneficiaries, relevant decision makers, and professionals in the design of combined individual and structural interventions. Each member of the planning group of the Teenage Mother Project had its own, unique contribution to the planning process, including bringing stakeholders together (ARDI staff), incorporating the needs of beneficiaries and implementers (representatives of these groups), contributing to the theory- and evidence-base (health promotion professional), and contributing to fit of the project with the community (community leaders and decision makers).

Given the context specific nature of the findings, planners should be cautious in generalising the results to other populations. Evidence shows that premarital fertility and motherhood is valued differently in other tribal contexts and cultures (Shell-Duncan \& Wimmer, 1999; Zwang \& Garenne, 2008). Consequences of stigma can differ for teenage mothers with better socioeconomic backgrounds, in communities where out-of-wedlock pregnancy and/or the position of female teenagers are less a taboo, or in a context with laws and policies that are either more or less protective for unmarried teenage mothers. Intervention Mapping provides a framework to use the findings of this study and systematically adapt the Teenage Mothers Project to other contexts or priority populations taking context specific needs, barriers, and existing structures into account (Leerlooijer et al., 2011).

\section{Conclusion}

Intervention Mapping provides a useful framework to structure the planning of community-based, complex interventions aiming at intrapersonal, interpersonal, organisational, and social change. The findings in our study cannot be copied as such, but provide a range of relevant elements that can be systematically adapted to other settings to mitigate the harmful social and psychological consequences of outof-wedlock pregnancy and motherhood for female teenagers in Africa and beyond. 


\section{Chapter 3}

Qualitative evaluation of the Teenage Mothers Project in Uganda: A community-based empowerment intervention for unmarried teenage mothers

Leerlooijer, J. N., Bos, A. E. R., Ruiter, R. A. C., Van Reeuwijk, M. A. J., Rijsdijk, L. E., Nshakira, N., \& Kok, G.

Under review 


\begin{abstract}
Many unmarried teenage mothers in Uganda face physical, psychological, and social problems after pregnancy and childbirth, such as obstetric complications, lack of education, and stigmatisation by the community. The Teenage Mothers Project in Manafwa district in rural Eastern Uganda has supported 1036 unmarried teenage mothers since 2000, through economic and social empowerment interventions and interventions aimed at supportive community norms. The present study explored the change processes that have resulted from the project and the factors that facilitated or limited these changes. In-depth interviews $(N=23)$ were conducted with teenage mothers, community leaders, and project implementers. Lifeline histories were obtained from 9 teenage mothers and existing quantitative monitoring data were analysed. The findings suggest that the Teenage Mothers Project has contributed to improved psychological and social well-being of unmarried teenage mothers. Continued education and income generation of teenage mothers appear to have contributed to increased agency and improved coping strategies, whereas changed social norms and parental support seem to be significant conditions for change. The findings provide insight in processes of change among unmarried teenage mothers and community members. The findings also show inhibiting factors for change. It is concluded that strengths of the communitybased Teenage Mothers Project seem to include the combination of individual and structural interventions, advocacy amongst and involvement of relevant stakeholders in planning and implementation, raising community awareness, counselling of parents and unmarried teenage mothers, and the importance of school attendance and income generation for the teenage mothers. The project could improve by earlier intervention among teenage mothers to avoid preventable traumatic experiences during pregnancy and early motherhood, and by increasing the support for parents to be able to financially support their daughters.
\end{abstract}




\section{Introduction}

Uganda is one of the sub-Saharan African countries with high rates of teenage pregnancy, of which a large proportion is out-of-wedlock and unplanned (Uganda Bureau of Statistics, 2012; Garenne \& Zwang, 2009). Out-of-wedlock teenage pregnancy has major physical, social, and psychological consequences. In addition to coping with motherhood, many unmarried teenage mothers face stigma, lack of schooling, and livelihood insecurity (Levandowski et al., 2012; Population Secretariat, 2001; Biddlecom, Gregory, Lloyd, \& Mensch, 2008; Atuyambe, Faxelid, et al., 2008; Atuyambe et al., 2005; Atuyambe et al., 2009). The psychological and social consequences of out-of-wedlock motherhood can be addressed by adjustment interventions for teenage mothers combined with interventions focusing on their social environment. Several studies and reviews suggest a comprehensive, community-based and ecological approach (Levandowski et al., 2012; Araújo Pedrosa et al., 2011; Logsdon, Hertweck, Ziegler, \& Pinto-Foltz, 2008; Van Horne et al., 2009; Beers \& Hollo, 2009).

An integrated ecological approach that simultaneously focuses on relevant intrapersonal, interpersonal, community, organisational, national, and global levels of influence and interaction moves beyond change of individual behaviours. It recognises and tackles the structural contexts which shape and limit people's agency and therefore ability to act (Green, Richard, \& Potvin, 1996; Bronfenbrenner, 1979). This approach is also reflected in an empowerment approach, whereby empowerment is a result of the interaction between individual agency (i.e., capacity to make purposive choices and to transform those choices into desired actions and outcomes) and opportunity structure (i.e., the broader institutional, social, and political context of formal and informal rules and norms within which actors pursue their interests) (Alsop, Bertelsen, \& Holland, 2006; Sen, 1985).

Increasingly, evidence about combined individual and structural interventions is generated by HIV prevention and care strategies (Blankenship, Friedman, Dworkin, \& Mantell, 2006; Auerbach, Parkhurst, \& Cáceres, 2011), HIV-stigma reduction interventions (Mbonu, Van Den Borne, \& De Vries, 2009; Bos, Schaalma, \& Pryor, 2008), intimate-partner violence interventions (Kim et al., 2007; Pronyk et al., 2006), and gender and micro-finance interventions (Gibbs, Willan, Misselhorn, \& Mangoma, 2012). There is a need for empirical studies to measure the impact of combined individual and structural interventions in general (Blankenship, Friedman, Dworkin, \& Mantell, 2006; Gibbs, Willan, Misselhorn, \& Mangoma, 2012) and of support interventions for unmarried teenage mothers in particular (Beers \& Hollo, 2009; Lachance, Burrus, \& Scott, 2012). Evaluation of complex interventions, however, presents a number of challenges, including restricted opportunities for randomisation, inadequate effect attribution to specific interventions, and limited control over implementation. Qualitative evaluation research can contribute to the identification of changes that result from specific intervention elements, which can be further explored in quantitative impact evaluation (Campbell et al., 2000). 
This chapter describes a retrospective and qualitative evaluation study exploring the changes that have occurred as a result of an ecological, community-based intervention in Eastern Uganda. The intervention being studied is the Teenage Mothers Project that aims to address psychological and social consequences of outof-wedlock pregnancy and motherhood among unmarried teenage mothers in the Manafwa district.

\section{The intervention: the Teenage Mothers Project}

The Teenage Mothers Project is a comprehensive community-based intervention, designed in a participatory planning process with volunteers of the community based organisation African Rural Development Initiatives (ARDI), community leaders and unmarried teenage mothers from the Manafwa district, and a health promotion professional (Leerlooijer, Kok, et al., submitted). The project design was guided by the Intervention Mapping framework to ensure that the intervention was grounded in theory and evidence and to maximise the likelihood of effectiveness (Bartholomew, Parcel, et al., 2011). Intervention Mapping is a stepwise planning framework and describes the iterative process of behaviour change programme development from problem identification to problem solving or mitigation. The first step was to conduct a needs assessment, revealing that out-of-wedlock teenage pregnancy, stigma, and violation of the rights of unmarried mothers, and unawareness of the magnitude of consequences of out-of-wedlock teenage pregnancies, were a major problem in the communities (Leerlooijer, 2001). It was decided to address this gap by intervening among various actors: the unmarried teenage mothers and their parents or guardians (referred to as parents in the remaining of this chapter), school administrators, religious leaders, tribal leaders, governmental leaders on village, sub-county, district and national level, journalists, and the community at large. The overall programme outcome was to improve the psychological and social well-being of unmarried teenage mothers in the Manafwa district by increasing their decision making power (agency) and creating a supportive environment (opportunity structure).

Behavioural outcomes for teenage mothers comprised effective coping with stigma and with motherhood, continuation with education, income generation, not having unprotected sex, and advocating for their rights. Outcomes to create a supportive environment included increased care for the unmarried teenage mother and her child and support for continued education of unmarried teenage mothers. The project started in 2000 with the provision of female goats to unmarried teenage mothers, which would supply them with milk to support the child, with offspring which could be traded for a cow, and ultimately would earn them respect from their family and community. The project is still being implemented at the time of writing (January 2013).

To address the behavioural and environmental outcomes, five intervention components were developed: community sensitisation, support groups, livelihood, counselling, and advocacy. The first component was community sensitisation, 
implemented through a variety of community meetings, including goats giving ceremonies. A ceremony was organised in the home community of approximately 30 teenage mothers, each receiving a goat. The ceremonies were attended by community leaders and decision makers and comprised of speeches by influential (national) leaders, discussion about out-of-wedlock teenage pregnancy, testimonies of teenage mothers and their parents, and songs and theatre plays (edutainment). The second component was the teenage mothers support group consisting of teenage mothers from a particular community. The support groups focused on social support, advocacy, income generation, and sexual and reproductive health and rights (SRHR) education. The third, livelihood component included income generation in the support groups and individually (i.e., goat rearing) and continued (formal) education of the teenage mothers. Counselling was the fourth component, aimed at coping with stigma, reconciliation of relationships between parents and teenage mothers, and counselling for continued education. Finally, the advocacy component targeted leaders on local, district and national levels to change and/or implement policies and legislation and to create more awareness and discussion about the well-being of unmarried teenage mothers in Uganda. Behavioural and environmental change methods included participatory planning, modelling, mobilisation of social networks, persuasive communication, entertainment education, advocacy, guided practice, provision of information about relevant others' approval, and social action.

The intervention was adopted and implemented by trained community based volunteers, ARDI staff, and community leaders. Table 3.1 provides an overview of the intervention components, beneficiaries, and deliverers of the Teenage Mothers Project. The intervention components are described in more detail elsewhere (Leerlooijer, Kok, et al., submitted).

\section{The present study}

This chapter describes a retrospective and qualitative evaluation study of the Teenage Mothers Project in Eastern Uganda, aiming to explore elements that determine psychological and social well-being of unmarried teenage mothers in rural communities in Eastern Uganda. Twenty-three semi-structured interviews were conducted with teenage mothers, community leaders, staff of the implementing organisation ARDI, and community based volunteers.

\section{Methods}

\section{Respondents and sampling procedure}

The study was conducted in March 2012 in the Manafwa district by a research team consisting of the principal researcher and two research assistants. The data collection methods included semi-structured interviews, a lifeline history methodology, and monitoring instruments. Interviews were conducted with 23 respondents. Nine interviews were conducted with teenage mothers aged 18-32 ( $M$ 
$=24.1, S D=4.50)$ who were not married when they joined the project and of whom 4 were married during the interview. The other respondents included 1 male parent, 1 male community elder, 2 male governmental village leaders, 2 male religious leaders, 2 school administrators ( 1 female and 1 male), 4 staff ( 1 female, 3 male) of the community based organisation ARDI, and 2 community based volunteers ( 1 male and 1 female). A variation of teenage mothers was selected, aiming at a selection of respondents who varied in age, location, and the extent to which they had continued their education and increased their income generation. The other selected respondents were connected to at least one of the teenage mothers (e.g., school administrator of a school that was attended by one of the respondents).

Table 3.1 Components, beneficiaries, and deliverers of Teenage Mothers Project

\begin{tabular}{|c|c|c|c|}
\hline \multirow{2}{*}{$\begin{array}{l}\text { Intervention } \\
\text { components }\end{array}$} & Beneficiaries & & \multirow[t]{2}{*}{ Deliverers } \\
\hline & $\begin{array}{l}\text { Unmarried } \\
\text { teenage } \\
\text { mothers }\end{array}$ & Environmental actors & \\
\hline $\begin{array}{l}\text { 1. Community } \\
\text { awareness } \\
\text { raising }\end{array}$ & & $\begin{array}{l}\text { - } \text { Community members } \\
\text { Parents } \\
\text { - National and district } \\
\text { leaders } \\
\text {. Clan, religious, village, } \\
\text { sub-county leaders } \\
\text {. School administrators }\end{array}$ & $\begin{array}{l}\text { Community based } \\
\text { volunteers } \\
\text { - ARDI staff } \\
\text { Clan, religious, village, } \\
\text { sub-county leaders }\end{array}$ \\
\hline $\begin{array}{l}\text { 2. Teenage } \\
\text { mothers } \\
\text { support group }\end{array}$ & $\begin{array}{l}\text { Unmarried } \\
\text { teenage } \\
\text { mothers }\end{array}$ & & $\begin{array}{l}\text { Community based } \\
\text { volunteers } \\
\text { Clan, religious, village, } \\
\text { sub-county leaders }\end{array}$ \\
\hline 3. Livelihood & $\begin{array}{l}\text { Unmarried } \\
\text { teenage } \\
\text { mothers }\end{array}$ & - School administrators & $\begin{array}{l}\text { Community based } \\
\text { volunteers } \\
\text { Clan, religious, village, } \\
\text { sub-county leaders }\end{array}$ \\
\hline 4. Counselling & $\begin{array}{l}\text { Unmarried } \\
\text { teenage } \\
\text { mothers }\end{array}$ & - Parents & $\begin{array}{l}\text { ARDI staff (counsellors) } \\
\text { - Community based } \\
\text { volunteers }\end{array}$ \\
\hline 5. Advocacy & & $\begin{array}{l}\text { National and district } \\
\text { leaders }\end{array}$ & $\begin{array}{l}\text { ARDI staff } \\
\text {. Unmarried teenage } \\
\text { mothers } \\
\text {. Journalists }\end{array}$ \\
\hline
\end{tabular}




\section{Procedure}

The study was approved by the Ethical Committee Psychology (ECP) of Maastricht University in the Netherlands. The chief administrative officer of the Manafwa district provided permission to conduct the interviews. Monitoring sheets with ARDI's monitoring data were updated and entered in data processing software for analysis. Interviews were conducted by the principal investigator, a Dutch female aged 34 (first author), and two research assistants: a Dutch male aged 43 and a female aged 24 from the Bugisu tribe living in the Manafwa district. The research assistants were selected based on their interview skills, language, and ability to be respected by the respondents. The interviews with teenage mothers were conducted by the Mugisu female, interviews with community leaders were conducted by the Dutch male, and interviews with organisation staff were conducted by the Dutch principal investigator. The Mugisu interviewer was able to accommodate respondents who were not familiar with English, and felt more comfortable expressing themselves in Lugisu (local language). A two day training of the research assistants was conducted aiming at explanation and planning of the research, at testing, practising, and adaptation of the methodology, and (back-) translation of the semi-structured interview guides.

Once recruited, interview respondents were informed about the study's purpose and procedure. Interviews were tape-recorded with consent of the respondents. Verbal informed consent was obtained and tape-recorded. All respondents were informed that they could withdraw from the study at any time. The interviews with most respondents were held at their homes. The interviews with the school administrators were held at their respective schools. The interviewer asked to use a quiet room or space to conduct the interviews.

Semi-structured interview guides were designed and were based on empowerment theories, exploring individual and environmental changes resulting from the Teenage Mothers Project and its supporting and inhibiting factors (Alsop \& Heinsohn, 2005). The interviews included similar topics for all respondents. The topics included existence of choice (e.g., 'How would you describe the Teenage Mothers Project?'), use of choice (e.g., 'Who influenced you (or a teenage mother) in the decisions that you (or a teenage mother) are taking?'), and effectiveness of choice (e.g., 'What has been the most significant change of the project for you (/unmarried teenage mothers)?' and 'What can be improved in the project?'). Questions in the interview guides for teenage mothers were directed at their personal experiences as well as their perceived experiences of other teenage mothers. The interview guides for the other respondents were directed at their personal experiences and their observations of possible changes in the community and among teenage mothers. The interviews with the teenage mothers started with drawing of a lifeline history to facilitate interviewer-respondent dialogue about life events (Gramling \& Carr, 2004). The interviewer introduced a sheet of paper with a single line printed across the landscaped page. At the left end of the line was the word 'birth'; and the right end was the word 'now' (see Figure 3.1). Instructions regarding the lifeline were read aloud to the respondent. 


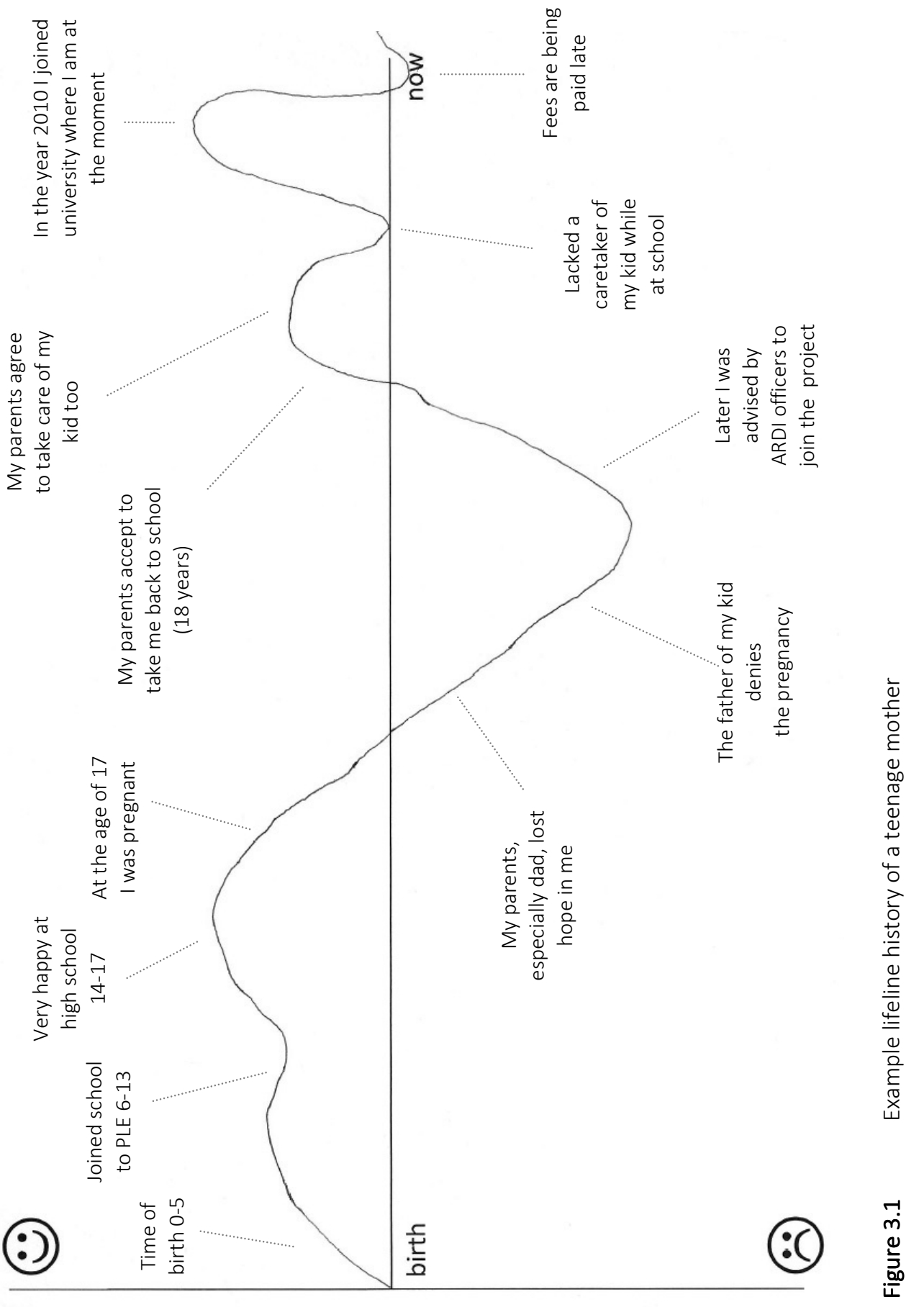




\section{Data analysis}

The interviews were transcribed verbatim and the paper sheets with lifeline histories were transformed into digital sheets. The transcript interview data and the digital sheets were processed with ATLAS.ti qualitative software. The data were analysed using a general inductive approach (Thomas, 2006). After data cleaning and preparation, the principal investigator carefully read the text and looked at the lifeline histories. The principal investigator used coding to identify categories and built a model based on the research questions and the empowerment approach (i.e., agency and opportunity structure). The categories included interpersonal and external elements that either contributed to or hindered psychological and social well-being of unmarried teenage mothers. Subsequently, sub-categories were identified. For example, the category 'coping' included the sub-categories 'coping with pregnancy and motherhood', 'coping with stigma', and 'marriage as coping strategy'. Optional quotes were highlighted in the data and the (sub-) categories were continuously revised and refined. After finalising the categorisation, preliminary findings were discussed during a consensus meeting of ARDI staff members and a teenage mother. Descriptive and frequency analyses were conducted to describe the characteristics of the participants in the Teenage Mothers Project.

\section{Results}

The overall aim of the Teenage Mothers Project was to address psychological and social consequences of out-of-wedlock pregnancy and motherhood among unmarried teenage mothers in the Manafwa district by increasing unmarried teenage mothers' decision making capacity and autonomy (agency) and by creating a supportive environment (opportunity structure). Between March 2000 and March 2012, 1036 unmarried teenage mothers had participated in the project. The majority had a Catholic background (73.2\%), a minority Muslim (3.5\%), and the remaining Protestant (23.3\%). In March 2012, the mean age of the1036 participants was 20.5 years (range 14-33) and a majority of 58\% (age > 16) was married at that time. The monitoring data indicated that $1.6 \%$ of participants had passed away, $49.4 \%$ had retracted from the project because of continued education or marriage, and $49.0 \%$ was still participating in the project. The mean age of the participants was 15.75 years $(S D=1.22$; range $10-18$ ) when they gave birth to their child and 16.53 years $(S D=1.36)$ when they joined the project.

The in-depth interviews resulted in five factors that seem to be crucial for the extent to which participants have been able to benefit from the Teenage Mothers Project: social norms, agency, coping, education, and income generation of the unmarried teenage mothers. In general, the ARDI staff, community based volunteers, and community leaders reported in a more common and more positive way about the results of the project than the teenage mothers did. The ARDI staff members estimated that approximately $60-80 \%$ of the 1036 participants in the Teenage Mothers Project had been able to benefit from the project, through 
continued education, increased economic benefits, improved relationships, and/or effective coping.

Even though it appears that quality of life of a large majority of participants had improved after joining the project, the interviews with the teenage mothers suggested that many of them still had to cope with challenges. These challenges included lack of funds to pay school fees to be able to continue education, lack of employment after finishing a certain level of education, and struggling with a husband who was not the father of the child. Figure 3.1 provides an example of a teenage mother respondent who was 22 years old, not married, and having one child. She had joined university, but at the time of the interview she could not proceed due to lack of funds to pay for school fees.

\section{Social norms}

The interview data suggest that community norms with regard to the unmarried teenage mothers and the Teenage Mothers Project had changed in the project period March 2000 - March 2012. Before the project started, parents and community members and leaders generally had a negative attitude towards unmarried teenage mothers. Parents and the wider community stigmatised unmarried teenage mothers, influenced by deeply embedded cultural and religious moral beliefs regarding out-of-wedlock pregnancy and sex. Based on the interviews it seems that these moral beliefs and norms have not changed in the course of the project. A pastor of a Christian church refers to out-of-wedlock sex and pregnancies as mistakes:

"They are guarded to understand the former mistakes the girl has made. And this gives the person now to repent or to turn away from the former mistakes and becomes a new person. And when somebody has gone back to school and realises 'This is what caught me to be helped and go back', it changes that person completely and they learn from the former mistakes. Because at times we learn by mistakes, we learn by the Spirit, we learn by the word of God". (Male pastor of a Christian church)

However, the response of the pastor also illustrates that norms with regard to the position of and possibilities for unmarried teenage mothers seem to have changed. These norms have become more supportive and less stigmatising for the teenage mothers. It seems that the project has contributed to more supportive norms with regard to education and delay of marriage of unmarried teenage mothers. One of the teenage mothers described this:

"I used to feel that I am already second hand, why should I go back to school? Even my mother told me to get married. You know what happens in polygamous family, when you get pregnant you get married. [...] That project really helped me, even my mum got encouragement from it. Coz' those people told her to take me back to school. Without, she had left me to go and 
get married because I was pregnant". (Teenage mother, 23 years old, married)

However, the interview data also give the impression that not all community members, leaders, peer youth, and parents had changed their opinion and behaviour. A school head master reported about stigma towards unmarried teenage mothers who have given birth (referred to by respondents as 'deliver' or 'produce'):

"Then there are peer groups. Some have these insulting words: 'You are married, what are you doing in school?' Because of that fear, some of them are abandoned. [...] So they are pointing: 'Look at that girl, she delivered, now what is she still doing?' [...] It is believed that when she produces, her life has ended. So that societal attitude may again discourage those ones to continue to be in class". (Head master secondary school)

A first step towards change in social norms appeared to be the involvement and consultation of influential community leaders in finding solutions for problems in the community, out-of-wedlock pregnancies being one of them. This included awareness raising about the magnitude of the problem and convincing community leaders of the need to jointly support unmarried teenage mothers. Initially, the community leaders were resistant and it required considerable efforts to convince community leaders of the need of the project. The interviews indicated that the change of norms had been a lengthy process:

"This particular project, the goats' project, has opened people's eyes. To really identify a problem that looked like it was hidden. People would not really come into realisation of this problem. [...] And now, whatever the case, people are slowly, slowly coming to realisation, they are thinking 'Eh, I think we have to do something about that'". (Male ARDI social worker)

One of the signs that attitudes of governmental leaders had changed, was their initiative to support teenage mothers support groups with a plot of land or a venue for their activities. Once influential community leaders were supportive to the project and its approach, they were increasingly involved in community sensitisation. The goats giving ceremonies appeared to be a significant strategy to sensitise the community. It seems that testimonies of parents of 'successful' unmarried teenage mothers about their own coping process were among the effective strategies to influence other parents. An ARDI staff member reported about a goats giving ceremony:

"There was one of the mothers of the children who succeeded. She came and talked here, before the rest of the people, and gave testimony of how she has supported this girl and how she is now very proud of her daughter. She was given time to really talk and I was really very impressed with her speech. And everybody was really listening. And of course those were now new parents and new girls and they were really listening. [...] And now the girl is really a 
hope for the entire family. And I feel that those stories are really inspiring".

(Male ARDI social worker)

It was reported that in later phases in the project, community norms also changed because of the successes and image of the teenage mothers in education and income generation.

\section{Agency}

The interviews give the impression that decision making freedom of unmarried teenage mothers in the Teenage Mothers Project has to a certain extent improved. It seems that particularly as a result of changed social norms and increased social support, continued education, and income generation, teenage mothers gained more freedom to do whatever they needed to do to achieve their goals (agency). The interviews give the impression that improved self-confidence and improved autonomy had contributed to increased agency. It appears that self-confidence of teenage mothers generally had been very low during pregnancy and early motherhood, but that this had improved as a result of counselling, participation in the teenage mothers support groups, and a more supportive environment. The section about coping further describes how belonging to a group contributed to their level of coping and self-confidence. Confidence of teenage mothers was also reflected in their capacity and responsibility to be an example for other teenage mothers and their parents. A teenage mother shared her vision:

"You can see where I have reached: I am now in campus. And I can also advise others. I advise parents who have their girl who produce at an early age. I advise them to take them back to school". (Teenage mother, 22 years old, unmarried)

On first sight it seems that teenage mothers' autonomy had also increased, particularly as a result of continued education and income generation, providing them with financial resources and with knowledge and skills to take care of themselves. However, further analysis of the data suggests that teenage mothers also remained to be dependent on the decisions of their father or their husband. After asking whether she could take her own decisions, a teenage mother reported:

"I can. Though I still depend on my parents. But I can. [...] Right now I take decisions myself, because I know what is good and what is bad. Generally I know what to do". (Teenage mother, 22 years old, unmarried)

It seems that if teenage mothers' goals correspond with the goals of their parents or husbands, there is no conflict. However, non-correspondence of goals can challenge teenage mothers to do what they need to do to achieve their goals. It appears that limited agency of teenage mothers strongly relates to the extent in which their social environment and other external factors were supportive. This is illustrated by an ARDI staff member: 
"In my view, there are limitations in these girls making decisions. Not because they can't make decisions, but sometimes they are influenced by circumstances around them. For example, you may want to be a person of principle, but there are certain things that make you drop your principles. For example, hunger. Hunger can sometimes force someone change their principles". (Male ARDI social worker)

The general impression that agency of teenage mothers had increased as a result of the project, was reflected in stories about improved care for their child, marriage with 'better' husbands, continuation with education, and prevention of early marriage and of transactional sex. Increased agency of teenage mothers seems to strongly relate to the extent they were able to generate their own income to care for their child, to pay their own school fees, and to purchase daily necessities. Increased agency also seemed to be related to the extent teenage mothers could decide when and whom they would marry. It appears that female teenagers who were better educated were more attractive for males, giving the teenage mothers more opportunities to choose a husband. The interviews indicated that this also increased the chance to get married to a husband who would care well for them and to a more equal relationship. One of the teenage mothers reported:

"I gave birth in 1999, but through counselling and sensitisation, I managed to stay without giving birth for a long time, until I gave birth to Rose in 2004. And out of that I have managed to look for a husband who can take good care of me. [...] And out of that, I have been able to go back to school. And now I earn my own money". (Teenage mother, 32 years old, married)

According to interview respondents (community leaders, community based volunteers, and ARDI staff), the number of early marriages and first and secondary pregnancies among teenage girls had decreased. The monitoring data indicated that a small proportion of participants had again given birth to a child out-of-wedlock. The interviewed teenage mothers attributed these declining figures to a decrease in (transactional) sex, which in turn would be a result of increased economic autonomy. One of them reported how increased income generation can prevent transactional sex:

"When you are employed somewhere, even if you get little amount of money, it can help you. You can be getting 200,000 shillings, you are able to buy clothes and take care of your child. But if you don't have anything, you cannot be okay, because you will be overthinking about how to make life go on. Because it is through those challenges that someone can get problems in the process of making ends meet, like having sex to get some money. Yet, he will end up giving you only 1000 or 2000 shilling. So it is better I get something to do for myself than depending on someone". (Teenage mother, 27 years old, boyfriend) 
Finally, it appears that the element of the Teenage Mothers Project whereby individual, marginalised, teenage mothers were brought together into a visible group of connected people had been a crucial factor. The teenage mothers had become visible in a positive way through registration of a majority of the 52 support groups as community based organisations, in media stories, and during community gatherings such as the goats giving ceremonies. Their visibility as a group of generally successful community citizens seems to have contributed to more supportive social norms (see the first factor) and to the collective power and in turn collective and individual agency of the teenage mothers. The community elder reported about this:

"These child mothers, like some of them had lost hope, they had no future. But those few recently, who changed their minds and went back to school, and have completed their schools, they are leaders. And I think that is the most significant change that we have seen around [...]. They decided to go back to school, they have completed their school. I think that is the biggest achievement. Because somebody who was, who would be useless, is now a leader". (Community elder)

\section{Coping}

The interview data and lifeline histories give the impression that many unmarried teenage mothers had to cope with great emotional turmoil as they strived to cope with pregnancy, delivery and early motherhood, a changed future perspective, lack of support of the father of the child, stigma of community members and peers, and negative responses of their parents. The lifeline histories showed that the period between discovery of their pregnancy and their introduction to the Teenage Mothers Project, had been among the most difficult periods in their lives. See for example the lifeline history displayed in Figure 3.1. Monitoring data revealed that the average time between delivery of the child and participation in ARDI's activities had been 10 months. One of the teenage mothers reported in her lifeline history about the period just after her pregnancy:

"I got that pregnancy in 1999. So that is when my life changed to be upside down. I wanted to abort but I had no advice about abortion. And my mother noticed it and told me 'Don't do anything'. But my life changed completely knowing that now I will not join school, I am now no longer still a girl. I am now a mother until I came to produce that girl. Now, the baby was sick and I had no help. Because the man, the pregnancy was just like accidentally. The man was not willing to help me. The man sometimes says that that baby is not his' and he keeps on denying". (Teenage mother, 29 years old, married)

The interviews give the impression that the Teenage Mothers Project has contributed among a majority of teenage mothers to effectively cope with the above mentioned challenges. The 'advice of ARDI' (counselling by counsellors and volunteers), and to a lesser extent the teenage mothers groups, were mentioned as 
important contributions to their coping capacity. The interviews suggest that teenage mothers felt taken seriously, listened to and treated as a valuable person by the ARDI staff and volunteers. This seems to have contributed to sharing of feelings and experiences, to the feeling that they mattered to others, increased selfconfidence, and the feeling of belonging. Before they joined the Teenage Mothers Project, most teenage mothers did not belong to the group of adult women, nor to their fellow non-pregnant peers, whereas participation in the project resulted in belonging to a group of unmarried teenage mothers. One of the teenage mothers reported:

"Having this education, like counselling meetings and income generating activity meetings have helped me change my life and I have learned a lot".

(Teenage mother, 32 years old, married)

It appears that the attitude and behaviour of parents had been an important determinant of teenage mothers' emotional turmoil as well as in their effective coping. Parents either contributed to or inhibited teenage mothers' well-being by whether they expelled them from home or allowed them back, delayed their marriage, gave them emotional support and forgiveness, and provided support in motherhood, income generation, and continued education. It appears that counselling of the parents as well as role model examples of other parents had been effective interventions in changing the attitudes and behaviours of parents. One of the teenage mothers reported:

"I felt bad and I stayed home for a whole year. And even after delivery I did not feel the joy of having a child. It was not until the ARDI people started counselling me that I started feeling that life is a little fine. The counsellor from ARDI talked to me personally and I felt okay. I was given a goat from ARDI and they also talked to my parents to take me back to school. And my parents accepted and took me back for the nursing assistant course and I joined. So I was happy". (Teenage mother, 24 years old, not married)

The father of a teenage mother explained how the Teenage Mothers Project had encouraged him to change his behaviour:

"As a parent I got annoyed, of course, I got shocked and decided to leave her for a full year at home as a punishment. [...] And through ARDI programme I also got some guiding and counselling. [...] In case it is a mistake, we should not regard them as mistreats or as wastage. But they are people. In case they listen to your advice as a parent and go back to school, you give them some support". (Father of a teenage mother)

However, it appears that a small proportion of teenage mothers found it difficult to cope with their new situation and applied ineffective coping strategies such as early marriage and transactional sex. Even though it appears that the number of early marriages gradually declined since the start of the Teenage Mothers Project in 
2000, ARDI staff members estimated that around 30-40\% of the 1036 participants had married at an early age, some with the father of the child. Teenage mothers decided themselves or parents encouraged their daughters to get married. For example, one of the teenage mothers reported:

"It was difficult to take care of the child and I needed a helper. So I decided to get married. [...] That child doesn't belong to this man, that doesn't help so much. But I decided to get married on my own". (Teenage mother, married, 29 years old)

Despite the emphasis of the Teenage Mothers Project on economic autonomy and on parental support, it appears that transactional sex has remained a coping strategy of a number of teenage mothers.

\section{Education}

All respondents unanimously perceived teenage mothers' continued education as the project's most significant change, because of the large number of teenage mothers who have returned to school, and its positive effects such as increased autonomy, self-confidence, and income generation. A school head mistress illustrated this change:

"The Teenage Mothers Project has helped teenage mothers to go back to school. Which is very good, because prior to that you would find that once a child gets pregnant, that is the end of the education. So it has created that sensitisation in the community that even giving birth to a child is not the end of the education. [...] I have seen girls that have dropped out of school, being able to come back to school. Which means that the environment, the mentality that they were having, has changed". (Head mistress secondary school)

The monitoring data indicated that up to March 2012, 65.4\% of the 1036 participants in the Teenage Mothers Project had returned to either primary or secondary school. The data showed that $79.1 \%$ completed at least primary education, $17.7 \%$ completed at least lower secondary education (S4), 5.8\% completed at least higher secondary education (S6), and that 3.7\% had attended or completed higher education or university. Teenage mothers who had not been able to continue formal education had been encouraged to attend vocational skills training, such as tailoring or administrative courses. Monitoring data revealed that $9.1 \%$ of teenage mothers had attended such a course.

The interview data indicated that the extent to which teenage mothers had continued education seemed to depend on teenage mothers' motivation, support of their parents and social norms regarding education and the school environment. It appears that a majority of teenage mothers was motivated to continue education, determined by their goal to take good care of the child, the observation of teenage mothers who had succeeded in school, their level of self-confidence and selfefficacy, and their increased awareness of the value of education because of the 
experience being expelled from school. It appears that stigmatising behaviour of peer students in the schools was one of the hindering factors for teenage mothers' motivation to return to school (see Social norms).

Various activities in the Teenage Mothers Project seem to have contributed to their motivation, of which individual counselling ('advice') was most frequently mentioned. A community based volunteer reported:

"The girls in my group that I have seen have taken my advice and they have gone back to school. I feel I am very proud of them and I feel the work I have done is not a waste of time because they listen and yield to advice. The success of these girls has helped me reach out to other parents. My work is easy because they now believe that giving birth at home is not the end of every good thing, they can still achieve more if they are supported". (Female community based volunteer)

However, it appears that not all teenage mothers had been motivated to continue their education, as was illustrated by a school head mistress:

"Okay, I have known of examples, like of recent, a girl was here in this school. She had reported back from school. The environment under which she was living is a privilege. The parents wanted her at school, but herself she has opted to go and marry; her own decision. Not that her parents were talking her out of home". (Head mistress secondary school)

However, parental support seemed to be the most important factor determining teenage mothers' continuation with education. Their support included financial support (school fees, school uniforms, school lunches, stationary) and childcare support when their daughter attended school. It appears that the level of support varied among parents, largely depending on their attitudes towards education of unmarried teenage mothers. Parents had to choose between marriage (and receiving dowry) and providing support for education, partly influenced by community norms (see Social norms). The respondents indicated that the attitudes and behaviours of parents had changed as a result of family counselling, follow up visits to their homes, changed community norms with regard to continued education, and good performance of teenage mothers in school. One of the teenage mothers described how her parents responded when they found out she was pregnant, and how they had changed as a result of counselling and her own efforts:

"Now, when they found out I was pregnant, my parents lost hope in me, especially my dad. He felt like sending me away from his home because he felt I was disobeying him and that I was not seeing the value of education. [...] John is the one who came up to home and talked to my dad. [...] They called me and asked me if I wanted to go to school. I said 'Me, I want'. He said 'It is ok, but now who will take care of the kid?' But still I said 'Me, I will go'. And my mum said 'I will take care of the kid'. When the results came back, I had 
passed and I was very happy. It also gave him the morale that I was serious there". (Teenage mother, 22 years old, unmarried)

It appears that parents who did not support their daughter's education either did not give this priority or lacked sufficient financial resources. The interviews provided numerous examples of teenage mothers who had not been able to continue education because their parents lacked resources to support them financially.

The interview data suggest that a supportive school environment has contributed to continued education of many teenage mothers. According to ARDI staff, awareness raising and persuasion of school administrators had changed their attitudes and allowed unmarried teenage mothers to return to school. A school head master reported about his changed attitude and behaviour:

"So in the course, they asked at the school 'Can you allow them to continue?' So I said, 'One, our problem is that these are the problem students, who are supposed to be in class. So now when they are mothers, it may be difficult'. But with the effort and their advice, we now allow them to become part of us, back to students' life. But we caution them that once in school, they remember that we do not allow them to be a mother again". (Head master secondary school)

\section{Income generation}

The Teenage Mothers Project also seems to have contributed to increased income generation by the teenage mothers, through individual and collective income generating activities. Individually, teenage mothers had generated income through goat keeping, business or employment. One of the teenage mothers explained how effective goats' management had enabled her to exchange goats for a cow:

"The goat grew and it produced. Although it was in bad health, I tried with my small money. I treated it, it grew, it produced and I got my cow now. I exchanged that cow to a female cow and I got a calf. Yah, it has helped because I can now sell that calf. I can pay for my girl. [...] This cow can produce milk and I sell. If it produces much and I sell and it remains, my child takes some of it, also to support their health". (Teenage mother, 29 years old, married)

It appears that parental support was conditional for the success of goats rearing as they were co-responsible for the goat often being at their property. Parents and teenage mothers with goats' management knowledge and skills appeared to be more successful in goat management and income generation. A community based volunteer illustrated this:

"Some parents are generally good and when the girls get the goat they protect it. And even when the girl has gone to school they feed the goats. While other parents are bad. Immediately the girl gets that goat, they sell it 
and use it for personal reason. And some do not feed the goats when the girls are in school. So you find that those with support are more successful than those without support". (Female community based volunteer)

It was estimated that approximately $15 \%$ of all the provided goats had died or was sold because of (urgent) expenditures such as health care or medicines. However, according to ARDI staff members, these numbers had gradually declined in the course of the project as a result of more intensive monitoring, a Farm Africa goats management training to ARDI staff and volunteers, and goats management contracts between ARDI, each new project participant, her parents and the respective village leader.

Collective income was generated through a variety of activities by the teenage mothers support groups, including pharmacy management, bee, poultry, cattle and pig farming, sale of local snacks or coffee plant seedlings, and cultivation and sale of tomatoes, maize and onions. Most groups had independently initiated these activities by a small financial investment by each of the group members. Once the activities were successful, ARDI reinforced this by providing support such as seedlings. A community based volunteer reported:

"Whenever we plant onions we get money, in fact good money, out of it. And we buy maize and currently we have stocked it in here in our store. Now after some time we sell, if we get a girl who has failed to raise enough for school. And we make our contribution and we equally help their young ones in terms of treatment when the mothers are away for school". (Female community based volunteer)

The interviews seem to suggest that the success of the income generating activities mainly relied on the leadership of the community based volunteers, the commitment of the teenage mothers and the support of the community members and leaders by providing groups with a piece of land or venue.

\section{Discussion}

There is a scarceness of research findings on the effectiveness of interventions aiming at improved psychological and social well-being of unmarried teenage mothers (Beers \& Hollo, 2009; Lachance, Burrus, \& Scott, 2012). In order to fill this gap in the existing literature, this study describes a retrospective, qualitative evaluation of the Teenage Mothers Project in rural communities in Eastern Uganda. The findings suggest that the project has contributed to various positive changes among the project participants and their social environment and give insight in elements that could be improved. The general image emerging from the study is that continued education and income generation of teenage mothers contributed to increased agency and improved coping strategies, and that changed social norms and parental support were significant conditions for this change. 
One of the prominent findings appears to be a shift towards more supportive social norms among many parents, community leaders and community members with regard to the value and future opportunities of unmarried teenage mothers and with regard to the Teenage Mothers Project itself. It seems that beliefs and norms with regard to premarital sex and pregnancy have remained unchanged among all project stakeholders, whereas social norms concerning early marriage and continued education of teenage mothers have become more supportive for teenage mothers' well-being. Although inhibiting norms were also recorded, this was not the dominant view. One of the elements that appears to have contributed to changed social norms is an intensive, laborious process of participation and persuasion of influential community leaders. Other research confirms the importance of involving people who are affected by the intervention in the change process as community participation increases community ownership, community capacity and programme maintenance (Shediac-Rizkallah \& Bone, 1998) and that that changing social norms regarding sensitive topics such as sexuality and out-of-wedlock motherhood can be challenging and can take considerable time (Auerbach, 2009). Other project activities, in addition to participatory planning, that seem to have contributed to changed norms include community awareness raising meetings attended by all relevant stakeholders, testimonies of successful parents and teenage mothers, supportive attitudes and behaviour of community leaders, and counselling of parents aimed at reconciliation with their daughter and at creating support for continuation with school instead of early marriage. There is still opportunity for the project to improve, particularly with regard to social norms among parents and among peer youths in schools. Even though social stigma has not been entirely alleviated, it appears that changed social norms have contributed to decreased stigma of and to improved support for the unmarried teenage mothers.

Another noticeable finding was the unanimous perception of respondents that the Teenage Mothers Project had particularly contributed to continued education of unmarried teenage mothers. Before the project started, a large majority did not continue education but got married or stayed at home, whereas the study showed that $65 \%$ had returned to school. Compared to women aged 15-49 in Eastern Uganda, participants in the Teenage Mothers Project had higher completion rates in higher secondary education (3.2\% and 5.8\% respectively) and higher attendance and completion rates in higher education or university $(2.6 \%$ and $3.7 \%$ respectively) (Uganda Bureau of Statistics, 2012). Corresponding with other studies, the present study shows that education tends to delay female's marriage, improves their access to income and increases their economic aspirations and success (Hargreaves et al., 2008; Wekesa, 2011). In general, schooling is highly valued in Eastern Uganda and many see it as a gateway to a better life, to hopes for employment, social mobility and being a modern person (Sekiwunga \& Whyte, 2010). Continued education appears to depend on teenage mothers' motivation to attend education, a supportive school environment, parental support, and resources to pay school fees.

The results give the impression that the Teenage Mothers Project contributed to changed attitudes and behaviour of parents and school staff, particularly through awareness raising, persuasion and/or counselling. The present study suggests that 
lack of parental support is one of the inhibiting determinants of education of teenage mothers, which is also reported in other research (Grant, 2012). Lack of resources for school tuition is among the most important and prevalent reasons for discontinued education. Even though other studies showed considerable reduction of dropout of school through cash transfer interventions (Hallfors et al., 2011) or provision of school uniforms (Duflo, Dupas, Kremer, \& Sinei, 2006), disadvantages of these interventions were the lack of support of out of school children (such as unmarried teenage mothers) and large financial inputs. Aiming at sustainability, the Teenage Mothers Project has provided training, counselling and a relatively small micro-credit (a goat) that appear to have supported critical thinking and own responsibility of parents and teenage mothers, within safe social spaces to enable them to think and act in new ways (Shediac-Rizkallah \& Bone, 1998). The project can be improved by increasing support for parents to generate resources for school fees, uniforms, lunches and stationary.

Closely related to the importance of continued education had been the income generation by teenage mothers, both contributing to their agency and coping strategies. Reviews regarding the impact of microfinance and other livelihood interventions for women show ambiguous results depending on context-specific factors (Van Rooyen, Stewart, \& De Wet, 2012; Kim, Pronyk, Barnett, \& Watts, 2008). The present study suggests that income generation has contributed to increased economic autonomy, resulting in improved care of the child, prevention of early marriage and of transactional sex, marriage with 'better' husbands, and financial contribution to their own school fees. Activities in the Teenage Mothers Project that have contributed to increased economic autonomy included the goat rearing, practical skills building such as tailoring and administrative skills, and the income generating activities of the teenage mothers groups. Even though efforts have been implemented to decrease the number of goats that die or are sold (Peacock, Ahuya, Ojango, \& Okeyo, 2011), the project can still improve by providing training and intensifying monitoring of the goats.

In addition to continued education and income generation, it appears that counselling and education have contributed to improved coping of the teenage mothers with early motherhood, the lack of support of the father of the child, stigma of community members and peers, a changed future perspective, and negative responses of their parents. It seems however that the point of time of engagement of the teenage mothers in the project (on average 10 months after delivery of the child), is too late and causing trauma which could be prevented when the project would intervene just after discovery of the pregnancy. Other research recommends providing psychological and social support to the unmarried mothers immediately after discovery of the pregnancy (Holub et al., 2007) to prevent traumatic experiences and internalisation of stigmatising norms and to increase the likelihood of better adjustment of unmarried teenage mothers and their children after birth.

Finally, the findings suggest a reinforcing interplay between the teenage mothers' improved agency and the support provided by the parents and community leaders and members (opportunity structure). Other studies that have assessed the 
impact of structural, comprehensive interventions have also reported this interaction between individual and environment (Gibbs, Willan, Misselhorn, \& Mangoma, 2012; Baytop, 2006). On the one hand, the unmarried teenage mothers seem to gain confidence, continue education and generate income because of the support of their parents and community. On the other hand, social norms in the community appear to have changed partly as a result of the visibility and successes of the teenage mothers. Teenage mothers as a group have become visible as a result of their collective action in the support groups, in media and community meetings. This has resulted in individual agency and has contributed to change in community norms and decrease in stigma. This phenomenon is also described in other studies exploring the influence of an individual versus a group of individuals (Drury \& Reicher, 2009). The findings support an ecological approach of interventions targeting all relevant actors including the teenage mothers, parents, community members, school administrators, and other community leaders (Araújo Pedrosa et al., 2011).

\section{Strengths and limitations}

Our study has both strengths and limitations. The study was conducted among a variety of respondents representing all relevant stakeholders in the communitybased Teenage Mothers Project. The advantage was the collection of a variety of perspectives from different angles in the community. A limitation of the study however was the small sample size of each group of respondents. Caution should therefore be observed in generalisation of the results for the study population. This also applies for the generalisation to other populations, as this study was tailored specifically to teenage mothers in a particular tribal and rural setting in Eastern Uganda. A strength of the study is the combination of monitoring data and qualitative in depth information about the changes that appear to have occurred as a result of the Teenage Mothers Project. Triangulation of data across methods (monitoring data, life line histories and semi-structured interviews) and respondents and checking of preliminary findings during a consensus meeting have contributed to credibility of the findings.

The study results provide recommendations for future research and practice. Understanding how parents can be supported to generate resources and income is an important area for further research. The study provides suggestions for other community based empowerment interventions aimed at improved psychological and social well-being of unmarried teenage mothers, in addition to the findings described above. We suggest to approach the mitigation of consequences of out-ofwedlock motherhood using a comprehensive approach: targeting both teenage mothers as well as their social environment on various ecological levels; using a variety of interventions ranging from counselling and education to income generating activities; and addressing needs and assets of the diverse group of unmarried teenage mothers.

Well-being of unmarried teenage mothers can be improved by providing them counselling and education, motivating them to return to school, and by initiating income generating activities. A supportive environment can be created by a process 
of participatory planning with community leaders, teenage mothers and other stakeholders from the start, awareness raising to reduce stigma in the community, and by providing counselling to parents to reconcile relationships and increase their support towards teenage mothers.

\section{Conclusion}

Concluding, from the retrospective, qualitative evaluation it appears that the community-based Teenage Mothers Project in Uganda has contributed to change in social norms with regard to opportunities for unmarried teenage mothers, to increased confidence and autonomy, to continued education and income generation by a large number of unmarried teenage mothers, and to improved ability to cope with challenges. Counselling of parents and teenage mothers and advocacy among and involvement of community leaders and members seem to be activities in the Teenage Mothers Project that have particularly contributed to these changes. The project can improve by earlier intervention among teenage mothers to prevent traumatic experiences, and by improving the possibilities for parents to be able to financially support their daughters. 


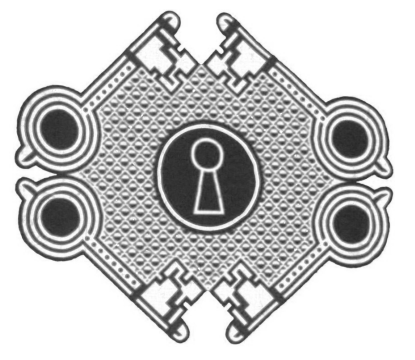

\section{Chapter 4}

Psychosocial correlates of the motivation to abstain from sexual intercourse among Indonesian adolescents

Leerlooijer, J. N., Ruiter, R. A. C., Damayanti, R. Rijsdijk, L. E., Eiling, E., Bos, A. E. R., \& Kok, G.

Under review 


\begin{abstract}
Adolescents in Indonesia have limited access to sexuality education, resulting in increased risk for negative health outcomes. This study aims to advance our understanding of psychosocial correlates of sexual abstinence intentions to inform future comprehensive sexuality education targeting sexual decision making. Data were collected in 79 secondary schools amongst 2315 students, aged 14-20 years, in Jambi, Lampung, DKI Jakarta and Bali. A self-completed questionnaire measured intentions, attitudes, subjective norms, and perceived behavioural control towards sexual abstinence. Significant associations with intention to abstain from sexual intercourse were found for experience with sexual intercourse, perceived behavioural control, attitude, and subjective norms of peers and parents, explaining $31 \%$ of the variance in abstinence intention. Sexuality education programmes in Indonesia may benefit from addressing past sexual behaviour and psychosocial correlates, especially perceived behavioural control, subjective norms of peers and attitudes, to promote adolescents' informed sexual decision making.
\end{abstract}




\section{Introduction}

In Indonesia, the rising number of adolescent pregnancies outside marriage indicates that the norm regarding premarital sex is changing. People get married and have children at an older age while becoming sexually active at a younger age (Simon \& Paxton, 2004; Riono \& Jazant, 2004), even though sex before marriage is socially not accepted (Utomo, 2003). These developments imply an increasing need for information on sexuality, especially among adolescents. However, sexuality education is not formally taught at school, communication about sexuality with parents is rare because of cultural norms, and talking about sex in public is a taboo. The lack of sexuality education, coupled with increased early and unprotected sex among adolescents, relates to a range of negative health outcomes including rising numbers of HIV/AIDS and other sexually transmitted infections (STI's), unplanned pregnancies, and unsafe abortions (Simon \& Paxton, 2004; Statistics Indonesia \& Macro International, 2008).

Prevention of negative health outcomes and promotion of adolescents' sexual and reproductive rights are elements of comprehensive sexuality education. According to the United Nations Convention of the Rights of the Child (United Nations, 1989), adolescents have the right to take their own well informed decisions about sexuality. One of the options for adolescents is to abstain from sexual intercourse, which is particularly promoted among younger adolescents. In this chapter we define abstinence from sexual intercourse as refraining from vaginal or anal intercourse until adolescents are mentally, physically, and emotionally ready for it. According a rights-based approach 'being ready' varies for each individual adolescent and entails informed decision making and having sexual intercourse when this is a consensual decision between both partners.

To address abstinence as one of the behavioural messages in evidence- and theory-based comprehensive sexuality education, insight in potentially modifiable cognitive antecedents of sexual behaviour and protective behaviours is essential (Bartholomew, Parcel, et al., 2011). Several theoretical frameworks have been empirically developed to assess social cognitive factors that explain people's motivation to perform a given behaviour, including the Theory of Planned Behaviour (Ajzen, 1991). The Theory of Planned Behaviour suggests that the most important predictor of behaviour is an individual's intention to perform or not to perform the behaviour (Webb \& Sheeran, 2006). Intention, in turn, is determined by (1) attitude, referring to a person's overall evaluation of the proposed behaviour, (2) subjective norms, which refer to beliefs about whether significant others like friends, family and society approve of behaviour and whether that approval is valued, and (3) perceived behavioural control, i.e., the person's anticipated mastery of the behaviour. Meta-analyses have provided evidence of the (causal) link between attitude, subjective norm and perceived behavioural control and the intention and behaviour (Armitage \& Conner, 2001; Sheeran, Abraham, \& Orbell, 1999; McEachan, Conner, Taylor, \& Lawton, 2011). 
Compared to the number of studies that have explored correlates of intention to use condoms (Sheeran, Abraham, \& Orbell, 1999), relatively few research studies have explored the correlates of adolescents' intention to abstain from sexual intercourse or intention to abstain from sex (Buhi \& Goodson, 2007). Studies that measured correlates of adolescents' intention to abstain from sexual intercourse found attitudes, subjective norms and perceived behavioural control being the strongest predictors (Basen-Engquist \& Parcel, 1992; Basen-Engquist, Tortolero, \& Parcel, 1997; Collazo, 2005; Villarruel, Jemmott III, Jemmott, \& Ronis, 2004). Other research reported gender (being female) and lack of previous sexual experience as predictors of intention to abstain from sexual intercourse (Nahom et al., 2001). Several studies included past behaviour as dependent variable, instead of intention and found that low frequency of being in sexual situations, positive attitudes towards abstinence from sex, perceived abstinence from sex among peers, higher education level of particularly father, high self-esteem, good parental relationships, and higher level of education are associated with abstinence from sexual intercourse (Mehrotra, Zimmerman, Noar, \& Dumenci, 2013; Carvajal et al., 1999; Price \& Hyde, 2009).

The study described in this chapter is conducted in a predominantly Muslim society. We found one study that assessed correlates of sexual abstinence of any sexual practice (including sexual intercourse) among male adolescents in the Islamic Republic of Iran (Mohtasham et al., 2009). The study identified subjective norms, perceived behavioural control, and perceived susceptibility to contract HIV as positive correlates of intention to abstain from sex until marriage, and employment of mother and higher daily allowance to be negative correlates. HIV/AIDS knowledge did not correlate significantly with intention to remain abstinent. No publications were found that have explored theory-based correlates of Indonesian adolescents' intention to abstain from sexual intercourse.

The aim of this study was to assess these behavioural correlates in a crosssectional survey study among school going adolescents in four provinces in Indonesia. Besides the concepts derived from the Theory of Planned Behaviour, two elements of the Health Belief Model were incorporated in the explanatory model: perceived severity, which refers to a person's perception of the seriousness of the consequences of contracting a disease; and perceived susceptibility, referring to a person's perception of the likelihood of contracting a disease (Janz \& Becker, 1984).

\section{Methods}

\section{Participants}

To measure behavioural correlates of adolescents' intention to abstain from sexual intercourse, participants were recruited from 79 secondary and vocational schools in Indonesia. The study was conducted in those schools that adopted the sexuality education programme 'The World Starts With Me'/ DAKU (Leerlooijer et al., 2011) and was carried out before implementation of the programme. For the present study, a representative sample of 80 schools was selected with regard to rural 
versus urban background; private versus public schools; and secondary versus vocational schools in the four provinces Jambi, Lampung, DKI Jakarta, and Bali. Twenty schools were selected in each province. One school (in DKI Jakarta) was discarded from the original sample, because the questionnaire was pre-tested in this school. This resulted in a total sample of 79 schools. In each secondary or vocational school, one class from the first two grades was randomly selected by the head master and all students present in each class (22-46 students) were surveyed. The total sample size in the four provinces was 2315 students, aged $14-20$ years $(M=$ $15.89, S D=0.89)$, of whom $61.7 \%$ was female and $38.3 \%$ was male. The sample schools had adopted 'The World Starts With Me'/ DAKU and females were more willing to voluntarily participate than males. This explains the larger proportion of female respondents.

\section{Instrument}

A measurement instrument was developed based on a review of literature, elements of a rights-based approach towards sexuality, and psychosocial theories (TPB, HBM) (Mathews et al., 2009). Most items were measured using 5-point Likert scales. Higher scores reflect a higher occurrence of the variable concerned. The 'I do not know' option was added to the Likert scale, as well as the non-disclosure option 'I don't want to talk about it' for questions addressing sensitive topics. Skip patterns were applied where relevant (e.g., respondents who never had sexual intercourse skipped questions about past condom use behaviour). Female and male versions of the questionnaire were developed. When relevant, the questions were phrased towards each of the two sexes to make the questionnaire understandable, for example: for males: 'Have you ever made one of the lovers you had sexual intercourse with, pregnant?' and for females: 'Have you ever been pregnant?'.

Factor analysis was conducted to assess the structure of the scales and reliability analysis was used to measure the resulting internal consistency of scores on items within scales. See Table 4.1 for an overview of variables including example items and scale reliability measured with Cronbach's $\alpha$ (3 or more items) or Pearson's correlations ( 2 items). The internal consistencies of the scales were satisfactory $(\alpha$ 's $>$.70; $\left.r^{\prime} s>.22, p^{\prime} s<.001\right)$.

\section{Procedure}

This study was approved by the Ethical Committee Psychology (ECP) of the Faculty of Psychology and Neuroscience at Maastricht University in the Netherlands and by District Education Officers and school administrators of schools in Indonesia. All respondents gave written informed consent. Confidentiality was assured by anonymous completion of the questionnaire and explanation that the questionnaires would be accessible for the research team only. Students did not write their names on the questionnaire and the questionnaires were collected from the students by external research teams. 
Table 4.1 Overview of scale measures

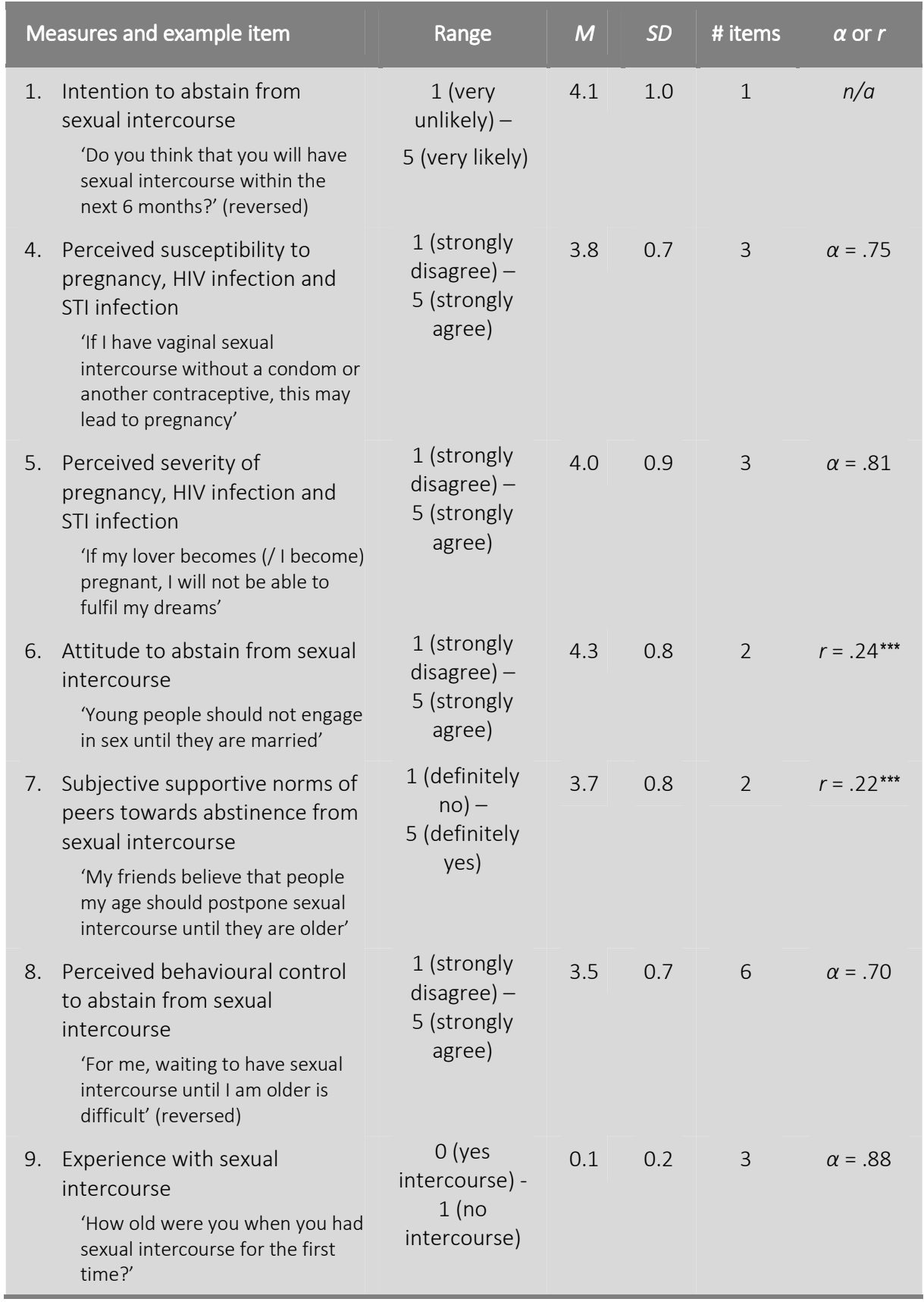

$n / a=$ not applicable, ${ }^{* * *} p<.001$ 
Data were obtained between November 2008 and February 2009. The questionnaires used a self-report closed response format. Research teams in each province were trained during a 4-day training which included topics such as sampling procedures, the research instrument, data recording, cross-checking and validating techniques, and pilot testing of the questionnaire among 90 students in DKI Jakarta. The testing resulted in minor changes in the instrument (e.g., rephrasing of questions towards male and female participants).

The research teams visited the schools on the day of the survey and explained in the selected classes the aims of the study, gave instruction on how to complete the questionnaire, and provided clarity in case of any questions. Participation was voluntary and students who did not want to participate could leave the classroom. All students accepted to participate in the study and gave their consent on paper. Distraction, teacher interference, fellow student interference and interaction in the class room were eliminated as much as possible by giving clear instructions at the start of questionnaire completion, and by not allowing teachers and other school students to come in or near the classroom.

\section{Data Analysis}

Software package SPSS for Windows Version 19.0 was used to analyse the data. Bivariate correlations were calculated for intention, demographic variables, and psychosocial variables. Multiple linear regression analysis was conducted to assess the total amount of variance explained in intention to abstain from sexual intercourse and explore the unique contribution of significant univariate demographic and psychosocial correlates in explaining intention. The Enter method was used for this purpose, allowing all study variables to be entered simultaneously. The same multiple linear regression analysis was conducted for males and females separately. A significance level of $p<.05$ was used throughout the study.

\section{Results}

\section{Sample characteristics}

The demographic details are presented in Table 4.2. The majority of respondents were female (61.7\%) and Muslim (68.2\%). Ages differed between 14 and 20 years $(M=15.89, S D=0.89)$. Almost half of the respondents attended a public school and the other half attended a private school. Most of them were in grade 1 and 2 and a minority was in grade 3 . Education level of parents and guardians was relatively high with $74.9 \%$ of father/male guardian and $66.0 \%$ of mother/female guardian having finished at least senior high school.

A majority of $89.5 \%$ (male: $82.6 \%$; female: $93.8 \%$ ) respondents reported they never had sexual intercourse, 3.8\% (male: 6.7\%; female: $2.0 \%$ ) reported they had sexual intercourse in life at least once, $2.4 \%$ (male: $4.6 \%$; female: $1.0 \%$ ) did not want to answer the three questions measuring experience with sexual intercourse, and 4.3\% (male: $6.1 \%$; female: $3.2 \%$ ) did not provide consistent answers to the three items. 
Table 4.2 Demographic variables

\begin{tabular}{|c|c|c|}
\hline Variables & $N=2315$ & $\%$ \\
\hline \multicolumn{3}{|l|}{ Gender } \\
\hline Male & 887 & 38.3 \\
\hline Female & 1428 & 61.7 \\
\hline \multicolumn{3}{|l|}{ Age $(N=2283)$} \\
\hline 14 & 69 & 3.0 \\
\hline 15 & 737 & 32.3 \\
\hline 16 & 945 & 41.4 \\
\hline 17 & 461 & 20.2 \\
\hline 18 & 60 & 2.6 \\
\hline 19 & 8 & 0.4 \\
\hline 20 & 3 & 0.1 \\
\hline \multicolumn{3}{|l|}{ Province } \\
\hline Jambi & 527 & 22.8 \\
\hline Lampung & 653 & 28.2 \\
\hline DKI Jakarta & 561 & 24.2 \\
\hline Bali & 574 & 24.8 \\
\hline \multicolumn{3}{|l|}{ Type of school } \\
\hline Public secondary school & 788 & 34.0 \\
\hline Public vocational school & 194 & 8.4 \\
\hline Private secondary school & 846 & 36.6 \\
\hline Private vocational school & 487 & 21.0 \\
\hline \multicolumn{3}{|l|}{ School grade } \\
\hline Grade 1 & 1073 & 46.3 \\
\hline Grade 2 & 1002 & 43.3 \\
\hline Grade 3 & 240 & 10.4 \\
\hline \multicolumn{3}{|l|}{ Religion } \\
\hline Catholic & 50 & 2.2 \\
\hline Protestant & 173 & 7.5 \\
\hline Muslim & 1579 & 68.2 \\
\hline Buddhism & 59 & 2.5 \\
\hline Hindu & 454 & 19.6 \\
\hline \multicolumn{3}{|c|}{ Education mother/ female guardian ( $N=2209)$} \\
\hline No formal schooling & 38 & 1.7 \\
\hline Primary school & 376 & 17.0 \\
\hline Junior high school & 337 & 15.3 \\
\hline Senior high school & 966 & 43.7 \\
\hline College/university & 492 & 22.3 \\
\hline \multicolumn{3}{|c|}{ Education father/ male guardian $(\mathrm{N}=2213$ ) } \\
\hline No formal schooling & 21 & 0.9 \\
\hline Primary school & 273 & 12.3 \\
\hline Junior high school & 260 & 11.7 \\
\hline Senior high school & 994 & 44.9 \\
\hline College/university & 665 & 30.0 \\
\hline
\end{tabular}

(Continued) 
Table 4.2 Continued

Variables

$N=2315$

Economic background at household level $(\mathrm{N}=2307)$

\begin{tabular}{|l|l|l|l} 
We don't have enough food & 46 & 2.0
\end{tabular}

\begin{tabular}{|l|l|l|}
\hline We have enough food, but not other basic items such as & 85 & 3.7
\end{tabular}

clothes

We have enough money for food and clothes but are very 1396.0

short

\begin{tabular}{|l|l|l|}
\hline We have the most important things, but few luxury goods & 1731 & 75.0 \\
\hline
\end{tabular}

We have money for luxury goods and extra things $\quad 306 \quad 13.3$

On average, respondents had a relatively high intention to abstain from sexual intercourse $(M=4.05, S D=1.03)$. A majority reported the likelihood of abstaining from sexual intercourse as likely or very likely (66.4\%), $12.9 \%$ reported neutral, $9.2 \%$ was unlikely or very unlikely to abstain, and $11.3 \%$ indicated they did not want to disclose their answer. The respondents who did not want to disclose their answer were excluded from correlation and multiple linear regression analyses.

\section{Correlation between intention and predictors to abstain from sexual intercourse}

Means and standard deviations of the psychosocial measures are presented in Table 4.1. Table 4.3 provides an overview of intercorrelations. Perceived behavioural control to abstain correlated most strongly and positively with abstinence intention. A strong negative correlation was found for respondents' experience with sexual intercourse. Moderate positive correlations were found for perceived supportive norms of peers towards abstinence, gender (being a girl), and attitude towards abstinence. A weak negative correlation was found for higher age. Past experience with sexual intercourse correlated most strongly with subjective norms, perceived behavioural control, and attitude towards abstinence. No significant associations were found for perceived susceptibility and perceived severity of pregnancy, HIV infection and STI infection.

\section{Multiple linear regression}

Multiple linear regression was employed to explore the correlates of intention. Table 4.4 displays the regression statistics, including the standardised regression coefficients $(\beta s)$. The regression model included gender, age, the TPB variables and past experience and was significant, $F(6,1980)=149.61, p<.001$. The predictors together explained 31.2 per cent of the variance in abstinence intentions $\left(R^{2}=.31\right)$. All predictors provided a significant unique contribution to the variance in intentions, with past experience with sexual intercourse and perceived behavioural control explaining most unique variance. Gender, attitude and subjective norms of peers contributed moderately, and age contributed weakly to the variance in abstinence intentions. 


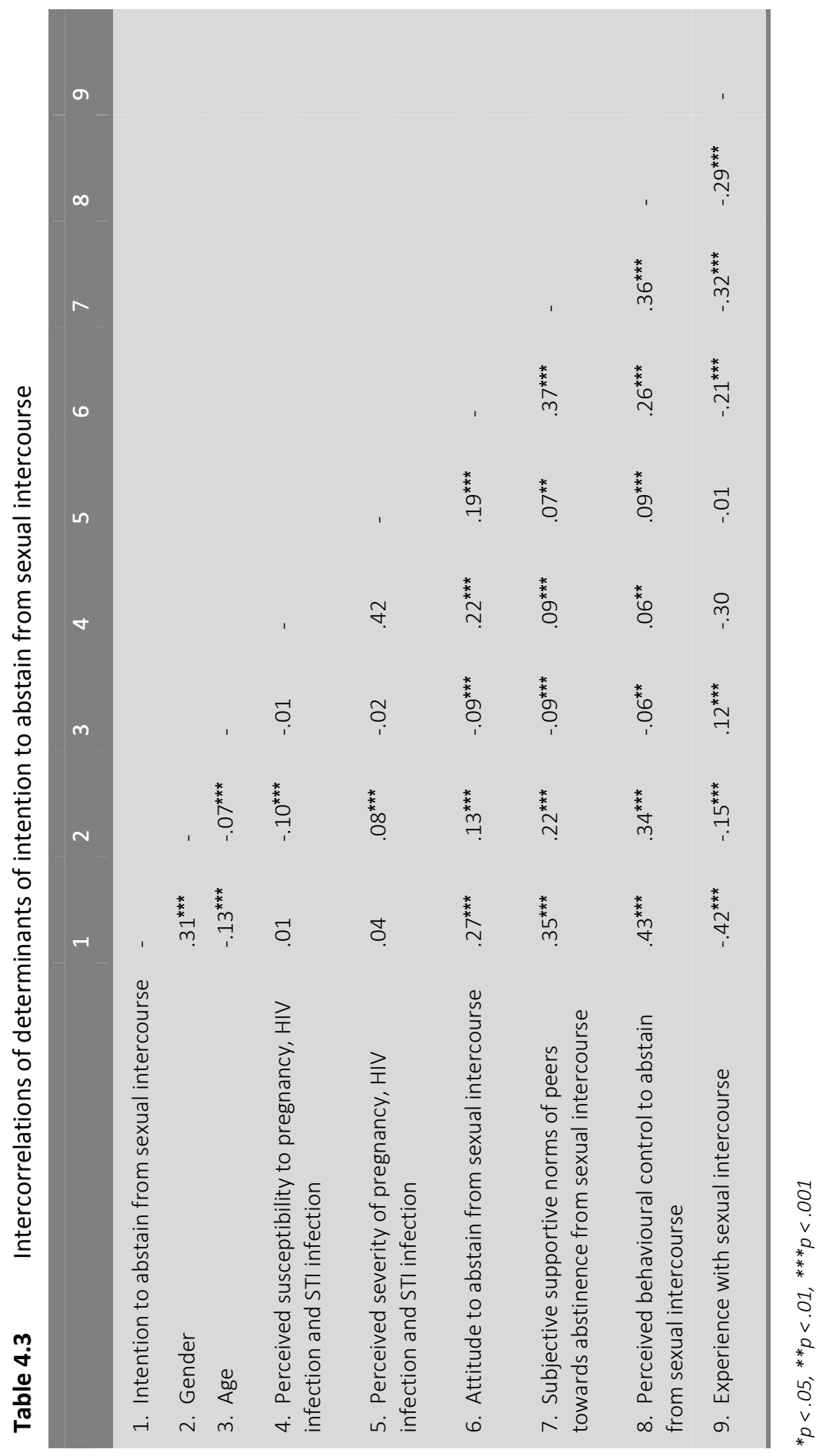




\section{Multiple linear regressions for males and females}

Separate multiple linear regression analyses were employed for male $(N=720)$ and female $(N=1267)$ respondents. Table 4.4 displays the standardised regression coefficients $(\beta s)$, unstandardized regression coefficients $(B s)$, and standard errors (SES) for males and females. Variance in abstinence intentions could be better explained by the univariate significant correlates for male $\left(R^{2}=.31\right)$ than for female $\left(R^{2}=.20\right)$ respondents. Regression models were significant for both groups, with $F(5,714)=62.56, p<.001$ for males and $F(5,1261)=38.52, p<.001$ for females. Similar to the general regression model, experience with sexual intercourse and perceived behavioural control explained most unique variance in abstinence intentions of both males and females. However, attitude towards abstinence only contributed significantly to variance in males' intentions. Perceived social norms of friends contributed moderately to males' and weakly to variance in females' intentions. Age did not contribute to the variance in males' abstinence intention, whereas it did to females' intention.

\section{Discussion}

The study described in this chapter explored psychosocial correlates of Indonesian adolescents' motivation to abstain from sexual intercourse. The findings provide guidance for evidence-based planning of sexuality education programmes in Indonesia and beyond. This is the first study in Indonesia that has explored correlates of adolescents' intention to abstain from sexual intercourse, using the Theory of Planned Behaviour extended with perceived susceptibility and perceived severity of the Health Belief Model. The study found that the Theory of Planned Behaviour provides a relatively good basis for understanding abstinence intentions of Indonesian adolescents, with similar success as other studies worldwide (BasenEngquist \& Parcel, 1992; Basen-Engquist, Tortolero, \& Parcel, 1997; Collazo, 2005; Villarruel, Jemmott III, Jemmott, \& Ronis, 2004; Mathews et al., 2009; Cha et al., 2007).

Perceived behavioural control regarding abstinence from sexual intercourse was most strongly correlated to abstinence intentions. This finding is similar to other studies (Buhi \& Goodson, 2007; Collazo, 2005) and implies that sexuality education programmes should focus on building adolescents' belief in and anticipation on their ability to abstain from sexual intercourse. This finding did not differ for male and female adolescents.

Past experience with sexual intercourse was the second important factor associated with adolescents' motivation to abstain. Relatively few studies have explored the influence of past experience with sexual intercourse on abstinence intentions of adolescents. These few studies however support the finding that lack of experience with sexual intercourse is an important predictor of adolescents' motivation to abstain (Basen-Engquist, Tortolero, \& Parcel, 1997; Nahom et al., 2001). 
Table 4.4 Results of multiple linear regression analysis for the total sample

\begin{tabular}{|c|c|c|c|c|c|c|c|c|c|}
\hline & \multicolumn{3}{|c|}{ Total $(N=1987)$} & \multicolumn{3}{|c|}{ Males $(N=720)$} & \multicolumn{3}{|c|}{ Females $(N=1267)$} \\
\hline & B & SE & $\beta$ & B & $S E$ & $\beta$ & $B$ & SE & $\beta$ \\
\hline $\begin{array}{l}\text { 1. Intention to } \\
\text { abstain from } \\
\text { sexual } \\
\text { intercourse }\end{array}$ & - & - & - & - & - & - & - & - & - \\
\hline 2. Gender & .31 & .04 & $.15^{* * *}$ & - & - & - & - & - & - \\
\hline 3. Age & -.06 & .02 & $-.06^{\star *}$ & -.06 & .04 & -.05 & -.07 & .03 & $-.07^{* *}$ \\
\hline $\begin{array}{l}\text { 4. Perceived } \\
\text { susceptibility to } \\
\text { pregnancy, HIV } \\
\text { infection and } \\
\text { STI infection }\end{array}$ & - & - & - & - & - & - & - & - & - \\
\hline $\begin{array}{l}\text { 5. Perceived } \\
\text { severity of } \\
\text { pregnancy, HIV } \\
\text { infection and } \\
\text { STI infection }\end{array}$ & - & - & - & - & - & - & - & - & - \\
\hline $\begin{array}{l}\text { 6. Attitude to } \\
\text { abstain from } \\
\text { sexual } \\
\text { intercourse }\end{array}$ & .12 & .03 & $.09^{* * *}$ & .20 & .05 & $.15^{* * *}$ & .06 & .03 & .05 \\
\hline $\begin{array}{l}\text { 7. Subjective } \\
\text { supportive } \\
\text { norms of peers } \\
\text { towards } \\
\text { abstinence } \\
\text { from sexual } \\
\text { intercourse }\end{array}$ & .12 & .03 & $.10^{* \star *}$ & .17 & .04 & $.14^{\star * *}$ & .08 & .03 & $.07^{*}$ \\
\hline $\begin{array}{l}\text { 8. Perceived } \\
\text { behavioural } \\
\text { control to } \\
\text { abstain from } \\
\text { sexual } \\
\text { intercourse }\end{array}$ & .32 & .03 & $.22^{* * *}$ & .35 & .05 & $.22^{* * *}$ & .29 & .04 & $.22^{* * *}$ \\
\hline $\begin{array}{l}\text { 9. Experience } \\
\text { with sexual } \\
\text { intercourse }\end{array}$ & -1.26 & .09 & $-.27^{\star * *}$ & -1.03 & .14 & $-.26^{\star * *}$ & -1.45 & .13 & $-.30^{\star * *}$ \\
\hline$R^{2}$ & & & .31 & & & .31 & & & .20 \\
\hline
\end{tabular}

${ }^{*} p<.05,{ }^{* *} p<.01,{ }^{* * *} p<.001$ 
This finding suggests that sexuality education programmes need to consider adolescents' past behaviour to meet the needs of both sexually experienced and inexperienced adolescents.

Perceived supportive norms of peers were found to be strongly associated with adolescents' motivation to abstain, which is also shown in similar studies (Cha et al., 2007; Fisher, Fisher, \& Rye, 1995). This study indicates that subjective norms of peers are a relevant predictor of males' intentions, whereas it is a weak predictor of females' abstinence intentions. These findings imply that supportive subjective norms of peers should be reinforced in sexuality education and that differences between males and females have to be taken into account. A positive attitude towards abstinence was positively and strongly associated with adolescents' motivation to abstain. Previous research shows similar findings (Basen-Engquist \& Parcel, 1992; Basen-Engquist, Tortolero, \& Parcel, 1997; Villarruel, Jemmott III, Jemmott, \& Ronis, 2004). The study also shows that perceived susceptibility and perceived severity of pregnancy, HIV infection and STI infection do not motivate adolescents to abstain from sexual intercourse. This can be explained by the relatively low prevalence of HIV, STIs and pregnancies among Indonesian adolescents and by a general finding that perceived susceptibility and perceived severity are not strong predictors of health behaviour (Carpenter, 2010). The findings suggest that education programmes should focus on change or reinforcement of positive attitudes of adolescents towards abstinence, but put less emphasis on perceived severity and susceptibility.

Finally, the study showed similarities and differences between males' and females' motivation to abstain from sexual intercourse. Females are generally more motivated to abstain than males and younger female adolescents are more motivated than older female adolescents. However, the measured psychosocial variables were better applicable to predict males' motivation than females' motivation to abstain. This could be explained by the larger proportion of males who reported experience with sexual intercourse, compared to a small proportion of females.

The study has strengths and limitations. The study's strength is its large sample size. One of the limitations however was the non-randomised sample utilised in this study, limiting generalizability of the findings. Another limitation was the larger proportion of female respondents compared to males, resulting in restrictions to compare the two groups. A third limitation was the inclusion of the option 'I don't want to talk about it' to the question measuring intention to abstain from sexual intercourse, which resulted in a relatively high percentage of $11.3 \%$ missing values for correlation and multiple linear regression analysis. Additional research can further investigate adolescents' self-disclosure regarding sensitive topics in questionnaires (Leerlooijer, Ruiter, Rijsdijk, et al., submitted). 


\section{Conclusion}

Concluding, this study is one of the first studies in an Islamic context, and the first in Indonesia, that explored theory-based predictors of adolescents' motivation to abstain from sexual intercourse. The study confirms the conclusions of other studies in Indonesia that psychosocial frameworks can assist programme planners to explore correlates of behavioural intentions in Indonesia (Liem, Hidayat, \& Soemarno, 2009). The study has improved our understanding of the psychosocial correlates of adolescents' motivation to abstain from sexual intercourse in Indonesia and contributes to the evidence that is essential to be able to design or adapt theory- and evidence-based sexuality education programmes (Leerlooijer et al., 2011; Sumintardja et al., 2009). The present study demonstrates that sexuality education in Indonesia should consider adolescents' experience with sexual intercourse, perceived behavioural control, perceived social norms and attitudes towards abstinence. To expand the evidence-base and contribute to the design of comprehensive programmes, future research could explore theory-based correlates of Indonesian adolescents' motivation to use condoms during sexual intercourse. 


\section{Chapter 5}

Breaking taboos about sexuality:

Effects of the school-based programme The World Starts with Me in Uganda and Thailand on disclosure about sensitive issues

Leerlooijer, J. N., Ruiter, R. A. C., Rijsdijk, L. E., Reinders, J., Bos, A. E. R., Wong, W., \& Kok, G.

Submitted 


\begin{abstract}
Sexuality related topics are taboo and are not openly communicated about in many cultural settings and populations. Adolescents' lack of self-disclosure about sensitive topics contributes to misconceptions and misunderstanding about relationships, sex and contraceptives. One of the aims of the comprehensive sexuality education programme 'The World Starts With Me' (WSWM) in Uganda and Thailand is to increase adolescents' self-disclosure about sensitive sexuality related topics. A quasiexperimental evaluation study was conducted in Uganda $(N=1446)$ and Thailand ( $N$ = 1862) measuring the effect of WSWM on adolescents' self-disclosure by adding the answer option 'I don't want to talk about it' to 29 'sensitive' questionnaire items. The study showed that disclosure level at baseline was higher in Uganda than in Thailand. WSWM significantly increased disclosure in Thailand and particularly contributed to disclosure about attitudes towards sensitive topics; experience with non-consensual sex; safe and consensual sex intentions; and health and services related experiences. It is concluded that comprehensive sexuality education programmes such as WSWM can increase self-disclosure if adolescents' level of selfdisclosure is relatively low at baseline. Interventions targeting individual selfdisclosure can be complemented with interventions aiming to address structural factors in society such as sexuality related taboos and social norms.
\end{abstract}




\section{Introduction}

In many cultural settings and populations worldwide, sexuality related topics are taboo and are not openly and explicitly communicated about (Evans, Avery, \& Pederson, 1999). Taboos can be defined as beliefs that constrain actions by making certain behaviours and communication about certain topics forbidden or discouraged (Montgomery, 2009). Examples of common sexuality related taboos regarding adolescents include personal disclosure about sexual orientation, HIVstatus, and experience with violence, out-of-wedlock pregnancy, or abortion; about sexual histories, sexual desires and preferences, boundaries, menstruation, sexual behaviour and contraceptive use; and about beliefs and intentions that may not align with societal or community norms (Montgomery, 2009; Wood, Maforah, \& Jewkes, 1998).

Lack of communication about sexuality related topics can lead to ambiguity, misunderstanding and misconceptions (Marston \& King, 2006; Varga, 1997; Ingham, Woodcock, \& Stenner, 1991; Schalet, 2011). On the contrary, adolescents' open communication with peers, parents, sexual partners, and health service providers and other professionals can contribute to problem solving and support seeking behaviours (Rodríguez, Sheldon, Bauer, \& Pérez-Stable, 2001), to expression of thoughts and feelings, to a sense of self and intimacy in relationships (Chaudoir \& Fisher, 2010; Greene, Derlega, \& Mathews, 2006; Derlega, Winstead, Mathews, \& Braitman, 2008), to decreased stigma and discrimination (Stutterheim et al., 2011), and to abstinence of sex, consensual sex, and use of condoms or contraceptives (Bastien, Kajula, \& Muhwezi, 2011; Sheeran, Abraham, \& Orbell, 1999; Allen, Emmers-Sommer, \& Crowell, 2002; Noar, Carlyle, \& Cole, 2006). This chapter concentrates on increasing disclosure about sensitive sexuality related topics by adolescents. Self-disclosure can be defined as an interaction between at least two individuals where one intends to deliberately reveal highly sensitive information such as personal fears, deeply held religious convictions, or potentially stigmatising information to another (Derlega, Metts, Petronio, \& Margulis, 1993; Greene, Derlega, \& Mathews, 2006).

Self-disclosure skills of adolescents are critical to be prepared for intimate and sexual interactions and for seeking support and services. Sexuality education programmes can contribute to self-disclosure skills by providing adolescents a safe opportunity to explore and articulate their thoughts about intimacy, sexuality, desires, preferences, and boundaries, and by supporting them to discuss these issues openly with their sexual partners (Widman, Welsh, McNulty, \& Little, 2006). A review of studies showed an effect of sexuality education programmes on communication with partners about AIDS, sexually transmitted infections (STIs), and past partners and on communication with parents or other adults about sex (Kirby, Laris, \& Rolleri, 2007). The review found limited effects regarding communication with a partner about abstinence or contraception. In our study we explored to what extent the comprehensive sexuality education programme 'The World Starts With 
Me' has contributed to disclosure about sexuality related topics among students in Uganda and Thailand.

The comprehensive sexuality education programme WSWM (Leerlooijer et al., 2011; Rijsdijk et al., 2011) for secondary school students was developed in Uganda in 2002 and systematically adapted to the context and target group in Thailand in 2006. The programme addresses a range of topics related to sexual and reproductive health and rights, including emotional, physical and social changes in adolescence, relationships with sexual partners and relevant others, gender and adolescents' rights, delay, abstinence, and safe and consensual sex, stigma, and prevention of HIV/AIDS, STIs, teenage pregnancy and sexual violence.

One of the aims of WSWM is to increase communication about sensitive topics between students and their sexual partners, parents, peers, health care providers and other professionals. This is done in various ways. Firstly, the tone and content of the text, illustrations, and pictures throughout the programme are explicit and represent an open and positive atmosphere. Students and facilitators agree upon ground rules with regard to confidentiality and respect for different opinions. Secondly, the facilitators (teachers and peer educators) are trained to communicate explicitly with students. Thirdly, communication about sensitive topics between students is encouraged by small group work behind one computer in a safe atmosphere. Fourthly, communication and discussion about sensitive topics between facilitators and students is initiated by digital presentations and exercises in the programme, unburdening facilitators to initiate this. Digital peer educators guide students through lessons and are examples in their explicit and open communication.

The programmes and approaches in both countries are similar to a large extent, but differ in some respects because of context specific needs. Based on the needs assessment, two topics were added to the Thai programme that were less extensively addressed in the Ugandan programme: (1) boys' communication about sensitive topics and expression of emotions, and (2) sexual orientation and homoand trans-phobia. In addition, a younger age group is addressed in Thailand (12-15 years old) compared to Uganda (14-20). In Thailand, the programme is implemented in government schools in the (semi-)urban Bangkok area, whereas in Uganda the programme is implemented in rural and urban areas across the country.

The present study investigated whether WSWM has contributed to more disclosure by adolescents in Uganda and Thailand about sensitive sexuality related issues. Non-disclosure was operationalized by adding the answer option 'I don't want talk about it' to items in the questionnaire that were marked as sensitive. The less this option was chosen, the more participants disclosed about themselves.

\section{Methods}

\section{Study design and population}

This quasi-experimental study used self-reported data collected from secondary school students in Uganda and Thailand as part of the evaluation of the sexuality 
education programme WSWM. More detailed information about the evaluation design and outcomes is described elsewhere (Rijsdijk et al., 2011; Wong et al., 2010). The purpose of the study was to measure the effects of the programme on safe and consensual sex intentions and its psychological correlates, and on sexuality disclosure about attitudes, intentions, and behavioural experiences.

School-level data were collected in intervention and comparison schools. Schools were not randomly selected, as the intervention schools had committed to WSWM implementation prior to the evaluation study. In Uganda, selection of intervention schools was based on (1) type of school (boarding; day; mixed), (2) geographical area (rural; urban) and (3) boys; girls; mixed school. In Thailand, selection was based on (1) school size and (2) geographical area in the Bangkok Municipality (semiurban; urban). All schools in Thailand were mixed boys' and girls' schools. Based on abovementioned criteria a matching comparison school was selected for each intervention school. The comparison schools would receive the programme in the next implementation round in case they were interested (waiting-list control group).

In Uganda, 48 schools (24 intervention and 24 comparison schools) were selected, equally distributed across the country. To ensure equal distribution of gender and age, the (head) teachers were asked to select a group of 50 students in their school based on gender and age. The response rate was $83 \%(N=1986)$ for the baseline (T0) and 67\% ( $N=1609)$ for the post-test (T1). Unavailability for post-test was primarily due to absenteeism, transfer to other schools, and school leave. Data from two respondents at post-test were removed, because they had not completed the baseline survey. Data from three intervention schools (in total 122 respondents) were also removed because at post-test these schools had finished only up to lesson 7 of the programme. Outcome analysis was carried out with a final dataset comprising 1795 respondents at baseline (784 intervention group; 1011 comparison group) and 1458 respondents at post-test (662 intervention group; 796 comparison group). Baseline data were obtained in March 2008 and post-test data in September/October 2008. The WSWM programme was implemented between April 2008 and September 2008 (6 months).

In Thailand, 21 schools (8 intervention schools and 13 comparison schools) were selected. All schools were located in the Bangkok Municipality. Classes were selected by the teachers in the schools and all students in these classes participated. Data from one comparison school $(N=101)$ were removed because post-test data were not collected. Outcome analysis was carried out with a final dataset comprising 1940 respondents at baseline (1033 intervention group; 907 comparison group) and 1559 respondents at post-test (826 intervention group; 733 comparison group). The dropout of the 400 respondents for post-test was primarily due to absenteeism and school leave. The baseline measurement was conducted in June 2008 and the posttest measurement in March 2009 (intervention group) and July 2009 (comparison group). WSWM was implemented between June 2008 and March 2009 (9 months). Measurements and implementation length in Thailand differed from Uganda because of different school schedules in both countries. 


\section{Procedure}

The study was approved by the Ethical Committee Psychology (ECP) of the Faculty of Psychology and Neuroscience at Maastricht University in the Netherlands. All respondents gave written informed consent. Confidentiality was assured by anonymous completion of the questionnaire and explanation that the questionnaires would be accessible for the research team only. Students did not write their names on the questionnaire and the questionnaires were collected from the students by external research teams.

Research teams in both countries participated in a training including topics such as sampling procedures, research instrument, and pilot testing of the questionnaire. The teams visited the schools on the day of the survey and explained to the students the aims of the study, how to complete the questionnaire, and provided clarity in case of any questions. Participation was voluntary and students who did not want to participate could leave the classroom. Distraction, teacher or fellow student interference, and interaction in the class room were eliminated as much as possible by giving clear instructions at the start of questionnaire completion and by not allowing teachers and other school students to come in or near the classroom.

\section{Measures}

A measurement instrument was developed to collect data on the sociodemographic characteristics of the respondents and on outcome variables that were central to the WSWM programme (Rijsdijk et al., 2011). Items and scales were based on a questionnaire previously used in Tanzania and South Africa (SATZ Project) (Mukoma et al., 2009). The instrument was pretested in both countries, which resulted in minor changes. The questions relevant for the study in this chapter were similar in the Ugandan and Thai questionnaires. Female and male versions of the questionnaire were developed. When relevant, the questions were phrased towards each of the two sexes. For example, 'Have you ever pressured someone to have sex with you when she didn't want to?' (males) and 'Have you ever pressured someone to have sex with you when he didn't want to?' (females). The same questionnaire was used for baseline (TO) and post-test (T1). Most items were measured using 5point Likert scales.

To measure the level of non-disclosure about sensitive topics, the answer option 'I don't want to talk about it' was added to questions that were marked as sensitive. By adding this option, respondents had the opportunity to indicate that they did not want to answer the question, rather than providing socially desirable answers. Few other studies have included similar answer options such as 'I prefer not to say' or 'Decline' (Joinson, Paine, Buchanan, \& Reips, 2008; Buchanan, Paine, Joinson, \& Reips, 2007; Knapp \& Kirk, 2003). To distinguish between 'sensitive' and 'nonsensitive' questions, a group of intervention developers and researchers in the respective countries applied the following criteria: (1) the extent to which questions touch on taboo topics that are perceived as inappropriate in everyday conversation; (2) the level of 'threat of disclosure' (i.e., concerns about possible consequences of giving a truthful answer should the information become known to a third party); and 
(3) the extent to which questions elicit answers that are socially unacceptable or undesirable (Tourangeau \& Yan, 2007). The selected 'sensitive' questions were recoded into dichotomous variables, with 1 = disclosure (answer to the question), 0 = non-disclosure (answer 'I don't want to talk about it', 'I don't know', and missing values).

In both countries, the instrument included 124 questions, of which 39 questions in Uganda and 41 questions in Thailand were marked as sensitive. The other questions included sociodemographic questions and questions that were marked as less or not sensitive. Descriptive analysis resulted in removal of questions from the Ugandan (10 questions) and Thai (12 questions) datasets, because of the large numbers (> 35\%) of missing values, resulting in 29 items that were marked as sensitive in both countries. The high number of missing values was partly a consequence of skip patterns. For example, only respondents who answered 'I ever used a condom' completed other condom use related questions. Questions that were excluded because of the large numbers of missing data comprised questions about past experiences with sexual intercourse and condom use (for example, 'All the times you used a condom, how often did the condom slip or break?').

Outcome analysis was carried out for both countries with a set of 29 items that were marked as sensitive and had sufficient numbers of respondents (see Table 5.1 for an overview). Outcome variable was the mean sum score on the 29 items, calculated by dividing the number of disclosed responses by the total number of 29 items.

Principle axis factor analysis was conducted to identify categories of sensitive questions, resulting in eight similar categories for both countries. Reliability analysis was used to check the resulting internal consistency of scores on items within scales. See Table 5.1 for an overview of variables, items and scale reliability measured with Cronbach's $\alpha$ ( 3 or more items) or Pearson's correlations (2 items). The internal consistencies of the scales were satisfactory $\left(\alpha^{\prime} s>.70 ; r^{\prime} s>.50\right)$. The eight categories are (1) attitudes towards sensitive topics, (2) experience with a lover or non-penetrative sex, (3) experience with condom use performance behaviours, (4) experience with sexual intercourse or condom use, (5) experience with nonconsensual sex, (6) experience with masturbation or anal intercourse, (7) safe and consensual sex intentions, and (8) health and services related experiences.

\section{Data analysis}

The questionnaire data were coded, validated and cleaned. Data were analysed with software package SPSS for Windows Version 19.0. Descriptive analysis was conducted to describe the sociodemographic characteristics of the study sample at baseline. To assess baseline differences and intervention effects, a linear mixed model procedure was used to accommodate the hierarchical structure of the data (i.e., students nested in schools). Due to the non-random nature of the distribution of schools, and therefore also participants across the intervention and control conditions, using analysis of variance (ANOVA) of change from baseline as the primary method of analysis rather than analysis of covariance (ANCOVA) of the outcome with the baseline as covariate was appropriate (Van Breukelen, 2006). 
Being part of the intervention or comparison group (group) and time (baseline vs. post-test) were considered as Level 1 indicators, whereas school was modelled as Level 2 variable. We were primarily interested in finding a significant group (intervention vs. control) x time (baseline vs. post-test) interaction effect, which would suggest that the intervention had an effect on the outcome variable. In cases where there was a significant group $\mathrm{x}$ time interaction effect, we conducted simple effects analyses testing the effect of group at both baseline and post-test in order to understand the nature of the intervention effect. Preliminary analyses were conducted to test for the effects of age, gender and urban/semi-urban/rural residence on disclosure and possible moderation of the intervention effect by these sociodemographic characteristics. No significant main or interaction effects were found after which the analyses were repeated without age, gender, and residence in the models. A significance level of $p<.05$ was used throughout the study.

\section{Results}

\section{Student characteristics}

Sociodemographic characteristics of students who participated in the study were different in Uganda and Thailand. The baseline sample in Uganda consisted of 836 boys (46.6\%) and 959 girls (53.4\%). Their average age was 16.1 years (SD = 1.9; range $12-20)$ and respondents lived in urban (14.7\%), semi-urban (41.2\%), semirural $(20.0 \%)$, or rural $(24.0 \%)$ areas. The sample in Thailand comprised of 1031 boys (53.1\%) and 909 girls (46.9\%). The average age was 13.5 (SD $=0.6 ; 12-17$ ) and respondents lived in urban (62.8\%), semi-urban (28.8\%), or rural (8.5\%) areas.

At baseline, there was a significant difference between Uganda and Thailand on disclosure, $F(1,3733)=286,20, p<.001$. Respondents in Uganda were more willing to disclose $(M=93.4 \% ; 95 \% \mathrm{Cl}=92.8-94.0)$ than respondents in Thailand $(M=$ 85.2\%; $95 \% \mathrm{Cl}=84.4-86.0)$. In both countries, there were no respondents who declined to disclose about all 29 items. At baseline, 51\% of Ugandan respondents disclosed about all 29 sensitive items compared to $23 \%$ of Thai respondents.

\section{Effect of WSWM on disclosure}

Multilevel analysis revealed a significant three-way interaction effect between country, time and group on disclosure suggesting that the intervention effect differed for both countries, $F(1,3283)=10.27, p<.001$. We therefore decided to test the intervention effect (group $x$ time) for both countries separately.

\section{Uganda}

Disclosure sum score. Multilevel analysis revealed no significant interaction between time and group, $F(1,1590)=1.35, p=.25$, suggesting that the intervention had no effect on the disclosure level across the 29 items (see Table 5.2 for the mean scores). Instead we found a main effect of time, $F(1,1579)=7.95, p<.01$, showing that disclosure was higher at post-test $(M=95.0 \% ; 95 \% \mathrm{Cl}=94.5-95.5)$ than at baseline $(M=93.4 \% ; 95 \% \mathrm{Cl}=92.8-94.0)$. No main effect of group was found, $F<$ $1.00, \mathrm{~ns}$. 


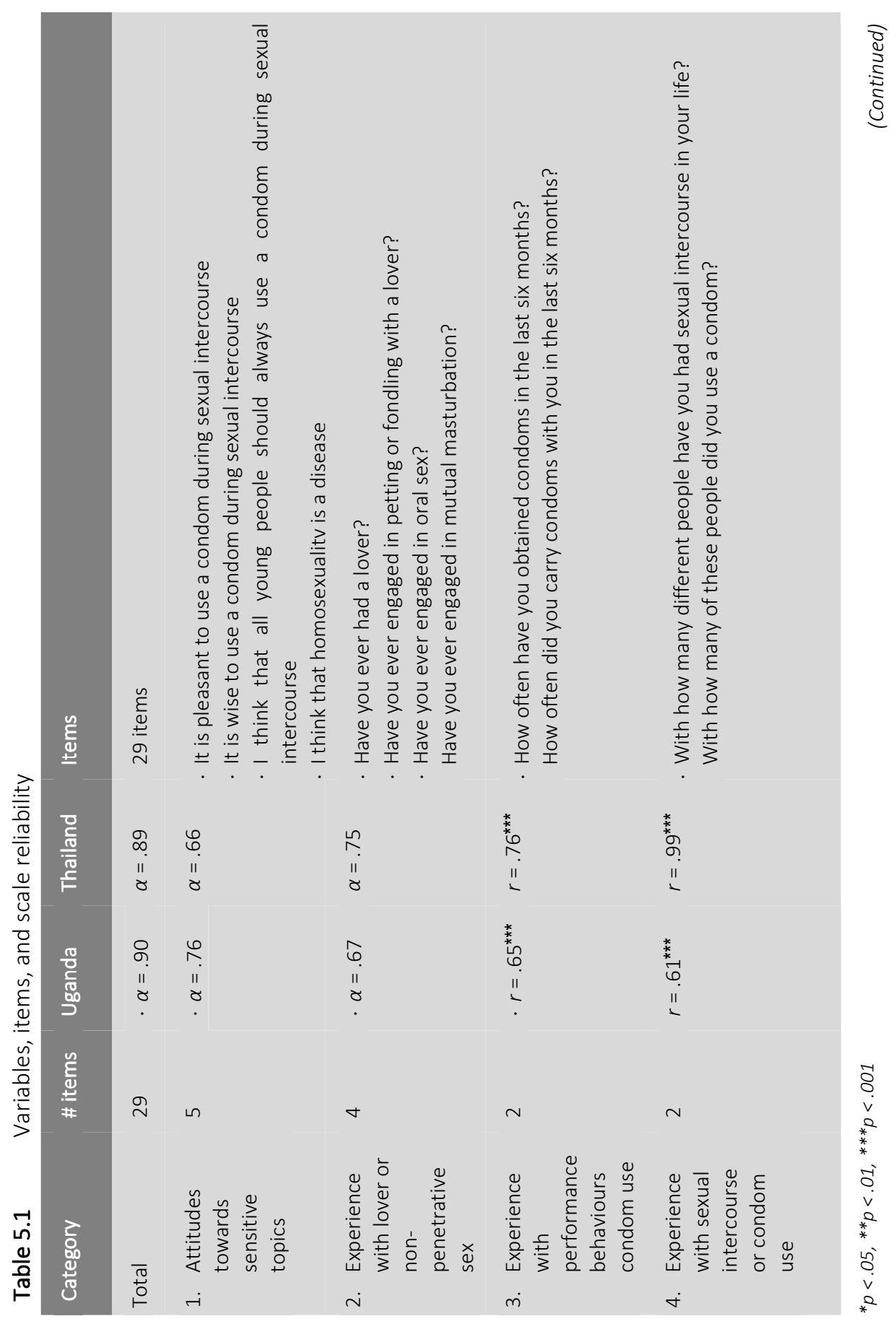




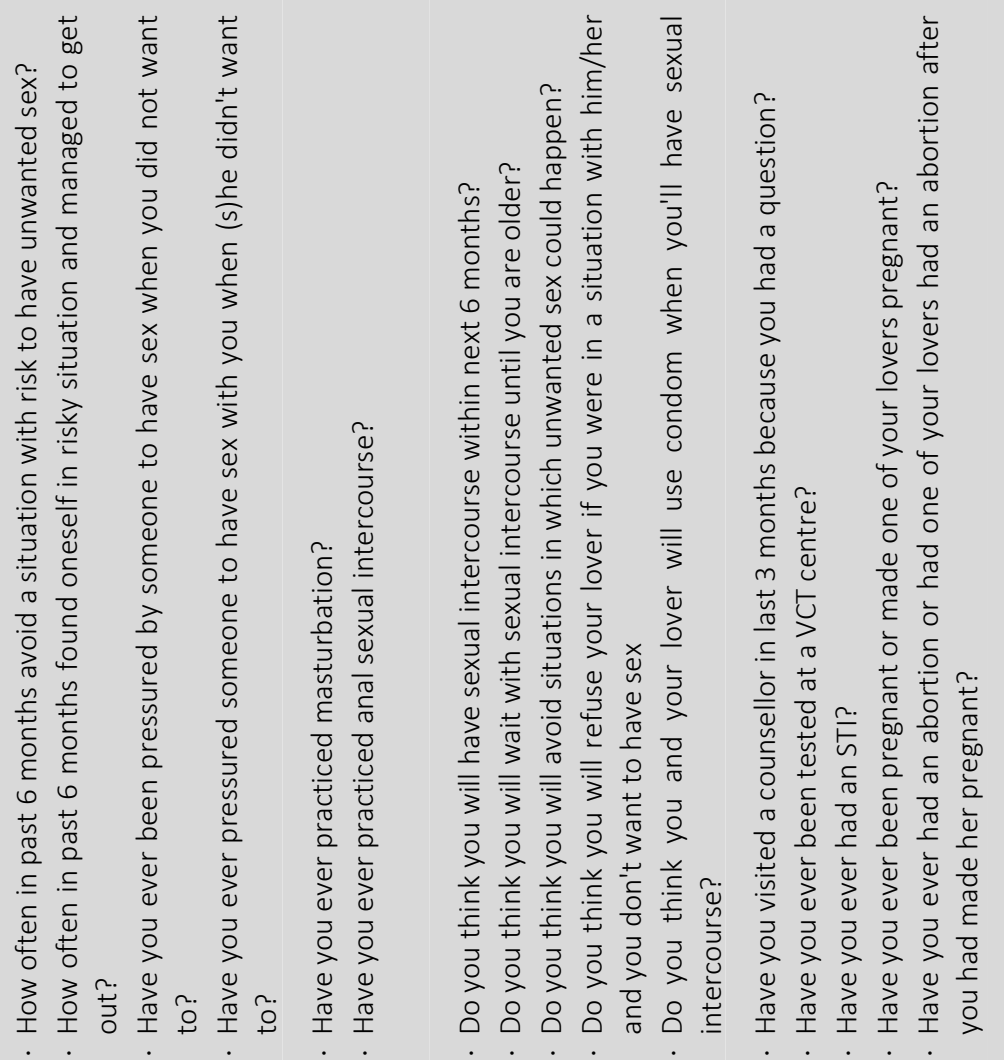

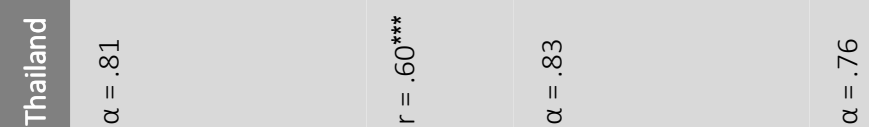
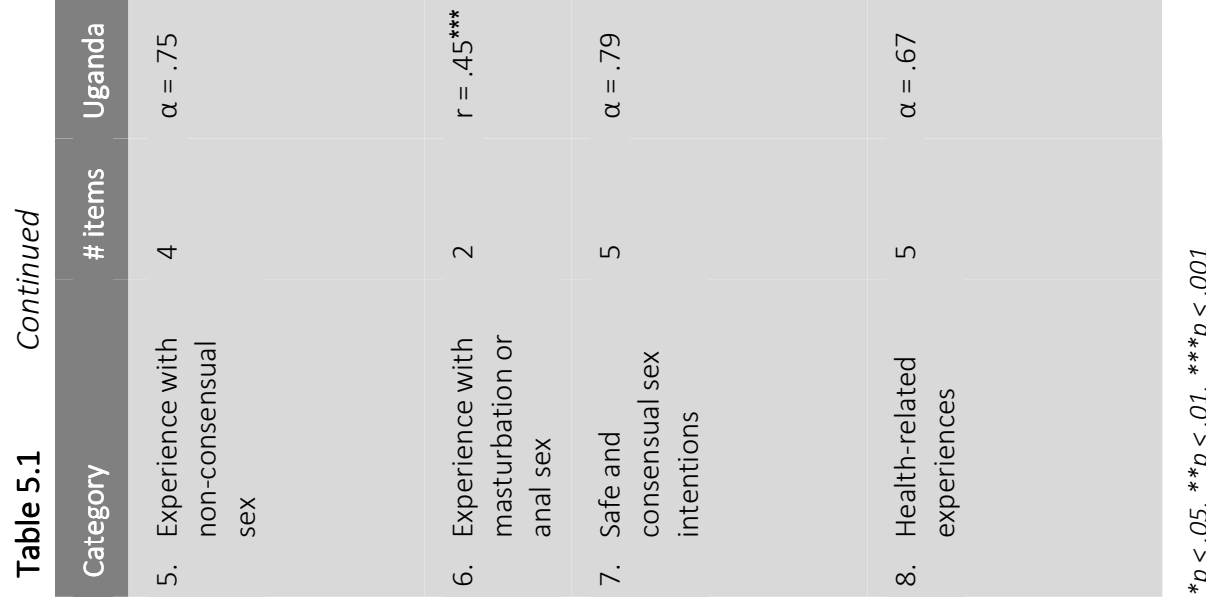
Disclosure categories. We found no significant intervention $x$ category $x$ time interaction, $F(7,1664)=1.11, p=.36$. However, we did find a significant category $x$ time interaction, suggesting a change over time independent of intervention exposure, that was different for the eight categories, $F(7,1664)=9.55, p<.001$. Simple effect analyses showed that the change over time was significant for all categories $\left(F^{\prime} s>4.20, p^{\prime} s<.05\right)$. See Table 5.2 for the mean scores per category.

\section{Thailand}

Disclosure sum score. Multilevel analysis revealed a significant interaction effect between time and group, $F(1,1738)=19.81, p<.001$ (see Table 5.3). Simple effect analyses showed that the effect of group was not significant at baseline, $F(1,1938)=$ $.21, p=.65$. At post-test, participants that received the intervention disclosed more across the 29 items than participants in the comparison group, $F(1,1557)=23.62, p$ $<.001$, suggesting that WSWM positively contributed to disclosure.

Disclosure categories. A significant three-way interaction effect was found between time, group and category, $F(7,1827)=5.36, p<.001$, suggesting that the intervention effect on disclosure was different for the eight categories. Analyses per category found significant interactions between time and group on attitudes towards sensitive topics, $F(1,1792)=8.26, p<.01$; experience with non-consensual sex, $F(1,1765)=5.00, p<.05$; safe and consensual sex intentions, $F(1,1813)=37.42$, $p<.001$; and health and services related experiences, $F(1,1767)=7.80, p<.01$, and no significant interactions between time and group for experience with sexual intercourse or condom use, $F(1,1863)=2.32, p=.13$; experience with lover or nonpenetrative sex, $F(1,1789)=.009, p=.92$; experience with condom use performance behaviours, $F(1,1796)=3.52, p=.06$; and experience with masturbation or anal intercourse, $F(1,1769)=1.67, p=.20$. See Table 5.3 for the mean scores per category.

Simple effect analyses showed that for all categories the effect of group was not significant at baseline ( $F^{\prime} s<2.45$, ns), was significant at post-test for six categories $\left(F^{\prime} s>5.72, p^{\prime} s<.05\right)$ and not significant for experience with a lover or nonpenetrative sex and for experience with masturbation or anal intercourse $\left(F^{\prime} s<2.65\right.$, ns).

\section{Discussion}

The study described in this chapter measured the effect of the comprehensive sexuality education programme WSWM on disclosure of students in Uganda and Thailand about sensitive sexuality related topics. The findings contribute to the limited evidence regarding adolescents' disclosure about sensitive topics (Derlega, Winstead, Mathews, \& Braitman, 2008). The study revealed that the intervention had effect on disclosure of students in Thailand, whereas no significant effect was found for Ugandan WSWM participants. 


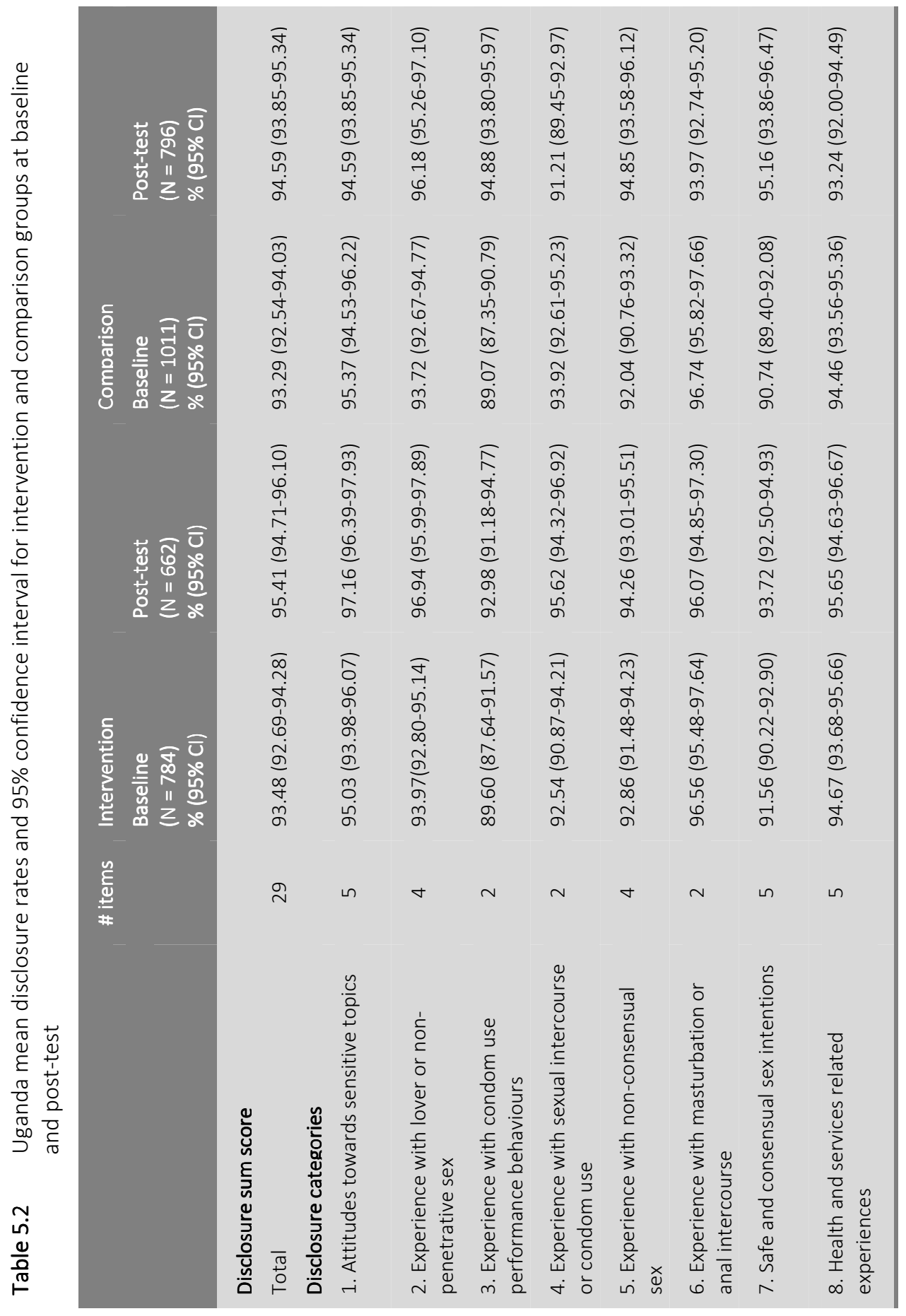




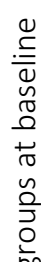

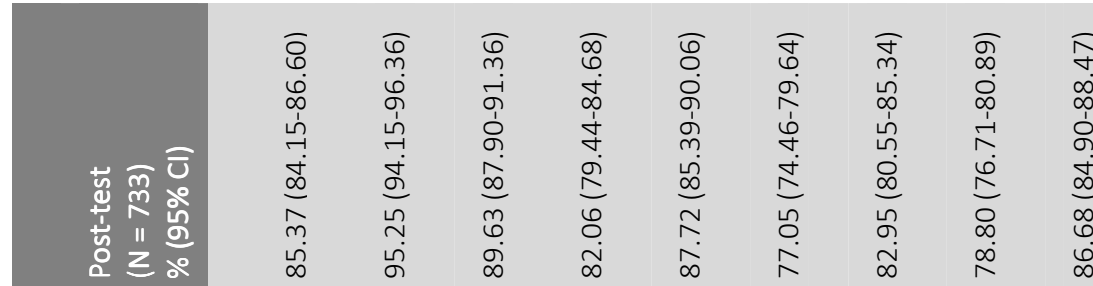

등

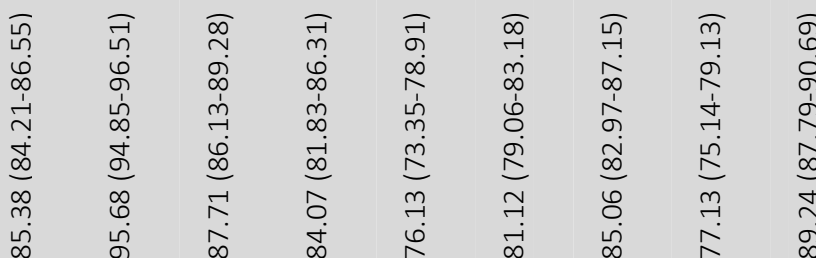

등 ญ

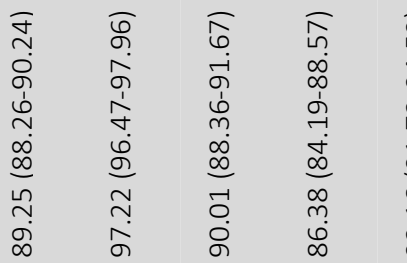

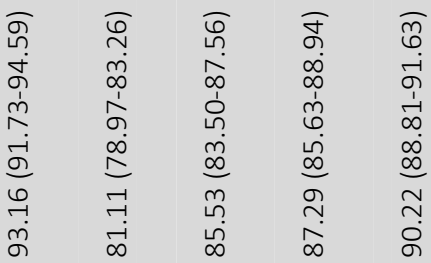

บับ

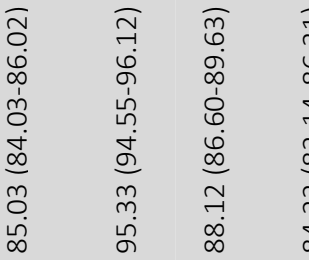

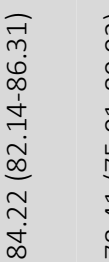

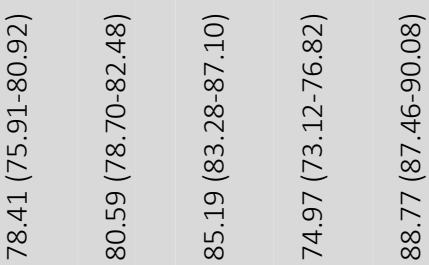

さ્ષ

ฯ

ก

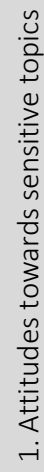

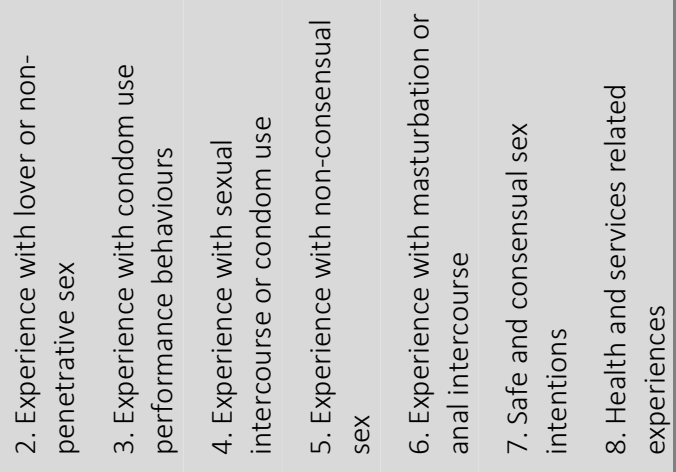


The positive effect of the WSWM programme on students' disclosure in Thailand can be attributed to a number of factors. Firstly, it appears that the relatively young WSWM participants in Thailand had not yet been intensively exposed to messages and education influencing their disclosure about sensitive sexuality related topics. Secondly, even though other studies suggest that females are generally more disclosing than males (Dindia \& Allen, 1992), in our study, no significant differences were found between boys' and girls' disclosure. The specific attention for boys' communication and empathy skills in WSWM in Thailand could have contributed to more openness.

The study also found that WSWM particularly contributed to disclosure about attitudes towards sensitive topics; experience with non-consensual sex; safe and consensual sex intentions; and health and services related experiences. Except for experience with non-consensual sex, the abovementioned topics can be labelled as less sensitive than the topics on which the programme showed no effects. The programme did not have an effect on disclosure about experience with sexual intercourse or condom use; experience with lovers or non-penetrative sexual acts such as petting; experience with condom use performance behaviours; and experience with masturbation or anal intercourse.

Finding no effect of WSWM on self-disclosure by Ugandan students can be attributed to the relatively high level of students' disclosure at baseline, referred to as the 'ceiling effect' (Bryman, Liao, \& Lewis-Beck, 2003). Even though disclosure of WSWM participants increased, they were already relatively open about sensitive topics before they participated in the programme, restraining the chance to measure significant changes. The relatively high disclosure level of Ugandan students at baseline can be explained by their age (16.1 years old). Another explanation for not finding an effect on students' disclosure in Uganda is the increased disclosure of both the WSWM participants and the comparison group. These findings indicate that all students in Uganda are exposed to information and skills building related to sensitive topics, prior to and next to the WSWM programme. This is also referred to as a high level of standard care (De Bruin et al., 2010), which could be explained by the provision of HIV/AIDS education in most primary schools in Uganda (Jacob, Morisky, Hite, \& Nsubuga, 2006) and by the open communication in Ugandan communities about HIV/AIDS and sexual behaviours in the 1990's in response to the high HIV-prevalence (Low-Beer \& Stoneburner, 2003). Rijsdijk et al. (2011) reported significant positive effects of WSWM in Uganda on students' intention to delay sexual intercourse, self-efficacy to deal with unwanted sex, and on condom use related attitudes, self-efficacy and intentions. This suggests that adolescents in Uganda are exposed to education contributing to openness about sensitive topics, and less to behaviour-specific education for adolescents including consensual sex and condom use.

Finally, cross-cultural differences in openness about sexuality related topics in Uganda and Thailand could explain higher disclosure levels in Uganda compared to Thailand. During the early years of the HIV/AIDS epidemic in the 1990's, both countries were examples of effective political intervention and successful reduction of new HIV infections (Low-Beer \& Stoneburner, 2003). In Uganda, people across the 
country and across groups were affected with HIV/AIDS, and so was communication about HIV/AIDS and preventive behaviours. In Thailand, HIV/AIDS was particularly prevalent in specific target groups (i.e., sex workers and their male clients) and most communication was aimed at these particular groups.

\section{Strengths and Limitations}

This study has strengths and limitations. A strength of the study is its large numbers of respondents. However, results have to be interpreted with care because schools were not randomly attributed to intervention of comparison groups. In addition, large numbers of data were missing with regard to questions about respondents' experiences with sexual intercourse and condom use, which probably were among the most sensitive questions in the questionnaire. This resulted in removal of these questions from the analysis. Finally, even though the study resulted in interesting findings with regard to self-disclosure, a disadvantage of inclusion of the answer option 'I don't want to talk about it' to sensitive questions was the large number of missing data in the studies measuring correlates of intention (Rijsdijk et al., 2012; Leerlooijer, Ruiter, Damayanti, et al., submitted).

\section{Conclusion}

The study contributed to the limited evidence regarding taboos and disclosure about sexuality communication in non-Western countries (Derlega, Winstead, Mathews, \& Braitman, 2008). The findings showed that the comprehensive sexuality education programme WSWM increased sexuality related disclosure in Thailand, particularly disclosure about attitudes towards sensitive topics; experience with non-consensual sex; safe and consensual sex intentions; and health and services related experiences. Future research can further explore cross-cultural differences in self-disclosure and how disclosure about sensitive topics is associated with selfdisclosure in interaction with relevant others. Interventions such as WSWM can contribute to adolescents' disclosure and can be complemented with interventions aiming to address structural factors in society such as sexuality related taboos and social norms. 


\title{
Chapter 6
}

The World Starts With Me: Using Intervention Mapping for the systematic adaptation and transfer of schoolbased sexuality education from Uganda to Indonesia

\author{
Leerlooijer, J. N., Ruiter, R. A. C., Reinders, J., Darwisyah, W., \\ Kok, G., \& Bartholomew, L. K.
}

Translational Behavioral Medicine: Practice, Policy and Research (2011), 2, 331-340 


\begin{abstract}
Evidence-based health promotion programmes, including HIV/AIDS prevention and sexuality education programmes, are often transferred to other cultures, priority groups and implementation settings. Challenges in this process include the identification of retaining core elements that relate to the programme's effectiveness while making changes that enhances acceptance in the new context and for the new priority group. This chapter describes the use of a systematic approach to programme adaptation using a case study as an example. Intervention Mapping, a protocol for the development of evidence-based behaviour change interventions, was used to adapt the comprehensive school-based sexuality education programme 'The World Starts With Me'. The programme was developed for a priority population in Uganda and adapted to a programme for Indonesian secondary school students. The approach helped to systematically address the complexity and challenges of programme adaptation and to find a balance between preservation of essential programme elements (i.e., logic models) that may be crucial to the programme's effectiveness, including key objectives and theoretical behaviour change methods, and the adaptation of the programme to be acceptable to the new priority group and the programme implementers.
\end{abstract}




\section{Introduction}

The transfer of health promotion programmes to other cultures, implementation settings, and for other priority groups is common practice in HIV/ AIDS prevention and sexuality education. Transfer is usually more cost-effective than developing a new intervention, and those interested in using the programme can save time and other resources by avoiding mistakes through lessons learned in the original programme. Although a systematic approach is found in the adaptation of existing sexuality education interventions (Tortolero et al., 2005; Paine-Andrews et al., 1999), too often, interventions are transferred without considering the extent to which the programme fits with the new priority group, context, and implementation setting. Four ways of adaptation are identified by Backer (Backer, 2001): adding or deleting programme components, changing programme components or content, changing the process or intensity of implementation, and making cultural modifications.

Planners can adapt interventions systematically or non-systematically. The disadvantage of a non-systematic approach to intervention adaptation is that adaptations are not documented, depend largely on individual decisions rather than formative research, and planners do not gain insight into why particular programme elements are removed, added, or maintained in the programme. A risk of nonsystematic adaptation is that the programme may not address the needs of the new priority group or fit with the new implementation setting. In addition, essential programme elements may be removed from the original programme, decreasing the programme's effectiveness (Paine-Andrews et al., 1999; Castro et al., 2004). To avoid these pitfalls of programme adaptation, planners should use a systematic approach when adapting existing programmes to a new context. This helps them to produce a programme that fits with the health needs and behaviour change focus of the priority group, is implementable in the new context, fits with governmental and organisational policies, matches the capacities of programme deliverers, and is culturally acceptable. Systematic adaptation is very important for preserving programme elements that are deemed necessary to change behaviours in the original programme and increases the chance of diffusion and sustainable implementation in the new setting (Cuijpers, De Graaf \& Bohlmeijer, 2005; Wandersman et al., 2008; Wingood \& DiClemente, 2008; Abraham \& Michie, 2008; Albarracín et al., 2005).

This chapter describes the importance of systematic intervention adaptation and how it can contribute to preserving crucial programme elements and promote the adoption, implementation, and sustainability of existing health promotion interventions in new situational contexts. This is illustrated with the case of the systematic adaptation of the comprehensive school-based sexuality education programme 'The World Starts With Me' (WSWM), which was developed for a priority population in Uganda and adapted to a programme for young people in secondary schools in Indonesia, titled DAKU. Intervention Mapping (Bartholomew, Parcel, et al., 2011), a protocol for the systematic development of evidence-based 
behaviour change programmes, is used to describe the different adaptation steps and the main outcomes of these steps.

\section{The World Starts With Me Programme}

The WSWM programme is a comprehensive sexuality education programme addressing the sexual and reproductive health needs and rights of secondary school students in Uganda. The programme was originally developed in 2002 by SchoolNet Uganda in collaboration with two Dutch organisations, Rutgers WPF and Butterfly Works. The programme is one of the 18 curricula underlying UNESCO's technical guidance on sexuality education (UNESCO, 2010) and was developed using the experiences of the planned development and implementation of the Dutch programme 'Long Live Love' (Schaalma, Kok, Poelman, \& Reinders, 1994), characteristics of effective sexuality education (Kirby, Laris, \& Rolleri, 2005; Kirby, 2007) and materials of existing sexuality education programmes of Rutgers WPF Vietnam, United Nations Children's Fund (UNICEF) Namibia, and Straight Talk Uganda.

WSWM is a computer-based programme complemented with teacher-led activities. A meta-analysis (Noar, Black, \& Pierce, 2009) shows that computer technology-based programmes have similar efficacy to more traditional humandelivered interventions with regard to increased condom use and reducing sexual activity, numbers of sex partners, and incident sexually transmitted infections (STIs). Given their low cost to deliver, ability to customise intervention content, flexible dissemination channels, and attractiveness to young people, computer technologybased interventions represent a promising strategy to deliver HIV/AIDS risk reduction programmes. In addition, computer assignments make interventions such as WSWM a student-driven programme, unburdening teachers from initiating discussions about sensitive issues such as sexuality.

The WSWM programme is based on the following principles: openness and acceptance of young people's sexuality, not on taboos; a positive, non-judgmental approach towards sexuality, not on fear or control; equity in gender and sexual orientation; the right of young people to complete and accurate information, to selfdetermination, and to protection; and active participation of young people in all stages of programme planning and implementation. The developers seek to empower young people to make their own responsible choices and perceive young people as the actors and social agents of change instead of mere recipients of messages or programmes.

The comprehensive programme consists of an introductory computer skills lesson and 14 lessons on adolescent development, decision making, and sexual and reproductive health and rights (SRHR). Each lesson includes practical applications to increase knowledge, develop attitudes, help youth recognise and cope with social influence and to learn skills, all of which have been shown to be characteristics of effective sexuality education programmes (Kirby, Laris, \& Rolleri, 2005). The programme starts with lessons on adolescent development and decision making 
including personality, norms and values, and emotional and physical development. After that, the programme continues with lessons related to social influences on personal decision making and behaviour, relationships with parents, friends, and peers, gender, and rights. Next, the programme addresses sexuality and love as positive and enjoyable parts of life and becoming sexually active as an important decision for which young people and their partners have to be mentally and physically ready. Further lessons address the possible negative consequences of being sexually active and ways to prevent and cope with pregnancy, HIV/AIDS, STIS, stigma and sexual abuse. The final lessons help students to reflect on what they learned, how the learning could help them to plan a healthy future, and how to disseminate what they learned among their peers and among a broader audience in and outside the school.

WSWM was adapted in 2005 to the Indonesian context and priority group of secondary school students and resulted in a sexuality education programme for secondary school students in Indonesia. The Indonesian programme is titled DAKU, from the Bahasa statement: 'Dunia remajaku seru', meaning 'My youth time is exciting'. A planning group consisting of representatives of Indonesian students and teachers and two organisations in Indonesia promoting SRHR, Rutgers WPF Indonesia and Yayasan Pelita IImu, conducted the adaptation of the programme from the Ugandan to the Indonesian context. The planning group collaborated closely with an Advisory Board comprising the Ministry of Education (Physical Health Centre), Fatayat NU (a Muslim women's association), Universitas Indonesia (Centre for Health Research, Faculty of Public Health), the Indonesian Planned Parenthood Association, UNESCO, UNICEF, PLAN Indonesia, the provincial AIDS commission, and school principals. In the period 2005-2010, the adapted WSWM programme DAKU has been implemented in 94 secondary schools in four provinces in Indonesia.

The adaptation was conducted following an Intervention Mapping toolkit on planning sexuality education programmes, developed by Rutgers WPF, specifying steps that describe how to practically adapt and implement WSWM for a specific culture and context (Leerlooijer, Reinders, \& Schaalma, 2008; Leerlooijer, 2009).

\section{Intervention Mapping}

The health promotion literature provides several frameworks to guide adaptation of programmes to a new setting and priority population (Backer, 2001; Wandersman et al., 2008; Wingood \& DiClemente, 2008; McKleroy et al., 2006; Lee, Altschul, \& Mowbray, 2008). Most of these list the tasks involved, such as (1) assessment of the new priority population and implementation context, (2) decision whether to adopt a programme with or without adaptation, (3) preparation by adapting (when necessary) and pre-testing intervention materials, (4) development of an implementation plan and pilot testing of the adapted intervention, and (5) implementation and evaluation of the intervention (McKleroy et al., 2006).

With regard to programme adaptation, these frameworks explicitly or implicitly address finding a balance between (1) fidelity to the original programme and (2) 
modifying the programme to fit the new cultural, organisational, and policy context (Castro, Barrera, \& Martinez, 2004; Bell et al., 2007). Fidelity to the original programme means that core elements, protocols, procedures, and content are kept in the new programme and the programme is implemented in the new setting as it was in the original programme evaluation. Core elements are the aspects of the programme that embody the theory and internal logic of the intervention and most likely produce the intervention's main effects: behaviour change among the priority population and/or relevant environmental actors and successful adoption and implementation (Castro, Barrera, \& Martinez, 2004; Backer, 2001; Kelly et al., 2000). Fidelity to the original programme can conflict with the implementation context in the new setting. For example, teaching condom-use skills as protective behaviour for young people may be appropriate in the original setting but may not be acceptable according to educational policies in the new context. Leaving out condom-use skills may harm the programme's fidelity and effectiveness, but preserving it may lead to non-adoption and non-implementation of the programme by schools and teachers.

Intervention Mapping (IM) provides a systematic approach that adds detailed 'how-to's' to the tasks in the frameworks mentioned above (Bartholomew, Fernández, et al., 2011). IM is a planning framework for the development of theoryand evidence-based behaviour change programmes. However, in practice, most programmes are not developed from scratch but are an adaptation of existing programmes. In programme adaptation, IM provides a series of iterative processes for finding the balance between fidelity to the original programme and modification for the new context.

IM guides planners through (1) needs assessment, (2) adaptation of objectives, (3) adaptation of methods and practical applications, (4) revision of programme materials, (5) planning or revising an implementation protocol, and (6) planning evaluation. IM is characterised by four perspectives that are applied during the planning process in all steps (Bartholomew, Parcel, et al., 2011). These perspectives are equally relevant for programme development and programme adaptation. At first, relevant stakeholders including the priority population and programme implementers should be involved in all aspects of decision making of adaptation. A linkage system, linking relevant stakeholders, organises the collaboration between the future programme users from the start of the adaptation process and involves relevant decision makers who can influence diffusion and sustainable implementation (Orlandi, Landers, Weston, \& Haley, 1990). Secondly, programme planners use multiple theories and supporting evidence to explain the problem of interest and to give guidance for change. Thirdly, an intervention is seen as an event occurring in a system. Other factors within the system can influence the targeted behaviour or environmental change. The fourth perspective is that IM approaches problems and their solutions from an ecological perspective of behaviour (change) of various actors (Green, Richard, \& Potvin, 1996): not only individuals who are at risk but taking into account social influence on interpersonal (e.g., peers, parents), community (e.g., school, health services), societal (e.g., cultural norms), and global levels (e.g., regional and international contexts). Environmental conditions influence 
individuals and other environmental conditions, while individuals may also influence higher-level environments.

\section{Intervention Mapping steps in adaptation}

We describe each IM step specifically for adaptation. This is illustrated with the case of the adaptation of WSWM from Uganda to Indonesia. Table 6.1 provides an overview of the IM tasks for each step of adaptation and presents the key aspects of change following the adaptation of WSWM to the Indonesian context.

\section{Step 1. Needs assessment/situation analysis}

To be able to decide whether or not to transfer an existing programme to a new setting, the adaptation process starts with a needs assessment and situation analysis (NA/SA) in the new context (Cuijpers, De Graaf, \& Bohlmeijer, 2005; Bartholomew, Fernández, et al., 2011). The planners assess the needs of people at risk for health problems and conduct an analysis of the possibilities to address these problems with the evidence-based programme under consideration for adoption. Planners compare the findings in the new setting with the assessment in the original setting. See Table 6.1 for an overview of tasks.

The assessment leads to a logic model of the problem, which consists of an analysis of the causes of health problems (e.g., the sexual and reproductive health status of young people). The logic model provides an overview of risk behaviours and their determinants within the at-risk group(s). It also depicts the environmental factors and their determinants that impact directly or indirectly on the risk behaviours (PRECEDE; Green \& Kreuter, 2005). Planners compare the priority populations of both the original and new settings, by looking at demographics, context, and the burden of, and factors related to, the health problem. Finally, planners assess the implementation setting including policies (e.g., educational policies), the existing resources and structures for implementation (e.g., school system), and other existing health promotion programmes (e.g., sexuality education programmes). Planners need this information to be able to decide whether the programme under consideration for adaptation matches sufficiently with the needs in the new context. In case of any gaps or discrepancies, the NA/SA provides evidence for systematic adaptation of the objectives (either addition or deletion) from the original programme.

For example, in Indonesia, the young people in the planning group used the NA/SA findings to convince the adult teachers, Ministry of Education and other decision makers that young people in Indonesia have unprotected sexual intercourse and that many of them do not receive comprehensive sexuality education, thus making the new sexuality education programme a necessary intervention. The NA/SA also showed that the participatory and outcome-based approach of WSWM matches well with the Indonesian educational policy of competency-based learning, initiated in 2004. 


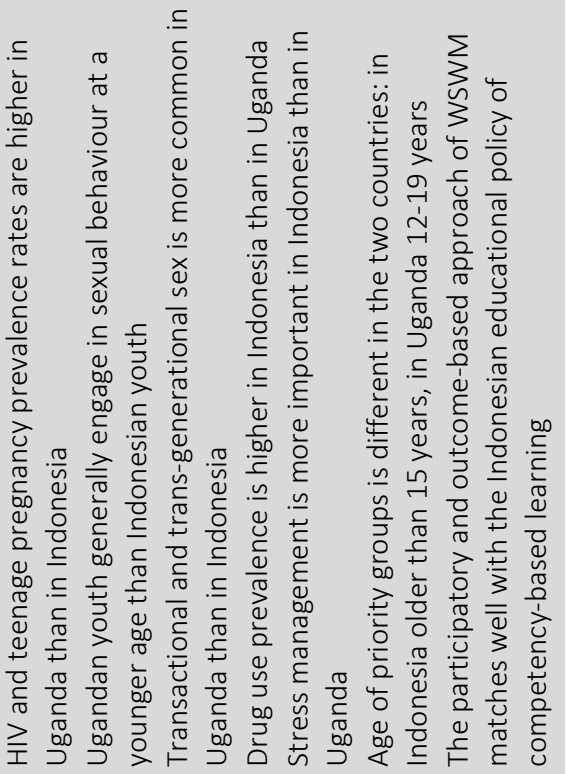

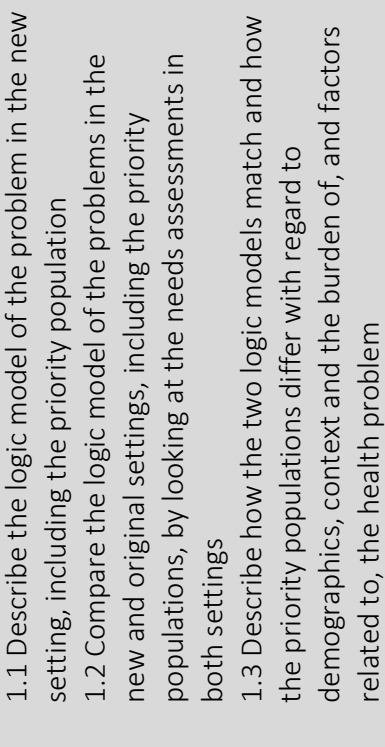

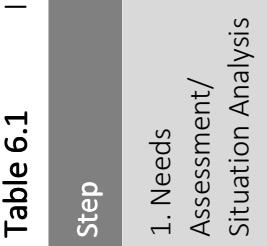

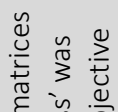

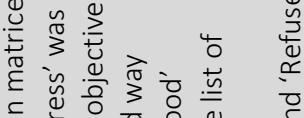

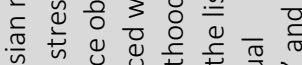

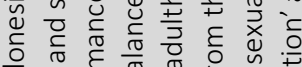

药

()

厂

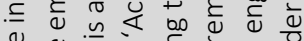

है 这

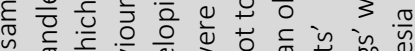
ब

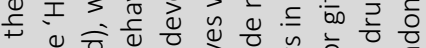

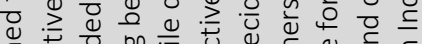

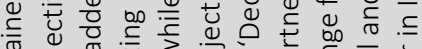
है 중 ब

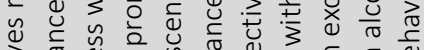
य

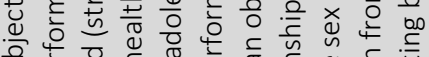

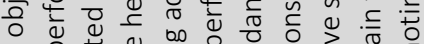

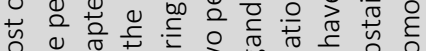

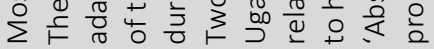

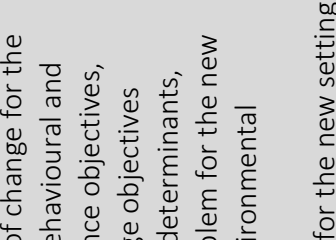
ᄂ

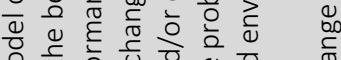

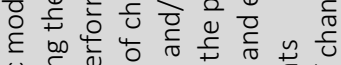

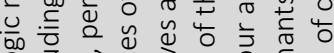

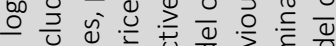
๘

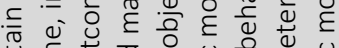

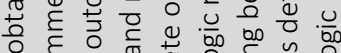

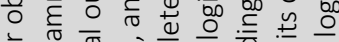

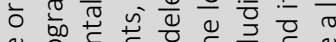

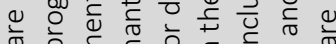

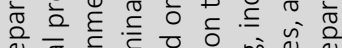

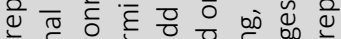
品

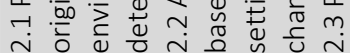

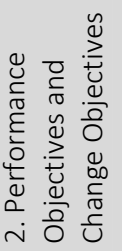




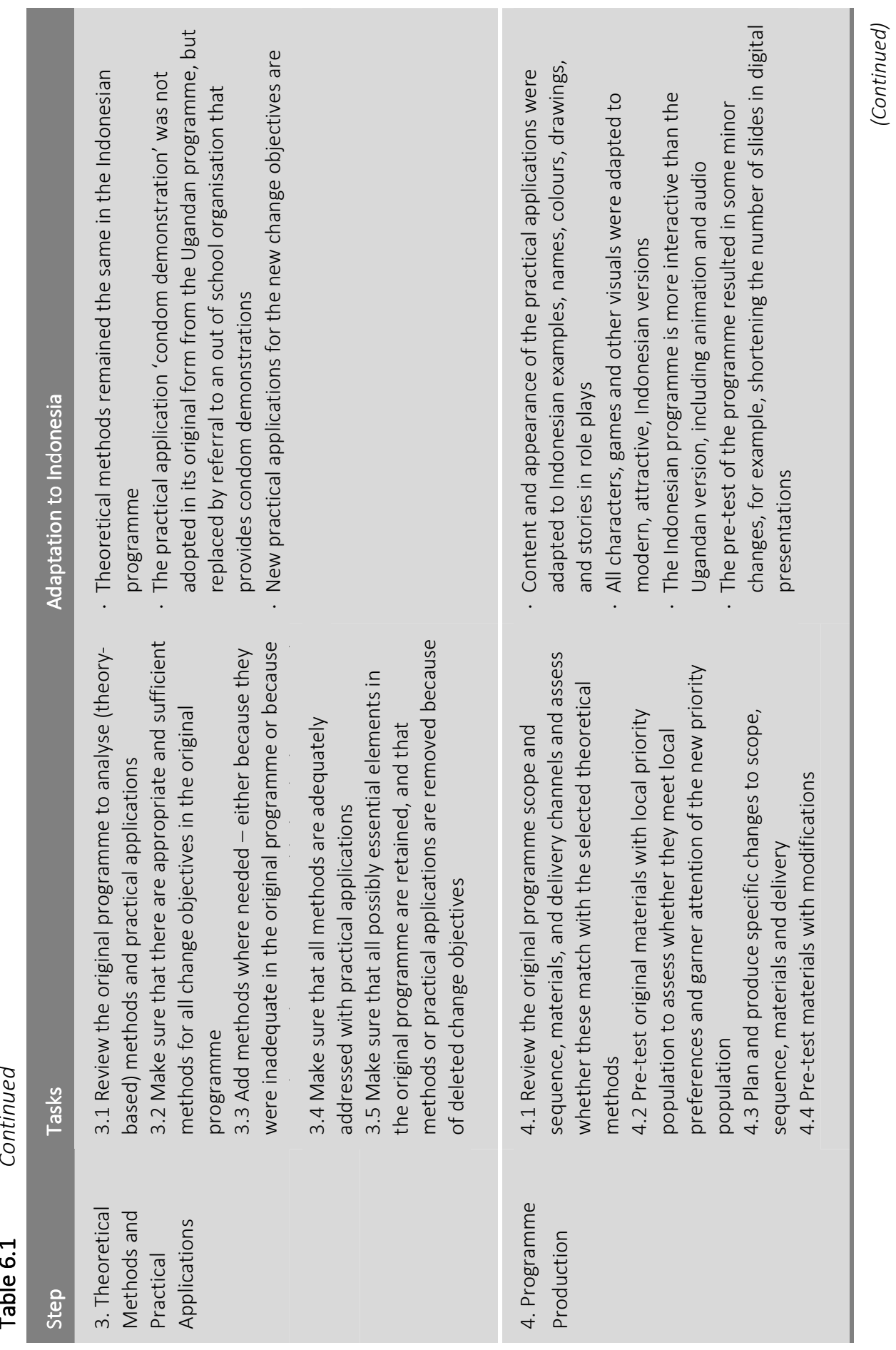




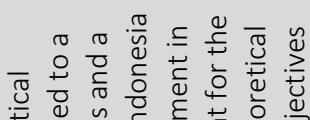

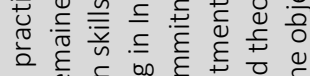

물 을 을

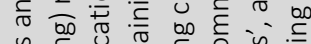

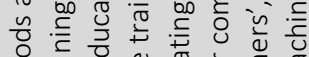

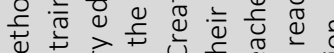

हैं

त

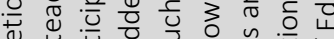

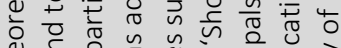

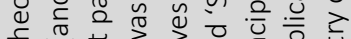

둔 3

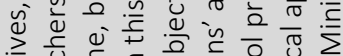

ऐ ट

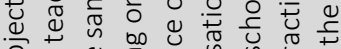

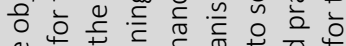

पु

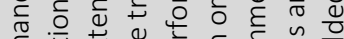

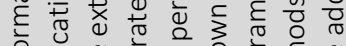

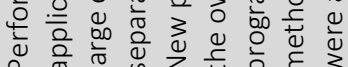

$\frac{\pi}{8}$

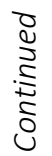

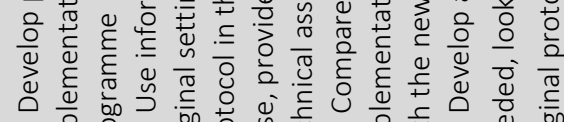

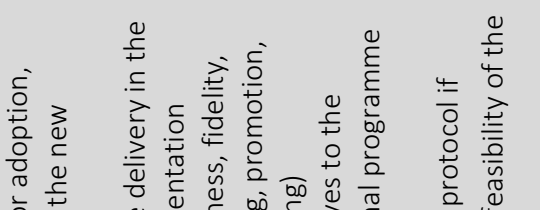

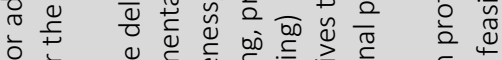

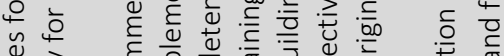

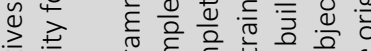

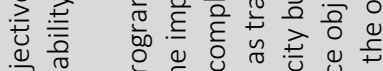

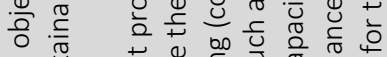

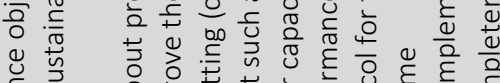

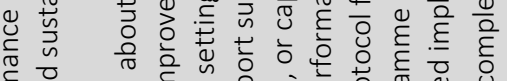

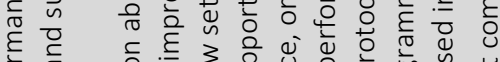

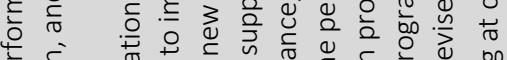

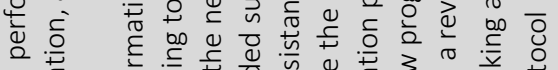

$\frac{\sqrt{2}}{\sqrt{10}}$

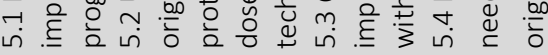

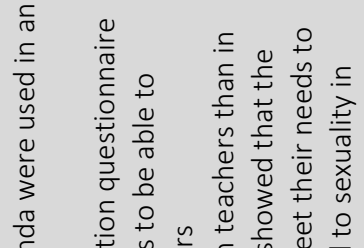

त

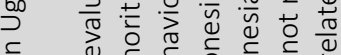

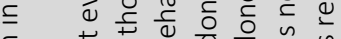

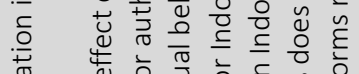

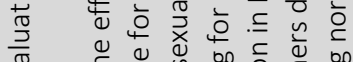

范

む)

苟苟

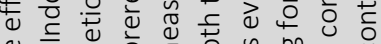

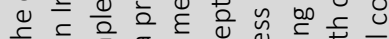
म

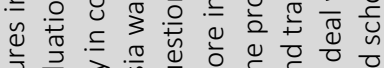

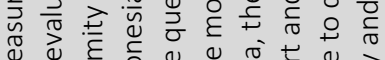

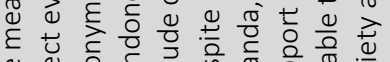

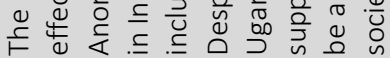

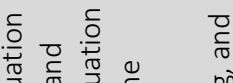

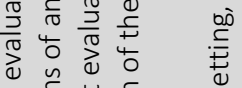
芯 ब

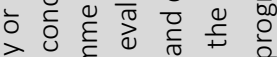

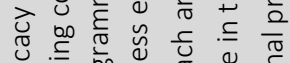

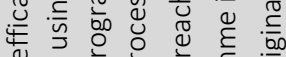
बे बे त ब एँ

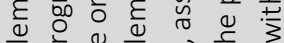

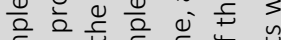

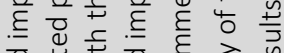
त

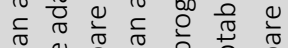
$\frac{\pi}{\alpha} \stackrel{0}{\frac{\pi}{2}} \frac{\pi}{\alpha} \frac{0}{2} \frac{0}{2}$

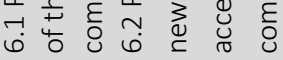
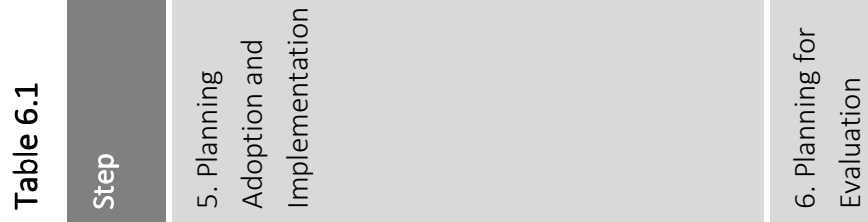
Both elements contributed to the support of the Ministry of Education for the new programme and the commitment and support of the teachers and decision makers for implementing the programme.

The comparison between the NA/SA findings in Indonesia and the logic model of the problem of the Ugandan WSWM programme resulted in the decision of the Indonesian planning group that there was a close enough match to continue with the adaptation. Even though there are important differences between young people in Uganda and Indonesia, most objectives of the sexuality education programme were relevant for both groups. For example, HIV and teenage pregnancy prevalence rates are much higher in Uganda than in Indonesia, and Ugandan youth generally engage in sexual behaviour at a younger age than Indonesian youth.

However, this information did not affect the content and logic model of the new programme, as young people in both settings need education to learn to make wellinformed decisions about their sexual development and behaviour. The comparison between the logic models of the problems in the two countries showed that it was necessary to implement the new programme among an older priority group in Indonesia (older than 15 years), whereas in Uganda, the priority group was aged 12 19 years. It was also decided to add objectives to the original programme with regard to some differences in the two contexts. Because of high drug use prevalence in Indonesia, the planning group decided to add drug use as important risk behaviour for HIV infection. Also, because of findings regarding stress in schools in Indonesia, stress management was added to the Indonesian DAKU! programme. Planners decided that transactional and trans-generational sex should be less emphasised, as these are important risk behaviours of Ugandan young people, but of lower prevalence in Indonesia.

\section{Step 2. Performance objectives and change objectives}

After the decision that the original programme fits well enough with the NA/SA findings in the adopting setting, the planning group assesses the fit between the logic model of change in the original programme and the proposed logic model of change for the new site (see Table 6.1 for an overview of tasks). The logic model of change includes a description of: (1) the targeted health-promoting behaviours of the at-risk population (for example, sexually active young people use condoms correctly and consistently) and of relevant 'actors' in the environment (for example, health care providers provide condoms to young people), (2) the performance objectives (or sub-behaviours) of each health-promoting behaviour-for example, correct and consistent condom use includes the following performance objectives: negotiating condom use with a sexual partner, obtaining condoms, taking condoms along, correct use of condoms, maintained condom use, and (3) the targeted change objectives (describing change in behavioural and environmental determinants) - for example, desired change in beliefs, attitudes, perceived social norms, self-efficacy, and skills that are needed to accomplish the performance objectives, such as negotiation of condom use or obtaining condoms for sexually active young people.

Health-promoting behaviours, performance objectives, and change objectives are then compared with the objectives of the original programme. The comparison 
between the two models of change is further shaped by discussions between programme planners, priority groups, implementers, and decision makers to assess to what extent the objectives are realistic and can be achieved in the new context. The result of step 2 is a systematic description of change objectives that should be added to or removed from the original programme, next to those objectives that should be maintained.

Some findings in the Indonesian NA/SA suggested that elements in the Ugandan programme conflicted with the social norms, religious beliefs, and the Indonesian law and were negotiated with the planning group and Advisory Board. For example, NA/SA evidence showed that many young people in Indonesia are sexually active and few use condoms during sexual intercourse. However, some members of the planning group strongly insisted on limiting the health-promoting behaviours to abstinence from sex and postponement of sexual intercourse until marriage. After careful considerations (for example, that the programme should address the needs of both sexually active and non-active young people) and discussions during official and informal meetings, the planning group made a final decision to acknowledge the reality of premarital sexual activities among Indonesian youth and to add the message to one of the lessons that sexual intercourse preferably takes place within a marriage relationship (see Table 6.1).

Step 2 resulted in objectives that match with the needs of Indonesian young people and received support and commitment from all relevant stakeholders including decision makers such as the Ministry of Education.

\section{Step 3. Theoretical behaviour change methods and practical applications}

In step 3, planners analyse the intervention for its theoretical methods (general techniques or processes for influencing changes in behavioural determinants) and practical applications (materials and activities) and make sure that essential behaviour change methods in the original programme are retained in the adapted programme in order to produce the desired effects in the change objectives (see Table 6.1). Systematic review of methods and applications in the original programme is required to define which theoretical methods of a given intervention are essential to success and which might be changed in order for the intervention to be of value elsewhere or with other populations (Albarracín et al., 2005; Schaalma \& Kok, 2009). For example, if a programme uses role modelling (a theoretical method from Bandura's Social Cognitive Theory; Bandura, 1986), the practical application of whether the role models are persons with whom the priority population can identify would be an important aspect of an effective translation of the behaviour change method to the new context. Equally important are the parameters of the practical application to be effective. For example, one of the parameters of successful identification of the priority population with role models is the credibility of the source, method, and channel, which may differ for each different social or cultural context. Planners should also assess whether circumstances in the new implementation setting allow the original practical applications or not. For the WSWM programme, some of the applications are teacher-led, but the majority is 
computer-based, making computer availability and accessibility in Indonesian schools a prerequisite.

The Indonesian planning group analysed the original theoretical methods and practical applications to identify whether they would fit with the Indonesian youth and in the Indonesian school setting. The participatory methods of WSWM (including modelling and skills training) fit well in the in 2004 initiated competencybased educational policy of the Indonesian Ministry of Education. However, not all practical applications could be retained. For example, the practical application 'condom demonstration' was not adopted in its original form from the Ugandan programme because the Advisory Board expected too much resistance from teachers and schools and wanted to avoid running the risk that DAKU would not be adopted at all. To be able to support students who need these skills, the DAKU planning group replaced the condom demonstration in the student section with referral to an out-of-school organisation that provides education and contraceptives, including condoms, to young people. The planning group selected new practical applications for the new change objectives. For instance, there was a new digital presentation on stress management, including learning to recognise different perspectives in case of problems. The lesson on drug use also included a presentation to provide information, as well as role play assignments to learn to refuse drugs that are offered by others.

\section{Step 4. Programme production}

The focus in step 4 is on the adaptation of the programme's presentation, to make one coherent programme, and pre-test the materials and activities with the priority population and programme deliverers (see Table 6.1). The acceptability, attractiveness, and persuasiveness for the new priority group and implementers are considered. Most of the adaptation changes recommended in this step address the match between the programme presentation and the characteristics of the new population and implementers. Elements of modification of the programme include the translation from one language to another-the most obvious form of programme adaptation. But modification moves beyond surface structure, such as changing the ethnicity or the appearance of role models, to deep structure, by addressing the core values, beliefs, norms, and other more significant aspects of the cultural group's world views and lifestyles (Resnikow et al., 2000). These aspects are thoroughly explored in steps 1 through 3 above and are well illustrated in the modification of objectives and practical applications in the adaptation process in Indonesia.

Adaptations in the programme's presentation, content and delivery require cultural sensitivity among programme planners, among those adapting the programme and among programme delivery staff (Skaff, Chesla, Mycue, \& Fisher, 2002). Planners have to consider age, gender, literacy, ethnicity, and urban/rural residence. To garner attention of the participants, the programme has to be attractive, seem credible and trustworthy, foster identification, and make use of preferred delivery channels. If planners decide to change the programme's presentation, this should be based on formative research that pre-tests the original 
programme and ascertains new host site preferences for modification (Lau, 2006). Once adaptations are made, they must also be pretested. After that, planners can pilot test the new intervention as a whole.

In the adaptation to Indonesia, the biggest changes are seen in this step. The content and appearance of the applications were adapted to Indonesian examples, names, colours, drawings and stories in role plays. For the new practical applications, new content was developed based on the relevant change objectives, methods and practical applications identified in steps 2 and 3. All characters, games and other visuals were adapted to modern, attractive, Indonesian versions. A challenge faced in translating from English was that the Bahasa language does not have some of the words for sensitive and taboo sexuality related topics. For sexual activities, such as petting and fondling, local words were found that were familiar to the young people. When the planning group could not find the local word to describe sexual organs, they used the English terminology.

The most essential change in the DAKU programme was the inclusion of the message that sexual activity preferably takes place within marriage, whereas other sections and messages related to sensitive topics, including masturbation, oral and anal sex, and sexual orientation, remained unchanged. The planning group, including students and teachers, together with the Advisory Board decided about the final layout of the programme. As a result, the Indonesian programme is more interactive than the Ugandan version, including animation and audio for the digital peer educators. The pre-test of the programme resulted in some minor changes: making the definition of gender more practical and understandable for young people than in the original programme and shortening the number of slides in some of the digital presentations.

\section{Step 5. Planning adoption and implementation}

Promoting full adoption and implementation of health promotion programmes is difficult and full programme use is unusual. For example, a study evaluating the adoption and implementation of a Dutch HIV/AIDS prevention programme found that around $70 \%$ of possible programme implementers became aware of a relevant programme, $50 \%$ adopted the programme with the intention to use it, while only $30 \%$ actually implemented the programme, and $10 \%$ eventually continued to use the programme to the point of institutionalising it (Paulussen, Kok, Schaalma, \& Parcel, 1995). Planning the adoption and implementation of any, including adapted, intervention is an important and often neglected step of programme planning. Systematic planning of adoption and implementation can be done by completing a number of tasks (see Table 6.1). Planners start with conducting an assessment of who will adopt and implement the programme, what exactly they will need to do, and what will determine the adoption and implementation behaviour. Once objectives are defined, theoretical methods and practical applications can be selected, and interventions can be designed to promote programme use (for example, a teacher training, that meets the needs of teachers). The behavioural determinants of people or organisations who are the intended adopters and implementers of the new programme should be analysed. Planners assess whether 
the willingness to adopt the new programme is equal to the willingness in the original context, whether similar methods and applications for promoting the adoption and implementation of the adapted intervention are applicable in the new setting, and whether the original training and support for implementers are sufficient for the new setting. They describe how programme implementation should be changed to obtain fidelity across adoption, implementation, and maintenance. As in step 4, modifications to the original implementation protocol should be pretested and pilot tested in the new site.

Organisational capacity and readiness for implementation are important conditions for this step (Tortolero et al., 2005; Wandersman et al., 2008; Mihalic, Fagan, \& Argamaso, 2008). Because most implementers are professionals working in organisations, planning for implementation is in itself an intervention at the organisational level. Programmes adapted with the agency's support have been found to have an increased chance to be institutionalised (Cuijpers, De Graaf, \& Bohlmeijer, 2005; Arthur \& Blitz, 2000; Glaser \& Backer, 1977; Rogers, 1995).

The adoption and implementation objectives for school administrators and teachers in Uganda were adopted in the Indonesian context. The theoretical methods and practical applications also remained to a large extent the same. For example, the objectives of and practical applications in teacher training and support are very similar in both countries. The original, Ugandan, teacher training included sessions on SRHR of young people, communication about sexuality, exercising the new programme, and exercising facilitation skills. As a result of discussions and interviews with teachers, who indicated the need for participatory education skills, an additional, separate training on facilitation skills was added to the Indonesian teacher training. New performance objectives were added for the Ministry of Education, as the Indonesian planning group involved them more intensively than had happened in Uganda. New applications and theoretical methods were selected to influence Ministry of Education representatives.

\section{Step 6. Planning for evaluation}

After adaptation, planners need to develop a plan for process and effect evaluation of the adapted programme, to be able to determine whether the intervention remains effective in the new setting with the programme changes that have been made (see Table 6.1 for an overview of tasks). The objectives of the adapted programme are the indicators of the evaluation and may therefore differ from the indicators of the original programme.

Planners evaluate both the objectives of the priority population (step 2) and the adoption and implementation objectives identified in step 5. An effect evaluation was conducted in Indonesia with a similar quasi-experimental design and questionnaire as was used in Uganda. The questionnaire includes questions related to reported sexual behaviour of the respondents. Initially, there was resistance against including these questions in the questionnaire. By making sure the respondents could complete the questionnaire anonymously, it was possible to include them. The questionnaire was designed based on the performance and change objectives of step 2 and includes measures on beliefs, attitudes, perceived 
social norms, perceived behavioural control, and intention of abstinence/delayed onset of sexual intercourse, correct and consistent condom use, and consensual sex, which showed some positive effects in the Ugandan effect evaluation (Rijsdijk et al., 2011).

The process evaluation in Indonesia measured programme reach, programme acceptance by the priority population and implementers in the new setting, and measured completeness and fidelity of programme delivery. Specific attention was paid to the evaluation of acceptance of the new programme elements (such as the lesson about drug use) in the new setting, both among teachers and students. Despite more in-depth training for Indonesian teachers than in Uganda, the process evaluation in Indonesia showed that the support and training for teachers do not meet their needs to be able to deal with conflicting norms in society and the school environment related to sexuality (Damayanti et al., 2010).

\section{Conclusion}

This chapter shows that the systematic adaptation of 'The World Starts With Me' programme from Uganda to Indonesia resulted in changes that created a fit between the programme and the needs of the priority group and its implementers in Indonesia. Objectives, practical applications, and programme materials were adapted, although the programme remained to a large extent the same as the original Ugandan programme. In a non-systematic approach to adaptation, the differences between the two settings may not have been observed, resulting in a programme not fitting well with the new setting and needs. On the other hand, differences may have dominated the process and jeopardised the core elements of the original programme by changing the logic model of change, theoretical methods, or practical applications.

In the WSWM adaptation, IM provided a useful, in-depth framework. The IM approach specifies not only 'what' should be done but also 'how' to perform the tasks in adaptation. The step-by-step approach made explicit and visible the extent to which fidelity to the original programme could be retained and which core elements should remain and to what extent the programme needed to be modified to match with the new context. The use of IM also encouraged the involvement in each of the adaptation steps of young people, teachers, and decision makers in the Advisory Board. This involvement turned out to be an intervention in itself that created commitment among relevant decision makers. This commitment contributed ultimately to the adoption and implementation of the DAKU programme.

For health promotion practitioners, using effective programmes beyond the settings for which they were originally developed can be challenging. Those wishing to adopt previously developed and tested programmes must identify acceptable programmes (such as the Uganda programme), assess fit of the original programme within the new context, and decide whether adaptation is necessary and appropriate. If adaptation is undertaken, practitioners must determine what should 
be adapted and what essential programme elements should be maintained. The essence of adaptation is comparing what would be optimal in the new situation with what is available in the original programme.

In the case study in this report, we followed the IM steps to compare the programme to be adapted with the needs of the new situation in a series of systematic processes. These processes began not with the programme itself, but at the first step of programme development-i.e., problem analysis. Starting from a comparison of health problems, behaviours, environment, and their determinants in step 1, we continued by identifying desired changes and methods to produce that change. Both a strength and a drawback of the IM process for adaptation is the continuous comparison of what is available and what is needed. The constant comparison of the logic models of the problem and change in the new situation with the logic models abstracted from the original programme can be difficult. One of the biggest challenges in this process is the necessary post hoc deconstruction of the intentions of the original programme's developers. In the case study in this report, this process was facilitated because several of the programme adapters were very familiar with the Uganda programme and could develop 'implied' logic models even when formal models were not available. In a situation where a practitioner is not familiar with the original programme and does not have direct communication with its developers, the underlying comparison tasks of adaptation are even more difficult.

Bartholomew, Fernández, and colleagues (2011) describe another central difficulty in adaptation, which is the designation of parts of the original programme that should not be changed. Lee and colleagues (2008) caution planners that when a programme is adapted in ways that modify its logic model of change, the programme is no longer evidence-based and may not be effective in the new population. This can be a major dilemma in programme adaptation, but adapters are not often helped by programme developers who generally do not have evidence at the level of programme components. So, we often do not know what constitutes essential elements and have difficulty protecting them when making changes in the original programme (Botvin, 2004; Norton et al., 2009). Bartholomew, Fernández, and colleagues (2011) have suggested that the programme's core elements are, for most programmes, a combination of the following: (1) theoretical methods that are intended to change determinants of behaviour of the at-risk group and the environmental agents, (2) practical applications of the methods, including delivery channels, (3) characteristics of programme materials and messages, including cultural elements, and (4) characteristics of programme implementation. In the adaptation described in this case, we paid particular attention to retaining most dimensions of these elements.

Despite the challenges, IM enabled the planning group for the Indonesian project to work through a series of tasks that resulted in an adapted programme that was well accepted by decision makers and is being implemented with good reach into the priority population and good fidelity to the intended theoretical methods and practical applications. 


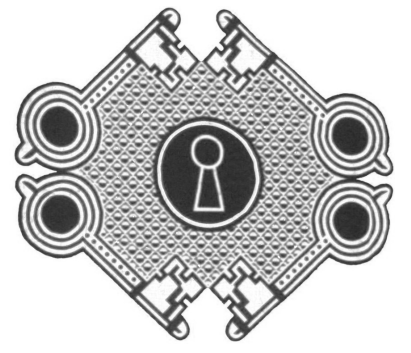

Chapter 7

General Discussion 
Chapter 7 
Adolescents in sub-Saharan Africa and the Asian Pacific region are vulnerable regarding their sexual and reproductive health and rights. In their transition to adulthood, adolescents have to adjust to physical, psychological, and social changes and many of them become sexually active and start to explore their sexuality and intimate relationships. Sexual activity also implies being at risk to contract diseases or to get pregnant at an early age. SRHR promotion interventions have been designed, implemented, and evaluated in the past decades to address the rights and needs of adolescents (Bearinger, Sieving, Ferguson, \& Sharma, 2007). This dissertation reported about the planning and evaluation of two interventions aimed at the promotion of adolescents' SRHR in Uganda, Indonesia, and Thailand.

\section{Community-based empowerment}

Chapter 3 described the effects of the Teenage Mothers Project, a community based empowerment intervention, on the psychological and social well-being of unmarried teenage mothers and their residential communities in rural Uganda. Findings of 23 in-depth interviews with teenage mothers, community leaders, and project implementers suggested that the Teenage Mothers Project had contributed to change in teenage mothers, to change in their social environment, and that in some respects, individual and environmental change strengthened each other. The study also revealed gaps with regard to parental support and the stage in which teenage mothers joined the project.

First, the evaluation study suggested that the Teenage Mother Project contributed to changes amongst the unmarried teenage mothers, but can also be improved to better meet the needs of the project's participants. The most significant, unanimously reported change was the project's contribution to continued education of unmarried teenage mothers. Education is highly valued in communities in Eastern Uganda as a means to income generation (Sekiwunga \& Whyte, 2010) and the study showed that education indeed had contributed to increased income and economic autonomy. This finding corresponds with other research showing that women's and girls' school attendance improves access to income and increases young women's economic aspirations and success (Hargreaves et al., 2008). Other studies reported about interventions that were effective in increasing girls' school attendance by providing them school uniforms or school fees (Hallfors et al., 2011; Duflo, Dupas, Kremer, \& Sinei, 2006). In contrast with these rather short-term contributions, it appeared that the Teenage Mothers Project contributed to more sustainable and structural changes amongst the teenage mothers and their social environment by changing attitudes towards valuing teenage mothers' education, through training and counselling, by providing a relatively small micro-credit (a female goat), and by encouraging teenage mothers to generate income. However, the study also indicated that not all teenage mothers continued their education, which could particularly be attributed to lack of parents' possibility or priority to provide school fees for their daughters. Research in Malawi showed that as a consequence of poverty parents seemed to favour the education 
of sons over daughters (Grant, 2012). These findings suggest that intervention planners and implementers sometimes have to balance between short term effectiveness (i.e., direct provision of school fees or school uniforms) or longer term structural changes (i.e., changing parents' attitudes en providing small micro-credits) (Gibbs, Willan, Misselhorn, \& Mangoma, 2012).

In addition to the positive effects of continued education, the Teenage Mothers Project also contributed to increased income generation through income generating activities by teenage mothers' groups. It appeared that increased economic autonomy contributed to improved care of the child, prevention of early marriage and of transactional sex, marriage with 'better' husbands, and financial contribution to their own school fees. This was also found in other studies (Hargreaves et al., 2008). In addition to continued education and income generation, it appears that particularly counselling had contributed to more effective coping of the teenage mothers with early motherhood, a changed future perspective, and with stigma and lack of support by the father of the child, parents, community members and peers. An inhibiting finding was that the point of time at which the teenage mothers joined the project (on average 10 months after delivery of the child) was too late. Trauma that had already been caused could have been prevented when the project would have intervened shortly after discovery of the pregnancy. Holub et al. (2007) recommends providing psychological and social support to unmarried mothers immediately after discovery of the pregnancy to prevent traumatic experiences and internalisation of stigmatising norms and to increase the likelihood of better adjustment of unmarried teenage mothers and their children after birth.

Second, the study reported about change towards more supportive social norms amongst the majority of parents, community leaders, and community members with regard to future opportunities of unmarried teenage mothers and with regard to the Teenage Mothers Project. For example, it seemed that social norms concerning early marriage and continued education of teenage mothers had become more supportive for the teenage mothers. Although inhibiting norms were also recorded, this was not the dominant view. It appeared that community norms had changed over a number of years, which is confirmed by other research indicating that changing social norms regarding sensitive topics such as sexuality and out-ofwedlock motherhood can be challenging and can take considerable time (Auerbach, 2009). The study also showed that negative beliefs and norms with regard to premarital sex and pregnancy had remained largely unchanged among the project's stakeholders, reflecting the messages that were provided in the project's activities (Leerlooijer et al., 2011). From a rights-based approach, planners could aim to advocate for adolescents' right to take their own decisions regarding sex, also if they would choose to have sex outside marriage. However, the planning group had decided to focus on providing de-stigmatising stereotype-inconsistent information about unmarried teenage mothers that was not too discrepant from community members' views, aiming to prevent resistance (Corrigan \& Kosyluk, 2013; Kunda \& Oleson, 1995). One of the elements that appeared to have contributed to changed social norms was an intensive, laborious process of creating commitment and ownership through participation and persuasion of influential community leaders. 
This is also observed in other interventions that aimed to change social norms (Shediac-Rizkallah \& Bone, 1998).

Third, the findings suggested a reinforcing interplay between the teenage mothers' improved agency and the support provided by their parents and community leaders. This reinforcing interaction between individual and environment initiated by comprehensive interventions is also reported by others (Gibbs, Willan, Misselhorn, \& Mangoma 2012; Baytop, 2006). On the one hand, the unmarried teenage mothers seemed to have gained confidence, continued their education, and generated income, partly as a result of the support of their parents and community. On the other hand, social norms in the community seemed to have changed partly as a result of the visibility and successes of the teenage mothers through their collective action in the support groups, in media, and in community meetings. The finding that group action and visibility appears to be much more influential than action and visibility of each individual was also found in other studies (Drury \& Reicher, 2009; Araújo Pedrosa et al., 2011).

\section{School-based sexuality education}

Chapter 4 described a study exploring psychosocial correlates of Indonesian adolescents' motivation to abstain from sexual intercourse, using the Theory of Planned Behaviour (TPB; Ajzen, 1991). This study was part of an outcome evaluation measuring the effect of The World Starts With Me (WSWM) on students' intentions, behavioural correlates, and disclosure about sensitive sexuality related topics in Uganda, Indonesia, and Thailand. The findings of these evaluation studies have been reported elsewhere (Rijsdijk et al., 2011; Wong et al., 2010; Damayanti et al., 2010). The baseline study in Chapter 4 showed that TPB is a suitable model to analyse correlates of abstinence intentions among Indonesian adolescents. Some have argued that TPB and other psychosocial theories do not incorporate culture and are essentially individualistic in their conceptualisation, focusing on the individual and his or her behaviour (Airhihenbuwa \& Obregon, 2000; Dutta-Bergman, 2005). As such, these theories would not be sufficient to analyse behaviours in cultures in, for example, African or Asian settings. However, according to Fishbein (2000), theoretical models such as TPB are culturally specific whereby the relative importance of each of the variables (i.e., attitudes, perceived social norms, perceived behavioural control, barriers, skills) is expected to vary as a function of both the behaviour and the population under consideration. This was confirmed in a review of studies in conducted in sub-Saharan Africa showing that TPB could predict sexual risk behaviour in young people (Protogerou, Flisher, Aar $\varnothing$, \& Mathews, 2012).

The findings in our study correspond with other studies exploring correlates of abstinence intentions (Basen-Engquist \& Parcel, 1992; Basen-Engquist, Tortolero, \& Parcel, 1997; Collazo, 2005; Villarruel, Jemmott III, Jemmott, \& Ronis, 2004; Mathews et al., 2009; Cha et al., 2007). Similar to other studies, intentions were most strongly associated with perceived behavioural control (Buhi \& Goodson, 2007; Collazo, 2005), with past abstinence experience (Basen-Engquist, Tortolero, \& 
Parcel, 1997; Nahom et al., 2001), with peer norms (Cha et al., 2007; Fisher, Fisher, \& Rye, 1995), and with attitudes towards abstinence (Basen-Engquist \& Parcel, 1992; Basen-Engquist, Tortolero, \& Parcel, 1997; Villarruel, Jemmott III, Jemmott, \& Ronis, 2004). The study also showed that perceived susceptibility and perceived severity of pregnancy, HIV infection and sexually transmitted infection (STI) did not motivate adolescents to abstain from sexual intercourse. This can be explained by the relatively low prevalence of HIV, STIs and pregnancies among Indonesian adolescents and by a general finding that perceived susceptibility and perceived severity are not strong predictors of health behaviour (Carpenter, 2010). The study also showed that perceived behavioural control, past experience, peer norms, and attitude explained $31 \%$ of the variance in abstinence intention, suggesting that abstinence intentions are to a large extent explained by psychosocial correlates, but also by other factors.

Chapter 5 described a study in Uganda and Thailand, exploring the effect of the comprehensive sexuality education programme 'The World Starts With Me' (WSWM) on students' self-disclosure about sensitive, sexuality related topics. The study revealed that the intervention increased self-disclosure of students in Thailand, whereas no significant effects were found for Ugandan WSWM participants.

The positive effect of the WSWM programme on students' disclosure in Thailand can be attributed to a number of factors. Firstly, it appears that the relatively young WSWM participants in Thailand had not yet been intensively exposed to messages and education influencing their disclosure about sensitive sexuality related topics. Secondly, even though other studies suggest that females are generally more disclosing than males (Dindia \& Allen, 1992), in our study, no significant differences were found between boys' and girls' disclosure. The specific attention for boys' communication and empathy skills in WSWM in Thailand could have contributed to more openness.

The study also found that WSWM particularly contributed to disclosure about attitudes towards sensitive topics; experience with non-consensual sex; safe and consensual sex intentions; and health and services related experiences. Except for experience with non-consensual sex, the above mentioned topics can be labelled as less sensitive than the topics on which the programme showed no effects. The programme did not have an effect on disclosure about experience with sexual intercourse or condom use; experience with lovers or non-penetrative sexual acts such as petting; experience with condom use performance behaviours; and experience with masturbation or anal intercourse.

Finding no effect of WSWM on self-disclosure by Ugandan students can be attributed to the relatively high level of students' disclosure at baseline, referred to as the 'ceiling effect' (Bryman, Liao, \& Lewis-Beck, 2003). Even though disclosure of WSWM participants increased, they were already relatively open about sensitive topics before they participated in the programme, restraining the chance to measure significant changes. The relatively high disclosure level of Ugandan students at baseline can be explained by their age (16.1 years old). 
Another explanation for not finding an effect on students' disclosure in Uganda is the increased disclosure of both the WSWM participants and the comparison group. These findings indicate that all students in Uganda are exposed to information and skills building related to sensitive topics, prior to, and next to the WSWM programme. This is also referred to as a high level of standard care (De Bruin et al., 2010), which could be explained by the provision of HIV/AIDS education in most primary schools in Uganda (Jacob, Morisky, Hite, \& Nsubuga, 2006) and by the communication in Ugandan communities about HIV/AIDS and sexual behaviours in the 1990's in response to the high HIV-prevalence (Low-Beer \& Stoneburner, 2003). Rijsdijk et al. (2011) reported significant positive effects of WSWM in Uganda on students' intention to delay sexual intercourse, self-efficacy to deal with unwanted sex, and on condom use related attitudes, self-efficacy and intentions. This suggests that adolescents in Uganda are exposed to education contributing to openness about sensitive topics, and less to behaviour-specific education for adolescents including consensual sex and condom use.

Finally, cross-cultural differences in openness about sexuality related topics in Uganda and Thailand could explain higher disclosure levels in Uganda compared to Thailand. During the early years of the HIV/AIDS epidemic in the 1990's, both countries were examples of effective political intervention and successful reduction of new HIV infections (Low-Beer \& Stoneburner, 2003). In Uganda, people across the country and across groups were affected with HIV/AIDS, and so was communication about HIV/AIDS and preventive behaviours. In Thailand, HIV/AIDS was particularly prevalent in specific target groups (i.e., sex workers and their male clients) and most communication was aimed at these particular groups.

\section{Use of Intervention Mapping in planning and adaptation of SRHR promotion programmes}

This dissertation comprises two case studies describing how Intervention Mapping (IM) was used as a framework to plan a new intervention and to adapt an existing intervention to a new context and priority group. Chapter 2 showed that IM facilitated the planning group of the Teenage Mothers Project to structure the iterative, participatory design of the ecological empowerment intervention and to use evidence and theory. Project planning was not a step by step linear process, but rather iterative. This was particularly a result of the time-consuming process of getting relevant stakeholders involved and having them commit to the rather controversial messages and activities of the Teenage Mothers Project. The design and implementation of the intervention was an iterative, deliberate process of (1) initiation of ideas by community leaders and project participants to address identified problems, (2) translation of these ideas into theory-based applications, facilitated by a health promotion professional, (3) monitoring of small scale implementation of these applications, and (4) adaptation (if needed) and up scaling of these applications. Most decisions in the planning process were not based on empirical evidence, but on the perspective that unmarried teenage mothers have 
the right to live a fulfilling life, on qualitative research, on ideas and opinions of the beneficiaries, community leaders and project managers, on theoretical methods and its conditions for use, and on monitoring results of pilot implementation of new practical applications.

Chapter 6 showed that IM provided an in-depth framework for the adaptation of the Ugandan comprehensive sexuality education programme WSWM to Indonesia. This resulted in changes that created a fit between the programme and the needs of the priority group and its implementers in Indonesia. The step-by-step approach facilitated the identification of core elements that had to remain in the Indonesian programme, to retain fidelity to the original programme, and which programme elements needed to be modified to match with the new context and students in Indonesia. The objectives, practical applications, and programme materials were systematically adapted to the Indonesian context and priority population. The programme remained to a large extent similar to the original Ugandan programme. In a non-systematic approach to adaptation, the differences between the two settings may not have been observed, resulting in a programme not fitting well with the new setting and needs. One of the differences between the two programmes is the older priority group (older than 15 years) compared to Uganda (12-19 years old). It was also decided to add objectives with regard to some differences in the two countries. Because of high drug use prevalence in Indonesia, the planning group decided to add drug use as important risk behaviour for HIV infection. Also, because of findings regarding stress in schools in Indonesia, stress management was added to the Indonesian programme. Planners decided that transactional and transgenerational sex had to be less emphasised, as these were important risk behaviours of Ugandan young people, but of lower prevalence in Indonesia. The major changes in the new programme were observed in the fourth step (intervention design) and included adaptation of appearance of the applications to Indonesian examples, names, colours, drawings and stories in role plays. In addition, in one of the lessons the message was included that sexual activity preferably takes place within a marriage relationship, whereas other sections and messages related to sensitive topics, including masturbation, oral and anal sex, and sexual orientation, remained unchanged.

Both case studies indicated that the involvement of the planning group contributed significantly to stakeholders' ownership and commitment to the intervention. In the adaptation of WSWM to Indonesia, young people, teachers, and decision makers were actively involved in each of the adaptation steps. This involvement turned out to be an intervention in itself that created commitment among relevant decision makers and contributed to the adoption and implementation of the programme. A similar process was observed in the participatory planning of the Teenage Mothers Project by community leaders, teenage mothers, and implementers. This resulted in ownership of the intervention and in governmental, religious, and tribal leaders, who developed into implementers of the intervention in their residential communities. The importance of commitment by implementers and communities for successful implementation of interventions 
addressing controversial interventions is also emphasised by others (e.g., Schaalma, Abraham, Gillmore, \& Kok, 2004; Laverack and Labonte, 2000).

\section{Reflections on methodology}

To be able to value the implications of this dissertation for practice and future research, the quality of methodology used in the studies is reflected upon. A strength of the dissertation is the combination of qualitative and quantitative studies, both contributing to systematic and informed health intervention planning (e.g., Johnson \& Onwuegbuzie, 2004).

A strength of the qualitative study (Chapter 3) was the variety of stakeholders in the sample. However, this also implied small sample sizes for each of the groups, which, combined with lack of random respondent selection, may have influenced the reliability of the findings. Caution should therefore be observed in generalisation of the results for the study population and other populations. To mitigate subjectivity of the principal researcher in data collection and analysis, and to contribute to validity of the findings, triangulation of data across data collectors (i.e., three interviewers), methods (i.e., in depth interviews, quantitative monitoring data, and lifeline histories), and across respondents (i.e., various groups of stakeholders were represented) was applied. A limitation of the study is the lack of triangulation across multiple analysts. Data analysis was conducted by the principal researcher, which may have affected the validity of the results (Kirk and Miller, 1985; Golafshani, 2003).

A strength of the two quantitative studies in Uganda, Indonesia, and Thailand were the large sample sizes $(N>1446)$. A limitation of the baseline study in Indonesia (Chapter 4) was the large numbers of missing data among respondents. This was largely a result of the use of skip patterns in the questionnaire (e.g., questions about condom use were only completed by respondents who had experience with sexual intercourse) and the addition of the answer option 'I don't want to talk about it' to items that were marked as sensitive. Another shortcoming of the baseline study was the single focus on exploring the correlates of abstinence intentions. Even though correlates of condom use intentions were measured in the questionnaire, the small number of respondents expressing the intention to use condoms in future $(N=581)$ resulted in unreliable results. A limitation of the study measuring the effect of WSWM on students' disclosure (Chapter 5) was the lack of randomisation of intervention and comparison schools. However, intervention and comparison schools were selected based on strict selection criteria. A quasiexperimental design was the most optimal option in this study, and is acknowledged and common in public health evaluations (Handley, Schillinger, \& Shiboski, 2011; Bonell et al., 2011). In addition, large numbers of data were missing with regard to questions about respondents' experiences with sexual intercourse and condom use, which probably were among the most sensitive questions in the questionnaire. This resulted in removal of these questions from the analysis. And even though the study resulted in interesting findings with regard to self-disclosure, a disadvantage of 
inclusion of the answer option 'I don't want to talk about it' to sensitive questions was the large number of missing data in the studies measuring correlates of behavioural intentions (Rijsdijk et al., 2012; Leerlooijer, Ruiter, Damayanti, et al., submitted).

A strength of the Intervention Mapping case studies is the incorporation of multiple factors and approaches in intervention planning and adaptation, and making this explicit in both case study descriptions. A strength of the case study described in Chapter 2 was the detailed description of the methods and applications of a comprehensive, ecological intervention, adding to the literature on Intervention Mapping. A shortcoming of the adaptation case (Chapter 6) is that the behavioural change theories and related change methods are not described in detail. If this was done more elaborately, effects or lack of effect of WSWM could be better and more specifically attributed to particular change methods in the intervention (Schaalma \& Kok, 2009; Albarracín et al., 2005; Abraham \& Michie, 2008). Another limitation of both case studies was the limited use of context specific scientific evidence. This was

a result of limited availability of existing evidence as well as restricted resources to collect new evidence.

\section{Implications for practice and further research}

\section{Implications for practice}

The studies in this dissertation showed that the planning of SRHR promotion interventions is a process of decision-making, not only based on evidence and theories but also on cultural and implementation contexts, which shape the content, messages, and delivery of interventions. Making these processes and decisions explicit contributes to our understanding of how changes occur in complex public health settings. This contributes to improving health promotion practices, and promotion of adolescents' SRHR in particular (Bartholomew, Parcel, et al., 2011; Schaalma, Abraham, Gillmore, \& Kok, 2004).

Three main approaches towards the promotion of adolescents' SRHR in policies and interventions include an empowerment, health promotion, and human rightsbased approach (Bearinger, Sieving, Ferguson, \& Sharma, 2007; Schaalma, Abraham, Gillmore, \& Kok, 2004; Chinman \& Linney, 1998). The case studies in this dissertation showed that the three approaches are complementary in the planning of SRHR promotion interventions and both case studies provided suggestions for health promotion practice.

First, a rights-based approach particularly contributes to an ethical framework to support and protect vulnerable groups in society. Where relevant, intervention planners can keep governments accountable for national policies and agreements they have subscribed, including the ICPD Plan of Action, Millennium Development Goals and other international conventions. Despite adolescents' rights to take their own decisions regarding their health, well-being and sexuality, adolescents' sexual decision making is a controversial topic in many societies and populations (Schaalma, Abraham, Gillmore, \& Kok, 2004; Petchesky, 2000). One of the ways by 
which planners can address this is by changing attitudes of adopters, implementers, policy makers, parents, and other community members through their involvement in the planning process. Both case studies in this dissertation showed that this can be a lengthy and elaborate process, requiring skills of intervention planners to negotiate effectively and be willing to adapt to a certain extent to the norms and values to avoid non-use of SRHR promotion interventions. A rights-based approach can also provide a framework for the design of SRHR interventions if limited reliable evidence in a particular context is available.

Second, intervention planners can apply an empowerment approach in adolescents' SRHR promotion to understand and change power relations. The studies in this dissertation with regard to a community based empowerment intervention showed that an empowerment approach is particularly relevant when addressing controversial and sensitive topics related to adolescents' SRHR and the interactions and power relations between parents and their children, between adult professionals and adolescents, and between males and females.

Third, a particular strength of a health promotion approach is its emphasis on the use of evidence and relevant theories in intervention planning (Bartholomew, Parcel, et al., 2011). The case study describing the systematic planning of the Teenage Mothers Project showed that a variety of theories was applied, including empowerment theories, stigma-related theories, and psychosocial theories. Depending on the behaviour, context, the problem to be addressed, and the population under consideration, planners can use theories that are particularly relevant and applicable to analyse the problem and its solutions, and to suggest behavioural and environmental change methods. Intervention Mapping provides a framework to systematically apply these theories, as well as theories that take specific cultural elements into account (e.g., Airhihenbuwa \& Webster, 2004). As was shown in the case studies in this dissertation, Intervention Mapping also provides a framework to integrate a rights-based approach into health promotion interventions. Adolescents' sexual and reproductive rights can be included in each of the planning steps: identification of gaps in adolescents' rights and relevant applicable policies (step 1), defining objectives that reflect those gaps (step 2), use these objectives as a starting point to identify behaviour and environmental change methods and practical applications (step 3), integrate them in a coherent intervention (step 4), convince adopters and implementers if necessary and support them to implement rights-based messages and interventions (step 5), and measure the effects of the intervention with regard to the rights-related objectives (step 6). The case study describing systematic adaptation of the sexuality education programme WSWM to a new context and priority population showed the need and opportunities for systematic adaptation of existing, evidence-based interventions. Transfer is usually more cost-effective than developing a new intervention, and can save time and other resources by avoiding mistakes through lessons learned in the original programme. Planners should adapt interventions systematically, finding a balance between retaining core elements in the original intervention, and adapting to the new context and priority population. 
Finally, a participatory approach and an ecological approach are central in all three abovementioned approaches (Gruskin, Bogecho, \& Ferguson, 2010; Kok, Gottlieb, Commers, \& Smerecnik, 2008; Campbell et al., 2000; Craig et al., 2008). When planners address sensitive topics such as adolescents' sexuality and out-of-wedlock pregnancy, they should carefully involve and convince relevant stakeholders of the need to contribute to adolescents' well-being and health. In addition, to be able to promote adolescents' SRHR, planners should aim to approach this from an ecological perspective. The studies in this dissertation confirm the suggestions and findings by others (Schaalma, Abraham, Gillmore, \& Kok, 2004; Wellings et al., 2006; DiClemente, Salazar, \& Crosby, 2007; Tan et al., 2011; Auerbach, Parkhurst, Caceres, \& Keller, 2009; Gupta et al., 2008). However, this dissertation also shows that the implementation of an ecological approach can be challenging, particularly when planners aim to address deeply embedded cultural social norms related to sensitive topics such as adolescents' sexuality, marriage, and gender. Comprehensive sexuality education programmes such as WSWM can contribute to increased openness of adolescents about sexuality related topics, one of the ways to address taboos and in the long run contribute to change in social norms.

\section{Implications for further research}

This dissertation has contributed to our theoretical understanding of planning and evaluation of health promoting interventions in countries in sub-Saharan Africa and the Asian Pacific region. The studies in this dissertation provide some suggestions for further research. Firstly, more evaluation research is needed to measure the effects of ecological interventions on adolescents' SRHR, their behaviours, behaviours of environmental actors, and underlying determinants. The need for systematic analysis of such interventions is also suggested by others (e.g., Kok, Gottlieb, Commers, \& Smerecnik, 2008). Qualitative analysis of change processes and how these could be attributed to behavioural and environmental change theories can be a first step. In addition, quantitative evaluation studies measuring and attributing changes to particular interventions should be conducted to demonstrate the relevance and importance of the qualitative findings (e.g., Craig et al., 2008). One of the prerequisites for such evaluation studies is a thorough description of the decisions made in the planning process, the interventions' content, and the behavioural and environmental change methods in the interventions, either prospectively or retrospectively (Schaalma \& Kok, 2009; Albarracín et al., 2005; Abraham \& Michie, 2008).

In addition, many empowerment and comprehensive sexuality education interventions in sub-Saharan Africa and the Asian Pacific region that target adolescents, aim for change in sexual behaviours and behavioural correlates, but to also contribute to their rights and empowerment. However, operationalization of a rights-based approach to health and of empowerment is challenging, partially as a consequence of a large variety of definitions (Gruskin, Bogecho, \& Ferguson, 2010; Ibrahim \& Alkire, 2007). In this dissertation and elsewhere (e.g., UNESCO, 2010), rights and empowerment are operationalized in behaviours that are specific for a particular group, problem, and context (e.g., adolescents convince leaders and 
decision makers of their rights) and in objectives concerning behavioural determinants (e.g., self-efficacy and skills: female adolescents describe step by step how they will return to or join education and how they deal with resistance in the community and in the school). Future research can further explore to what extent SRHR promoting interventions can improve adolescents' rights and empowerment. A similar approach can be used to identify and evaluate the behaviours and behavioural determinants of actors in adolescents' social environment who are responsible for or have the power to create a supportive environment.

To add to the international evidence-base, more research is needed with regard to adolescents' SRHR in countries in sub-Saharan Africa, and particularly in the Asian Pacific region. Limited evidence about adolescents' (sexual) behaviours and behavioural determinants is available. Future research can explore behaviours and behavioural correlates of adolescents. This will contribute to the design of evidencebased SRHR promotion interventions (Kirby, Laris, \& Rolleri, 2005; Sumintardja et al., 2009; Gray et al., 2011). In addition, particularly in the Asian Pacific region, there is a need for evaluations of comprehensive sexuality education programmes. With increasing premarital sexual activity and increasing HIV-prevalence in a number of Asian countries (e.g., Indonesia), future studies can investigate to what extent context-specific SRHR promotion interventions for adolescents are effective in contributing to their rights, empowerment, and (sexual) behaviour.

Finally, future research can further investigate adolescents' self-disclosure about sensitive topics in questionnaires. The assumption that the answer option 'I don't want to talk about it' increases reliability of effect evaluation results has to be further explored. In addition, future studies can explore the association between adolescents' self-disclosure level and their self-disclosure and breaking of taboos on sensitive topics in interpersonal communication with peers, parents, sexual partners, and health service providers and other professionals. This can contribute to the design of interventions aiming at increasing adolescents' communication about sensitive sexuality related topics, their support seeking behaviours, expression of thoughts and feelings, decreased stigma and discrimination, and to safer sexual behaviour (Rodríguez, Sheldon, Bauer, \& Pérez-Stable, 2001; Stutterheim et al., 2011; Derlega, Winstead, Mathews, \& Braitman, 2008; Noar, Carlyle, \& Cole, 2006). Research can also further explore how to contribute to a safe social environment and change of social norms that support open communicate about sensitive sexuality related topics (e.g., Bos, Pryor, Reeder, \& Stutterheim, 2013).

\section{Conclusions}

Overall, the study findings have provided insight in the systematic planning and evaluation of community-based and school-based interventions that promote adolescents' SRHR in Uganda, Indonesia, and Thailand. An empowerment approach and a rights-based approach contributed to the systematic, theory- and evidence planning and adaptation of rather controversial SRHR interventions. Programmes that promote adolescents' SRHR should be planned in close collaboration with all 


\section{Chapter 7}

relevant stakeholders including adolescents, intended programme adopters and implementers, and other relevant decision makers, to create ownership and plan or adapt a programme that fits with their needs and context (Schaalma, Abraham, Gillmore, \& Kok, 2004). In addition, SRHR programmes should be planned from an ecological approach, aiming to address adolescents' needs and to create a supportive social environment. Comprehensive sexuality education programmes can contribute to open communication of adolescents about sensitive sexuality related topics and community-based empowerment programmes can contribute to changed social norms with regard to sensitive sexuality related topics. Future research should focus on evaluation of complex, multi-level interventions and on explorative and evaluation studies assessing adolescents' SRHR behaviours and SRHR interventions in sub-Saharan Africa and, particularly, the Asian Pacific region. 


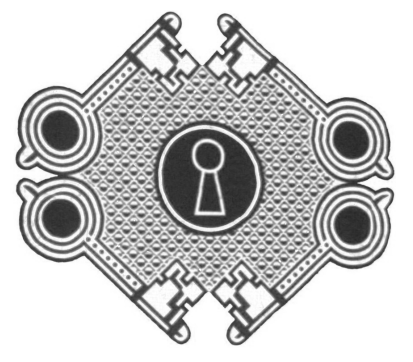

References 
Abraham, C., \& Michie, S. (2008). A taxonomy of behavior change techniques used in interventions. Health Psychology, 27(3), 379-387.

Abrejo, F. G., Shaikh, B. T., \& Saleem, S. (2008). ICPD to MDGs: Missing links and common grounds. Reproductive Health, 5(1), 4.

Agyei, W., Mukiza-Gapere, J., \& Epema, E. (1994). Sexual behaviour, reproductive health and contraceptive use among adolescents and young adults in Mbale District, Uganda. Journal of Tropical Medicine and Hygiene, 97, 219-227.

Airhihenbuwa, C. O., \& Webster, J. D. (2004). Culture and African contexts of HIV/AIDS prevention, care and support. Journal of Social Aspects of HIV/AIDS 1(1), 4-13.

Airhihenbuwa, C. O., \& Obregon, R. (2000). A critical assessment of theories/models used in health communication for HIV/AIDS. Journal of Health Communication, 5(S1), 5-15.

Ajzen, I. (1991). The theory of planned behavior. Organizational Behavior and Human Decision Processes, 50, 179-211.

Ajzen, I., \& Fishbein, M. (1980). Understanding attitudes and predicting social behavior. Englewood Cliffs NJ: Prentice-Hall.

Albarracín, D., Gillette, J. C., Earl, A. N., Glasman, L. R., Durantini, M. R., \& Ho, M. H. (2005). A test of major assumptions about behavior change: A comprehensive look at the effects of passive and active HIV-prevention interventions since the beginning of the epidemic. Psychological Bulletin, 131(6), 856-897.

Albarracín, D., Johnson, B. T., Fishbein, M., \& Muellerleile, P. A. (2001). Theories of reasoned action and planned behavior as models of condom use: A meta-analysis. Psychological Bulletin, 127(1), 142.

Allen, M., Emmers-Sommer, T. M., \& Crowell, T. L. (2002). Couples negotiating safer sex behaviors: A meta-analysis of the impact of conversation and gender. In M. Allen, R. W. Preiss, B.M. Gayle, \& N. A. Burrell (Eds.), Interpersonal communication research: Advances through meta-analysis (pp. 263-279). Mahwah NJ: Lawrence Erlbaum Associates.

Allport, G. W. (1954). The Nature of Prejudice. Cambridge MA: Addison-Wesley.

Alsop, R., Bertelsen, M., \& Holland, J. (2006). Empowerment in practice: From analysis to implementation. Washington DC: World Bank.

Alsop, R., \& Heinsohn, N. (2005). Measuring empowerment in practice: Structuring analysis and framing indicators. Policy Research Working Paper 3510. Washington DC: World Bank.

Annas, G. J. (1998). Human rights and health: The universal declaration of human rights at 50. New England Journal of Medicine 339(24), 1778-1781.

Araújo Pedrosa, A., Pires, R., Carvalho, P., Canavarro, M.C., \& Dattilio, F. (2011). Ecological contexts in adolescent pregnancy: The role of individual, sociodemographic, familial and relational variables in understanding risk of occurrence and adjustment patterns. Contemporary Family Therapy, 33, 107-127.

Armitage, C. J., \& Conner, M. (2001). Efficacy of the Theory of Planned Behaviour: A metaanalytic review. British Journal of Social Psychology, 40, 471-499.

Arthur, M., \& Blitz, C. (2000). Bridging the gap between research and practice in drug abuse prevention through needs assessment and strategic community planning. Journal of Community Psychology, 28(3), 241-256.

Atuyambe, L., Faxelid, E., Mirembe, F., Kirumira, E. K., \& Annika, J. (2008). Coping responses during pregnancy and early motherhood among adolescents in central Uganda. UPManila Journal, 13, 1-18. 
Atuyambe, L., Mirembe, F., Annika, J., Kirumira, E. K., \& Faxelid, E. (2009). Seeking safety and empathy: Adolescent health seeking behavior during pregnancy and early motherhood in central Uganda. Journal of Adolescence, 32, 781-796.

Atuyambe, L., Mirembe, F., Johansson, A., Kirumira, E. K., \& Faxelid, E. (2005). Experiences of pregnant adolescents-voices from Wakiso district, Uganda. African Health Sciences, 5, 304-309.

Atuyambe, L., Mirembe, F., Tumwesigye, N. M., Annika, J., Kirumira, E., \& Faxelid, E. (2008). Adolescent and adult first time mothers' health seeking practices during pregnancy and early motherhood in Wakiso district, central Uganda. Reproductive Health, 5, 13.

Auerbach, J. (2009). Transforming social structures and environments to help in HIV prevention. Health Affairs, 28, 1655-1665.

Auerbach, J. D., Parkhurst, J. O., \& Cáceres, C. F. (2011). Addressing social drivers of HIV/AIDS for the long-term response: Conceptual and methodological considerations. Global Public Health, 6(Suppl 3), 293-309.

Backer, T. E. (2001). Finding the balance: Program fidelity and adaptation in substance abuse prevention: A state-of the art review. Rockville, MD: Department of Health and Human Services, Substance Abuse and Mental Health Services Administration, Center for Substance Abuse Prevention.

Bandura, A. (1986). Social foundations of thought and action: A social cognitive theory. Englewood Cliffs: Prentice-Hall.

Bartholomew, L. K., Fernández, M., Leerlooijer, J. N., James, S., Reinders, J., \& Mullen, P. D. (2011). Using Intervention Mapping to adapt evidence-based programs to new settings and populations. In L. K. Bartholomew, G. S. Parcel, G. Kok, N. H. Gottlieb, \& M. E. Fernández (Eds.), Planning health promotion programs: An Intervention Mapping approach (3rd ed., pp. 553-632). San Francisco CA: Jossey Bass.

Bartholomew, L. K., Parcel, G. S., \& Kok, G. (1998). Intervention Mapping: A process for designing theory- and evidence-based health education programs. Health Education \& Behavior, 25, 545-563.

Bartholomew, L. K., Parcel, G. S., Kok, G., \& Gottlieb, N. H. (2001). Intervention Mapping; designing theory- and evidence-based health promotion programs. Mountain View CA: Mayfield.

Bartholomew, L. K., Parcel, G. S., Kok, G., \& Gottlieb, N. H. (2006). Planning health promotion programs: An Intervention Mapping approach (2nd ed.). San Francisco CA: Jossey-Bass.

Bartholomew, L. K., Parcel, G. S., Kok, G., Gottlieb, N. H., \& Fernández, M. E. (2011). Planning health promotion programs: An Intervention Mapping approach (3rd ed.). San Francisco CA: Jossey-Bass.

Basen-Engquist, K., \& Parcel, G. S. (1992). Attitudes, norms, and self-efficacy: A model of adolescents' HIV-related sexual risk behavior. Health Education \& Behavior, 19, 263-277.

Basen-Engquist, K., Tortolero, S., \& Parcel, G. S. (1997). HIV risk behavior and theory-based psychosocial determinants in Hispanic and non-Hispanic white adolescents. Journal of Health Education, 28, S44-S50.

Bastien, S., Kajula, L., \& Muhwezi, W. (2011). A review of studies of parent-child communication about sexuality and HIV/AIDS in sub-Saharan Africa. Reproductive Health, 8(1), 25.

Baytop, C. M. (2006). Evaluating the effectiveness of programs to improve educational attainment of unwed African American teen mothers: A meta-analysis. The Journal of Negro Education, 75, 458-477. 
Bearinger, L. H., Sieving, R. E., Ferguson, J., \& Sharma, V. (2007). Global perspectives on the sexual and reproductive health of adolescents: Patterns, prevention, and potential. The Lancet, 369(9568), 1220-1231.

Beers, S. L., \& Hollo, R.E. (2009). Approaching the adolescent-headed family: A review of teen parenting. Current Problems in Pediatric and Adolescent Health Care, 39, 216-233.

Bell, S. G., Newcomer, S. F., Bachrach, C., Borawski, E., Jemmott, J. B., Morrison, D., Stanton, B., Tortolero, S., \& Zimmerman, R. (2007). Challenges in replicating interventions. The Journal of Adolescent Health, 40(6), 514-520.

Biddlecom, A., Gregory, R., Lloyd, C. B., \& Mensch, B. S. (2008). Associations between premarital sex and leaving school in four sub-Saharan African countries. Studies in Family Planning, 39, 337-350.

Blankenship, K. M., Friedman, S. R., Dworkin, S., \& Mantell, J. E. (2006). Structural interventions: Concepts, challenges and opportunities for research. Journal of Urban Health, 83(1), 59-72.

Blum, R. W., \& Nelson-Mmari, K. (2004). The health of young people in a global context. Journal of Adolescent Health, 35(5), 402-418.

Bohmer, L., \& Kirumbira, E. (2000). Socio-economic context and the sexual behaviour of Ugandan out of school youth. Culture, Health and Sexuality, 2, 269-285.

Bonell, C. P., Hargreaves, J., Cousens, S., Ross, D., Hayes, R., Petticrew, M., \& Kirkwood, B. (2011). Alternatives to randomisation in the evaluation of public health interventions: Design challenges and solutions. Journal of Epidemiology and Community Health, 65(7), 582-587.

Bos, A. E. R., Schaalma, H. P., \& Pryor, J. B. (2008). Reducing AIDS-related stigma in developing countries: The importance of theory- and evidence-based interventions. Psychology, Health \& Medicine, 13, 450-460.

Bos, A. E. R., Pryor, J. B., Reeder, G. D., \& Stutterheim, S. E. (2013). Stigma: Advances in theory and research. Basic and Applied Social Psychology, 35(1), 1-9.

Botvin, G. J. (2004). Advancing prevention science and practice: Challenges, critical issues, and future directions. Prevention Science, 5, 69-72.

Bracht, N. F. (1999). Health promotion at the community level: New advances. Thousand Oaks: Sage.

Bronfenbrenner, U. (1979). The ecology of human development: Experiments by nature and design. Cambridge: Harvard University Press.

Bryman, A. E., Liao, T. F., \& Lewis-Beck, M. (2003). The Sage encyclopedia of social science research methods (Vol. 1). Thousand Oaks: Sage.

Buchanan, T., Paine, C. B., Joinson, A. N., \& Reips, U.-D. (2007). Development of measures of online privacy concern and protection for use on the Internet. Journal of the American Society for Information Science and Technology, 58, 157-165.

Buhi, E. R., \& Goodson, P. (2007). Predictors of adolescent sexual behavior and intention: A theory-guided systematic review. Journal of Adolescent Health, 40, 4-21.

Campbell, M., Fitzpatrick, R., Haines, A., Kinmonth, A. L., Sandercock, P., Spiegelhalter, D., \& Tyrer, P. (2000). Framework for design and evaluation of complex interventions to improve health. British Medical Journal, 321(7262), 694.

Carpenter, C. J. (2010). A meta-analysis of the effectiveness of Health Belief Model variables in predicting behavior. Health Communication, 25, 661-669. 
Carvajal, S. C., Parcel, G. S., Basen-Engquist, K., Banspach, S. W., Coyle, K. K., Kirby, D., \& Chan, W. (1999). Psychosocial predictors of delay of first sexual intercourse by adolescents. Health Psychology, 18, 443-452.

Castro, F. G., Barrera, M. Jr., \& Martinez, C. R. Jr. (2004). The cultural adaptation of prevention interventions: Resolving tensions between fidelity and fit. Prevention Science, 5(1), 41-45.

Cha, E. S., Doswell, W. M., Kim, K. H., Charron-Prochownik, D., \& Patrick, T .E. (2007). Evaluating the theory of planned behavior to explain intention to engage in premarital sex amongst Korean college students: A questionnaire survey. International Journal of Nursing Studies, 44, 1147-1157.

Chaudoir, S. R., \& Fisher, J. D. (2010). The disclosure processes model: Understanding disclosure decision making and postdisclosure outcomes among people living with a concealable stigmatized identity. Psychological Bulletin, 136(2), 236.

Chin, H. B., Sipe, T. A., Elder, R., Mercer, S. L., Chattopadhyay, S. K., Jacob, V., Wethington, H. R., Kirby, D., Elliston, D. B., \& Griffith, M. (2012). The effectiveness of group-based comprehensive risk-reduction and abstinence education interventions to prevent or reduce the risk of adolescent pregnancy, human immunodeficiency virus, and sexually transmitted infections: Two systematic reviews for the Guide to Community Preventive Services. American Journal of Preventive Medicine, 42(3), 272-294.

Chinman, M. J., \& Linney, J. A. (1998). Toward a model of adolescent empowerment: Theoretical and empirical evidence. The Journal of Primary Prevention, 18(4), 393-413.

Collazo, A. A. (2005). Theory-based predictors of intention to engage in precautionary sexual behavior among Puerto Rican high school adolescents. Journal of HIV/AIDS Prevention in Children \& Youth, 6, 91-120.

Corcoran, J., \& Pillai, V. K. (2007). Effectiveness of secondary pregnancy prevention programs: A meta-analysis. Research on Social Work Practice, 17, 5-18.

Cornwall, A., \& Nyamu-Musembi, C. (2004). Putting the 'rights-based approach' to development into perspective. Third World Quarterly, 25(8), 1415-1437.

Corrigan, P. W., \& Kosyluk, K. A. (2013). Erasing the stigma: Where science meets advocacy. Basic and Applied Social Psychology 35(1), 131-140.

Cowan, F. M., Pascoe, S. J. S., Langhaug, L. F., Dirawo, J., Chidiya, S., Jaffar, S., Mbizvo, M., Stephenson, J. M., Johnson, A. M., \& Power, R. M. (2008). The Regai Dzive Shiri Project: A cluster randomised controlled trial to determine the effectiveness of a multi-component community-based HIV prevention intervention for rural youth in Zimbabwe - study design and baseline results. Tropical Medicine \& International Health, 13(10), 1235-1244.

Craig, P., Dieppe, P., Macintyre, S., Michie, S., Nazareth, I., \& Petticrew, M. (2008). Developing and evaluating complex interventions: The new Medical Research Council guidance. British Medical Journal, 337, a1655-a1655.

Cuijpers, P., De Graaf, I., \& Bohlmeijer, E. (2005). Adapting and disseminating effective public health interventions in another country: Towards a systematic approach. European Journal of Public Health, 15(2), 166-169.

Damayanti, R., Dadun, A., Dachlia, D. Hartati, H., \& Mamdy, Z. (2010). WSWM evaluation, Indonesia report. Depok, Indonesia: Universitas Indonesia.

De Bruin, M., Viechtbauer, W., Schaalma, H. P., Kok, G., Abraham, C., \& Hospers, H. J. (2010). Standard care impact on effects of highly active antiretroviral therapy adherence interventions: A meta-analysis of randomized controlled trials. Archives of Internal Medicine, 170(3), 240. 
De Grace, A., \& Clarke, A. (2012). Promising Practices in the Prevention of Intimate Partner Violence Among Adolescents. Violence and Victims, 27(6), 849-859.

De Vos, P., De Ceukelaire, W., Malaise, G., Pérez, D., Lefèvre, P., \& Van der Stuyft, P (2009). Health through people's empowerment: A rights-based approach to participation. Health and Human Rights, 11(1), 23-35.

Derlega, V. J., Winstead, B. A., Mathews, A., \& Braitman, A. L. (2008). Why does someone reveal highly personal information? Attributions for and against self-disclosure in close relationships. Communication Research Reports, 25(2), 115-130.

Derlega, V., Metts, S., Petronio, S., \& Margulis, S. T. (1993). Self-disclosure. Newbury Park CA: Sage.

DiClemente, R. J., Salazar, L. F., \& Crosby, R. A. (2007). A review of STD/HIV preventive interventions for adolescents: Sustaining effects using an ecological approach. Journal of Pediatric Psychology, 32(8), 888-906.

Dijker, A. J., \& Koomen, W. (2003). Extending Weiner's attribution-emotion model of stigmatization of ill persons. Basic and Applied Social Psychology, 25, 51-68.

Dindia, K., \& Allen, M. (1992). Sex differences in self-disclosure: A meta-analysis. Psychological Bulletin, 112(1), 106.

Doyle, A. M., Mavedzenge, S. N., Plummer, M. L., \& Ross, D. A. (2012). The sexual behaviour of adolescents in sub-Saharan Africa: Patterns and trends from national surveys. Tropical Medicine \& International Health, 17(7), 796-807.

Drury, J., \& Reicher, S. (2009). Collective psychological empowerment as a model of social change: Researching crowds and power. Journal of Social Issues, 65, 707-725.

Duflo, E., Dupas, P., Kremer, M., \& Sinei, S. (2006). Education and HIV/AIDS prevention: Evidence from a randomized evaluation in Western Kenya. Washington DC: World Bank.

Dutta-Bergman, M. J. (2005). Theory and practice in health communication campaigns: A critical interrogation. Health Communication 18(2), 103-122.

Dworkin, S., \& Blankenship, K. (2009). Microfinance and HIV/AIDS prevention: Assessing its promise and limitations. AIDS and Behaviour, 13(3), 463469.

Evans, R. W., Avery, P. G., \& Pederson, P. V. (1999). Taboo topics: Cultural restraint on teaching social issues. The Social Studies, 90(5), 218-224.

Fishbein, M., \& Ajzen, I. (1975). Belief, attitude, intention, and behavior: An introduction to theory and research. Reading MA: Addison-Wesley.

Fishbein, M. (2008). A reasoned action approach to health promotion. Medical Decision Making, 28, 834-844.

Fisher, W. A., Fisher, J. D., \& Rye, B.J. (1995). Understanding and promoting AIDS-preventive behavior: Insights from the theory of reasoned action. Health Psychology, 14, 255-264.

Forsyth, D. R. (2006). Group dynamics. Belmont CA: Thompson-Wadsworth.

Foss, A. M., Hossain, M., Vickerman, P. T., \& Watts, C. H. (2007). A systematic review of published evidence on intervention impact on condom use in sub-Saharan Africa and Asia. Sexually Transmitted Infections, 83, 510-516.

Garenne, M., \& Zwang, J. (2009). Premarital fertility and HIV/AIDS in sub-Saharan Africa. African Journal of Reproductive Health, 12, 64-74.

Gibbs, A., Willan, S., Misselhorn, A., \& Mangoma, J. (2012). Combined structural interventions for gender equality and livelihood security: A critical review of the evidence from southern and eastern Africa and the implications for young people. Journal of the International AIDS Society, 15(Suppl 1), 17362. 
Glaser, E., \& Backer, T. (1977). Innovation redefined: Durability and local adaptation. Evaluation, 4, 131-135.

Glasier, A., Gülmezoglu, A. M., Schmid, G. P., Moreno, C. G., \& Van Look, P. F. (2006). Sexual and reproductive health: A matter of life and death. The Lancet, 368(9547), 1595-1607.

Godin, G., Gagnon, H., Alary, M., Levy, J. J., \& Otis, J. (2007). The degree of planning: An indicator of the potential success of health education programs. Promotion \& Education, 3, 138-142.

Golafshani, N. (2003). Understanding reliability and validity in qualitative research. The Qualitative Report, 8(4), 597-607.

Gouws, E., \& Cuchi, P. (2012). Focusing the HIV response through estimating the major modes of HIV transmission: A multi-country analysis. Sexually Transmitted Infections, 88(Suppl 2), i76-i85.

Gramling, L. F., \& Carr, R. L. (2004). Lifelines: A life history methodology. Nursing Research, 53(3), 207-210.

Grant, M. J. (2012). Girls' schooling and the perceived threat of adolescent sexual activity in rural Malawi. Culture, Health and Sexuality, 14(1), 73-86.

Gray, N., Azzopardi, P., Kennedy, E., Willersdorf, E., \& Creati, M. (2011). Improving adolescent reproductive health in Asia and the Pacific: Do we have the data? A review of DHS and MICS surveys in nine countries. Asia-Pacific Journal of Public Health, 25(2), 134-144.

Green, J., \& Tones, K. (2010). Health promotion: Planning and strategies. London UK: Sage.

Green, L. W., \& Kreuter, M. W. (2005). Health program planning: An educational and ecological approach (4th ed.). New York: McGraw Hill Professional.

Green, L. W., Richard, L., \& Potvin, L. (1996). Ecological foundations of health promotion. American Journal of Health Promotion, 10(4), 270-281.

Greene, K., Derlega, V. J., \& Mathews, A. (2006). Self-disclosure in personal relationships. In A. Vangelisti \& D. Perlman (Eds.), Cambridge handbook of personal relationships (pp. 409427). Cambridge UK: Cambridge University Press.

Gruskin, S., Bogecho, D., \& Ferguson, L. (2010). 'Rights-based approaches' to health policies and programs: Articulations, ambiguities, and assessment. Journal of Public Health Policy, 31(2), 129-145.

Gruskin, S., Mills, E.J., \& Tarantola, D. (2007) History, principles, and practice of health and human rights. The Lancet 370(9585), 449-455.

Gupta, N., Katende, C., \& Bessinger, R. (2003). Associations of mass media exposure with family planning attitudes and practices in Uganda. Studies in Family Planning, 34(1), 1931.

Hallfors, D., Cho, H., Rusakaniko, S., Iritani, B., Mapfumo, J., \& Halpern, C. (2011). Supporting adolescent orphan girls to stay in school as HIV risk prevention: Evidence from a randomized controlled trial in Zimbabwe. American Journal of Public Health, 101(6), 10821088.

Handley, M. A., Schillinger, D., \& Shiboski, S. (2011). Quasi-experimental designs in practicebased research settings: Design and implementation considerations. The Journal of the American Board of Family Medicine, 24(5), 589-596.

Hargreaves, J. R., Bonell, C. P., Boler, T., Boccia, D., Birdthistle, I., Fletcher, A., Pronyk, P. M., \& Glynn, J. R. (2008). Systematic review exploring time trends in the association between educational attainment and risk of HIV infection in sub-Saharan Africa. AIDS, 22(3), 403414. 
Haslegrave, M. (2004). Implementing the ICPD Programme of Action: What a difference a decade makes. Reproductive Health Matters, 12(23), 12-18.

Heald S (1999). Manhood and Morality: Sex, violence and ritual in Gisu society. London UK: Routledge.

Hindin, M. J., \& Fatusi, A. O. (2009). Adolescent sexual and reproductive health in developing countries: An overview of trends and interventions. International Perspectives on Sexual and Reproductive Health, 35(2), 58-62.

Hindin, M. J., Christiansen, C. S., \& Ferguson, B. J. (2013). Setting research priorities for adolescent sexual and reproductive health in low-and middle-income countries. Bulletin of the World Health Organization, 91(1), 10-18.

Holub, C. K., Kershaw, T. S., Ethier, K. A., Lewis, J. B., Milan, S., \& Ickovics, J. R. (2007). Prenatal and parenting stress on adolescent maternal adjustment: Identifying a high-risk subgroup. Maternal and Child Health Journal, 11(2), 153-159.

House, J. S. (1981). Work stress and social support. Reading MA: Addison-Wesley.

Hunt, P. (2002). The right to health: From the margins to the mainstream. The Lancet, 360(9348), 1878.

Ibrahim, S., \& Alkire, S. (2007). Agency and Empowerment: A Proposal for Internationally Comparable Indicators. Oxford Development Studies, 35(4), 379-403.

Ingham, R., Woodcock, A., \& Stenner, K. (1991). Getting to know you... Young people's knowledge of their partners at first intercourse. Journal of Community \& Applied Social Psychology, 1(2), 117-132.

Jacob, W. J., Morisky, D. E., Hite, S., \& Nsubuga, Y. K. (2006). Evaluation of HIV/AIDS education programs in Uganda. In D. E. Morisky, W. J. Jacob, Y. K. Nsubuga, \& S. J. Hite (Eds.) Overcoming AIDS: Lessons learned from Uganda (pp. 104-114). Hartford CT: Information Age Publishing.

James, S., Van Rooyen, D., \& Strümpher, D. C. (2012). Experiences of teenage pregnancy among Xhosa families. Midwifery, 28(2), 190-197.

Janz, N. K., \& Becker, M. H. (1984). The health belief model: A decade later. Health Education \& Behavior, 11(1), 1-47.

Johnson, R. B., \& Onwuegbuzie, A. J. (2004). Mixed methods research: A research paradigm whose time has come. Educational Researcher 33(7), 14-26.

Joinson, A. N., Paine, C., Buchanan, T., \& Reips, U. D. (2008). Measuring self-disclosure online: Blurring and non-response to sensitive items in web-based surveys. Computers in Human Behavior, 24(5), 2158-2171.

Kaaya, S. F., Flisher, A. J., Mbwambo, J. K., Schaalma, H., Aaro, L. E., \& Klepp, K. I. (2002). A review of studies of sexual behaviour of school students in sub-Saharan Africa. Scandinavian Journal of Public Health, 30(2), 148-160.

Kaaya, S. F., Mukoma, W., Flisher, A. J., \& Klepp, K. (2002). School-based sexual health interventions in sub-Saharan Africa: A review. Social Dynamics: A Journal of African Studies, 28, 64-88.

Kabeer, N. (1999). Resources, agency, achievements: Reflections on the measurement of women's empowerment. Development and Change, 30(3), 435-464.

Kamali, A., Carpenter, L. M., Whitworth, J. A. G., Pool, R., Ruberantwari, A., \& Ojwiya, A. (2000). Seven-year trends in HIV-1 infection rates, and changes in sexual behaviour, among adults in rural Uganda. AIDS, 14(4), 427-434.

Kar, S. B., Pascual, C. A., \& Chickering, K. L. (1999). Empowerment of women for health promotion: A meta-analysis. Social Science \& Medicine, 49(11), 1431-1460. 
Kay, N. S., Jones, M. R., \& Jantaraweragul, S. (2010). Teaching Sex Education in Thailand. Journal of Research, 5(2), 10-16.

Kelly, J. A., Heckman, T. G., Stevenson, L. Y., Williams, P. N., Ertl, T., Hays, R. B., Leonard, N. R., O'Donnell, L., Terry, M. A., \& Sogolow, E. D. (2000). Transfer of research-based HIV prevention interventions to community service providers: Fidelity and adaptation. AIDS Education and Prevention, 12(5 Suppl A), 87-98.

Kelly, R. J., Gray, R. H., Sewankambo, N. K., Serwadda, D., Wabwire-Mangen, F., Lutalo, T., \& Wawer, M. J. (2003). Age differences in sexual partners and risk of HIV-1 infection in rural Uganda. Journal of Acquired Immune Deficiency Syndromes, 32(4), 446-451.

Keyes, C. L. M. (1998). Social well-being. Social Psychology Quarterly, 61, 121-140.

Kim, J., Pronyk, P., Barnett, T., \& Watts, C. (2008). Exploring the role of economic empowerment in HIV prevention. AIDS, 22, S57-S71.

Kim, J. C., Watts, C. H., Hargreaves, J. R., Ndhlovu, L. X., Phetla, G., Morison, L. A., Busza, J., Porter, J. D. H., \& Pronyk, P. (2007). Understanding the impact of a microfinance-based intervention on women's empowerment and the reduction of intimate partner violence in South Africa. American Journal of Public Health, 97(10), 1794.

Kirby, D. B. (2007). Emerging answers 2007: Research findings on programs to reduce teen pregnancy and sexually transmitted diseases. Washington, DC: The National Campaign to Prevent Teen and Unplanned Pregnancy.

Kirby, D. B. (2008). The impact of abstinence and comprehensive sex and STD/HIV education programs on adolescent sexual behavior. Sexuality Research and Social Policy, 5(3), 18-27.

Kirby, D. B., Laris, B. A., \& Rolleri, L. A. (2005). The impact of sex and HIV education programs on sexual behaviors of youth in developing and developed countries. Research Triangle Park: Family Health International.

Kirby, D. B., Laris, B. A., \& Rolleri, L. A. (2007). Sex and HIV education programs: Their impact on sexual behaviors of young people throughout the world. Journal of Adolescent Health, 40(3), 206-217.

Kirk, J., \& Miller, M. L. (1985). Reliability and Validity in Qualitative Research. Beverly Hills CA: Sage.

Knapp, H., \& Kirk, S. A. (2003). Using pencil and paper, Internet and touch-tone phones for self-administered surveys: Does methodology matter? Computers in Human Behavior, 19(1), 117-134.

Kohler, P. K., Manhart, L. E., \& Lafferty, W. E. (2008). Abstinence-only and comprehensive sex education and the initiation of sexual activity and teen pregnancy. Journal of Adolescent Health, 42(4), 344-351.

Kok, G., Gottlieb, N. H., Commers, M., \& Smerecnik, C. (2008). The ecological approach in health promotion programs: A decade later. American Journal of Health Promotion, 22(6), 437-442.

Kreuter, M. W., \& McClure, S. M. (2004). The role of culture in health communication. Annual Review of Public Health, 25, 439-455.

Kulin, H. E. (1988). Adolescent pregnancy in Africa: a programmatic focus. Social Science \& Medicine, 26, 727-735.

Kunda, Z., \& Oleson, K. C. (1995). Maintaining stereotypes in the face of disconfirmation: Constructing grounds for sub-typing deviants. Journal of Personality and Social Psychology, 68, 565-579.

La Fontaine, J. S. (1959). The Gisu of Uganda. London UK: International African Institute. 
Lachance, C. R., Burrus, B. B., \& Scott, A. R. (2012). Building an evidence base to inform interventions for pregnant and parenting adolescents: A call for rigorous evaluation. American Journal of Public Health, 13, 1826-1832.

Lau, A. (2006). Making the case for selective and directed cultural adaptations of evidencebased treatments: Examples from parent training. Clinical Psychology: Science and Practice, 13(4), 295-310.

Laverack, G. (2011). Improving health outcomes through community empowerment: A review of the literature. Journal of Health, Population and Nutrition, 24(1), 113-120.

Laverack, G., \& Labonte, R. (2000). A planning framework for community empowerment goals within health promotion. Health Policy and Planning, 15(3), 255-262.

Lee, S. J., Altschul, I., \& Mowbray, C. T. (2008). Using planned adaptation to implement evidence-based programs with new populations. American Journal of Community Psychology, 41, 290-303.

Leerlooijer, J. N., Ruiter, R. A. C., Damayanti, R., Rijsdijk, L. E., Eiling, E., Bos, A. E. R., \& Kok, G. Psychosocial correlates of the motivation to abstain from sexual intercourse among Indonesian adolescents. Submitted for publication.

Leerlooijer, J. N., Bos, A. E. R., Ruiter, R. A. C., Van Reeuwijk, M. A. J., Rijsdijk, L. E., Nshakira, N., \& Kok, G. Qualitative evaluation of the Teenage Mothers Project in Uganda: A community-based empowerment intervention for unmarried teenage mothers. Under revision.

Leerlooijer, J. N., Ruiter, R. A. C., Rijsdijk, L. E., Reinders, J., Bos, A. E. R., Wong, W., \& Kok, G. Breaking taboos about sexuality: Effects of the school-based programme The World Starts with $\mathrm{Me}$ in Uganda and Thailand on disclosure about sensitive issues. Submitted for publication.

Leerlooijer, J. N., Kok, G., Weyusya, J., Bos, A. E. R., Ruiter, R. A. C., Rijsdijk, L. E., Nshakira, N., \& Bartholomew, L. K. Empowering teenage mothers in Uganda: The development of a community-based intervention to improve psychological and social well-being of unmarried teenage mothers. Submitted for publication.

Leerlooijer, J. N. (2001). Promoting and inhibiting factors of sexual abstinence among female adolescents in Mbale district, Uganda. MSC thesis. Maastricht University, Health Promotion and Health Education.

Leerlooijer, J. N. (2009). Evidence-based planning \& support tool for SRHR/HIV-prevention interventions. The Netherlands: World Population Foundation \& STOP AIDS NOW!.

Leerlooijer, J. N., Reinders, J., \& Schaalma, H. (2008). Intervention Mapping toolkit for planning sexuality education programs: Using Intervention Mapping in planning schoolbased sexual and reproductive health and rights (SRHR) education programs. The Netherlands: World Population Foundation \& RESHAPE Maastricht University.

Leerlooijer, J. N., Ruiter, R. A. C., Reinders, J., Darwisyah, W., Kok, G., \& Bartholomew, L. K. (2011). The World Starts With Me: Using Intervention Mapping for the systematic adaptation and transfer of school-based sexuality education from Uganda to Indonesia. Translational Behavioral Medicine: Practice, Policy and Research, 2, 331-340.

Levandowski, B. A., Kalilani-Phiri, L., Kachale, F., Awah, P., Kangaude, G., \& Mhango, C. (2012). Investigating social consequences of unwanted pregnancy and unsafe abortion in Malawi: The role of stigma. International Journal of Gynecology \& Obstetrics, 118, S167-S171. 
Liem, A. D., Hidayat, S. S., \& Soemarno, S. (2009). Do general beliefs predict specific behavioral intentions in Indonesia? The role of social axioms within the Theory of Planned Behaviour. In K. Leung, \& M. H. Bond (Eds.), Psychological Aspects of Social Axioms (217238). New York NY: Springer SBM.

Link, B. G., \& Phelan, J. C. (2001). Conceptualizing stigma. Annual Review of Sociology, 27, 363-385.

Logsdon, M. C., Hertweck, P., Ziegler, C., \& Pinto-Foltz, M. (2008). Testing a bioecological model to examine social support in postpartum adolescents. Journal of Nursing Scholarship, 40(2), 116-123.

Lopez-Claros, A., \& Zahidi, S. (2005). Women's empowerment: Measuring the global gender gap. Geneva: World Economic Forum.

Low, N., Broutet, N., Adu-Sarkodie, Y., Barton, P., Hossain, M., \& Hawkes, S. (2006). Global control of sexually transmitted infections. The Lancet, 368(9551), 2001-2016.

Low-Beer, D., \& Stoneburner, R. L. (2003). Behaviour and communication change in reducing HIV: Is Uganda unique? African Journal of AIDS Research, 2(1), 9-21.

MacQueen, K. M., McLellan, E., Metzger, D. S., Kegeles, S., Strauss, R. P., Scotti, R., Blanchard, L., \& Trotter, R. T. (2001). What is community? An evidence-based definition for participatory public health. Journal Information, 91(12), 1929-1938.

Major, B., \& O'Brien, L. T. (2005). The social psychology of stigma. Annual Review of Psychology, 56, 393-421.

Marston, C., \& King, E. (2006). Factors that shape young people's sexual behaviour: A systematic review. The Lancet, 368(9547), 1581-1586.

Mathews, C., Aarø, L. E., Flisher, A. J., Mukoma, W., Wubs, A. G., \& Schaalma, H. (2009). Predictors of early first sexual intercourse among adolescents in Cape Town, South Africa. Health Education Research, 24(1), 1-10.

Mbonu, N. C., Van Den Borne, B., \& De Vries, N. K. (2009). Stigma of people with HIV/AIDS in Sub-Saharan Africa: A literature review. Journal of Tropical Medicine, Art. ID 145891, 14. DOI:10.1155/2009/145891

McAlister, A. L., Perry, C. L., \& Parcel, G. S. (2008). How individuals, environments, and health behaviours interact. In K. Glanz, F. M. Lewis, \& B. K. Rimer (Eds.), Health behaviour and health education: Theory, research and practice (pp. 169-188). San Francisco CA: Jossey Bass.

McEachan, R. R. C., Conner, M., Taylor, N. J., \& Lawton, R. J. (2011). Prospective prediction of health-related behaviours with the Theory of Planned Behaviour: A meta-analysis. Health Psychology Review, 5(2), 97-144.

McKleroy, V. S., Galbraith, J. S., Cummings, B., Jones, P., Harshbarger, C., Collins, C., Gelaude, D. Carey, J.W., \& ADAPT, T. (2006). Adapting evidence-based behavioral interventions for new settings and target populations. AIDS Education and Prevention, 18, 59-73.

Mehrotra, P., Zimmerman, R. S., Noar, S. M., \& Dumenci, L. (2011). A test of an adapted multiple domain model in predicting sexual behaviors among unmarried young adults in India. Journal of Sex Research, 50(2), 116-127.

Michielsen, K., Chersich, M. F., Luchters, S., De Koker, P., Van Rossem, R., \& Temmerman, M. (2010). Effectiveness of HIV prevention for youth in sub-Saharan Africa: Systematic review and meta-analysis of randomized and nonrandomized trials. AIDS, 24(8), 1193-1202.

Mihalic, S. F., Fagan, A.A., \& Argamaso, S. (2008). Implementing the life skills training drug prevention program: Factors related to implementation fidelity. Implementation Science, 3,5 . 
Minkler, M., \& Wallerstein, N. (2011). Community-based participatory research for health: From process to outcomes. San Francisco CA: Jossey-Bass.

Mngadi, P., Thembi, I., Ransjö-Arvidson, A. B., \& Ahlberg, B. (2002). Quality of maternity care for adolescent mothers in Mbabane, Swaziland. International Nursing Review, 49(1), 3846.

Mohtasham, G., Shamsaddin, N., Bazargan, M., Anosheravan, K., Elaheh, M., \& Fazlolah, G. (2009). Correlates of the intention to remain sexually inactive among male adolescents in an Islamic country: Case of the Republic of Iran. Journal of School Health, 79(3), 123-129.

Montano, D. E., \& Kasprzyk, D. (2008). Theory of reasoned action, theory of planned behavior, and the integrated behavioral model. Health Behavior and Health Education: Theory, Research, and Practice, 4, 67-95.

Montgomery, R. E. (2009). A cross-cultural study of menstruation, menstrual taboos, and related social variables. Ethos, 2(2), 137-170.

Mukoma, W., Flisher, A. J., Helleve, A., Aarø, L. E., Mathews, C., Kaaya, S., \& Klepp, K. I. (2009). Development and test-retest reliability of a research instrument designed to evaluate school-based HIV/AIDS interventions in South Africa and Tanzania. Scandinavian Journal of Public Health, 37(Suppl 2), 7-15.

Mullen, P. D., Ramirez, G., Strouse, D., Hedges, L. V., \& Sogolow, E. (2002). Meta-analysis of the effects of behavioral HIV prevention interventions on the sexual risk behavior of sexually experienced adolescents in controlled studies in the United States. Journal of Acquired Immune Deficiency Syndromes, 30(Suppl 1), S94-S105.

Nahom, D., Wells, E., Gillmore, M. R., Hoppe, M., Morrison, D. M., Archibald, M., Murowchick, E., Wilsdon, A., \& Graham, L. (2001). Differences by gender and sexual experience in adolescent sexual behavior: Implications for education and HIV prevention. Journal of School Health, 71(4), 153-158.

Napierala Mavedzenge, S. M., Doyle, A. M., \& Ross, D. A. (2011). HIV prevention in young people in sub-Saharan Africa: A systematic review. Journal of Adolescent Health, 49(6), 568-586.

Nash, E. S. (1990). Teenage pregnancy - need a child bear a child? South African Medical Journal, 77, 147-151.

Noar, S. M., Black, H. G., \& Pierce, L. B. (2009). Efficacy of computer technology-based HIV prevention interventions: A meta-analysis. AIDS, 23(1), 107-115.

Noar, S. M., Carlyle, K., \& Cole, C. (2006). Why communication is crucial: Meta-analysis of the relationship between safer sexual communication and condom use. Journal of Health Communication, 11(4), 365-390.

Norton, W. E., Amico, K. R., Cornman, D. H., Fisher, W. A., \& Fisher, J. D. (2009). An agenda for advancing the science of implementation of evidence-based HIV prevention interventions. AIDS and Behavior, 13, 424-429.

Nutbeam, D. (2008). What would the Ottawa Charter look like if it were written today? Critical Public Health, 18(4), 435-441.

Orlandi, M. A., Landers, C., Weston, R., \& Haley, N. (1990). Diffusion of health promotion innovations. In K. Glanz, F. M. Lewis, \& B. K. Rimer (Eds.), Health behaviour and health education: Theory, research and practice (pp. 288-313). San Francisco CA: Jossey Bass.

Oronje, R. N., Crichton, J., Theobald, S., Oye Lithur, N., \& Ibisomi, L. (2011). Operationalising sexual and reproductive health and rights in sub-Saharan Africa: Constraints, dilemmas and strategies. BMC International Health and Human Rights, 11, 1-11. 
Paine-Andrews, A., Harris, K. J., Fisher, J. L., Lewis, R. K., Williams, E. L., Fawcett, S. B., \& Vincent, M. L. (1999). Effects of a replication of a multicomponent model for preventing adolescent pregnancy in three Kansas communities. Family Planning Perspectives, 31(4), 182-189.

Parikh, S. A. (2012). 'They arrested me for loving a schoolgirl': Ethnography, HIV, and a feminist assessment of the age of consent law as a gender-based structural intervention in Uganda. Social Science \& Medicine, 74, 1774-1782.

Paul-Ebhohimhen, V., Poobalan, A., \& van Teijlingen, E. (2008). A systematic review of schoolbased sexual health interventions to prevent STI/HIV in sub-Saharan Africa. BMC Public Health, 8(1), 4.

Paulussen, Th G W, Kok, G., Schaalma, H. P., \& Parcel, G. S. (1995). Diffusion of AIDS curricula among Dutch secondary school teachers. Health Education Quarterly, 22(2), 227-243.

Peacock, C., Ahuya, C., Ojango, J., \& Okeyo, A. (2011). Practical crossbreeding for improved livelihoods in developing countries: The FARM Africa goat project. Livestock Science, 136(1), 38-44.

Perkins, D. D., \& Zimmerman, M. A. (1995). Empowerment theory, research, and application. American Journal of Community Psychology, 23(5), 569-579.

Petchesky, R. P. (2000). Sexual rights, Inventing a concept, mapping an international practice. In R. G. Parker, R. M. Barbosa, \& P. Aggleton (Eds.), Framing the sexual subject: The politics of gender, sexuality, and power (pp. 81-103). Berkeley: University of California Press.

Pettigrew, T. F., \& Tropp, L. R. (2008). How does intergroup contact reduce prejudice? Meta-analytic tests of three mediators. European Journal of Social Psychology, 38(6), 922934.

Petty, R. E., Barden, J., \& Wheeler, S. C. (2009). The Elaboration Likelihood Model of Persuasion: Developing health promotions for sustained behavioral change. In R. J. DiClemente, R. A. Crosby, \& M. Kegler (Eds.), Emerging theories in health promotion practice and research (pp. 185-214). San Francisco CA: Jossey-Bass.

Poobalan, A. S., Pitchforth, E., Imamura, M., Tucker, J. S., Philip, K., Spratt, J., Mandava, L., \& Van Teijlingen, E. (2009). Characteristics of effective interventions in improving young people's sexual health: A review of reviews. Sex Education: Sexuality, Society and Learning, 9(3), 319-336.

Population Reference Bureau (2011). 2011 World population datasheet. Washington, DC: Population Reference Bureau.

Population Secretariat, Ministry of Finance, Planning and Economic Development (2001). Uganda: Population, reproductive health and development. Kampala, Uganda: Population Secretariat.

Price, M. N., \& Hyde, J. S. (2009). When two isn't better than one: Predictors of early sexual activity in adolescence using a cumulative risk model. Journal of Youth and Adolescence, 38(8), 1059-1071.

Prochaska, J. O., Redding, C. A., \& Evers, K. E. (2008). The transtheoretical model and stages of change. In K. Glanz, B. K. Rimer, \& K. Viswanath (Eds.), Health behavior and health education: Theory, research, and practice (pp. 97-121). San Francisco CA: Jossey-Bass.

Pronyk, P. M., Hargreaves, J. R., Kim, J. C., Morison, L. A., Phetla, G., Watts, C., Busza. J., \& Porter, J. D. H. (2006). Effect of a structural intervention for the prevention of intimatepartner violence and HIV in rural South Africa: A cluster randomised trial. The Lancet, 368(9551), 1973-1983. 
Protogerou, C., Flisher, A. J., Aarø, L. E., \& Mathews, C. (2012). The theory of planned behaviour as a framework for predicting sexual risk behaviour in sub-Saharan African youth: A critical review. Journal of Child \& Adolescent Mental Health, 24(1), 15-35.

Pryor, J. B., \& Reeder, G. D. (2011). HIV-related stigma. In J. C. Hall, B. J. Hall, C. J. Cockerell, \& C. T. Shelton (Eds.), HIV/AIDS in the Post-HAART era: Manifestations, treatment, and epidemiology (pp. 790-806). PMPH-USA Ltd.

Resnikow, K., Soler, R., Braithwait, R. L., Ahluwalia, J. S., \& Butler, J. (2000). Cultural sensitivity in substance abuse prevention. Journal of Community Psychology, 28(3), 271-290.

Reynolds, H., \& Wright, K. (2004). Maternal care among adolescents. Arlington: YouthNet.

Rijsdijk, L. E., Bos, A. E. R., Ruiter, R., Leerlooijer, J. N., De Haas, B., \& Schaalma, H. (2011). The World Starts With Me: A multilevel evaluation of a comprehensive sex education programme targeting adolescents in Uganda. BMC Public Health, 11, 334.

Rijsdijk, L. E., Bos, A. E. R., Lie, R., Ruiter R. A. C., Leerlooijer, J. N., \& Kok, G. (2012). Correlates of delayed sexual intercourse and condom use among adolescents in Uganda: A crosssectional study. BMC Public Health, 12, 817.

Riono, P., \& Jazant, S. (2004). The current situation of HIV/AIDS epidemic in Indonesia. AIDS Education and Prevention, 16(Suppl A),78-90.

Robertson, A., \& Minkler, M. (1994). New health promotion movement: A critical examination. Health Education Quarterly, 21, 295-312.

Rodríguez, M. A., Sheldon, W. R., Bauer, H. M., \& Pérez-Stable, E. J. (2001). The factors associated with disclosure of intimate partner abuse to clinicians. Journal of Family Practice, 50(4), 338-344.

Rogers, E. M. (1995). Diffusion of innovations (4th ed.). New York: Free Press.

Romero, L. M., Galbraith, J. S., Wilson-Williams, L., \& Gloppen, K. M. (2011). HIV prevention among African American youth: How well have evidence-based interventions addressed key theoretical constructs? AIDS and Behavior, 15(5), 976-991.

Romo, L. F., \& Nadeem, E. (2007). School connectedness, mental health, and well-being of adolescent mothers. Theory Into Practice, 46(2), 130-137.

Ross, D. A., Changalucha, J., Obasi, A. I., Todd, J., Plummer, M. L., Cleophas-Mazige, B., Anemona, A., Everett, D., Weiss, H. A., \& Mabey, D. C. (2007). Biological and behavioural impact of an adolescent sexual health intervention in Tanzania: A community-randomized trial. AIDS, 21(14), 1943-1955.

Rotheram-Borus, M. J., Ingram, B. L., Swendeman, D., \& Flannery, D. (2009). Common principles embedded in effective adolescent HIV prevention programs. AIDS and Behavior, 13(3), 387-398.

Ryff, C. D., \& Keyes, C. L. M. (1995). The structure of psychological well-being revisited. Journal of Personality and Social Psychology, 69(4), 719-727.

Schaalma, H. P., Abraham, C., Gillmore, M. R., \& Kok, G. (2004). Sex education as health promotion: What does it take? Archives of Sexual Behavior, 33(3), 259-269.

Schaalma, H., \& Kok, G. (2009). Decoding health education interventions: The times are achangin'. Psychology \& Health, 24(1), 5-9.

Schaalma, H., Kok, G., Poelman, J., \& Reinders, J. (1994). The development of AIDS education for Dutch secondary schools: A systematic approach based on research, theories, and cooperation. In D. R. Rutter (Ed.), The social psychology of health and safety: European perspectives (pp. 175-194). Aldershot: Avebury. 
Schaffer, M. A., Goodhue, A., Stennes, K., \& Lanigan, C. (2012). Evaluation of a public health nurse visiting program for pregnant and parenting teens. Public Health Nursing, 29, 218231.

Schalet, A. T. (2011). Beyond abstinence and risk: A new paradigm for adolescent sexual health. Women's Health Issues, 21(3S), S5-S7.

Sekiwunga, R., \& Whyte, S. R. (2010). Poor parenting: Teenagers' views on adolescent pregnancies in Eastern Uganda. African Journal of Reproductive Health, 13, 113-127.

Sen, A. (1985). Well-being, agency and freedom: The Dewey lectures 1984. The Journal of Philosophy, LXXXII, 169-221.

Sen, A. K. (1999). Development as freedom. Oxford: Oxford University Press.

Shah, I., \& Åhman, E. (2004). Age patterns of unsafe abortion in developing country regions. Reproductive Health Matters, 12(24), 9-17.

Shanok, A., \& Miller, L. (2007). Depression and treatment with inner city pregnant and parenting teens. Archives of Women's Mental Health, 10(5), 199-210.

Shaw, D. (2009). Access to sexual and reproductive health for young people: Bridging the disconnect between rights and reality. International Journal of Gynaecology and Obstetrics, 106(2), 132-136.

Shediac-Rizkallah, M. C., \& Bone, L. R. (1998). Planning for the sustainability of communitybased health programs: Conceptual frameworks and future directions for research, practice and policy. Health Education Research, 13(1), 87-108.

Sheeran, P., Abraham, C., \& Orbell, S. (1999). Psychosocial correlates of heterosexual condom use: A meta-analysis. Psychological Bulletin, 125(1), 90-132.

Shell-Duncan, B., \& Wimmer, M. (1999). Premarital childbearing in northwest Kenya: Challenging the concept of illegitimacy. Biodemography and Social Biology, 46, 47-61.

Simon S., \& Paxton, S. J. (2004). Sexual risk attitudes and behaviours among young adult Indonesians. Culture, Health and Sexuality, 6, 393-409.

Sieger, K., \& Renk, K. (2007). Pregnant and parenting adolescents: A study of ethnic identity, emotional and behavioral functioning, child characteristics, and social support. Journal of Youth and Adolescence, 36(4), 567-581.

Singh, S., Prada, E., Mirembe, F., \& Kiggundu, C. (2005). The incidence of induced abortion in Uganda. International Family Planning Perspectives, 31, 183-191.

Skaff, M. M., Chesla, C. A., Mycue, V. D., \& Fisher, L. (2002). Lessons in cultural competence: Adapting research methodology for Latino participants. Journal of Community Psychology, 30(3), 305-323.

Smith, G., Kippax, S., Aggleton, P., \& Tyrer, P. (2003). HIV/AIDS school-based education in selected Asia-Pacific countries. Sex Education: Sexuality, Society and Learning, 3(1), 3-21.

Speizer, I. S., Magnani, R. J., \& Colvin, C. E. (2003). The effectiveness of adolescent reproductive health interventions in developing countries: A review of the evidence. Journal of Adolescent Health, 33(5), 324-348.

Standing, H., Hawkins, K., Mills, E., Theobald, S., \& Undie, C. C. (2011). Introduction: Contextualising 'rights' in sexual and reproductive health. BMC International Health and Human Rights, 11(Suppl 3), S1.

Statistics Indonesia (Badan Pusat Statistik - BPS) \& Macro International (2008). Indonesia young adult reproductive health survey 2007. Calverton MA: BPS \& Macro International. 
Stutterheim, S. E., Pryor, J. B., Bos, A. E. R., Hoogendijk, R., Muris, P., \& Schaalma, H. P. (2009). HIV-related stigma and psychological distress: The harmful effects of specific stigma manifestations in various social settings. AIDS, 23(17), 2353-2357.

Stutterheim, S. E., Bos, A. E. R., Pryor, J. B., Brands, R., Liebregts, M., \& Schaalma, H. P. (2011). Psychological and social correlates of HIV status disclosure: The significance of stigma visibility. AIDS Education and Prevention, 23, 382-392.

Sumintardja, E. N., Pinxten, L. W. J., Siregar, J. R., Suherman, H., Wisaksana, R., Iskandar, S., Tasya, I. A., \& Hinduan, Z. R. (2011). Behavioral aspects of Hiv Prevention and care in Indonesia; a plea for a multi-disciplinary, theory- and evidence-based approach. Acta Medica Indonesia (The Indonesian Journal of Internal Medicine), 41(Suppl 1),79-86.

Tajfel, H., \& Turner, J. C. (1986). The social identity theory of intergroup behavior. In S. Worchel, \& W. Austin. (Eds.), The psychology of intergroup relations (2nd ed., pp 7-24). Chicago: Nelson-Hall.

Tan, J. Y., Huedo-Medina, T. B., Warren, M. R., Carey, M., \& Johnson, B. T. (2011). A metaanalysis of efficacy of HIV/AIDS prevention interventions in Asia, 1995-2009. Social Science \& Medicine, $x, 1-12$.

Thato, R., Jenkins, R., \& Dusitsin, N. (2008). Effects of the culturally-sensitive comprehensive sex education programme among Thai secondary school students. Journal of Advanced Nursing, 62(4), 457-469.

Thomas, D. R. (2006). A general inductive approach for analyzing qualitative evaluation data. American Journal of Evaluation, 27(2), 237-246.

Tortolero, S. R., Markham, C. M., Parcel, G. S., Peters, R. J. Jr., Escobar-Chaves, S. L., BasenEngquist, K., \& Lewis, H. L. (2005). Using Intervention Mapping to adapt an effective HIV, sexually transmitted disease, and pregnancy prevention program for high-risk minority youth. Health Promotion Practice, 6(3), 286-298.

Tourangeau, R., \& Yan, T. (2007). Sensitive questions in surveys. Psychological Bulletin, 133(5), 859-883.

Trenholm, C., Devaney, B., Fortson, K., Clark, M., Quay, L., \& Wheeler, J. (2008). Impacts of abstinence education on teen sexual activity, risk of pregnancy, and risk of sexually transmitted diseases. Journal of Policy Analysis and Management, 27(2), 255-276.

Ueno, K. (2005). Sexual orientation and psychological distress in adolescence: Examining interpersonal stressors and social support processes. Social Psychology Quarterly, 68(3), 258-277.

Uganda Bureau of Statistics (UBOS), ICF International Inc. (2012). Uganda Demographic and Health Survey 2011. Kampala, Uganda: UBOS and Calverton, Maryland: ICF International Inc.

Underhill, K., Montgomery, P., \& Operario, D. (2007). Sexual abstinence only programmes to prevent HIV infection in high income countries: Systematic review. Britisch Medical Journal, 335(7613), 248.

UNESCO. (2010). International technical guidance on sexuality education: An evidenceinformed approach for schools, teachers and health educators. Paris: UNESCO.

UNFPA (2012a). About ICPD Beyond 2014. New York: ICPD Secretariat, UNFPA. http://icpdbeyond2014.org/, accessed March 16th 2013.

UNFPA (2012b). The state of the world population: By choice, not by chance. Family planning, human rights and development. New York: UNFPA.

United Nations (1989). Convention on the Rights of the Child, United Nations treaty collection. New York: United Nations. 
United Nations (1994). Programme of action adopted at the International Conference on Population and Development, Cairo, 5-13 September 1994. New York: United Nations.

United Nations (1995). Beijing Declaration and Platform for Action. New York: United Nations.

United Nations (2000). A/RES/55/2: United Nations Millennium Declaration: Resolution adopted by the General Assembly 55/2, September 18, 2000. New York: United Nations.

United Nations (2011). World Population Prospects: The 2010 Revision. New York: United Nations, Department of Economic and Social Affairs, Population Division.

United Nations Secretary General (1997). Renewing the UN: A programme for reform (A/51/950). http://www.un.org/millennium/documents/a_51_950, accessed 15 March 2013.

Utomo, I. D. (2003). Adolescent Reproductive Health in Indonesia status, policies, programs, and issues. Canberra: Australian National University, POLICY Project.

Van Breukelen, G. J. (2006). ANCOVA versus change from baseline had more power in randomized studies and more bias in nonrandomized studies. Journal of Clinical Epidemiology, 59(9), 920-925.

Van Horne, B. S., Wiemann, C. M., Berenson, A. B., Horwitz, I. B., \& Volk, R. J. (2009). Multilevel predictors of inconsistent condom use among adolescent mothers. American Journal of Public Health, 99(Suppl 2), 417- 424.

Van Rooyen, C., Stewart, R., \& De Wet, T. (2012). The impact of microfinance in sub-Saharan Africa: A systematic review of the evidence. London UK: Institute of Education.

Varga, C. A. (1997). Sexual decision-making and negotiation in the midst of AIDS: Youth in KwaZulu-Natal, South Africa. Health Transition Review, 7 (Suppl 3), 45-67.

Varkey, P., Kureshi, S., \& Lesnick, T. (2010). Empowerment of women and its association with the health of the community. Journal of Women's Health, 19(1), 71-76.

Villarruel, A. M., Jemmott III, J. B., Jemmott, L. S., \& Ronis, D. L. (2004). Predictors of sexual intercourse and condom use intentions among Spanish-dominant Latino youth: A test of the planned behavior theory. Nursing Research, 53(3), 172-181.

Vyas, S., \& Watts, C. (2009). How does economic empowerment affect women's risk of intimate partner violence in low and middle income countries? A systematic review of published evidence. Journal of International Development, 21(5), 577-602.

Wandersman, A., Duffy, J., Flaspohler, P., Noonan, R., Lubell, K., Stillman, L., Blachman, M., Dunville, R., \& Saul, J. (2008). Bridging the gap between prevention research and practice: The interactive systems framework for dissemination and implementation. American Journal of Community Psychology, 41(3-4), 171-181.

Webb, T. L., \& Sheeran, P. (2006). Does changing behavioral intentions engender behavior change? A meta-analysis of the experimental evidence. Psychological Bulletin, 132(2), 249-268.

Wekesa, A. N. (2011). Bending the private-public gender norms: Negotiating schooling for young mothers from low-income households in Kenya. Working Paper Series/General Series 515. The Hague, the Netherlands: ISS.

Wellings, K., Collumbien, M., Slaymaker, E., Singh, S., Hodges, Z., Patel, D., \& Bajos, N. (2006). Sexual behaviour in context: A global perspective. The Lancet, 368(9548), 1706-1728.

Wheeler, M. (1999). ICPD and its aftermath: Throwing out the baby? Bulletin of the World Health Organization, 77, 778-779.

Widman, L., Welsh, D. P., McNulty, J. K., \& Little, K. C. (2006). Sexual communication and contraceptive use in adolescent dating couples. Journal of Adolescent Health, 39(6), 893899. 
Wingood, G. M., \& DiClemente, R. J. (2008). The ADAPT-ITT model; a novel method of adapting evidence-based HIV interventions. Journal of Acquired Immune Deficiency Syndromes, 47(Suppl 1), S40-S46.

Wong, W., Bhongvei, M., Leerlooijer, J. N., Eiling, E., \& Rijsdijk, L. E. (2010). WSWM evaluation, Thailand report. Utrecht, the Netherlands: World Population Foundation.

Wood, K., Maforah, F., \& Jewkes, R. (1998). 'He forced me to love him': Putting violence on adolescent sexual health agendas. Social Science \& Medicine, 47(2), 233-242.

Woodall, J. R., Warwick-Booth, L., \& Cross, R. (2012). Has empowerment lost its power? Health Education Research, 27(4), 742-745.

Woodall, J., Raine, G., South, J., \& Warwick-Booth, L. (2010). Empowerment \& health and wellbeing: Evidence review. Leeds: Centre for Health Promotion Research, Leeds Metropolitan University.

World Health Organization (1986). Ottawa Charter for Health Promotion. Copenhagen, Denmark: World Health Organization.

World Health Organization (2001). Global prevalence and incidence of selected curable sexually transmitted infections: Overview and estimates. Geneva: World Health Organization.

World Health Organization (2009). Global health risks: Mortality and burden of disease attributable to selected major risks. Geneva: World Health Organization.

World Health Organization (2010). Developing sexual health programmes; A framework for action. Geneva: World Health Organization.

Zimmerman, M. A., \& Rappaport, J. (1988). Citizen participation, perceived control, and psychological empowerment. American Journal of Community Psychology, 16(5), 725-750.

Zuo, X., Lou, C., Gao, E., Cheng, Y., Niu, H., \& Zabin, L. S. (2012). Gender differences in adolescent premarital sexual permissiveness in three Asian cities: Effects of gender-role attitudes. Journal of Adolescent Health, 50(3), S18-S25.

Zwang, J., \& Garenne, M. (2009). Social context of premarital fertility in rural South-Africa. African Journal of Reproductive Health, 12(2), 98-110. 


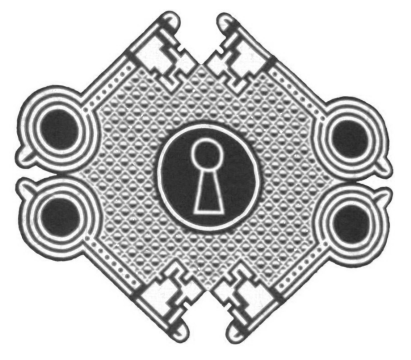

Summary

Samenvatting

Dankwoord/ Acknowledgements

About the Author

Publication List 


\section{Summary}

Adolescence is a period of transition, marked by physical, psychological, and cognitive changes. Adolescents start to explore their sexuality and intimate relationships and many of them become sexually active. Sexual activity also implies increased sexual and reproductive health risks, impairing the health of adolescents worldwide and particularly in countries in sub-Saharan Africa and the Asian Pacific region. Many adolescents are not or insufficiently provided with information and services to manage their transition, to develop and explore themselves, to prevent pregnancy and sexually transmitted infections including HIV/AIDS, or to cope with sexual violence, inhibiting sexuality related social norms, and stigma and discrimination. Three main approaches in sub-Saharan Africa and the Asian Pacific region towards the promotion of adolescents' sexual and reproductive health and rights (SRHR) are an empowerment approach, a health promotion approach, and a rights-based approach. In this dissertation the three approaches are integrated in the planning and evaluation of two interventions, a community-based and a schoolbased intervention, that aim to promote the adolescents' SRHR. Chapter 1 provides an overview of adolescents' SRHR in sub-Saharan Africa and the Asian Pacific region, three approaches towards SRHR promotion, SRHR promotion interventions, and Intervention Mapping, a framework for systematic health promotion planning.

The first part of the dissertation describes the planning and evaluation of the community-based Teenage Mothers Project in Uganda, an intervention aiming to empower unmarried teenage mothers and their social environment. In Chapter 2, the systematic planning of the Teenage Mothers Project is described, using Intervention Mapping. The project comprises five intervention components: community awareness raising, teenage mother support groups, education and income generation, counselling, and advocacy. The interventions are based on a variety of theoretical methods, including participatory planning, modelling, mobilisation of social networks, persuasive communication, entertainment education, advocacy, guided practice, provision of information about relevant others' approval, and social action. Between March 2000 and March 2012, 1,036 unmarried teenage mothers participated in the project. The interventions were developed and implemented by a planning group consisting of community leaders, teenage mothers, staff of a community based organisation, and a health promotion professional. Intervention Mapping facilitated the planning group to structure the iterative, participatory design of the interventions and to use evidence and theory.

A qualitative effect evaluation was conducted to get insight in the effects of the Teenage Mothers Project on the well-being of the teenage mothers and the attitude of environmental actors in their residential communities. The evaluation results are described in Chapter 3. In-depth interviews with teenage mothers, community leaders, and project implementers, lifeline histories of teenage mothers, and quantitative data suggested that the intervention particularly contributed to continued education and income generation of teenage mothers, resulting in increased agency and improved coping strategies. The project could be improved by 
active involvement of unmarried teenage mothers during their pregnancy. The evaluation showed that the female adolescents could access counselling during their pregnancy, but that they were only actively involved in the support groups ten months after delivery of the child. Active involvement of the pregnant adolescents in an earlier stage could prevent trauma. The results suggest an interaction between positive visibility of the teenage mothers in the community and more positive attitude and support by parents, relatives, and community leaders. The project could improve by providing support and counselling to parents for them to be able to financially support their daughters.

The second part of the dissertation addresses the comprehensive sexuality education programme 'The World Starts With Me' (WSWM), a school-based programme aiming at the promotion of adolescents' sexual and reproductive health and rights in Uganda, Indonesia, and Thailand. Chapter 4 describes a study exploring psychosocial correlates of sexual abstinence intentions of Indonesian secondary school students. Significant associations with intention to abstain from sexual intercourse were found for experience with sexual intercourse, perceived behavioural control, attitude, and subjective norms of peers and parents. These correlates explained $31 \%$ of the variance in students' abstinence intentions.

Chapter 5 reports about the effect of WSWM on adolescents' self-disclosure about sensitive sexuality related topics in Thailand and Uganda. Self-disclosure was operationalized by adding the answer option 'I don't want to talk about it' to 29 questionnaire items that were marked as sensitive. The study showed that disclosure level at baseline was higher in Uganda than in Thailand. WSWM significantly increased disclosure in Thailand and particularly contributed to disclosure about safe and consensual sex intentions, attitudes towards controversial topics, experience with non-consensual sex, and health and health services related experiences.

Chapter 6 gives insight in the adaptation of WSWM to a new context and priority population in Indonesia. The programme was developed for a priority population in Uganda and adapted to a programme for Indonesian secondary school students. The adaptation was guided by Intervention Mapping, which facilitated to systematically address the complexity and challenges of programme adaptation and to find a balance between preservation of essential programme elements (i.e., logic models including key objectives and theoretical behaviour change methods) in the Ugandan programme and the adaptation of the programme to be acceptable to the new priority group and the programme implementers in Indonesia. Challenges in this process included the identification of retaining core elements of the original programme's effectiveness while making changes that enhanced acceptance in the new context and for the new priority group.

The final chapter of this dissertation, Chapter 7, is a general discussion of the research findings in the qualitative and quantitative studies and the two case studies that describe systematic intervention planning and adaptation. Overall, the study findings have provided insight in the systematic planning and evaluation of community-based and school-based interventions that promote adolescents' SRHR in Uganda, Indonesia, and Thailand. The most important findings are summarised 
and discussed with existing literature and the three common approaches to promote adolescents' SRHR. In addition, the research methodology and implications for practice and future research are discussed. 


\section{Samenvatting}

In hun ontwikkeling naar volwassenheid hebben jongeren te maken met fysieke, psychologische en sociale veranderingen. Een deel van de jongeren is seksueel actief en loopt een risico om ziek te worden of zwanger te raken. Veel jongeren in Afrika en Azië hebben beperkt toegang tot informatie over het omgaan met de veranderingen en bewustzijn van hun eigen wensen en grenzen. Daarnaast hebben veel jongeren onvoldoende toegang tot zorg rondom zwangerschap, seksueel overdraagbare aandoeningen (waaronder HIV/AIDS), seksueel geweld en stigma en discriminatie.

Bij het bevorderen van de seksuele en reproductieve gezondheid en rechten (SRGR) van jongeren wordt vaak uitgegaan van de rechten van jongeren, empowerment van jongeren en/of gezondheidsbevordering. In dit proefschrift zijn de drie benaderingen geïntegreerd bij het plannen en evalueren van twee SRGR programma's. Hoofdstuk 1 geeft een overzicht van de drie benaderingen, van de SRGR van jongeren in Sub-Sahara Afrika en Pacifisch Azië, en van programma's die de SRGR van jongeren bevorderen. Ook beschrijft het eerste hoofdstuk Intervention Mapping, een model om programma's planmatig en met behulp van onderzoek en theorieën te ontwikkelen. Vervolgens gaat het proefschrift in op twee SRGR programma's, namelijk het Tienermoederproject in Oeganda en het seksuele vormingsprogramma 'The World Starts With Me' in Indonesië, Oeganda en Thailand.

In het eerste deel worden het ontwikkelproces en een kwalitatieve evaluatie van het Tienermoederproject beschreven. Het Tienermoederproject is ontwikkeld op het platteland van Oost-Oeganda en heeft als doel om ongehuwde tienermoeders en hun sociale omgeving in staat te stellen zelf beslissingen te nemen over hun leven en toekomst. In Hoofdstuk 2 wordt de planmatige ontwikkeling van het project beschreven aan de hand van Intervention Mapping. Het project bestaat uit vijf onderdelen: (1) creëren van bewustwording in de sociale omgeving van de tienermoeders, (2) zelfhulpgroepen voor tienermoeders, (3) onderwijs en inkomstenwerving, (4) counseling en psychosociale steun en (5) advocacy. De programmaonderdelen zijn gebaseerd op diverse theoretische methoden, waaronder participatieve planning, inzetten van rolmodellen, mobilisatie van sociale netwerken, overtuigende communicatie, educatie waarbij gebruik wordt gemaakt van entertainment, advocacy, begeleiding in de praktijk, het geven van informatie over de goedkeuring door relevante anderen, en sociale actie. Het programma is ontwikkeld en mede geïmplementeerd door een planningsgroep die bestond uit gemeenschapsleiders, tienermoeders, vrijwilligers en staf van de community based organisatie ARDI en een gezondheidsbevorderingsexpert. De planningsgroep ontwikkelde het programma met behulp van Intervention Mapping. Het Intervention Mapping model bood een raamwerk voor het doorlopen van een participatief, niet-lineair en complex ontwikkelproces en voor het gebruiken van onderzoek en theorieën. Tussen maart 2000 en maart 2012 deden 1036 ongehuwde tienermoeders actief mee in het programma. 
Om een beeld te krijgen van de mate waarin het Tienermoederproject invloed heeft gehad op het welzijn van de tienermoeders en op ouders en gemeenschaps-leiders is het project geëvalueerd. De resultaten van deze kwalitatieve evaluatie zijn beschreven in Hoofdstuk 3. Informatie werd verzameld door middel van interviews met tienermoeders, gemeenschapsleiders en projectuitvoerders, en aangevuld met kwantitatieve gegevens en de beschrijving van de levensloop van een aantal tienermoeders. Deze bronnen lieten zien dat het project voornamelijk lijkt te hebben bijgedragen aan de terugkeer naar school en het verwerven van inkomsten door de tienermoeders. En deze veranderingen lijken weer te hebben bijgedragen aan meer zeggenschap over hun eigen leven en aan betere strategieën om met lastige situaties om te kunnen gaan. Daarnaast laten de resultaten een wisselwerking zien tussen enerzijds meer en positievere zichtbaarheid van de tienermoeders in hun sociale omgeving en anderzijds een positievere houding van en ondersteuning door ouders en gemeenschapsleiders. Naast deze positieve veranderingen bleek dat het programma op een aantal punten kan worden verbeterd. Allereerst bleek dat de tienermoeders al tijdens hun zwangerschap gebruik konden maken van counseling, maar dat zij gemiddeld pas 10 maanden na de bevalling lid werden van een zelfhulpgroep en actief deelnamen aan het project. Door de tieners in een vroeger stadium actief te betrekken zou mogelijk trauma tijdens en vlak na de zwangerschap voorkomen kunnen worden. Ook bleek dat de mate waarin tienermoeders teruggingen naar school of zelf inkomsten genereerden in hoge mate afhankelijk lijkt te zijn van hun ouders en dat een deel van de tienermoeders niet voldoende door de ouders lijkt te worden ondersteund.

Het tweede deel van dit proefschrift richt zich op het seksuele vormingsprogramma 'The World Starts With Me'. Dit programma wordt met behulp van computers op scholen geïmplementeerd en is gericht op het bevorderen van SRGR van jongeren in Indonesië, Oeganda en Thailand. Hoofdstuk 4 beschrijft een studie warin is onderzocht in welke mate sociaalpsychologische factoren de intentie van Indonesische scholieren bepalen om wel of geen geslachtsgemeenschap te hebben en op welke factoren seksuele vormingsprogramma's als 'The World Starts With Me' zich zouden moeten richten. De studie liet een positief significant verband zien tussen enerzijds intentie ten aanzien van seksuele onthouding en anderzijds gebrek aan ervaring met geslachtsgemeenschap, eigen-effectiviteit om geen seks te hebben, de attitude ten aanzien van seksuele onthouding, en de inschatting hoe andere jongeren denken over seksuele onthouding. Gezamenlijk verklaren deze factoren $31 \%$ van de variantie in intentie om zich van geslachtsgemeenschap te onthouden.

Hoofdstuk 5 beschrijft het effect van 'The World Starts With Me' op de mate waarin jongeren in Thailand en Oeganda antwoord willen geven op vragen over seksualiteit-gerelateerde onderwerpen. Openheid over deze gevoelige onderwerpen werd gemeten door de antwoordmogelijkheid 'Ik wil er niet over praten' toe te voegen aan 29 vragen in de vragenlijst. De studie toonde aan dat jongeren in Oeganda voorafgaand aan deelname aan het programma opener waren dan jongeren in Thailand. Ook liet de studie zien dat het programma significant heeft bijgedragen aan meer openheid van jongeren in Thailand, maar niet van jongeren in 
Oeganda. Jongeren in Thailand waren na deelname vooral opener over hun intenties met betrekking tot veilige en vrijwillige seks, over opvattingen aangaande controversiële onderwerpen zoals homoseksualiteit en abortus, over hun ervaring met onvrijwillige seks en over hun eigen seksuele gezondheid en ervaringen met gezondheidszorg.

Hoofdstuk 6 geeft inzicht in de wijze warop 'The World Starts With Me' is aangepast aan een nieuwe context en doelgroep in Indonesië. Het programma is ontwikkeld voor schoolgaande jongeren in Oeganda. Met behulp van Intervention Mapping is het programma aangepast om het relevant te maken voor schoolgaande jongeren in Indonesië. Het programma werd planmatig aangepast om een balans te vinden tussen (1) het behouden van essentiële programmaonderdelen uit het Oegandese programma, waaronder de belangrijkste doelstellingen en theoretische gedragsveranderingsmethoden en (2) het aanpassen van het programma om het aan te laten sluiten bij de jongeren en scholen in Indonesië. Het vinden van deze balans was de grootste uitdaging in het aanpassen van het programma.

Het laatste hoofdstuk van dit proefschrift, Hoofdstuk 7, vormt een algemene discussie van de onderzoeksresultaten van de kwalitatieve evaluatie van het Tienermoederproject in Oeganda, de kwantitatieve analyse van sociaalpsychologische factoren die de intentie van Indonesische scholieren bepalen om wel of geen geslachtsgemeenschap te hebben, de kwantitatieve evaluatie van het effect van 'The World Starts With Me' op de openheid van jongeren in Oeganda en Thailand over gevoelige onderwerpen, en de twee case studies die beschrijven hoe Intervention Mapping kan worden gebruikt om een nieuwe SRGR interventie te ontwikkelen en een bestaande interventie aan te passen voor een nieuwe doelgroep en context. De bevindingen in de vijf studies geven inzicht in de systematische planning en evaluatie van SRGR interventies voor jongeren in Oeganda, Indonesië en Thailand. De belangrijkste bevindingen zijn samengevat en geplaatst in de context van andere relevante literatuur en de benaderingen gericht op rechten, empowerment en gezondheidsbevordering die worden toegepast bij het ontwikkelen van SRGR programma's. Daarnaast worden de onderzoeksmethodologie en implicaties voor de praktijk en vervolgonderzoek besproken. 


\section{Dankwoord/ Acknowledgements}

Mijn proefschriftavontuur begon met Herman, Jo en Henk. 'Begin maar met een artikel, dan schrijf je er nog één, en dan ben je al bijna op de helft' zei Herman en daarmee durfde ik het wel aan. Ik heb hem gemist na zijn plotselinge overlijden in 2009. Hij speelde een grote rol bij de WSWM evaluatie, bij de start van het geitenproject en bij het vormen van mijn visie op health promotion in de (Afrikaanse) praktijk.

Jo, bedankt voor je inspiratie, feedback en gezelschap tijdens onze vele reizen naar bijzondere plekken in Afrika en Azië, teveel om hier te noemen. Henk, veel dank voor alle kansen en je steun van de afgelopen jaren. Je hebt me af en toe in het diepe laten springen, maar ik drijf nog steeds. Directeuren van (Rutgers) WPF, Frans Baneke en Dianda Veldman, wil ik bedanken voor de mogelijkheid om deels in werktijd aan mijn onderzoek en proefschrift te werken.

Rob, Gerjo en Arjan, mede dankzij jullie heb ik mijn proefschrift tot een mooi einde gebracht. Bedankt Rob voor al je meedenken, feedback, vertrouwen en relativering. Vooral dat laatste was op lastige momenten een goede stimulans om verder te gaan. Gerjo, bedankt voor je grote Intervention Mapping wijsheid en inspiratie. En Arjan, jouw kennis over stigma was onmisbaar voor de twee 'geitenartikelen'. Bedankt voor je gedegen en stimulerende feedback.

Liesbeth, samen begonnen we ruim vijf jaar geleden aan de WSWM evaluatie en terugkijkend zouden we veel dingen anders hebben aangepakt. Maar het is gelukt! Bijzonder dat we onze proefschriften langs onze eigen routes rond dezelfde tijd hebben afgerond. Bedankt voor al die sparmomenten en voor je steun en meeschrijven aan rapporten en artikelen. Linette, vanaf het moment dat ik bij WPF kwam werken, was ik blij dat je er was. Bedankt voor je vriendschap, je steun tijdens de WSWM evaluatie en je waardevolle adviezen voor Adopteer een Geit. Liesbeth en Linette, paranimfcommissie, bedankt!

Ook Maartje, Ellen en Hilde en andere oud-collega's bij (Rutgers) WPF, bedankt voor al die bijkletsmomenten over persoonlijke en werk gerelateerde hoogte- en dieptepunten. Het vormen van mijn mening over theorieën van gedragsverandering en empowerment kwam in een stroomversnelling na de fusie van WPF en RNG. Ine, Miranda en Ruth, onze gesprekken hierover waren niet altijd makkelijk, maar ze hebben me zeer gevormd. Dank daarvoor.

I want to thank all colleagues of Rutgers WPF in Indonesia, APSW in Thailand, CSA and Nairobits in Kenya, and School Net in Uganda for carrying out the WSWM evaluation research and for all our interactions that have shaped my thinking: Wati, Kus, Rita, Wijit, Maytinee, Albert, Martin, Anne, Alex, Allen, and Daniel. Thanks to all the schools, teachers, and students who participated in the studies. Bedankt ook Miriam en andere STOP AIDS NOW! collega's. Geweldig dat ik met jullie kon werken aan het delen van kennis over effectieve seksuele vorming voor jongeren in Afrika en Azië en dat dit met succes doorgaat. 
Annemien en Pieter, bedankt voor de ruimte en tijd die jullie me het afgelopen half jaar hebben gegeven om dit proefschrift af te ronden. Jullie waren een goede stimulans om de vaart erin te houden.

Wanjala nabi Joseph, Josepher, Joel, John, John, and ARDI volunteers. When I left Uganda in 2000, we hoped that we would meet again. Well, we did. The more I visit your villages, the more I realise how little I know about the Magisu. Thanks for answering all my questions and for your contributions to the evaluation study. I admire you, Christine, Edith, Justine, and other UWCM and PEFO colleagues and volunteers, for your vision and efforts to implement the Teenage Mothers Project together with community leaders in Eastern Uganda. A special thanks to the teenage mothers, parents, and leaders who participated in the interviews. Annelyn, thank you for conducting and transcribing the interviews with the teenage mothers. Nathan, thank you, again, for your valuable and thorough feedback.

Dear Weyusya family, I have been coming to your home in Uganda since 1999. Thank you for your hospitality and for letting me be part of your family. You have taught me that nothing is what it seems at first sight and that changing reproductive rights and gender norms is not that easy. Thanks for your love and friendship.

Chris, 13 jaar geleden, bij die eerste drie geiten, hadden we niet gedacht dat er op dit moment meer dan 2000 Adopteer een Geit-geiten in Oeganda zouden rondlopen. Gelukkig waren daar Henk Willem, Maartje, Marianne, Nora en Ottelien. Bedankt voor jullie zakelijke, creatieve en praktische inbreng. Wat was en is het leuk en inspirerend om samen met jullie en veel anderen Adopteer een Geit vorm te geven. Op naar Adopteer een Geit 2.0.

Bedankt lieve vriendinnen, vrienden, broers, schoonzussen, opa en oma, en ma Ine voor jullie vriendschap, gastvrijheid, reisgezelschap, meeleven en positieve afleiding de afgelopen jaren! Mijn proefschrift is af maar ik heb er heel wat etentjes, wijntjes en feestjes voor moeten laten. 't Wordt tijd om dat weer in te halen!

Pa en ma, jullie houding heeft mijn hele leven al geholpen te komen waar ik nu ben: probeer het maar en als het niet lukt dan stop je er gewoon weer mee. Daarmee belandde ik onder andere op het VWO, in de VS en in Oeganda. Bedankt voor jullie vertrouwen en stimulans om datgene te doen waar ik plezier in heb en in geloof.

Lieve Sven, drie jaar geleden zeilde jij mijn leven binnen, wat een geluk! We hebben Intervention Mapping regelmatig toegepast op Mister Vee en jouw marketingboekjes op mijn onderzoek. Geweldig dat je mee bent gegaan naar dat voor jou toen zo onwerkelijke Oeganda. Bedankt voor al het sparren, je creatieve ideeën, je Engelse taalcorrecties, het draaiende houden van ons gezamenlijke leven en dat je me af en toe achter mijn computer vandaan kwam halen.

Tenslotte Nora, bedankt voor de zeer passende, mooie omslag. De cirkel is rond. 


\section{About the Author}

Joanne Leerlooijer was born on March 29" 1977 in 's-Hertogenbosch, the Netherlands. After completing secondary education in 1995 (VWO, Koningin Wilhelmina College, Culemborg), she studied Health Sciences at Maastricht University. In 2003 she completed the Master of Science in Mental Health and the Master of Science in Health Education and Promotion. As part of the Master of Science in Mental Health, she completed an eight month internship as clinical psychologist at STAGG in Houten. As part of the Master of Science in Health Education and Promotion, she completed a 6-month master research internship at Action Aid in Uganda. The research resulted in a thesis on sexual abstinence among female adolescents in rural Uganda. She received the Catharina Pijls Aanmoedigingsprijs for her thesis, an award of the Faculty of Health Sciences at Maastricht University.

In 2002, Joanne worked at the prevention departments of two mental health care organisations (RIAGG Amersfoort and RIAGG Gouda). Following her graduation in Health Sciences in 2003, she started working as research assistant at Maastricht University in the EU funded SATZ research project in South Africa and Tanzania. In 2004 she got employed by the World Population Foundation (now Rutgers WPF) and was involved in research, and project planning, monitoring and evaluation of comprehensive sexuality education targeting adolescents. She contributed to the design and evaluation of 'The World Starts With Me' programme and was involved in the design of various tools and training materials targeting public health practice professionals worldwide.

Joanne completed her PhD as external candidate at Maastricht University while she worked at Rutgers WPF. She was one of the founders of the Dutch Adopteer een Geit Foundation and was voluntarily involved as health promotion professional in the design of the Teenage Mothers Project in Uganda.

Since September 2012, Joanne works as postdoc/ lecturer at the Division of Human Nutrition at Wageningen University on systematic theory- and evidence-based intervention planning in public health. She is involved in the design of the online distance learning Master programme 'Epidemiology and Public Health'. She is also involved in evaluation research of the Academische Werkplaats AGORA and the Evaluation Bureau of GGD Noord- en Oost Gelderland in Apeldoorn. 


\section{Publication List}

\section{Peer reviewed and submitted articles}

Leerlooijer, J. N., Bos, A. E. R., Ruiter, R. A. C., Van Reeuwijk, M. A. J., Rijsdijk, L. E., Nshakira, N., \& Kok, G. Qualitative evaluation of the Teenage Mothers Project in Uganda: A community-based empowerment intervention for unmarried teenage mothers. Under review.

Leerlooijer, J. N., Ruiter, R. A. C., Damayanti, R. Rijsdijk, L. E., Eiling, E. Bos, A. E. R., \& Kok, G. Psychosocial correlates of the motivation to abstain from sexual intercourse among Indonesian adolescents. Under review.

Leerlooijer, J. N., Ruiter, R. A. C., Reinders, J., Darwisyah, W., Kok, G., \& Bartholomew, L. K. (2011). The World Starts With Me: Using Intervention Mapping for the systematic adaptation and transfer of school-based sexuality education from Uganda to Indonesia. Translational Behavioral Medicine: Practice, Policy and Research, 2, 331-340.

Leerlooijer, J. N., Ruiter, R. A. C., Rijsdijk, L. E., Reinders, J., Bos, A. E. R., Wong, W., \& Kok, G. Breaking taboos about sexuality: Effects of the school-based programme The World Starts with $\mathrm{Me}$ in Uganda and Thailand on disclosure about sensitive issues. Submitted for publication.

Leerlooijer, J. N., Kok, G., Weyusya, J., Bos, A. E. R., Ruiter, R. A. C., Rijsdijk, L. E., Nshakira, N., \& Bartholomew, L. K. Empowering teenage mothers in Uganda: The development of a community-based intervention to improve psychological and social well-being of unmarried teenage mothers. Submitted for publication.

Mkumbo, K, Schaalma, H, Kaaya, S, Leerlooijer, J. Mbwambo, J \& Kilonzo, G. (2009). The application of Intervention Mapping in developing and implementing school-based sexuality and HIV/AIDS education in a developing country context: The case of Tanzania. Scandinavian Journal of Public Health, 37 (Suppl 2), 28-36.

Rijsdijk, L. E., Bos, A. E. R., Lie, R., Leerlooijer, J. N., Eiling, E., Atema, V., Gebhardt, W., \& Ruiter, R. A. C. Implementation of The World Starts With Me, a comprehensive rightsbased sex education programme in Uganda. Submitted for publication.

Rijsdijk, L. E., Bos, A. E. R., Lie, R., Ruiter R. A. C., Leerlooijer, J. N., \& Kok, G. (2012). Correlates of delayed sexual intercourse and condom use among adolescents in Uganda: A crosssectional study. BMC Public Health, 12, 817.

Rijsdijk, L. E., Bos, A. E. R., Ruiter, R., Leerlooijer, J. N., De Haas, B., \& Schaalma, H. (2011). The World Starts With Me: A multilevel evaluation of a comprehensive sex education programme targeting adolescents in Uganda. BMC Public Health, 11, 334.

Rijsdijk, L. E., Lie, R., Bos, A. E., Leerlooijer, J. N., \& Kok, G. (2012). Sexual and reproductive health and rights: Implications for comprehensive sex education among young people in Uganda. Sex Education: Sexuality, Society and Learning, DOI:10.1080/14681811.2012. 747432 


\section{Book chapters}

Bartholomew, L. K., Fernández, M., Leerlooijer, J. N., James, S., Reinders, J., \& Mullen, P. D. (2011). Using Intervention Mapping to adapt evidence-based programs to new settings and populations. In L. K. Bartholomew, G. S. Parcel, G. Kok, N. H. Gottlieb, \& M. E. Fernández (Eds.), Planning health promotion programs: An Intervention Mapping approach (3rd ed., pp. 553-632). San Francisco CA: Jossey Bass.

\section{Other publications}

Groenhof, M., Leerlooijer, J. N., Agegnehu, S., \& Mkaronda, J. (2012). Enabling youths to make informed decisions. Exchange on HIV/AIDS, Sexuality and Gender, p. 4-6.

Leerlooijer, J. N., Groenhof, M., Eiling, E., \& Reinders, J. (June 2012). Effectievere seksuele voorlichting aan jongeren in ontwikkelingslanden. Seksoa.

http://www.seksoa.nl/artikelen/effectievere-seksuele-voorlichting-aan-jongeren-inontwikkelingslanden

\section{Guidelines and tools}

Leerlooijer, J. N. (2009). Evidence-based planning \& support tool for SRHR/HIV-prevention interventions. The Netherlands: World Population Foundation \& STOP AIDS NOW!. http://www.rutgerswpf.nl/article/planning-and-support-tool

Leerlooijer, J. N., et al. (2012). Are you on the right track? Six steps to measure the effects of your programme activities. The Netherlands: STOP AIDS NOW! \& Rutgers WPF. http://www.rutgerswpf.nl/article/workbook-are-you-on-the-right-track

Leerlooijer, J. N., Ploem, R., Eiling, E., et al. (2012). Toolkit for men - male counselling in the context of intimate partner violence: Guidelines adaptation and implementation. The Netherlands: Rutgers WPF.

http://www.rutgerswpf.org/article/toolkit-men-male-counselling-context-intimatepartner-violence

Leerlooijer, J. N., Reinders, J., \& Schaalma, H. (2008). Intervention Mapping toolkit for planning sexuality education programs: Using Intervention Mapping in planning schoolbased sexual and reproductive health and rights (SRHR) education programs. The Netherlands: World Population Foundation \& RESHAPE Maastricht University. http://www.rutgerswpf.org/article/intervention-mapping-toolkit-planning-sexualityeducation-programmes

\section{Poster and oral presentations}

Leerlooijer, J.N., Reinders, J., Jansen, S., Kekena, M.R., Mkumbo, K.A.K., Aarø, L.E. \& Schaalma, H.P. (July 2004). Systematic development of theory- and evidence-based sexuality education programs for schools in South Africa and Tanzania. Poster presentation at XV International AIDS Conference, Thailand.

Leerlooijer, J. N., Reinders, J., Roy, S, \& Van Vliet, L. (2008). Linking and learning as a network to mainstream HIV/AIDS prevention \& SRH promotion in education programmes; experiences from the MAIN PHASE network in India. Poster presentation at XVII International AIDS Conference, Mexico. Abstract no. CDC0701. 
Leerlooijer, J. N., Reinders, J., \& Schaalma, H. (2009). Bridging the gap between science and practice; the Intervention Mapping Toolkit for planning comprehensive, evidence-based sexuality education programs. Oral presentation at IV Biennial International Sex and Relationships Education Conference, Birmingham UK. 